
\section{Morphology and Pathophysiology}

DESIGN OF ALVEOLO-CAPILLARY SYSTEM: GAS AND FLUID EXCHANGE BARRIERS. E.R. Weibel, Department of Anatomy, University of Berne, Berne, Switzerland

The design of the alveolar septum displays a number of features that favor the maintenance of a dry air-blood barrier in the interest of gas exchange. Whereas gas exchange occurs in relation to a 2-compartment model - alveolar air space and capillary blood space separated by the tissue barrier - the control of fluid movements is understood on the basis a 3-compartment model, with the cellular sheets of epithelium and endothelium separating three fluid spaces: plasma, interstitium, and alveolar lining layer. The capillary endothelial cell lining is continuous, but the intercellular junctions are leaky, allowing smaller solutes to be easily exchanged between plasma and interstitial fluid. In contrast, the alveolar epithelium is made of a mosaic of squamous type I cells and cuboidal type II cells; the epithelial intercellular junctions are tight, preventing simple solute exchange between interstitium and alveolar lining layer. In the interest of optimizing barrier structure for gas exchange the type I cells are of vast expanse, highly complex in their architecture. As a consequence they are very vulnerable and their repair upon damage is difficult. Regeneration of alveolar epithelium must occur from type II cells as stem cells. An important question is how the alveolar septum prevents fluid from accumulating in the tissue space. It appears that the compliance of the a] veolar septal interstitium is restricted by design: (1) by eliminating an actual interstitial space on large parts of the surface due to fusion of epithelial and endothelial basenent membranes; (2) by the myofibroblasts in the actual interstitial space. Moreover, any fluid accumulating in the septum is rapidly drained away towards the juxtaalveolar fluid sumps and lymphatics.

MORPHOLOGY IN ARDS CONSIDERING STRUCTUREFUNCTION RELATIONS. M. Bachofen, Department of Anesthesiology, University of Berne, Berne, Switzerland.

The acute stage of ARDS is characterized by an interstitial and alveolar edema due to focal alveolo-capillary barriex destruction regardless of whether the primary action site of the noxious stimulus may have been alveolar space or capillary lumen. While epithelial lesions can easily be visualized endothelial defects are sparse although occasional large amounts of red blood cells and fibrin strands in the subendothelial and interstitial space are strong evidence of temporary capillary leaks. Different cell repair mechanisms, a fast one for the endothelium and a time consuming two stage repair process for the type I epithelial cells, account for this observation. The thickening of alveolar septa by proliferation of type II epithelial cells and an accumulation of cells and fibers in the interstitial space, intraalveolar fibrosis, changes in extraalveolar vessels and structural rearrangements of peripheral air spaces are distinctive features of the subacute stage of the disease. Its duration does not necessarily correlate with the severity of structural alterations. Cases of severe functional impairment may go along with extremely reduced capillary volumes and a very low oxygen diffusion capacity as estimated by morphometry. Rapid improvement of gas exchanging and ventilatory lung function may reflect a partial restoration of the geometry of oeripheral airspaces rather than a reversion of fibrotic lesions.
3

IMPACT OF MECHANICAL FORCES ON GAS EXCHANGING STRUCTURES. H. Bachofen, Department of Medicine, University of Berne, Berne, Switzerland.

Efficent gas exchange in the lung requires a short diffusion distance between alveolar air and capillary blood over a wide contact area. To this aim the tissue mass of lung parenchyma is extremely reduced: the capillary bed is covered by a thin tissue nembrane and supported by a flimsy connective tissue network. Obviously, these delicate structures are easily deformable, and the dimensions of structural elements important for gas exchange, i.e. the alveolar surface area, the thickness of the blood-gas barrier, and the capillary volume are profoundly affected by the interaction of four mechanical forces: 1) tissue forces; 2) the microvascular pressure; 3) the alveolar pressure; and 4) the surfaces forces. Within the lung volume range of normal breathing the surface forces have a strong impact on the free surface area, since alveolar walls appear to be negligible mechanical components except as platforms for surface tension. Compared with fluj.d filled lungs normal air filled lungs reveal a reduced free alveolar surface area by folding of the alveolar septa beneath the surface lining layer. Abnormally increased surface forces further reduce the surface area. The peripheral airspaces become unusually wide, and are separated by bulky tissue masses of piled-up septa of "collapsed" alveoli. Among other features these structurefunction relations may explain impaired gas diffusion, increased right-to-left shunts, and increased alveolar dead spaces in lung diseases affecting the properties of alveolar surface lining layers only.

4

PATHOGENETIC FACTORS OF INCREASED CAPILLARY PERMEABILITY IN ARDS. M. LAMY, M. BRAUN, C. DEBY, G. DEBY-DUPONT, J. DUCHATEAU, M. HAAS, J. VAN ERCK (Universities of Liège and Brussels, Belgium).

The pulmonary edema of the ARDS is due- to loss of integrity of pulmonary capillary walls. ARDS complicates pulmonary and systemic infections, hypoperfusion states, inhalation of toxic gases including oxygen, aspiration of damaging liquids, intravascular coagulation or embolism, platelet and leukocyte aggregation, immunopathies and a Tlergic reactions, and hypoxia, ail of which may lead directly or indirectly to endothelial cell damage. Many humoral factors are involved (in vitro and in vivo animal studies, very few human studies) : activated complement fractions, prostanoids, leukotrienes, proteases, peptides and coagulation and fibrinolys is products. We have studied complement activation, thromboxane and prostacycline metabolites (TXB, and 6-oxo-PGF, ), and immunoreactive and enzymat?cally active thypsin in plasma from 50 ARDS patients. Abnormal $C_{3}$ consumption (as measured by $C_{3 d} / C_{3}$ ratio) and elevated plasma C -like activity as measured by a leukocyte aggregation assay) were associated with, respectively, 84 $\%$ and $86 \%$ of cases of ARDS. Both tests were more sensitive indicators of complement consumption than assays of total hemolytic complement activity (CH50) or total $C_{3}$. Sequential samples on both sides of the pulmonary circulation showed initial pulmonary clearance followed by liberation of $C_{5}$-like activity. Abnormal TXB plasmatic values were found in $58 \%$ of ARDS patfents, during consecutive days of evolution; values up to $8000 \mathrm{pg} / \mathrm{ml}$ were measured. Tryps in values were enhanced (> $70 \mathrm{ng} / \mathrm{m} 7$ ) in $87 \%$ of ARDS patients, particularly in septic cases; repetitive high trypsine values correlated with high mortality rate. Our data confirm the participation of the complement-leukocyte cascade in the increased pulmonary capillary permeability of ARDS. 


\section{Experimental Studies}

5

ROLE OF EIASTASE AND GRANULOCYTES IN EXXERIMENTAL MODELS OF ARDS.

H.Burchardi, T.Stokke, I.Hensel, W.H.Hörl 1, G.Schlag 2, Zentrum Anaesthesiologie, Universität Göttingen, WestGermany, ( 1 wïrzburg, 2 Wien).

Selective sequestration of polymorphonuclear neutrophils (PMNis) in the lung seems to play a central role in early ARDS. Sequestered PMNs may damage lung tissue either directly or by releasing mediators such as lysosomal proteases (f.e. elastase). We studied the possible role of PMNs and of elastase on lung function by infusing elastase in normal and in agranulocytic minipigs.

METHODS: Among 16 minipigs studied (anaesthetized and ventilated) 4 were pretreated with dimethylmyleran which depleted granulocytes completely. 3 pigs without pretreatment or elastase infusion for control. Elastase was infused $(330 \mathrm{U} / \mathrm{kg} \cdot \mathrm{h})$ continously for $3-4$ hours in the elastase and in the agranulocytic group. Mhltiple determinations of cardio-respiratory functions were repeated in short intervalls before and during the treatment. Finally, morphological studies were performed.

RESULTS: The control group revealed steady state conditions during the whole experiment. However, elastase caused typical effects both in the normal as well as in the agranulocytic pigs: Immediately after onset of elastase pulm.art.pressure (PAP) increased but only temporar1ly. Oxygenation $\left(\mathrm{AaDO}_{2}\right)$ deteriorated after one hour when PAP again had returned to baseline. Pulm. diffusing capacity decreased slightly. In the non-pretreated pigs elastase infusion caused a significant sequestration of PMNs in the lung. But, as the effects on lung function were nearly identical in the normal as well as in the agranulocytic group, this could primarily be an elastase effect independent of the presence of PMNs in the lung. CONCLUSION: Elastase, released by PMNs sequestered in the lung, may (interacting with other systems?) play a role in early ARDS. Elastase itself seems to induce pulmonary PMN secquestration by neurophil activation.

7

HYPOXIC PULMONARY VASOCONSTRICTION IN PATHOLOGICAL CONDITIONS. M.K.Sykes, Nuffield Department of Anaesthetics, Radcliffe Infirmary; Oxford, OX2 6HF, United Kingdom.

The pulmonary circulation is a low pressure, low resistance system which accommodates the marked increases of cardiac output associated with exercise by recruitment and distension of the pulmonary vasculature. The required distribution of perfusion is governed primarily by the relationship between alveolar, pulmonary arterial and left atrial pressures, blood flow being least in the non-dependent zones and maximal in its dependent zones, whatever the body position. Regional blood flow is reduced by a reduction in regional lung volume (which narrows the extra-alveolar vessels) and by regional underventilation (which leads to a reduction in alveolar $\mathrm{PO}_{2}$ and increases in alveolar $\mathrm{PCO}_{2}$ ). The reduction in regional flow from hypoxic pulmonary vasoconstriction (EPV) is primarily governed by alveolar P02. However, in collapsed regions of lung the mixed venous $\mathrm{PO} 2$ determines vascular tone. HPV is, therefore, accentuated when cardiac output is reduced and decreased when output is increased. This may account for the well known direct relationship between shunt and cardiac output. An increase in shunt may also occur when UPV is inhibited by drugs, raised pulmonary artery or left atrial pressure or hypothermia, or when drugs cause vasoconstriction in the oxygenated areas of lung.
POSTTRAUMATIC ULTRASTRUCTURAL CHANGES AND THE ROLE OF GRANULOCYTES IN THE LUNGS, LIVER AND SKELETAI MUSCLE, G. Schlag, H. Redl, Ludwig Boltzmann Institute of experimental Traumatology. Vienna, Austria

The posttraumatic-hypovolemic shock results in pulmonary changes which predominantly affect the cellular and subcellular levels. Morphologically 2 distinct stages are present, the "lung in shock" within the first hour and the "shock lung syndrome" which manifest itself after 24 to $48 \mathrm{~h}$. The early stage "lung in shock" is characterized by a multitude of changes in the microvascular syster: massive leukostasis, polymorphonuclear granulocyte (PMN) degranulation, and endothelial cell swelling. The purpose of the study was to compare the ultrastructural findings of the lung, Iiver and skeletal muscle with respect to the granulocytes (PMN) and the endothelial cell damage. In many phases, the endothelial celis are considerably swollen in the lung and skeletal muscle.

But whereas many polymorphonuclear granulocytes present in the alveolar capillaries of the lung. only a few isolated granulocytes are seen in the vessels of the skeletal muscle tissue.

Leucostasis in the lung was also confirmed quantitatively using ${ }^{1}{ }^{1}$ In-oxine labeled PMN; in the liver it was present to a much lesser extent, while there were no changes versus the pre-shock period in skeletal muscle.

The granulocytes might be responsible for the onset of lung damage after shock, acting on the endotheilal cells (reactive oxygen species). One needs to consider other causes of analogues in striated muscle (hypoxia?) 
9

PHYSIOLOGY OF PULMONARY CIRCULATION AND RIGHT HEART PERFORMAiVCE. A.Versprille, Deptm. of pulmonary diseases, Erasmus University, Rotterdarn, The Netherlands.

The cyclic changes in heart performance during artifjcial ventilation have to be ascribed to mechanisms with short time constants because they occur and recover witnin the period of a ventilatory cycle. Therefore, nervous and humoral control as well as cardiac contractility changes are rejected as mechanisms explaining the cyclic events.

Guyton's theory, that venous return $\left(\dot{Q}_{V}\right)$ is controlled by central venous pressure $\left(P_{C v}\right)$, also counts for the cyclic events during artificial ventilation. $\mathrm{P}_{\mathrm{CV}}$ is mainly dependent on intrathoracic pressure $\left(\mathrm{P}_{\mathrm{th}}\right)$, although a decrease of $\mathrm{P}_{\mathrm{CV}}, \mathrm{tm}$ (transmural) occurs during insufflation: the decrease in venous return due to the increase in $P_{C y}$ causes a decrease in filling pressure i.e. preload. Also transmural pulmonary artery pressure $(\mathrm{Ppa}, \mathrm{tm})$ decreases during insufflation when PEEP is below about $6 \mathrm{cmH} 2 \mathrm{O}$. This fall in afterload might contribute to the decrease in RV-filling pressure. Above a PEEP of $6 \mathrm{cmH}_{2} \mathrm{O}, \mathrm{p}_{\mathrm{pa}} \mathrm{tm}$ at peak insufflation increases progressively, when PEEP increases, undoubtedly due to a progressive obstruction of the pulmonary circulation. The fall in venous return to the left ventricle (LV) can be ascribed to the fall in RV-output. The time delay can be explained by a squeezing effect on the pulmonary circulation during early insufflation. Plved, tm fell during late insufflation and early expiration concomitantly with the fall in pulmonary venous return. Tinis fall also caused a fall in transmural aortic pressure. Cardiac compression and ventricular interdependence were rejected as mechanisms controlling heart action during artificial ventilation.

10

EFFECTS OF PEEP ON RIGHT VENTRICULAR FUNCTION IN ARDS PATIENTS. J.E. Dhainaut, J.Y. Devaux, B. Schlemmer, O. Salmon, V. Fourestié, A. Carli et J.F. Monsallier. Departments of Intensive Care and Nuclear Medicine. Hop. Cochin.F 75674 PARIS Cédex 14 .

To identify the mechanisms responsible for decreased right ventricular (RV) performance during mechanical ventilation with high levels of PEEP in ARDS pts and the effects of mormalizing cardiac output by volume expansion (VE), we studied 10 such pts. RV volumes (EDV-ESV) were calculated by both thermodilution and radionuclide studies at $0,15,20,25 \mathrm{~cm} \mathrm{H} 2 \mathrm{O}$ PEEP and after VE. While heart rate remained unchanged, stroke yolume (SV) gradually fell with PEEP from $40 \pm 2$ TO $31 \pm 3 \mathrm{ml} / \mathrm{M} 2$ at $25 \mathrm{~cm}$ $\mathrm{H} 2$ O PEEP and returned to prePEEP values afterVE.

\begin{tabular}{lrrrrrr} 
& & & \multicolumn{2}{c}{25} & $25+\mathrm{VE}$ \\
EDV & $85 \pm$ & 5 & 64 & \pm & $8^{\circ}$ & $85 \pm$ \\
ESV & $45 \pm$ & 5 & $33 \pm$ & \pm & $7^{\circ}$ & $44 \pm 9$ \\
EF & $.47 \pm$ & \pm 4 & .49 & \pm & .05 & $.48 \pm .05$ \\
ESPt & $28 \pm$ & 5 & $31 \pm$ & \pm & $37 \pm 7^{\circ}$
\end{tabular}

$E F=$ ejection fraction, ESPt $=$ transmural endsystolic pressure, .p $<$. OI PEEP O vs 25

Conclusions : In ARDS pts, PEEP decreases RVSV by imposed limitation on EDV (due to increased intrathoracic pressure) despite a higher after load. RV contractility tends to increase (left ward shift of the RVESPt-V relationship) probably due to increased catecholamine levels. After VE, SV returns to prePEEP values in relation to increased preload and sustained increase in contractility.

\section{1}

LV FUISTION DURING IIECHAIICAL VENTILATION. J.L. Robotham, liniversity of iexas Health Science Center at San Antonio, San Antonio, Texas.

Conventional wisdom sugges ts that the dominant hemodynamic factor during IPPV is the inspiratory reduction in systemic venous return and hence a secondary reduction in LV output. The purpose of this paper is to question tilis simp1iscic approach to analysis of the LV during IPPV in critically ill patients. Under pathologic conditions, (e.g. congestive failure) other factors will theoreticaliy become increasingly important based on a physiologic analys is of IPPV.

Variables to be examined which have been found to influence LV performance during IPPV include: a) inspiratory expiratory variation in RV and LV stroke volume b) influence of respiratory rate (from 10 breaths per minute to 10 per second) and the influence of the I-E ratio c) changes in pulmonary vascular volume, e.g. hypovolemia or pulmonary edema d) end expiratory lung volume, i.e. PEEP e) changes in tidal volume and its effects bo toi on pulmonary vascular volume and mechanical compression of the heart by the lung $f$ ) changes in heart volume on mechanical heart-lung interaction g) the increases in inspiratory pleural pressure acting to effectively reduce $L V$ afterload $h$ ) respiratory changes in abdominal pressure which may influence not oniy venous return but also LV afterload and regional distribution of cardiac output $i$ ) regional changes in LV geometry produced by IPPV with and without PEEP, and $j$ ) the influence variation in right heart volume during the respiratory cycle on LV performance.

From analysis of the above, it is concluded that under pathologic conditions, multiple factors other than changes in sys temic venous return may significantiy affect LV performance during IPPV. It is hypothesized that when better understood, IPPV may be able to assist LV performance in critically compromised patients. 


\section{New Trends in Therapy}

NEW METHODS FOR ASSESSING GAS EXCHANGE. F. LEMAIRE, Hôpital Henri Mondor, F - 94010 CRETEIL Cédex.

The oxygen method (Berggreen, 1942) is routinely used in the ICU to evaluate venous admixture. However, values obtained by this method may vary according to the inspired $\mathrm{FiO}_{2}$. New methods have emerged to provide reliable assessment of gas exchange. The Kryptonm 83 scintigram can be used to evaluate the distribution of regional $V A / Q$. This short lived isotope, highly soluble in ras and liquid phase, provides scintigrams of ventilation and perfusion when inhaled and infused intravenously. The two scans can be compared and VA/Q ratio can be evaluated zone by zone. This method best used when regional al terations of ventilation and/or perfusion are suspected (outmonary enbolism, emphysema, unilateral pneumonia) and evaluate the role of changes in body position on gas exchange.

The six inert gas method, proposed by Wagner et Evans in 1974 , assesses the abnormalities in $V A / \dot{Q}$ distribution, irrespective of their topography. The high sensitivity of this method is its major advantage, since the use of highty insoluble gas (SF6, ethane) can detect zones with $V A / Q$ ratios of lower than 0,01 . The infusion of the most soluble gas (acetone, ether) provides a measurement of dead space. Additionally, this method is not dependent on $\mathrm{FiO}_{2}$ and oxygen diffusion. It can be applied to patients with mechanical ventilation in the ICU, without changing the $\mathrm{FiO}_{2}$. So far, this method has been mainly directed at evaluating the effect of mechanical ventilation, with and without PEEP, anesthesia, decubitus, pulmonary edema, ARDS. However, technical difficulties require highly specialized laboratory, and prevent its routine use. The method offers a sophisticated aporoach for understanding the complex $V_{A} / Q$ relationshio in lung disease.

13

DIFFERENTIAL VENTILATION IN BILATERAL LUNG DISFASE. G. Hedenstierna, Dept. of Clinical Physiology, Huddince Hospita 1, Stockholm, Sweden

Anaesthesia and acute respiratory failure impede vnetilation of dependent luna units and perfusion of non-dependent ones, creating considerable ventilation-perfusion $(\dot{V} / \hat{Q})$ mismatch. General PEEP can improve $\dot{V} / \dot{Q}$ but it cannot restore it to normal. To improve matching, ventilation must be distributed in proportion to regional blood flow. This can be accomplished by 1) placing the subject in the lateral position, 2) ventilating each lung in proportion to its blood flow (differential ventilation) and 3) applying PEEP solely to the dependent lung to ensure even distribution of inspired gas within that lung (selective PEEP). Differential ventilation with equal distribution of the tidal volume between the lungs and a selective PEEP of $10 \mathrm{~cm} \mathrm{H} O$ to the dependent lung resulted in equal distribution of perfusion between the lunas in anaesthetized lung-healthy subjects, suggesting "optimum" $\dot{V} / 0$ matching. Using this ventilator setting as a rule of thumb in patients with acute, severe, bilateral lung disease, arterial oxygen tension was improved by an average of $45 \%$ compared with that during general PEEP, with no reduction in cardiac output. It is concluded that differential ventilation with selective PEEP can offer considerable improvement in gas exchange in acute, bilateral lung disease.

Table Cardiac output $\left(\dot{Q}_{T}\right)$, venous admixture $\left(\dot{Q}_{S} / \dot{Q}_{T}\right)$, arterial oxygen tension ( $P_{2}$ ) and oxygen avajlability $\left(\mathrm{O}_{\text {2avait }}\right)$ in 8 patients with acute bilateral lung disease Supine Supine Left lateral Left lateral

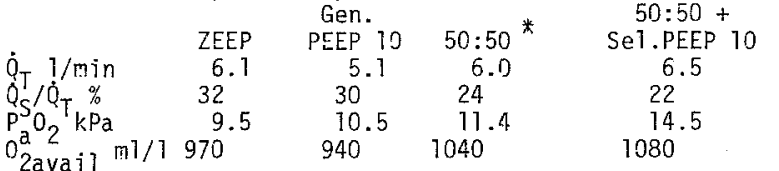

*: equal distribution of ventilation between the lungs.
HIGH FREQUENCY VENTILATION (HFV) : UPDATE ON INDICATIONS AND TECHNIQUES.H.Benzer,M.Baum,St.Duma, W. Koller, N.Mutz, G.Pauser, Klinik für Anaesthesie u. Allgem. Intensivmed, ,Universität Wien, Austria

Since the introduction of High Frequency Jet Ver tilation (HFJV) $\left(f=1,5-5 \mathrm{~Hz}, V_{\mathrm{T}}>\mathrm{V}\right.$ ) other HFV systems has been designed. In High Frequency Pulsation (HFP) better elimination of $\mathrm{CO}_{2}$ is managed by transversely flowing current of fresh gas and in using a circle with $\mathrm{CO}_{2}$-absorber $(\mathrm{f}=5-9 \mathrm{~Hz})$, $\left.V_{\eta} \leqslant V_{D}\right)$. In Forced Diffusion Ventilation(FDV) 2 jet nozzles are located at the distal end of the tube ( $f=u p$ to $25 \mathrm{~Hz}, v_{\mathrm{T}}=10-3 \mathrm{oml}$ ). In the field of High Fre quency Oscillation(HFO) we developed the so called Pneumatic $\mathrm{HFO}(\mathrm{f}=\mathrm{up}$ to $12 \mathrm{~Hz}$ ). Indications for $H F V$ are based upon our clinical experiences in 137 patients: 1. Postoperative ventilation in car diac patients $(n=45)$. Gasexchange could be maintained well during controlled ventilation and the weaning period. Conteraction to hemodynamics depends on $f, I / E-r a t i o$ and primary pressure. 2. Intraoperative application of HFV (lung surgery) $(n=36)$ is favourable (extensive resting position of the lungs, reduced gas loss through pleural leakage).3. Intensive care patients $(n=56)$. In ARDS better $\mathrm{PaO}_{2}$ in comparison to conventional ventilation could be established in using high frequencies $(5 \mathrm{~Hz})$ long $\mathrm{I} / \mathrm{E}$ ratio and high primary pressure. Bronchopleural fistulae were managed with FDV (low $\mathrm{V}_{\mathrm{T}}$ ), the combination with IPPV faciliated $\mathrm{CO}_{2}$ elimination. In normal lung function low frequencies $(1,5-5 \mathrm{~Hz})$ short $\mathrm{I} / \mathrm{E}-$ ratio and low primary pressure $(1,5-2$ bar) achieved satisfactory gas exchange with low

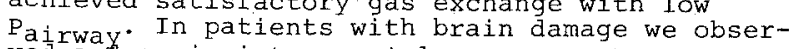
ved a arop in intracranial pressure. HFP acts as a advantageous method of augmented ventilation (flail chest) and is a suitable method for breathing therapy.

15

HIGH FREQUENCY OSCILLATION: EFFECTS ON LUNG MECHANICS AND CARDIAC FUNCTION. J. Armengol, R.L. Jones, E.G. King. Hospital de Sant Pau, Barcelona, Spain and University Hospital, Edmonton, Canada.

We studied the effects of high frequency oscillatory ventilation (HFOV) on gas exchange, hemodynamics and basic pulmonary mechanics in dogs with normal and stiff lungs. In a group of 9 healthy animals, HFOV maintained normal gas exchange but cardiac output decreased and pulmonary and peripheral resistances rose. In another group of 5 dogs, HFOV was found to increase functional residual capacity (FRC), mean airway and pleural pressures. This effect was more accentuated at high oscillatory frequencies. The FRC was measured over a 16 minute period and found to increase around $60 \%$ during the first minute, after which it remained stable. The effects of HFov were also studied in 8 other dogs which were first lavaged with saline to remove some surfactant and produce stiff and unstable lungs. HFOV produced a higher FRC than positive endexpiratory pressure even though mean airway pressures were similar. In these animals $\mathrm{A}^{-} \mathrm{DDO}_{2}$ gradients were lower during HFOV but $\mathrm{CO}_{2}$ ' elimination was somewhat decreased. We conclude that although HFOV can achieve gas exchange in normal and stiff lungs, the cardiovascular function may be impaired, probably due to its effect on lung volumes. 
16

INDICATIONS FOR EXTRACORPOREAL $\mathrm{CO}_{2}$ REMOVAL

L. Gattinoni

Istituto di Anestesia e Rianimazione, Univer-

sità di Milano, Milano, Italia

Extracorporeal $\mathrm{CO}_{2}$ removal $\left(\mathrm{ECCO}_{2} \mathrm{R}\right)$ with low frequency positive pressure ventilation (LFPPV) has been introduced in clinical practice in 1979. Most of the experience with this technique has been gained in Milano (22 pts) even tought few other pts recently underwent LFPPV-ECCO $R$ in West Germany, U.S.A. and Australia. All the pts had severe ARDS of various etiology: politrauma, viral and bacterial pneumonia, fat embolism and septic, toxic shock lung. The relatively small number of patients does not allow to suggest any indication on etiological basis, even tought an higher rate of success has been reached in some etiological group (Shock lung, fat embolism, virus and bacterial pneumonia). To date the entry criteria are based on functional data: 1) blood gases values under defined ventilatory conditions, as proposed in the American extracorporeal membrane lung oxygenation study; 2) total static lung compliance lower than $30 \mathrm{ml} \mathrm{cmH} \mathrm{O}^{-1}$, when measured at 10 $\mathrm{ml} \mathrm{kg}{ }^{-1}$ lung inflaction. These criteria still entail a mortality rate close to $100 \%$ with conventional treatment.

Controindications to the treatment remain systemic degenerative diseases, severe head injury and pulmonary active bleeding (including hemothorax). 


\section{Cardiovascular Intensive Care I. Acute Arrhythmias}

EXPERIMENTAL ELECTROPHYSIOLOGICAL BASIS OF ARRHYTHMTAS IN ISCHEMIC HEART DISEASE - H.Antoni, Physiolog. Inst. Univ. of Freiburg i.Br., Hermann Herder Str. 7 D 7800 Freiburg i.Br.

Cardiac arrhythmias accompanying ischemic heart disease include disturbances of impulse formation (depressed or enhanced automaticity) as well as of impulse conduction (block of conduction, reentry). The primary causes of these disturbances are the decreases of the ionic gradients $(\mathrm{K}, \mathrm{Na}, \mathrm{Ca})$ due to the lack of energy supply and specific effects of acidosis or of metabolites due to inappropriate perfusion.

Depression of the regular automaticity as well as of impulse conduction is favoured by the decrease of the $\mathrm{KS}-, \mathrm{Na}-$, and $\mathrm{Ca}-$ gradients and by acidosis. Ectopic focal activity is enhanced by the release of sympathetic transmitters and by injury currents occuring in the border zone of an acute myocardial infarction. Horeover, acidosis favours the development of ectopic focal activity by inducing early afterdepolarizations in Purkinje fibres.

The production of reentry requixes shortening of the waves of excitation either by accelerated repolarization or by slowing of the propagation of impulses or by both. The slowing of impulse conduction might be due to the generation of slow responses in depolarized fibres exposed to sympathetic stimulation. Moreover, an appropriate delay of conduction may also result from the electrotonic spread of excitation across damaged inexcitable tissue. A non-homogeneous state of excitability of the heart forms another condition indispensible for reentry because it enables unidirectional conduction to take place. Nonhomageneous excitability is normally encountered during the early phase of recovery in the cardiac excitatory cycle (vulnerable period) and is strongly increased by frequent extrasystoles.

21

CLINICAL PHARMACOLOGY OF ANTIARRHYTMIC DRUGS. F. Follath. Division of Clinical Pharmacology, Department of Medicine, University Hospital, Base1, Switzer]and.

An exact knowledge of the pharmacodynamic and pharmacokinetic properties of antiarrhytmic agents is essential for their optimum use in intensive care patients. The electrophysiological mechanisms of action, as well as possible effects on sinoatrial, atrioventricular or intraventricular conduction, myocardial contractility and peripheral resistance should be taken into account when a particular drug is selected to treat acute ventricular or supraventricular arrhytmias.A further decisive factor for therapeutic success is the choice of an adequate dosage regimen. Potentially effective drugs may fail because the therapeutic serum drug levels are not reached and/or maintained during a dosage interval. Drug el imination rate in acutely i] 1 patients is often altered by cardiac, hepatic and rena] failure or by interacting drugs administered simultaneously. Individualization of antiarrhytmic drug dosage is therefore necessary to obtain maximum benefit and to avoid unwanted side-effects. This task can be facilitated by serum drug concentration monitoring. Rapid and reliable techniques for measuring 7 idocaine, procainamide, quinidine and disopyramide concentrations are now available. The practicability and utility of this approach will be illustrated by data on lidocaine treatment in patients with ventricular arrhythmias following myocardial infarction.
22

DETECTION AND DOCUMENTATION OF ARRHYTHMIAS - R. Ritz, Intensive Care Unit, Dep. Internal Med., University of Basle

The computerized arrhythmia-monitoring system allows 1) recognition of ectopic beats, for a potentially prophylactic treatment, 2) instantaneous alerting to the first occurrence of life-threatening arrhythmias, including documentation of the preceding rhythm, 3) detection of a need for special procedures, e.g. pacemaker, by announcing even short periods of "omitted beats" (sick sinus), and 4)checking of therapeutic management, e.g. testing of antiarrhythmic drugs in chronic coronary heart disease or paceriaker function.

In patients with acute coronary heart disease the value of antiarrhythmic treatment of the so-called "warning" ventricular ectopic beats to prevent ventriculax tachycardia or fibrillation is still questionable. As long as such arrhythmias are treated routinely in most coronary care units, worldwide, the reliable detection of ectopic beats is essential. The conservative methods of continuous ECG observation on a scope of up to eight patients at a time is no longer a justifiable task for well trained and highly skilled CCU personnel, for two reasons: 1) Even persons specialized in rhythm recognition miss up to $60 \%$ of ectopic beats during more or less continuous observation of an ECG display screen. 2) ECG reading is a typical task for the computer. An investigation of the specificity and sensitivity of our arrhythmia-monitoring system (HP 78220) still revealed a considerable number of false-positive alams, disturbing the nursing staff unnecessarily, but ahigh sensitivity of more than $90 \%$ in the detection of ectopic beats $(n=10.400)$ represents an increased level of security for the patients. Histographical presentation of the trend of the arrhythmias facilitates the overview, while TV display in all. rooms of the $\mathrm{CCU}$ and the proven reliability of the system give the nursing staff more freedom in patient care. our nurses would now certainly not like to have to live without the system.

23

ANTIARRHYTHMIC PROPHYLAXIS IN ACUTE MYOCARDIAL INFARCTION K.I. Lie, Department of Cardiology \& Clinical Physiology, Wilhelmina Gasthuis, Amsterdam, the Netherlands

Nany antiarrhythmic drugs have been studied on their efficacy in preventing primary ventricular fibrillation in acute myocardial infarction, but only lidocaine given in rather high dosages has been shown to be effective in one randomized controlled study. In view of the rather high incidence of side effects this latter study and the equal mortality rates in both groups, prophylactic antiarrhythmic treatment in a 11 patients admitted to the CCU because of acute myocardial infarction is questionnable. However, recent uncontrolled observations on lidocaine have indicated a very low incidence of primary ventricular fibrillation and one case controlled study showed a lower hospital mortality in lidocaine treated patients. Moreover $20 \%$ of untreated patients will develop recurrent attacks of ventricular fibrillation which may lead to extension of infarction and higher mortality rates. other studies have suggested that effective lidocaine prophylaxis during 48 hours can be achieved with an acceptable incidence of minor side effects and a low toxicity provided that the following measures are undertaken:

1. adequate loading dosages of $200 \mathrm{mg}$ given in $10-20$ minutes,

2. continuous administration using automatic infusion pumps in dosages averaging $3 \mathrm{mg} / \mathrm{minute}$,

3. carefull monitoring of side effects and abrupt discontinuing when they supervene,

4. reducing dosages by at 1 east $50 \%$ in shock, heart failure or hepatocellular disease.

It may be concluded that prophylactic antiarrhythmic treatment with lidocaine is preferable than placebo, provided that adequate measures are undertaken. 
MASSIVE PULMONARY EMBOLISM : DIAGNOSTIC ASPECTS. P. Even, D.Safran, G.Dennewald, M.Stern, P.Reynaud, H.Sors.Hôpital Laennec, 75007 Paris, France.

500 patients with pulmonary embolism (PE) were studied by heart catheterization, perfusion lung scan (PS) and angio graphy (PA) and some by ventilation scan (VS) or digitalized substraction angiography; $40 \%$ had massive PE $(\geqslant 60 \%$ vascular obstruction-Miller index). In spite of new sophisticated investigation methods the initial diagnosis remained desperately erratic and delayed (1-90 days) with an eqal number $(60 \%)$ of false positives or false negatives el iciting dramatic consequences : recurrent PE and undue and hazardous anticoagulation or surgery. The main errors were : a) in non-massive PE, acute or chronic lung diseases (pneumonias, atelectasis, cancer, as thma, pleu-. risy) b) in massive PE, heart, abdominal, septic or nervous diseases (myocardial infarction, cardiac tamponade, dissecting aneurysm, hypovolaemic or septic shocks, acute peritonitis, liver or sub-phrenic abcesses, acute cholecystitis or pancreatitis, stroke). To improve the diagnosis performance we have reexamined the sensitivity and specificity of clinical and laboratory findings rather their frequency order. We propose the following statements : 1) always think to PE but never accept it without proof, 2) there is no benign PE but only benign first $\mathrm{PE}, 3)$ there is no unic massive and lethal PE but only multirecurrent $P E, 4)$ a suspected PE has to be urgently proved or disproved and energically treated whatever its importance, 5) the decreasing order of specifity is : PA (to affirm) $=-P S$ (to eliminate) $>$ Chest $X$-ray $\gg$ phiebitis, associated symptoms (pain + dyspnea + hemoptysis), etiology, EKG, hemodynamics, 》 isolated symptom, blood gas, enzymes, iung scan (to affirm), 6) VS gives rarely more infarmation than PS, 7) recurrency has to be proved by PA and not by PS, 8) PA has to be performed as frequert7y as possible to establish the diagnosis, specify the site and size of the clots and control the venous itiocaval axis.

\section{6}

ACUTE RIGHT HEART FAILURE IN MASSIVE PULMONARY EMBOLISM. A. Bloch, O. Guinand, Hôpital de la Tour, Meyrin-Geneva, Switzerland. Massive pulmonary embolism (MPE), obstructing more than $50 \%$ of the pulmonary circulation, leads to an increase in pulmonary artery (PA) resistance, PA pressure and right ventricular (RV) work. This will lead to acute RV failure (acute cor pulmonale) and decrease of pulmonary flow and cardiac output.

Echocardiography has revealed several abnormalities in patients with MPE. 1) Dilatation of the $\mathrm{PA}$ and right ventricle. The size of the PA appears to correlate well with the mean PA pressure. 2) Decrease of the left ventricular dimension. Additional inspiratory decrease in left heart volume may lead to failure of aortic valve opening and therefore to paradoxical pulse. 3) $\mathrm{Ab}-$ normally high ratio of right/left ventricular enddiastolic diameter. This index correlates well with the angiographic severity of the embolic obstruction in patients without prior cardio pulmonary disease. 4) Abnormal (paradoxical) diastolic motion of the interventricular septum. 5) Abnormal motion of mitral or tricuspid valve. Echocardiographic association of a large right ventricle, a small left ventricle and a paradoxical motion of the septum is very common in MPE and allows to explain the physical findings. Dyspnea, tachypnea and tachycardia are usually present in MPE. Other findings may indicate acute cor pulmonale: accentuation of the pulmonic closing sound, RV diastolic gallop, elevated jugular venous pressure with large $\mathrm{A}$ waves. These abnormal signs and symptoms will progressively disappear with the spontaneous or therapeutical removal of pulmonary embolic obstruction.
MASSIVE PULMONARY EMBOLISM - FIBRINOLYSIS INDICATIONS AND LIMITS. G.A.H. Miller, Cardiac Department, Brompton Hospital, Fulham Road, London. SW3 6HP

Fibrinolysis is not indicated in minor embolism where there is no haemodynamic disturbance and is ineffective in chronic thromboembolism. Its use is limited to acute massive embolism (with or without shock) when it is the treatment of choice. In such patients accelerated resolution has been demonstrated (as compared with anticoagulant therapy) in a number of studies. Improved survival has not been demonstrated and would require larger studies than have been practicable. Fibrinolysis is contraindicated when there is an increased risk of bleeding or where haemorrhage would have a high risk. Fibrinolysis may be contraindicated in supra-massive embolism where only embolectomy provides rapid enough reversal of the haemodynamic disturbance. Fibrinolysis becomes less effective when the duration of embolism extends beyond 48 hours. Bleeding complications are no more common than with anticoagulant therapy. Whatever the initial treatment there is little if any late mortality or morbidity in survivors of massive embolism who received energetic treatment.

TROMBENDARTERECTOMY OF THE PULMONARY ARTERY IN CHRCNIC PULMONARY EMBOLISM WITH PULMONARY HYPBRTENSION AND COR PULMONALE, V.O.Björk, I. Bengtsson, A. Holmgren. Dept.of Thoracic Surgery, Karolinska hospital, Stockholm, Sweden.

Chronic pulmonary embolism with pulmonary hypertension and cor pulmonale can, after intense functional and anatomic investigation, be treated succesfully with TEA of the pulmonaxy artery. Perfusion scintigram is for screening a simple and informative procedure. Pulmonary angiogram is accurate for anatomical localisation, and angiogram of the bronchial arteries important to assure a well functioning periferal circulation of the pulmonary vessels. Heart catheterization is necessary to evaluate the degree of pulmonaxy hypertension, which is the most important prognostic variable for succesful surgery, the better profnosis the lower pressure. The cases of three young women with chronic pulmonary embolism with systolic pulmonary pressure of three different levels about 25,80 and125 $\mathrm{mm} \mathrm{Hg}$ respectively were all operated with IEA at clinic of Thoracic surgery, Karolinska hospital, Stockholm, with results corresponding to preoperative pulmonary pressure. The importance of early diagnosis before severe pulmonary hypertension has developed is stressed and the value of adequate diagnostic methods is illustrated. Operation is to be done with cardio-pulmonary by pass stand by. With proper investigation and treatment in cooperation with surgeons, cardiologists, physiologists and radiologists the prognosis for chronio pulmonary embolism with pulmonary hypertension and cor pulmonale encouraging for many patients, where although optimal pharmacological treatment, progressive heart and pulmonary incompetence develops. 


\section{Aortic Dissection}

29

AORTIC DISSECTION - CLASSIFICATION AND DIAGNOSTIC PROCEDURES. F.G.M. ROSS, E.R. Davies, Bristol Royal Infirmary, Bristol BS2 8HW, England. The universally accepted classification of Dissecting Aortic Aneurysms defined by De Bakey et al (1965) will be described and two others mentioned. The role of diagnostic imaging methods, particularly radiology, ultrasound and computed tomography in determining the presence of a dissecting aneurysm of the aorta and in demonstrating its site and extent, including involvement of branches of the aorta, will be discussed and illustrated. A review of 15 cases of surgically treated dissecting aortic aneurysms will be presented.

Reference: De Bakey et al (1965). Surgical Management of Dissecting Aneurysm of the Aorta. J. Thorac. Cardiovasc. Surg. 49, $130-149$.
31

ACUTE AORTIC DISSECTION: SURGICAL MANAGEMENT AND RESULTS. Tam Treasure and R.K.Firmin; The Middlesex and The London Chest Hospitals.

We use the classification suggested by Shumway group in which all dissections invalving the ascending aorta are TYPE $A$ and those confined to the descending aorta are termed TYFE B. We have reviewed a series of 24 cases (17 men and 7 women) where the eatheter diagnosis was aortic dissection: 19 TYFE $A$ end 5 TYFE B. Surgical correction was attempted in 17 and 2 cases with a hospital mortality of $24 \%$ and $50 \%$ respectively. These small numbers are in general agregment with published series. We have therefore adopted the follawing policy. Acuta TYPE A dissections are managed surgically and operation is performed as soon as fossible. Medical management carries a mortality of $30-90 \%$ with death being due to rupture into the pericardium, coronary artery acclusion or severe aortic regurgitation. Surgery reduces this to the region of $25-35 \%$. Freoperative hypotensive measures are considered to be important and the operation should be kept to the minimum consistert with repairing the ascending aorta and assoriated iesions. TYPE $D$ dissections have a mortality of around so\% whether managed medically or surgically with spinal cord complications an additional operative hazard. TYPE $B$ are thergfore managed medically. We use CT scanning as an indicator of coritinuing erilargement of the aneurysm and resort to surgary in that sut-group.

30

AORTIC DISSECTION: NATURAL COURSE AND MEDICAL MANAGEMENT. P.C. Baumann, Medical Intensive Therapy Unit, University Hospital, $\mathrm{CH}-809]$ Zurich, Switzerland

The mortality of aortic dissection is very high and the death rate is approximately $83 \%$ one month from date of onset, if the course is not altered by treatment (1).

The prognosis is influenced by the localization of the dissection. Without surgical treatment it is extremely poor in patients with proximal dissections (type A or

I/II by the DeBakey classification) with early rupture into the pericardium being the main cause of death. Medical management al one should not be considered unless there are serious contraindications to surgery.

Patients with distal dissections (type B or III) should be treated medically in the acute phase, if there are no major complications such as bleeding, obstruction of major arteries or continuing enlargement and pain.

If there is no hypotension medical therapy usually consists of a peripheral vasodilator (e.g. sodium nitroprusside) to lower blood pressure in combination with a beta-adrenergic blocking agent to reduce myocardial contractile force. Blood pressure is kept as low as possible. A diuretic and medications for pain and sedation may be added.

From 1975 to 1982123 patients with acute aortic dissections ( 80 type $A, 43$ type B) were admitted to our Medical Intensive Therapy Unit. Therapy in the acute phase was purely medical in $64 \%$ with type $A$ and in $79 \%$ with type $B$. Death rate within 4 weeks was $84 \%(A)$ and $29 \%$ (B). Death rate in those who were operated in the acute phase was $34 \%(A)$ and $56 \%$ (B).

Ref.: (1) Anagnostopou 1os C.E. et al. Am J Cardiol 1972; 30: 263-73. 


\section{Formation}

\section{$32 \mathrm{~A}$}

RECRUTMENT OF PERSONNEL FOR I.C.U. E. Staub, Bern. This report concerns our experience in the I.C.U. in the Inselspital in Bern. In an I.C.U. recognized for specialized education some regulations exist concerning the minimum number of nurses, as well as the ratio between nurses in training and I.C.U. staff. We could only achieve satisfactory results after greatly increasing the number of trained nurses. The change from one I.C.U. to another is a great problem not only for trained I.C.U. nurses but even more so for I.C.U. student nurses, who have to complete their education in a second unit. Since unfortunateTy supply is less than demand, departing I.C.U. nurses with "capacity certificates"often must be replaced by untrained nurses in the I.C.U. The number of candidates for I.C.U. training courses is sufficient to satisty demand, but not enough to allow a selection of highly capable I. C.U. nurses.

PRACTICAL EDUCATION OF NURSES J. Grosqurin-Robert, Soins Intensifs de Medecine, Genève.

A group of head nurses working in ten different size swiss hospital.s developped a programme to achieve common practical goals which could be inserted into the educative programm of intensive care nurses. This programme will be presented.
$32 \mathrm{D}$

PROBL GYIS OF A TRAINING UNIT. M. HOESS, UTIVERSITAETSSPITAL ZUERICH， 8092 ZUERICH

I would like to indicate the problems and trends of developement:

I. Overstrain by the increase of dangerously ill patients, 2. Physical and psychical strain on the nursing staff, 3. Increasing technicalisation of the intensive care

To point I: The nurses starting their intensive care training are often unable to cope with the hish demands in supervision. The only answer to these problems is a thorough and gradual introduction. I would like to consider in detail the introductory concept of the Universitätsspital

Zïirich.

To point 2 : In the future the shift work will confront us with serious problems. It has to be possible to find specific solutions for special units. The continuous monitoring requires a maximum of concentration and senæof responsibilj. ty. The daily confrontation with other peoples destiny must not turn into ones own fate. The constant confrontation with live and death requires strong personalities.

To point 3: The technical developement has to be critically abserved by the stafi since a continuos supervision and control of the equipment means security for the patient. Technology is only ment to serve as an aid to do the daily work.

We should open our intensive care units to the public so that critical persons too may get an insight of the security described by patients who have been in an intensive care unit. To give the whole staff the possibility to take part in the developements, directives if necessary definition of position, should be worked out. Only he who accepts the challenge can look forward to the future.

\section{$32 \mathrm{E}$}

STAFFING AND EDUCATION OF NURSES IN OXFORD. C.E. Church SRN.DipN(LON)Nursing Officer ITU/CCU John Radcliffe Hospital, Oxford, England.

The Intensive Therapy Unit (ITU) in Oxford is classed as a general Unit for there is a separate Coronary Care Unit and paediatric ITU. The ITU is set up with 8 beds, 2 of which are high dependancy and medically the Unit is run by anaesthetists. There is a small commitment to cardio-thoracic surgery, otherwise general medicine,surgery, trauma and renal cases are admitted. To cover these 8 beds there is a total of 47 trained nurses plus 2 Student nurses in basic training; for a period of 1 month, and post basic course nurses. These are people undertaking National recognised Courses in various specialities; Intensive Care, Accident and Emergency Nursing and Anaesthetic Nursing. There are 6 ITU Course members, of which we have a minimum of 2 and maximum of 6 at anyone time. The other 2 Courses never send more than 2 members each at anyone time. A part from these various other people from different areas come for a period of orientation ie Renal Course, theatre assistant trainees. of the 47 permanent team, 6 are Sisters, 31 are Staff Nurses (3 yr.general training) and 10 Enrolled Nurses (2 yr.general training). The Unit is covered with two-eight hr. shifts overlapping during the day and an $11 \frac{1}{2} \mathrm{hr}$ night. There is a minimum of 8 nurses per shift plus basic and post basic learners. The average lenght of stay of staff is about 7 month, that means a continual recruitment programme, stepped up just before the Summer as this is when the ma in drop occurs $70 \%$ of the permanent team hold a nationally recognised ITU nursing certificate, the other $30 \%$ are made up of people with little or no experience in this speciality, consequently the teaching input has to be high, and the overlap period in the afternoon is an ideal time to do lectures.Education of all staff not only Course members and learners, but experienced staff must be an ongoing process to train and maintain motivation.ATl staff, commen- 
cing employment undergo a 3 day general hospital orientation. Staff within the Unjt then work with experienced members of staff for the first two weeks and have lectures on basic monitoring and ventilating equipment technique. Following this, those staff programme involving lectures and clinical teaching on basic ITU knowledge and skills ie Care of Ventilated patient, from both staff nurses and Sisters. Intravenous additives and arterial line assessments are taken by all staff before they are able to administer drugs or take blood specimens from arterial lines. Staff are predominantiy trained by the bedside with one to one teaching which is ideal for gauging knowledge and adaptibility of the learner. Impromptu lectures are given by all staff including Doctors, depending on work load on the Unit.Available each day are lectures for staff to attend; general hospital sessions, lectures from all disciplines specifically for ITU nurses, XRay conferences; to short talks given by the staff nurses themselves. The nationally recognised ITU Course is run in Oxford and whilst they have a clinical tutor attached to the Course, the Sisters are very much involved in teaching members, and 271 course lectures are open for all Unit staff to attend. The Heal th Authority periodically run Courses mainly for Sisters to extend their managerial skills ie Art of Assessing, Interviewing Skills and every 6 months all staff are seen, to be given career guidance and counselling, so they and their seniors are aware of their progress, capabilities, new avenues to be explored, and where they are going in the future.

\section{Dotation en Personnel}

\section{$32 \mathrm{~F} \mathrm{H}$}

PATIENT CATEGORIES IN INTENSIVE CARE: THE SYSTEM USED IN SWITZERLAND. F. Trembley, Soins Intensifs de Chirurgie, Genève.

In 1976 guidelines for categorizing intensive care patients and staffing requirement, were issued by the Swiss Society of Intensive Care Medecine. The patients are divided into 3 main categories, according to the equipment required for therapeutic intervention. The guidel ines do not el iminate completely the problem of allocation of patients to different categories; this varies between I.C.U's.Once the category is established a simple formula is used to determine the staffing required.

CRITERIA FOR NURSING STAFF REQUIREMENTS IN THE I.C.U. F. Trembley, Soins. Intensifs de Chirurgie, Genève. Since no satisfactory rules exist on how to staff adequatly an I.C.U., a group of nurses and physicians was created in order to attempt to establish objective criteria for staffing the I.C.U.For that purpose a protocol was created to produce data concerning the time involved in different nursing care procedures, administration and education.

PROBLEMS AND SPECIFICITY OF AN INTENSIVE CARE UNIT IN A REGIONAL HOSPITAL.F.Payot R.H., Hôpial Régional, 2900 Porrentruy, Switzerland.

The organization and topography of an I.C.U. in a Regional Hospital are presented. The following problems are considered :-Guidance for the team,-personal responsability of nurses facing emergencies,-difficulties in recruitingstaff nurses for remote and non-urban areas.

NURSING CARE PROBLEMS IN PATIENTS TREATED BY LAPAROTOMY L. Douchamps-F. Turc-P.Meier- Soins Intensifs de Chirurgie, Genêve.

Presentation of a patient treated with laparostomy for several weeks and the specific problems, their implications on nursing care. Aims, actions, evaluation of the treatment.
$32 \mathrm{G}$

SEVERITY INDEXES (S.I.) IN INTENSIVE CARE UNITS (ICU) Jean-Roger LE GALL -HENRI MONDOR HOSPITAL-CRETEIL-FRANCE

Recent advances in medical technology have increased our ability to treat many ilinesses included those involving previously fatal physiologic problems. New questions have come about when to use an how to determine value of these new developments. A classification of patients based upon the acute severity of their illness would be very helpful not to predict survival for individual patients, but to provide a precise estimate of risk of death for groups of acutely ill patients and, perhaps, a precise estimate of the staff requirements.

Two methods can be used to built a S.I. : the discriminant analysis and the subjective methods. In all cases the SI will be used by other hospitals only if it has reliability, validity criteria, data requirements, mathematical consistency.

For ICU patients special SI are currently used, such as coronary prognosis index, or the indexes for burns. Several general SI for all patients have been proposed such as. the complication impact index, the concition index score, but rarely employed. Only two indexes till now are used by several hospitals in several countries : the TISS system and the APACHE.

The TISS system (therapeutic investigation scoring system) of D. CULLEN is not strictiy speaking, a. S.I. Nevertheless it can be used for a same technologic level as an out come prediction for groups of patients.

The APACHE (Acute Physiologic and chronic health evalua tion) has been proposed by W.A. KNAUS and others : it is reliable, valid and has been used to compare different ICU in USA as well as in a french US comparison. Further research should be directed at mathematical and statistical techniques to maximize the amount of observation that can be obtained. from a lesser data set. 


\section{$32 \mathrm{~J}$}

QUANTIFICATION OF INTENSIVE CARE : NURSING REQUIREMENTS AND DIAGNOSTIC CRITERIA. A MULTICENTER TRIAL.

F.C.Muller, H.Bergmann, K. Steinbereithner, Depts.of Anesthesiology General Hospital

Mödling, General Hospital Linz and University Clinics of Anesthesia and Intensive Care, Vienna, Austria.

In a multicenter study intensive care nursing requirements of 10 different Austrian ICUs have been evaluated using the scoring systems of CULLEN (TISS), and of HUDSON.

The average TISS points per patient are in the range between 5,3 (poison center Vienna) and 30,4 (Rudolfspital Vienna, operative ICU ), the HUDSON points are ranging from 24,7 to 125,2 respectively. Altogether a mean of 187,8 patient days per ICU has been assessed. Calculations of nurse/patient ratios depending on the average TISS points have been done for each ICU taking into account the general working conditions for nurses in Austria. HUDSON/TISS ratios lie between 3,67 and 9,48 possibly giving some hints as to the adequacy of the number of ICU personnel.

Finally the TISS-situation of each ICU has been studied in detail as well as the TISS number for the different diagnoses and their changes in the course of the disease.

In conclusion it can be stated that wide quantitative differences in the intensity of intensive care and in the patient material exist even within the same type of ICU. To assess real nurse requirements of any ICU quantitative data including well known score systems are absolutely necessary thus presenting hard data which cannot be overlooked by the hospital administration.

\section{$32 \mathrm{~K}$}

NURSES' MOTIVATIONS FOR PARTICIPATING IN CRITICAL CARE CONTINUING EDUCATION. J.A. Bennett, M. Creegan, A. O'Connor Long Island College Hospital, Brooklyn, New York, U.S.A. The study was undertaken to identify dimensions or motivational orientations, that underlie nurses' participation in a critical care continuing education program (CE). Thile the need for continuing education in the health professions is generally accepted, the value of legally mandating specific numbers of hours of CE has been debated, with few states adopting, such requirements. The increasing investment of health care dollars in nursing CE requires a continuing evaluation of the objectives of these programs and their impact on patient care. Previous research, viewing participation as motivated behavior rather than a phenomenon in itself, identified motivational dimensions of adults participating in education programs as goal-oriented, activity-oriented, or learning-oriented. Subsequent research has identified other motivational orientations. It was hypothesized that critical care nurses would differ in motivational orientation from the general nursing population due to a perception of greater or quicker obsolesence and therefore a greater need for more frequent or even continuous updating. The study sampled participants in a two day critical care symposium sponsored by a professional organization which focused on both clinical content and personal/ professional development. 93 questionnaires (32\% of the participants) were returned. The Education Participation Scale is a self report instrument in which learners rate the influence of 56 motivating factors in their decision to participate in a CE program. Varimax orthogonal rotation was used to analyze responses, finding eight factors meaningful. Chronbach's alpha method was used to determine internal consistency and Pearson product moment correlation was used to analyze relationships of factors to demographic variables. While the orientations identified indicate that participation is primarily for professional reasons, job competence and credentials acquisition did not "load." No correlations with personal data characteristics were identified. Subsequent study is currently in progress to afford extended data with emphasis on critical care clinical foci. 


\section{Research and Training in Intensive Care Medicine A. Formation and Teaching in Intensive Care Medicine}

$33 \mathrm{~A}$

FORMATION AND TEACHING IN INTENSIVE CARE MEDICINE - AN INTRODUCTION. K. Steinbereithner, Boltzmann-Inst. of Exp. Anaesthesiology \& Research in Intensive Care Medicine, University Hospital, Vienna, Austria

Though the interdisciplinary character as well as the fact that Intensive Care Medicine (ICM) eventually might require full time engagement become evident more and more, besides Australia the formation of a (sub) specialty has only been decided upon in outlines in the USA (4), first certification not to be awaited before July 1984 (5). In most other countries (cf. subsequent discussions) there are still but negotiations if any; Austria did include ICM obligatory into the 4 yrs postgraduate scheme for anaesthetists by sept. 1981. - A similar discomposure is to be observed as to core curriculum (necessary knowledge and skills, not to speak of attitude and experience), special training in emergency (and disaster) medicine, and to prior qualification. Concerning time of training a rising tendency cannot be ignored: Programs of more than $1 \mathrm{yr}$ 's duration were offered in $38 \%$ for 1980 compared to $66 \%$ of all USA fellowships in $1982(2,3)$. scheme adapted to individual needs reaching from introduction tc training 9 specialists. According to scattered experiences "basal" training does improve general inhospital acute care substantially. As ICU nurses are trained now largely on a 1-2 yrs basis unsupervised medical activities or appointments in ICM without equivalent special training are hardly justifiable by today.

1) Bergmann H, Steinbereithner $K$, in press

2) Greenbaum DM, Holbrook PR, Crit Care Med 8 (1980) 693

3) Greenbaum DM, Holbrook PR, Crit Care Med 1o (1982) 347

4) Grenvik A, Leonard JL et al, Crit Care Med 9 (1981) 117

5) SCCM Newsletter Dec 1982 We (1) have tried to develop a "step by step" training

$33 \mathrm{C}$

TEACHING AND QUALIFICATION IN "INTENSIVE CARE" IN FRANCE (J. MOTIN)

Service de Réanimation Hôpital Edouarä-Herriot, Lioñance The term "Intensive Care" usually stands for the practice of active medicine in the Department of Surgery, Medicine or Speciality. The name "Critical Care". (or Reanimation"), in France, defines similar medical practice usually performed in a Department set up to receive a more acute or polyvalent pathology. In reality, there exists a confusion between the vernacular and the facts :

"Cardiac critical care", "Hematological critical care", "Surgical critical care"... This ambiguity persists in the teaching and the professional training conditions. "Medical Critical Care" (Réanimation Medicale Polyvalente) is a subject taught for a period of three years in certain Universities, although not leading to a National Degree. Anesthesiology is one of the great speciolities which provides intensive care and/or critical care. It is recognized by the University. There are three yeors of training at the end of which a degree in "AnesthesiologyCritical Care" is obtained. This recovery is mostly employed in traumatology or post-surgery, and of ten polyvalent.

The qualification for "Medical Critical Care" may be obtained without the speciolized exams if the University Hospital residency boards are passed and two years in the approved departments fulfilled. Anesthesiology Critical Care residents may obtain an equivalency of the National Degree in "Anesthesiology - Critical Care" and are qualified in Medical Critical Core after three semesters in the approved Departments of Anesthesiology and four semesters in Critical Core and Intensive Care Deportments.

Thus there is major discrepancy between the theoretical and clinical qualification of recovery experts. From 1984 a reform will allow specialists to undergo more homogeneous training.

\section{$33 \mathrm{C}$ Bis}

WHO SHOULD PRACTISE INTENSIVE CARE MEDICINE? Hillman KM, ICU, Charing Cross Hospital, London, UK.

Intensive Care Medicine is a specialty which encompasses the acute aspects of everyone else's specialty. The expertise necessary to treat critically ill patients comes from adequate training of the doctors and constant exposure to the patients' problems. Anaesthetists, Physicians and Surgeons are not specifically trained in Intensive Care Medicine, and because they are specialists in other branches of medicine cannot spend most of their time caring for seriously ill patients. Thus one either becomes proficient in one's parent specialty (Anaesthetics, Medicine, Surgery) or in Intensive Care Medicine. Intensive Care Medicine has become too complicated and demanding to be treated as a hobby. It is a specialty requiring cer tain Anaesthetic knowledge and skills, such as applied physiology, rapid reaction to problems, ability to perform a wide range of invasive procedures and familiarity with monitoring and support equipment. It also requires certain Medical knowledge and skills, such as a broad knowledge of conventional medicine, and the ability to interpret diagnostic data. However, further specialised knowledge about bacteriology, radiology, surgery, resuscitation, and administration is required. More importantly, knowledge of acute organ failure and multiorgan failure is essential for an Intensive Care Physician. This is poorly understood by most conventional physicians and anaesthetists. Furthermore, the specialist Intensivist must ideally be familiar with research principles and current journals, as much of Intensive Care Medicine is being defined now. It doesn't matter who practises Intensive Care Medicine (other than a committee); as long as he or she devotes most of their clinical time to working in an Intensive Care Unit.
THE INTEGRATED SYSTEM OF TEACHING; TRAININTG AND CONTINUING EDUCATION IN INTENSIVE CARR MEDICINE IN THE GERWAN DEMOCRATIC REPUBIIC H. Neyer, Chair of Anaegthesiology/Intensive Care Medicine, Academy of Postgraduate Medical Education of the GDR, Berlin, GDR Anaesthesiology/Intensive Care Medicine is one of 32 specialities licensed in the GDR. The medical curriculum at the universities schedules this field in the first, fourth and fifth year of studies in which the first year is given to an interdisciplinary lecture series on "Emergency Situations" and "First Aid". The fourth and fifth year is reserved for lectures, seminars and practical courses of $30 \mathrm{hrs,}$ and 45 hrs per year, respectively. The body of knowledge in Intensive Care Medicine forms a substantial part of the State Exeminetion in Medicine.

For quality reasons the postgraduate training in any speciality follows nationwide standards. The standard for this speciality were worked out in close cooperation between the chair of Anaesthesiology/Intensive Care Medicine of the Acedemy of Postgreduate Medical Education, and the Society of Ansesthesiology and Intensive Therapy of the GDR. All these standards are subject to final approval by the Ministry of Heslth.

The training takes place in departments and hospitals which are especialiy appointed for thet purpose, and the period of training is 4 years for all specialities. Certification as a specialist is only achievable by passing a final examination before the Board of Examiners of the Academy. After qualification a system of continuing education follows to keep the level high during $a 11$ the professional life. 
$33 \mathrm{D}$

"INTENSIVIST" : 'TOWARDS A RECOGNIZEE SPECIAYITY

J.Vincent, Department of Intensive Care, Erasme Hospital, Free University of Brussels, Belgium.

Intensive care was born from several specialities, including internal medicine, anesthesiology, surgery and pediatrics. The will of these primary specialties to keep critically ill patients within their owm department has impeded the development of multidisciplinary intensive care units. These specialities have also feared that recognition of intensive care medicine as a distinct entity would amputate their own competence. However, a multidisciplinary approach to an unique "intensive care" improves both comprehension and management of critical states. The introduction of large autonomous departments of intensive care has been facilitated by the construction of new hospitals. Nevertheless, critical should be better defined throughout the world. Responsabilities in intensive care, coronary care, neonatology and even emergency medicine can be very different not only from town to town but even sometimes from hospital to hospital within the same town.

In our 31-bed medico-surgical department, internists, anesthesiologists and surgeons who are in rotation represent 8 of the 16 members of the medical staff. They are eager to spend this training period and very concemed about instruction in our discipline. Each patient has one "intensivist" directly responsible for his care, in good relationship with consultants and primary physician. Specialization in intensive care medicine is rendered essential by the complexity of comprehension and management of critical illnesses more than by purely technical aspects of their care. We suggest specialty in intensive care medicine to be recognized to those who have had a two year period of training in a department of intensive care, after full training in one of the primary specialties.

\section{B. Research in Intensive Care Medicine}

\section{$33 \mathrm{~F}$}

RESEARCH IN INTENSIVE CARE MEDICINE - SOME CURRENT PROBLEMS. K. Steinbereithner, Boltzmann-Inst. of Exp. Anaesthesiology \& Research in Intensive Care Medicine, University Hospital, Vienna, Austria

In Intensive Care Medicine (ICM), a rather young branch of medical sciences, almost day by day sets of problems are encountered, some of them "shouting with urgency" for rapid answers. Systematic research efforts in this field, however, are not yet taken for granted. A cumulative survey for 1980/82 comparing 3 leading anaesthesiological (A: Anesthesiology, BJA, Anaesthesist) with the same number of Intensive Care periodicals (I: Critical Care Medicine, Intensive Care Medicine, Intensivmedizin) revealed a striking difference in research activities: $64.9 \%$ of papers in (A) vs. only $31.4 \%$ in (I) were devoted to scientific investigations (studies related to morbidity, epidemiology, assessment of economic and personnel requirements not being taken into consideration). In our own institution $56.8 \%$ of ICM-papers referred to research programs. - Besides that a wide scatter in intensity of interest is to be seen: Subjects like cardiovascular and/or pulmonary pathophysiology etc. covering $45 \%$ of all publications are opposed to poorly if not insufficiently $(\langle 1 \%)$ treated topics like e.g. renal function or immunology. In order to enhance interest and to overcome the abovementioned gaps being eventually also detrimental to ICUpatients organisational (access to experimental departments, research programs (1), and computing facilities; provision of biomedical and laboratory technicians working IN the ICU etc.) as well as other motivating measures (editorial policy of journals, improvement in career structures etc.) should be promoted.

1) Greenbaum DM, Crit Care Med 8 (1980) 69o

\section{$33 \mathrm{E}$}

SHOULD INTENSIVE CARE MEDECINE BE AN INDEPENDENT SPECIALTY? J.P.Gardaz, P.M.Suter, Department d'Anesthiésiologie, Hôpital Cantonal Universitaire, Genève.

The structures of intensive care medecine(ICI1)vary widely from country to country. In France, Japan and South Africa, for example, there are university departments of critical care medecine headed by full professors in ICl.It has become a primary speciality of its own in Spain and Australia. The United States has opted for a subspecialty in critical care medicine rather than a primary discipline, whereas others countries Iike the United Kingdom, Switzeriand do not recognize ICM officially. These differencesencountrered in the academic and medical structures reveal the complexity of the problem. Intensive care medecine is a "multidisciplinary"endavour crossing traditional departmental an speciality lines and it is conceivable to create autonomous departments of multidisciplinary IC:1 runned by primary specialits in intensive therapy. Although we recognize that there is a need for special knowledge and skills on the part of those providing patient care in intensive care units, we do not support the specialty of "intensivist" as primary specialty for the following reasons:First ICH physicians should have a solid training in Internal Medicine and Anesthesia(or Pediatrics for pediatric ICl) before training and practicing ICY. Second, at the present time there is no specific training programme, no uniform career structure nor academic future ensured in the majority of countries of Western Europe. Furthermore intensive care medicine as primary specialty can be hazardous, because, outside intensive care units, there is no professional a $7 \mathrm{~m}$ ternative for intensivists who whish or have to change their medical activity at a later time. This point is of particular importance because good ICM needs dynamism, fresh ideas and a great physical and psychological commitment, factors found usually in greater quantity in people at 30 than at 60 years of age.

\section{$33 \mathrm{H}$}

LINKING CLINICAL PROBLEMS TO RESEARCH: Hil1man KM, ICU Charing Cross Hospital, London, UK.

Much of our current knowledge and clinical practice in Intensive Care is based on animal experiments and conventional medical principles and may not be relevant to treating critically ill patients. As an Intensive Care specialist, I have tried to document the three most common important problems I face each day; on the basis that this is where our research should have priority. My first is getting enough money to run the ICU, and being able to justify to my colleagues and the community that my treatment makes a difference and that the difference is worthwhile. Because this is one of the hardest areas to define and from which to gather meaningful results, it does not mean that we should not collectively attempt it. It is important now and crucial for the future. My second problem is how to assess, treat and predict outcome after cerebral damage - from whatever cause. I of ten feel I am working without hard facts or guidelines, and too of ten with"personal experience" and instincts. The third major problem I have in clinical practice, and not necessarily the least important, is how to prevent or treat septicaemia. I feel current recipes temporarily improve the "numbers" but do not substantially affect outcome.

Our research should be linked to our clinical challenges. ICUs treat a sma11 number of patients and we have little control over the type of admission. The patients often have complicated multiorgan diseases. To answer the questions I have posed we need large numbers of patients, changing only one variable, and using controls. To achieve this we need multi-centre; national and international controlled trials. Furthermore we should all collect the same information about our patients; preferably on common computerised record-keeping systems. This would expedite our research and give us meaningful comparisons on cost, autcome, workload and prognostic information. 
INVESTIGATION IN INTENSIVE CARE MEDICINE

J.L.VINCENT, Department of Intensive Care, Erasme Hospita?, Free University of Brussels, Belgium.

In the intensive care unit, both the large variety of critical illnesses and the availability of sophisticated material and motivated personal foster clinical investigation. Spectrum of research activities is very broad, going from cardiovascular, respiratory or metabolic studies to search for technical developments, establishment of prognostic indexes or discussion of ethical problems. Studies can focus on gross clinical abnormalities as well as on precise cellular or biochemical mechanics underlying pathologic states. Multidisciplinary approach to intensive care and collaboration with specialists in basic research should be encouraged to improve the quality of the investigation. Systematic collection of datais essential to yield comprehensive clinical studies. Some forms of treatment, such as fluid challenge or PEEP administration, should be standardized. In our department, a minimum daily set of laboratory data is defined, including arterial lactate concentration, colloid osmotic pressure and urine osmolarity. A simple, mobile cart has been designed to perform routine hemodynamic studies at intervals in patients with invasive monitoring.

Clinical practice raises questions that need an experimental support to be answered. Clinical investigation in the intensive care unit should be closely linked to an animal laboratory. Difficulties in the development of reproducible experimental models of acute organ failure should be challenging rather than dissuasive. We have set up a dog laboratory for hemodynamic studies of acute states, for which fonding has been essentially supplied by external support, in a spirit of positive collaboration between the private industry and the university.
RADIONUCLIDE TECHNIQUES IN THE DETECTIDN AND EVALUATION OF PATIENTS WITH ACUTE MYOCARDIAL INFARCTION. A. Righetti, Centre de Cardiologie, Hôpital Cantonal Universitaire. Genève, Suisse

Tracer techniques such thallium-201 (TI-20I) and technetium-99m pyrophasphate (To-PYP) myocardial imaging and radionuclide ventriculography (RNV) are increasingly used to evaluate patients (pts) with acute myocardial infarction (AMI). These techniques are non invasive and may be applied to critically ill pts at the bedside without appreciable extra risk or discomfort.

Approximately 90 percent of the pts with transmural or non transmural AMI can be detected by Tc-PYP if the imaging is performed 24 to $72 \mathrm{hrs}$ after the onset of the symptoms. Tc-PYP has beer utilized in localizing the site and determining the extent of AMI. The "doughout" pattern is associated with a large incidence of subsequent congestive heart failure and death.

Tl-20l performed within 24 hours of AMI has been usefuI for recognizing, localizing and roughiy sizing areas of infarction and surrounding ischemia. The extent of T1-201 defect in an initial image may have important value, for separating high-risk and law-risk subgroups of hemodynamically stable pts with AMI.

Short and long term prognosis after AMI appears to be determined essentially by residual ventricular function. RNV provides the means for assessing the evolutionary changes in regional performance after AMI. In pts with complicated AMI and cardiogenic shock a combination of TI201 and RNV should be considered to identify those with massive LV damage from those with residual ischemia or right ventriculer damage. Quantitative evaluation of regional LV motion after pharmacologic or surgical treatment in pts with AMI may provide usaful information regarding the efficacy of a variety of interventions.

\section{Acute Renal Failure}

34

PATHOPHYSIOLOGY OF ACUTE RENAL FAILURE. K.Thurau, Department of Physiology, University of Munich, Munich, FRG

In order to reprocess the chemical composition of body fluids, the kidneys deliver a large volume of filtrate from plasma to the tubular epithelium, which then forms the final urine by selective reabsorption of filtered water and substances and the secretion of substances from the blood into the urine. Both processes, filtration and reabsorption/secretion, are powered by different energy sources, filtration by myocardial metabolism and reabsorption by tubular cellular metabolism. Normally, the large reabsorptive capacity of the tubules allows the kidney to deliver $100-150 \mathrm{ml}$ filtrate/min to the tubules which have inherent discriminatory activities in the selection of filtered constituents for reabsorption or excretion. This high turn-over of extracellular fluid serves the important function in the kidney of continuously reprocessing the plasma. It contains an inherent danger - that of severe fluid loss if the tubular reabsorptive mechanism should fail due to nephrotoxins or renal hypoxia. There is evidence that the primary site of action of nephrotoxins and hypoxia is located in the tubular cells. The pathobiochemistry of the kidney in acute failure includes defects in the membrane-bound properties for fluid reabsorption, such as changes in permeability and active salt transports. These initial cellular defects may produce secondary phenomena such as activation of the tubulo-glomerular feedback, the intrarenal renin angiotensin system, a fall in GFR, tubular occlusion, vascular constriction etc. The foremost "secondary phenomenon". appears to depend critically on the type of renal insult, its severity and time course.

A rational treatment of acute renal failure, aimed at treating the causes rather than the symptoms, should restore the disturbed cellular functions. Since, at present, there is no specific cellular treatment known, dialysis and careful fluid and metabolic balance constitute the only possibility of supporting the patient until spontaneous healing occurs.

\section{6}

EARLY DIAGNOSIS OF ACUTE RENAL FAILURE.

H. Favre, B. Ody, Departments of medicine and radiology, Hopital cantonal universitaire, Geneva, Switzerland. The causes of acute renal failure (ARF) have to be early recognized in order to put the patients into one of the 3 following categories : prerenal, renal or postrenal. The two first situations could be separeted on the basis of several urinary indices among which the most efficient is the fractional sodium excretion ( $\mathrm{FeNa}$ ). This parameter classifies correctly $99 \%$ of the patients. Fena allowed, in our personal series, an early diagnosis of prerenal or renal ARF in 50 patients at the time where serum creatinine was rising from $120+30$ to $250+50$ umol/1. Limitations to this index concern mostly patients with nonoliguric ARF associated with salt retaining states. Some of these patients could be considered as prerenal while they are actually renal. In these peculiar setting, measurements of enzymuria could provide an accurate diagnosis. Radiological investigations have to be done in all patients in whom an obstruction of the upper urinary tract is suspected or could not be ruled out. Nowadays, the method of choice to demonstrate pyelocaliceal dilatation is sonographic examination. Its specificity and sensitivity is very high. Rare false positive results are due to a very recent obstruction or to large calculi whereas false positive are due to prior dilatations or to constitutive large cavities without abstruction at the time of ARF.

In cases of dilatation, sonography must be completed by intravenous (antero.or retrograde) ureteropyelography to determine the nature and the location of the obstruction. Canclusions. Use of $\mathrm{FeNa}$ and sonography provides an early diagnosis of the causes of $A R F$ and permits the choice of the appropriate therapy which prevents a further degradation of renal function and may change the outcome of the patients. Exceptional causes of ARF such as acute glomerulonephritis or vascular obstruction need a different approach based on clinical ground. 
37

Therapeutic modalities in acute renal failure J.P. Wauters, Division of Nephrology, University fospital, Lausanne, Switzerland. The classical treatment of acute renal failure (ARF) i.e. peritoneal dialysis or hemodialysis once uremic symptoms appear, has now been largely replaced by a more aggressive and individualized therapeutic approach. The importance of an adequate caloric and protein intake has been better understood. At least $35 \mathrm{Kcal} / \mathrm{kg}$ and 0.5 $\mathrm{gr} / \mathrm{kg}$ of protein should be given daily. Therefore the management of fluid and electrolyte balance is not always possible by conservative means. It is presently admitted that once oliguric ARF is established there is no further reason for diuretic or mannitol administration. Among the substitutive therapies, peritoneal dialysis became easier through the experience gained with the CAPD technique. Hemodialysis can now be performed with the use of bicarbonate in dialysate, sequential ultrafiltration and/or volumetricaly monitored ultrafiltration during dialysis. Other substitutive therapies have been proposed : 1) hemofiltration can be usefull when cardio-vascular instability precludes the use of conventional dialysis; 2) plasmapheresis by centrifugation or filtration techniques has been recommended when $A R F$ is due to acute intoxications by poisons which are largely bound to proteins; 3) spontaneous femoral arterio-venous hemofiltration appears as an easily applicable bedside technique allowing to overcome simultaneously the fluid balance and uremic problems, without the continuous need for dialysis equipment and staff. Despite those advances, the complication rate during ARF remains high and is still responsible for the persistently high mortality.

\section{Pediatric Intensive Care}

\section{8}

PERSISTANCE OF THE FETAL CTRCULATION, D. MOULIN, Soins In tensiŕs Pédiatriques, Clin. Univ. Saint-Luc (U.C.L.), 10 Avenue Hippocrate, B-1200 Bruxelles.

In 1969, Gersony, Duc and Sinclair reported the fatal out come of two term neonates who had severe hypoxemia within the first 24 hours of Iife. Carefull investigations and post-mortem examination had failed to demonstrate any underlying abnormalities. In order to explain these observations, the authors suggested that a suprasystemic pulmonary vascular resistance may have create a right to left shunt through the foramen ovale and/or the ductus arterio sus and therefore decreased dramatically the pulmonary perfusion. This hypothesis was thereafter applied to various situations of neonatal cardiopulmonary distress with severe hypoxemia and where no cardiac defect could be detected. Different conditions have been demonstrated to participate in increasing the pulmonary vascular resis tance 1 . increased blood viscosity 2 , inadequate development of the pulmonary vascular bed 3. pulmonary vasoconstriction and 4. extrinsic or intrinsic pulmonary vascular obstruction. At birth, the term neonate has functionnally closed fetal shunts; he also has very reactive and musculated pulmonary vessels. This makes him particularly prone to develop persistent fetal circulation, even more so as pulmonary vascular smooth muscle can be further hypertrophied by chronic hypoxemia or premature ductal closure during fetal life. In assessing the neonates who pre sent severe hypoxemia resistant to optimal oxygen therapy, echocardiography seems to be the most appropriate procedure. It helps 1 , to rule out a structural cardiac defect 2 . to objectivate concomitant cardiac dysfunction and 3 . to document pulmonary hypertension, pulmonary hypoperfusion and/or right to left shunt. Therapy should first try to suppress any factors favoring pulmonary vasoconstriction. If inefficient it may be completed by the carefur use of vasodilator drugs and for respiratory alkalosis.
39.1

ASSESSEMENT OF NEONATAL RISK FOR RDS BY PULMONARY COMPLIANCE IN AN EXPERIMENTAL MODEL. M. Solca, T. Kolobon, R. Fumagalli, P. Arosio, A. Pesenti, L. Gattinoni. Ist. Anestesiologia e Rianinazione, Università Milano, Italy, and Lab. Technical Development, NIH, Bethesda MD, USA. Fetal lambs are widely regarded as a useful experimental nodel of human RDS. We studied 115 animals between 125 and 134 days gestation (term 147-150 days) to determine the optimal pulmonary management for RDS prevention. In 70 cases we performed a cesarean section, exposed the head of the fetus, and intubated the trachea, leaving the fetus still connected to the rother through the intact umbilical cord and placenta. The lungs were inflated to a pressure of $35 \mathrm{~cm} \mathrm{HO}$ for 5 secs for 3 times; we then measured the total compliance injecting known quantity of gas in the lungs and recording the resulting pressure. Thereafter 32 aninals were inmediately delivered and treated with state of the art ventilatory care, while 38 underwent apneic oxygenation while stili on placenta, until total compliance exceeded $0.5 \mathrm{ml}(\mathrm{cm} \mathrm{H} 0)^{-1} \mathrm{~kg}^{-1}$. Overall mortality rate was $0.3:$, totally for RDS, and was not different between treatment groups. Survivors had a total compliance markedly higher than non-survivors $\left(0.28 \pm 0.11\right.$ vs. $\left.0.12 \pm 0.04 \mathrm{ml}(\mathrm{cm} \mathrm{H}, 0)^{-1} \mathrm{~kg}^{-1}, P<0.001\right)$ : this suggested a key role of puimonary mechanics in insurgence and severity of ROS in preinature fetuses. He were then able to delineate a descriminant value of total compliance between the two groups: $0.205 \mathrm{ml}\left(\mathrm{cm} \mathrm{H}_{2} \mathrm{O}\right)^{-1} \mathrm{~kg}^{-1}\left(\chi^{2} 37.14, \mathrm{P}<0.001\right.$; predictive index $\left.87 \%\right)$. It carries a $\alpha$ error of $1.7 \%$ and a $\beta$ error of $25 \%$ : in our study none of the non-survivors had a higher compliance, and only $19 \%$ of survivars had a lower value. This implies that we can predict within $2 \%$ of error which animal is at great risk for developing RDS, and subsequent death, with a very simple and safe procedure: inflation of the lungs and measurement of total compliance. 
MECHANICAL VENTILATION OF IDIOPATHIC RESPIRATORY DISTRESS SYNDROME (IRDS) OF THE NEWBORN INFANT WITH OPTIMAL PEEP DE TERMINED BY PRESSURE-VOLUME (P/V) CURVES OF THE TOTAL RESPIRATORY SYSTEM. J.C. MATHE (1) J.Y.CHEVAL IER (1), C. GAULtier (2), J. COSTIL (1). (1) Service de Réanimation Polyvalente et d'Hémodialyse Pédiatriques, (2) Laboratoire Central d'Explorations fonctionnelles. Hôpital Trousseau 26 Avenue du Dr.A. Netter 75012 PARIS 30 newborn infants (mean gestational age : 34 weeks (28 40), mean birth weight 2100 grams $(1300-3500)$ with IRDS (mean $0_{2}$ alveolo arterial difference : 500 torr $(293-643)$ vere treated with mechanical ventilation with optimal PEEP determined by $P / V$ curves of total respiratory system. 37 $\mathrm{P} / \mathrm{V}$ curves vere performed by slow constant thoracic inflow according to a previously described method. ( $J . C$. MATHE Int. Care Med. $1982-8-246$ Abst). The mean optimal PEEP were $9.25 \pm 3.2 \mathrm{~cm} \mathrm{H} O(4-17)$

Optimal PEEP were applied before $H 48$ in 23 patients and after $\mathrm{H} 48$ in 7 patients. Mean exposure to $\mathrm{FiO} 2>0.4$. were signifiantly reduced in the first group $(32.1+18.1$ hours $(5-84)$ vs $128.4 \pm 45.2$ hours $(60-192) p<0.001)$. 5 pneumothorax vere observed and no bronchodysplasia. 2 intraventricular hemorrhages $(\mathrm{I} V \mathrm{H})$ and 1 periventricular hemorrhage vere investigated by means of 18 cranial ultra sonography and 3 ventricular punctures. 3 patients died (2 IVH, I nosocomial infection).

The mechanical ventilation with optimal PEEP in IRDS is a method well tolerated which reduces exposure to Fi02 $>0.4$. and provides a successfull treatment for the most severely impaired patients.
INHIBITION OF INTRALIPID ${ }^{R}$ AND OXIDANTS INDUCED PULMONARY VASOCONSTRICTION BY NIEEDIPINE. H.Stopfkuchen, J.C.Maggi, M.C.Rogers and D.Schranz. Universitätskinderklinik Mainz and Dept. of Anesthesiology and Critical Care Medicine, Johns Hopkins Medical Institutions, Baltimore MD

oxidants and unsaturated lipids cause a marked pulmonary vasoconstriction which can be blocked by Indomethacin and is correlated with the presence of Thromboxane in the effluent perfusate (Crit Care Med 10 (3):290,1982). In order to evaluate the effect of nifedipine on pulmonary hypertension induced by infusion of oxidants and lipids, we carried out the present experiment, using isolated rabbit lungs ventilated with $5 \% \mathrm{CO}_{2}$ in room air and perfused at $50 \mathrm{ml} / \mathrm{min}$ with Krebs Hensleit buffer in a nonrecirculating manner.

Pulmonary hypertension was induced in 12 rabbits by infusing $69 \mathrm{mM}$ tertiary butyl hydroperoxide $t-B u O O H$ (mean $\mathrm{Ppa}=13.41$ torr \pm 3.52 SE) or a $10 \%$ Intralipid ${ }^{R}$ infusion (mean $\mathrm{Ppa}=$ $13.66 \pm 3.13 \mathrm{SE}$ ). While reaching a plateau in the pulmonary artery pressure and still infusing the pressor drug, Nifedipine $20 \mu \mathrm{g} / \mathrm{kg}$ were given. Significant decreases in pulmonary artery pressure (mean Ppa $7.54 \pm 1.33 \mathrm{SE}$ ) were noted regardless of the challenge.

Results were evaluated by analysis of variance which showed a significant inhibitory effect by Nifedipine of the vasoconstriction caused by both agents $(p<0.001)$.

We conclude that Nifedipine can inhibit pulmonary vasoconstriction induced by oxidants.

\section{3}

HANDLING AND REILIABILITY OF THE TRANSCUTANEOUS POO $\left(\mathrm{TCPCO}_{2}\right)$ IN THE NEONATAL, INITENSIVE CARE, HU.BUCHER, G.DUC ${ }^{2}$ D.WETTENSCHWILER, A.HUCH, R.HUCH, Divisions of Neonatology and Perinatal Physiology, Univ, of zürich, Switzerland.

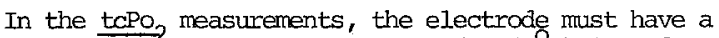
relatively high core tenperature $\left(44-45^{\circ} \mathrm{C}\right)$ in order to achieve a sufficient hyperaemia and it has to be changed to different places every 2 to 4 hours. Some good experiences with lower temperatures for $t c \mathrm{PcO}$-measurements have been reported (I) which allow for a long-time monitoring without the risk of skin burns, we have examined how different temperatures ( 41 and $44^{\circ} \mathrm{C}$ ) influence the calibration stability, the reproductibility, the response time and the correlation to the $\mathrm{PCO}_{2}$ in blood samples. The measurements were carried out on premature infants in servo-controlled incubators. We used two industrial prototypes (Draeger and Radioneter) which were calibrated at 40 and at 80 Torr, fixed simultaneously on the thorax. and compared values with the $\mathrm{PCO}_{2}$ in capillary or arterial blood samples. Except for the expected slower response time there was no disadvantage at $4 \mathrm{I}^{\circ} \mathrm{C}$. With both temperatures the $\mathrm{tcPCO}_{2}$ was largely increased for both prototypes compared to the ${ }^{2} \mathrm{PCO}$ in blood samples. There were strikingly large interindividual differences. This makes a general instrument built compensation difficult.

(1) Continuous Transcutaneous Blood Gas Monitoring II, edited by R.HUCH, A.HUCH, Marcel DEKKER, London, New York, in press.
40

HIGH FREQUEFICY VENIIIATION (HFV) IN PEDIATRICS. DJ.BOhn, The Hospital for sick children, Toronto, Canada.

Since the introduction ofpositive pressure ventilation into clinical medicine, the parameters used in mechanical. ventilation tended to mimic those seen in normal respiration. While in most instances this proves to be an effective method of managing respiratory failure, there are still many patients with severe parenchymal lung disease who have a hypoxemia, refractory to any manipulation of the respirator. (changing $I: E$ ratio, wave forms, end expiratory pressure). With the introduction of HEV, a new era has opened up in ventilator management of patients with severe respiratory disease. High frequency positive pressure ventilation (FFPPV) includes all ventilators that can cycle at rates between 60 and 120 (facility available on some modern conventional mechanical ventilators). High frequency jet ventilation (HFJV) includes a group of ventilators that use a high pressure gas source ventilating at volumes at or below dead space at rates up to $5 \mathrm{~Hz}$. High frequency oscillation (HFO) uses rates of $1-40 \mathrm{~Hz}$. generated by high frequency sine wave. These technic have features and characteristics which are unique but the theory is essentially the same : patients may be ventilated at volumes substantially less than dead space, with lower mean airway pressures than seen with conventional ventilation. There are now numerous studies in the literature to show that both HFJV and HFO are extremly efficient in terms of $\mathrm{CO}_{2}$ elimination with low mean airway pressures. However, in order for this technique to make a transition from a physiological curiosity to a therapeutic advance, it requires that it can be shown to improve patients with severe respiratory diseases (refractory hypoxemia secondary to either alveolar or interstitial lung disease). As oxygen transfer occurs during both inspiration and expiration, the major problem remains to open alveoli and keep them open throughout the respiratorycycle. HFV is an efficient way to achieving gas exchange in both normal and diseased lungs. 
41

Preliminary results from its use in hyaline membrane disease and ARDS are encouraging, but a large multicentre trial is necessary to prove its advantages over conventional ventilation in these diseases. There is no doubt that it is a major advance in the treating of broncho-pleural fisulae, and in laryngeal and tracheal surgery where substantially lower mean airway pressures are of undoubted benefit. The proponents of HFV also advocate its use in thoracic and neurosurgical procedures where a motionless operating field would be of great assistance to the surgeon.

Before widespread introduction into clinical practices, several major mechanical and safety features have to be ironed out. Humidification is a problem common to all types of high frequency ventilation. The humidification systems currently in use are not entirely satisfactory, but there does not seem to have been a problem with mucociliary clearance in human studies. The second major problem is that of patient safety. 'The very high gas flow used in both HFO and HFJV can lead to a rapid buildup of pressure within the lung if the gas outflow becomes obstructed. A rapidly responsive blowoff system needs to be incorporated to relieve the pressure within the system, if the gas exit becomes occluded.

HFV stands on the verge of becoming a major advance in respiratory care. A well controlled study is urgently needed betore it can be clearly demonstrated that it is superior to conventional ventilation in patients with severe lung disease. HFV will never replace conventional ventilation as the standard form of ventilator, but the day is probably not too far off when every ICU will have one or two high frequency ventilators to cope with patients with severe parenchymal lung disease.
CONGENITAL LARYNGEAL ANOMALIES - P. Narcy, Y. Manac'h, S. Bobin. Service O.R.L. - Hôpital Bretonneau - 75.877 Paris Cédex 18 - France.

Congenital laryngeal anomalies are a frequent etiology of upper airway obstruction in new-borns and infants, and must be wej.l known by all physicians who care for neonates. The clinical picture is usually a combination of stridor, obstructive dyspnea, dysphonia, and swallowing disorders. But less typical features are possible, such as apnea, cyanotic attaks, bradycardia or cardiac arrest. This presentation is a retrospective study on 680 new borns and infants with congenital laryngeal anomalies seen at our pediatric otolaryngology department from 6 1st 1974 to 5 31th 1982 .

The diagnosis was : idiopathic congenital laryngeal stridor (laryngomalacia) in 348 cases $(51 \%), 15 \%$ of witch were severe, with respiratory distress and/or feeding difficulties ; laryngeal paralys is in 161 cases $(24 \%)$, among witch 56 were bilateral and 105 unilateral; laryngeal incoordination in 23 cases ; laryngeal stenosis in 79 cases ( $12 \%$ ), among witch there were 58 subglottic stenosis, 18 webs and 3 atresias ; subglottic hemangioma in 45 cases ; ary-epiglottic and hypoglossal cysts in 15 cases ; leryngo-esophageal cleft in 8 cases and bifid epiglottis in one case.

For each one of these anomalies, clinical features, radiologic evaluation, endoscopic findings and treatment are reviewed. 
42.1

BACTERIOLOGICAL DIAGNOSIS OF PNEUMONIA IN CHILDREN WITH MECHANICAL VENTILATION. J. Costil, J.C. Mathe, C. Safran J.Y. Chevalier, M. Menoret. Service de Réanimation pédiatrique - Hôpital Trousseau, 26 Rue du Dr. Arnold Netter 75571 Paris Cedex 12 - France.

Specific etiological diagnosis of pneumonia in children with endotracheal tubes is often difficult since upper airvay colonization with multiple organisms is frequent. 39 children intubated or tracheostomized, aged 1 day to 10 years, and having $X$-ray evidence of pulmonary infiltrate were studied with the technique of uncontaminated peripheral airway samples (UPAS) described by E.B. Mat.thew (Crit Care Med 1977; 5 : 76 - 81). 41 UPAS were performed, no complication was observed. 29 UPAS shaved no growth though one pathogen was recovered from 17 tracheal samples. In 28 patients pulmonary course was favourable without antibiotic therapy. In I patient false negative UPAS was observed. In 12 UPAS pure culture of a single organism was obtained, in 8 cases the pathogene recovered from tracheal samples was identical, in 2 cases it was different, in 2 cases tracheal samples vere sterile. The organism's role in producing pneumonia was confirmed by its isolation in 4 patients from blood or empyema fluid. UPAS in children is a single, safe and reliable technique. It shows that most pulmonary infiltrates in children with endotracheal tubes have not a bacteriological etiology and do not need antibiotic therapy. Pnsitive UPAS gives a specific etiological diagnosis ; however its interpretation is more difficult when tracheal pathogen is identical.
42.3

RAPID DIAGNOSIS OF RESPIRATORY SYNCYTIAL VIRUS INFECTION BY IMMLNOFLUORESCENCE IN CHILDHDOD. P. Blanchard, A.Goudeau, J.Orucker, R. Thompson, Y.Lebranchu, B.Grenier, F.Gold, J.Laugier. Hopital Enfants de Clocheville. Laboratoire de Virologie. CHU, 37000 TOURS.

Nasopharyngeal specimens were collected from december 1981 to march 1982 in 85 hospitalized children (2 weeks to 22 months old, 45 under 3 months) with lower respiratory illness to study respiratory syncytial (RS) virus antigen by an indirect immunafluorescence technic (IFI). Collected by - rasapharyngeal aspiration, the specimens were flushed with phosphate-buffered saline $1,5 \mathrm{ml}$, then centrifuged at $1500 \mathrm{rpm}$ for ten minutes three times. The cellular pellet was used to prepare smears, which were air dried and fixed in acetone for ten minutes. The slides were stained with anti RS antibody (Wellcome), then with antiimmunoglobulin fluorescent conjugate (Wellcome). A slide was considered positive when several epithelial cells showed a granulous cytoplasmic fluorescence. Result could be obtainable 6 to 12 hours later. Thirteen children with no respiratory illness were used as a control group ; all samples were negative. 37 of 59 samples of children with wheezing associated respiratory infection were positive. Among 10 children with bronchitis without wheezing, 5 were also positive. Three children had evidenced apneas of whom two had positive specimens. Overall RS antigen was found in 44 out of 72 children ( $61 \%$ ) suffering of lower respiratory illness. A correlation with levels of total and anti RS virus immunoglobulins present in serum and in secretions is under investigation.

This study demonstrate that RS detection using $\mathrm{MFI}$ is a convenient ram pid diagnostic test to precise the etiology of infant viral respiratory illness and to decrease antibiotics prescriptions. We have now extended this approach as a rapid diagnosis technic of RS and others potential viral agents of respiratory illness in children.
42.2

DIAGNOSIS OF PULMONARY INFECTIONS IN AN P.I.C.A : COMPARISON BETWEEN BACTERIAL TRACHEAL AND POSTMORTEM SPECIMEN

S.Marchand, E.Borderon, J.C.Borderon, M.C.Grangeponte F.Gold, J.Laugier *

* Hôpital G. de Clocheville, 49 Bd Béranger

37 O44 TOURS CEDEX

The bacterial quantification is difficult in small samples. The comparison between cultural characters of tracheal secretions and pulmonary biopsy may be an reliable approach for the diagnosis of the pulmonary infection. This study included 22 neonates and infants who died from different diseases. They had been intubated few hours to 57 days. The tracheal secretions were collected for culture twice a week ; the last sample collected on the day of death. Pulmonary tissue specimens were obtained by needle puncture immediately after death. Pathology has been known for $19 / 22$ cases. All positive cultures on the day of death were monobacterial. - 12 pulmonary culture were negative ; among them, 7 patients had no bacteria in their tracheal secretions and one germ was found in 5 patients. In these 12 cases, no histologic sign of infection has been reported. - 10 pulmonary culture were positive; among them, in 7 cases the same bacte ria was found in tracheal secretions (with 5 times, histological signs of pulmonary infection) and in 3 cases a different germ was isolated. The bacteriological concordance between pulmonary tissue specimens and tracheal secretions was present 14 times. In 8 cases no concordance was observed. This study allows to conclude that : - absence of germ in tracheal secretions is a favorable factor, statistically likked with an absence of pulmonary infection ; - presence of germ should be followed by clinical, biologlcal and radiological investigation looking for an pulmonary infection. Their absence with presence of a germ correspond to a colonisation of the tracheal trube.
42.4

ADULT RESPIRATORY DISTRESS SYNDROME (ARDS) AND INFECTIONS. J. Pfenninger, University Childrens Hospital, Berne, Switzerland

The ARDS is a complex sequela of shock, trauma, sepsis, near drowning and many other insults. In a series of 20 children suffering from ARDS*, selected on strict criteria, 7 had a septic process most often of intraabdominal origin, leading to ARDS. 8 children of the whole series died. The cause of death consisted most often in an unresolved basic medical und surgical problem, complicated by multiple organ failure and septicemia. Thus, septicemia plays a major role in the genesis and mortality of ARDS.

The third aspect of ARDS and infections are the bronchopneumonias. The main reason for frequent bronchopulmonary infections lies in by-passing natural defence mechanisms by prolonged nasotracheal intubation, exposing the lower airways and lungs to exogenous and endogenous microorganisms. In our series these were most often Pselidomonas, Klebsiella and Enterobacter. The infections complications of ARDS can be minimized by using strict aseptic techniques, monitoring of the bacterial flora of the patient and the ICU, and a carefully selected antibiotic treatment, if indicated. Attention should also be paid to adequate nutritional support which may help to improve the host defence mechanisms.

* Pfenninger $\mathrm{J}$. et al.: Adult respiratory distress syndrome in children. J. Pediatr. 101: 352,1982 


\section{5}

ACUTE PNEUMONITIS WITH RESPIRATORY DISTRESS CAUSED BY CLAMYDIA TRACHOMATIS IN INFANTS LESS THAN TWO MONTHS OF AGE.

G.KRIM, B.RISBOURG, CI.HERBAUT, G.OLEWNICZAK, 0. WEMBONYAMA, M.CHENTOJF. Department of Pediatrics (Intensive Care Unit) Hospital Amiens, France.

Four infants lesg than two months of age were admitted in the Pediatric Intengive Care Uni.t with severe impairment of general condition and respiratory distress, crused by CHTAMYDIA TRACHOMATIS (C.T) pneumonitis. Diagnosis could be quickly achieved by a specific micro-immunofluorescent method. Three infants required assisted ventilation but in all cases the treatment with erythromycin terminated shedding of C.T.

Since the course of the illnega is usually considered to be mild, it is of interest to be aware of this aspect of natally acquired C.T. infection.

KEY WORDS : Chlamydia trachomatis, newborn infant; pneumonitis, respiratory distress

\section{7}

SCORING SYSTHNS IN PEDIATRIC TNTTEISTIVE CARE - F. BEAUFIIS D. AZFMA-S. CHANTEREAU-J.C MERCIER-Y.BOMPARD - PARIS

3 patients classification systems developped for adult population since 10 years has been tried for pediatric patients. I) The Clinical Classification System CCS (1), a bedside assessment of patient stability and care needs dividing the patients in 4 classes of severity. II) The Severity Score (2) a weighted sum of 36 physiological measurements obtained from the patient's clinical record. We will propose a simplified score with only 14 variables. III) The Therapeutic Intervention Scoring System TISS (1) consisting in 84 interventions ranging $0-4$ points.

The following informations can be obtained by collecting these data :

a) Classification of the patients and identification of inappropriate admissions in the ICU.

b) Evaluation of results and comparison between different institutions, which otherwise, would be difficult because of heterogenous diagnosis and severity of illness : almost a.ll the deaths are among patients class IV. In the future, multicenter collaborative studies should also take into account the organ system requiring the most attention - respiratory, cardiovascular, etc...

c) a guide for the decision of discharge by daily evaIuation of TISS (3).

d) evaluation of nurse patient ratio in the ICU, and definition of medical staff. For example : class IV patients require a $1 / 1$ nurse/patient ratio.

e) definition of the number of beds needed in a country from a correct classification of patients who should be edmitted in ICU.

All this aspects will be illustrated and discussed with personal data and with data from adult and pediatric jiterature $(4,5)$.

References : 1) Cul.ien D.J et al. Crit. Care Med. 1974,2, 57. 2) Knaus W.A et al. Crit. Care Med. 1981, 9, 591. 3) Keene A.R et al. Crit. Care Med. 1983, 11, 1. 4) Rothstein P. et a.I. Crit. Care Med. 1982, 10, 34. 5) Yeh

T.S et aI. Crit. Care Med. 1982, 10, 497.

\section{6}

TREATNENT OF NOSOCOMIAL RESPIRATORY INEECTION IN THE MECHANICALLY VENTITATEED CHIJD. A.BAROIS, B.ESTOURNET, J.BATAIIIE. Service de Réanimation Infantile, H8̂pital R.Poincaré 92380 GARCHES FRANCE.

In this report we study 130 mechanically ventilated children observed during 1982. All had bacteriological tracheal or uncontaminated peripheral airways samples, weekly in acute, or monthly in chronic diseases.

Among these children : -75 were intubated ; 21 younger than 1 year (mean age $4,6 \pm 2,5$ months) 54 older than 1 year (mean age $6,8 \pm 4,8$ years) -55 were tracheostomised : 7 younger than 1 year (mean age $6,3 \pm 2,9$ months) and 48 older than 1 year (mean age $11,7 \pm 6,5$ years).

Results are the same in the two groups of age. Among intubated children, we only treated 12 original pulmonary infections (Haemophilus 6, Pneumococcus 2 , Staphylococcus 4) and 2 nosocomial infections (Staphylococous).

The airways of infants are usually colonized with a variety of Gram - organisms (Serratia, Pseudomonas Klebsiella, Acinetobacter) we only treated them by preventing retention of pulmonary secretions. Among tracheostomised patients 6 had alternate antibiotics treatment for bronchopulmonary dysplasia. All these children have chronic diseases (neurological or pulmonary) and are ventilated all year long. During 1982, we treated 13 children for Staphylococcus, 6 for Pneumococcus and 18 for Heemophilus. Conclusion : Adequate humidification of inspired gases, regular position changes, chest physiotherapy and frequent tracheal suctioning often avoid antibiotic treatment during mechanical ventilation. We only treat Gram + organisms and hemophilus. These infections often occur on an epidemic way. 


\section{Parenteral Nutrition in Intensive Care I. Principles of Nutrition in the Critically III Patient}

43

METABOLIC AND HORMONAL CHANGES IN THE CRITICALLY ILL.
STONER, H.B. MEDICAL RESEARCH COUNCIL TRAUMA UNIT, MANCHESTER UNIVERSITY, MANCHESTER M13 9PT. ENGLAND.

Patients who have suffered severe injuries and those with active sepsis occurring as a complication of either accidental trauma or of surgical operation show many similar metabolic features. In these patients, for instance, the distribution of metabolic substrates in the plasma and tissues is altered. The changes in the carbohydrate and lipid substrates are clearest after accidental trauma but similar changes occur in sepsis, al though the pattern is more variable. Basically, the stores of both carbohydrate and fat are mobilized so that it might seem that these patients have a choice of fuel oxidation. In fact, these very ill patients oxidize predominently fat. This occurs even when they are presented with extra glucose during parenteral feeding. The mechanism of this metabolic effect is not understood but it may be related to those in the endocrine system following trauma and sepsis.

There are widespread changes in endocrine function in these patients. Starting with the activation of the adrenal medullary-sympathetic nervous system to give an increased catechclaminergic effect, there are changes in the vasopressin, growth hormone, ACTH, cortisol and insulin concentrations in the plasma. The variations in the last two are particularly complex and, again, these are best seen after accidental trauma. Given the initial role of the adrenal medulla and sympathetic nervous system in the mobilisation of the stores of carbohydrate and fat the subsequent changes in cortisol and insul in may be important in determining the metabolic features of this group of patients. The presence of insulin resistance after both injury and sepsis may be particularly significant. There is growing evidence that the decrease in tissue sensitivity to insulin is due to a post-receptor block and this may be important both in deciding the fuel oxidized by these patients and for the abnormal protein metabolism which is also present.

\section{4}

\section{ENERGY REQUIRE IEITS AND ITS SUPPLY}

Yvon A. CARPENTIER, Hôpital Saint-Pierre, Université Libre de Bruxelles, Brussels (Belgium).

Accurate measurements of energy expenditure can be performed in man by direct or indirect calorimetry. The values obtained by such measurements are very often below those found in the classical literature. In the absence of precise measurements, the energy expenditure of various types of patients is usually overestimated.

Hypercaloric parenteral nutrition with high glucose intake can induce severe metabolic complications in critically ill patients : hyperglycaemia due to insulin resistence, hyperosmolarity, essential fatty acid deficiency, but also respiratory distress due to high $\mathrm{CO}$ production and increased incidence of liver dysfunction.

During the hypermetabolic phase of criticaliy ill patients, endogenous and exogenous fat appear to be a preferential fuel for - at least - some tissues.

Adjusting the total calorie intake to the patients energy expenditure and introducing exogenous lipids in the TPN reqimen significantly decreases the incidence and the magnitude of metabolic side-effects.

\section{5}

CATABOLISM \& NITROGEN SPARING IN THE CRITICALLY ILL PATIENT . Herbert R. Freund, Department of Surgery, Hebrew University - Hadassah Medica1 Schoo1, Jerusalem, Israel.

The severly injured or septic critically ill patient sufferes a major catabolic insult leading to increased proteolysis and nitrogen loss, accompanied by a modified carbohydrate and fat metabolism. This special metabolic set-up of the critically ill patient dictates a modified nutritional support regime:

1. Decrease calorie / nitrogen ratio.

2. Do not supply calories in excess of need.

3. Increase part of fat in total caloric intake.

4. Increase amino acid intake.

5. Increase amount of branched chain amino acids in total amino acid intake.

6. Decrease fluid load.

7. Apply metabolic monitoring if possible.
46

NUTRITIONAL ASPECTS IN SEPTIC CONDITIONS. M.D. D.Schwander, Fôpital Cantonal, $\mathrm{CH}-1700$ Fribourg.

The most important metabolic variations typical of a septic ill patient are as follow: glucid related metabolic perturbations, increase of body metabolism and rise of oxygen consumption, increase of protein catabolism and ureogenesis. These changes are the outcome of centrally controlled neuroendocrine incidents. They mobilize in fact an excess of endogenous substrates. These three kinds of disturbances escort in fact every trauma or important stress, but for the septic patient, they are characterized by their persistence and by the fact that unhappily most of the time, the evolution turn to be an uncontrolable multiple organ failure whose mortality is very high.

Before infusing the necessary substrates to spare the essential proteins for a good body function, one must try first to suppress or inhibit the condition who maintains the stress and it's catabolic reaction what means to control

the patient milieu, his adaption to stress and the pathological conditions responsable or whorsening stress and infection.

The treatment must aim to perfuse and bring enough calories to cover the needs without causing suplementary work to the body by means of lipogenesis, glucogenogenesis and ureogenesis in particulary for the failing liver. In practice most of the times one can only infuse a minimum of 125 to $150 \mathrm{~g}$ of glucose, 100 to $500 \mathrm{ml}$ of $10 \%$ Intralipid and 10 to $20 \mathrm{~g}$ nitrogen as a rich in branchchained aminoacids solution.

Only repeated calorimetric measurements will allow to quantify the metabolic monitoring and to document the global metabolic care. 


\section{7}

PARENTAL NUTRITION IN ACUTELLY ILL DIABETIC PATIENTS. G. Kleinberger; 1st Dept. Internal Medicine, Univ. of Vienna, Austria.

Diet plays an important role in the treatment of diabetes melijitus and should be considered when parenteral nutrition is used. A complete nutrition solution with a calorie content consisting of $44 \%$ carbohydrate, $17 \% 1$-amino acids and $39 \%$ fat is recommended. In uncontrolled diabetes mellitus parenteral nutrition should be started after water and electrolyte imbalances is corrected and blood glucose level is decreased below $10 \mathrm{mmol} / 1$ and beta-hydroxy butyrate below $3 \mathrm{mmol} / 7$. This can be obtained by a low dose insul in regime and rehydratation with a glucosefree electrolyte solution with $90 \mathrm{mmol}$ sodium, 60 mmol chlaride, 25 mmol potassiuri, 10 mmol phosphate, $0.5 \mathrm{mmol}$ calcium, $1.5 \mathrm{mmol}$ mangesjum and $43 \mathrm{mmol}$ malate within $1000 \mathrm{ml} \mathrm{H} \mathrm{H}$ and an infusion volume adjusted to the value of the cen tral venous pressure.

Total parenteral nutrition of acutelly 111 diabetic patients containing $2.9 \mathrm{~g}$ carbohydrates, $1.1 \mathrm{~g} 1$-amino acids and $1.1 \mathrm{~g}$ fat with a calorie content of $26 \mathrm{kcal}$ $(110 \mathrm{~kJ}) / \mathrm{kg} \mathrm{KG} / \mathrm{d}$ has been under current investigation. The results showed that the blood glucose level is ma intained well by a continuous intravenous insulin dosage of $3+0.6$ IU and no deviation of osmolality and serum lactate occured. The blood gas analys is remained unchanged. The triglycerides concentration was $0.8 \pm 0.12$ mmol/1 at the beginning and reached a steady state of $1.3+0.26$ mmol/1. The beta-hydroxy butyrate concentration showed a transient increase from $0.6+0.05$ to $0.9+0.22 \mathrm{mmol} / 1$ and afterwards decreased to the normal range. The intravenous infusion of a standard amino acid mixture caused no derangement of the plasma amino acid concentration during adequate supply of insulin. Therefore it can be concluded that insul in treated patients with diabetes mellitus do not need a special amino acid mixture.
50

II.PARENTERAL NUTRITION IN ACUTE ORGAN FAILURE. MULTIPLE ORGA'N FAILURE: E.R. Schmitz, Institut für Anästhesiologie der Ludwig Maximilians-Universität München, FRG

Since the possibilities of a combined, subtle cardiopulmonary, renal, and nutritional support, are at the disposal of the intensive care units, the failure of multiple organs (MOF) has been identified not only as a disturbed function of some organs but as a syndrome-like entity with an expected mortality of more than $50 \%$. Characterized by its progressive nature MOF may end in a complex reduction of nearly all organ functions with an at last untreatable cardiopulmona$r y$ insufficiency. The controlling factors in MOF are not well understood. Neuronal, hormonal, and other influences change the metabolic state and -as for the nutritional aspect in a wider sense of the word-one general conclusion can be drawn: in MOF cells, tissues, and organs are more or less unable to provide energy and protein synthesis in as sufficient amounts as they are needed and exactly there, where they should be used. From a practical point of view organ failure in intensive care units is connected with modalities of nutrition in different ways: it is a fact, that an incomplete nutrition or a state of malnutrition always means a risk for an additional organ failure. It is evident too, that a failing organ troubles the metabolic homeostasis so, that a normal "classical" nutrition is dangerous. Therefore nutrition therapy in MOF means to find a way between the necessity of avoiding symptoms of malnutrition by substituting enough substrates and between the knowledge, that this may lead to metabolic disturbances followed by a worsening of the state of iliness.

\section{8}

ACUTE RENAL FAILURE (AF). P. Fürst, Inst, for Biological Chemistry and Nutrition, Univ. of Hohenheim, Stuttgart. A major contributing factor to the high mortality observed in $\mathrm{AF}$ is the net breakdown of body cell mass. Nutritional therapy in $\mathrm{AF}$ is thus, mandatory. Modern principles imply frequent dialysis or ultrafiltration as early as possible after the patient has become definitely oliguric, thus allowing an adequate nutritional supply by the parenteral route. Energy should be provided as much as any intensive care patient, i.e. 10.5-12.5 MS/day or considerably more, if the patient has a marked hypermetabolism as for instance in severe burns. At least $200 \mathrm{~g}$ should be provided as carbohydrate in order to decrease gluconeogenes is of ketoacids. To cover the increased energy requirements the use of fat emulsions are of special value since they provide the patient with a high amount of energy in a low volume of fluid. Fat emulsion should, however, not be given unless the need of carbohydrates is satisfied. Parenteral administration of amino acids should be given to all patients with $\mathrm{AF}$ of more than 2-3 days duration who cannot take protein by mouth. The administration should not start until the uremic state is controlled by adequate dialysis. The optimal proportion between essential amino acids and non-essential amino acids with a daily amount of $30-60 \mathrm{~g}$ is to emphasize. Electrolytes and water soluble vitamins should be provided as for any intensive care patients. Patients in whom the problems are restricted primarily to the kidneys usually survive the acute phase, if adequately dialysed, even when the renal function has not returned. There is yet no conclusive evidence existing that the use of parenteral nutrition in $\mathrm{AF}$ will.increase survival when associated with sepsis or other severe organ failure. There are reports, though anecdotic, that vigorous nutritional therapy with glucose, insuline, fat and anino acids combined with frequent dialysis or ultrafiltration therapy promote survival even in high-risk patients. Certainly, it is justified to make every efforts to prevent these patients from starvation and internal canibalísm. 
51

PROTE IN WASTING IN THE CRITICALLY ILL: PATHOGENESIS AND CLINICAL IMPLICATIONS. U. Keller, Department of Internal Medicine, University Hospital, $\mathrm{CH}-4031$ Basel, Switzerland

The classical view of protein wasting in severe illness as developped by Cuthbertson in the 1930 ies has been that protein breakdown results from substrate mobilisation to cover energy demands. Today we have more detailed explanations for the pathogenesis of disturbed protein dynamics in catabolic states. The general view is that negative nitrogen balance in moderate trauma results from diminished protein synthesis without major increase in protein breakdown; adequate nutrition may restore in part the impairment of protein synthesis. In contrast, severe trauma is associated with accelerated protein breakdown out of proportion to energy requirements. Protein synthesis may be enhanced provided that adequate nutrition is supplied. The overall metabolic alterations in severe catabolic states are enhanced protein breakdown, ongoing fat oxidation, relative inhibition of glucose oxidation, and failure to increase hepatic production of ketone bodies as alternative fuel. This maladaptation is, at least in part, explained by elevated stress hormones, such as glucocorticoids and epinephrine. They result in enhanced protein breakdown and fat mobilisation, they induce insulin resistance and thus hyperinsulinemia. Results are presented demonstrating inhibition of hepatic ketogenesis by insulin; glucose utilization may be impaired due to elevated free fatty acid levels.

Therapeutic measures include avoidance of stress, catabolic hormones and administration of insulin as a potent anticatabolic agent. In addition, adapted nutrition should cover the altered requirements of carbohydrates, fat and amino acids.

\section{Bis}

THE EUTHYROID SICK SYNDROME A.G. Bürger Thyroid Research Unit, Geneva, Switzerland

Among the known iodothyronines only T3 is nowadays considered to be biologically relevant. Contrary to genera belief, T3 is not a secretory product of the thyroid, it is mainly produced by monodeiodination in the liver, kidneys and brain. It is now well established that in illness this pathway is blocked while the inactive pathway of $\mathrm{T} 4$ degradation via $\mathrm{rT} 3$ remains intact. Hence in disease serum T3 can be as low as in severe hypothyroidism and serum $T 4$ values can also be markedly reduced. Clinically it is however easy to exclude primary hypothyroidism (but not secondary hypothyroidism) by a serum TSH measurement which will remain normal even if both, serum T3 and T4 are marked1y decreased, the low serum T3 and total and free T4 levels being therefore diagnosticalily useless. Are these hormona1 changes adequate adaptations to the sick state or do they indicate a partial deficiency in thyroid hormones? The majority of indices favor the hypothesis of an adequate adaptation : kinetic studies have shown that the low serum T4 levels are in part explained by an increased metabolic clearance rate, the production rate being only moderatly reduced. The effect on the target tissues have been studied in the model of the starving rat : there is evidence for a partial resistance to T3 with nuclear receptors clearly decreased which is not typical for hypothyroidism. However in rats with renal insufficiency T3 can have some beneficial effects on enzymes.

A definite answer to the question raised will therefore have to awaide a better understanding of thyroid hormone action.
52

HYPOTHYROIDISM IN THE CRITICALLY ILL - PART OF THE DISEASE OR EPIPHENOMENON? P.R. Bratusch-Marrain, I. Medizinische Universitätsklinik, Vienna, Austria Systematic evaluation of endocrine systems during critical non-endocrine illness is severely hampered by the heterogeneity of diseases and the variety of applied treatments. Yet, interpretation of endocrine function tests in severely ill patients may be mandatory to uncover underlying or accompanying endocrine disorders.

In the present study the impact of non-thyroidal disease upon the pituitary-thyroid axis was evaluated. Out of 335 consecutive patients admitted to an intensive care unit 20 patients suffering from severe non-endocrine diseases (septicaemia, fulminant hepatic and renal failure, acute pancreatitis, polytrauma, cerebral haemorrhage) were found to have serum total thyroxine (TT4) levels in the hypothyroid range (below $4 \mu \mathrm{g} / \mathrm{d}$ ). Serum concentrations of TrT $(2.3+0.2 \mu \mathrm{g} / \mathrm{dl})$, trilodothyronine $(\mathrm{TT} 3,0.23+0.03 \mathrm{ng} / \mathrm{ml})$, and thyroxine binding globuline $(15.5+1.3 \mu \mathrm{q} / \mathrm{im} 1)$ were reduced, but were above normal for reverse T3 $10.43+0.06 \mathrm{ng} /$ $\mathrm{ml})$. The response of TSH secretion to iv TRF was found to be either normal, lowered or absent. Primary hypothyroidism was excluded, as no enhanced TSH response was observed in any case. Although decreased TT4 levels may be due to increased thyroid hormone degradation it appears that associated impaired TSH responsiveness to TRH may result from illness-related inhibition of pituitary TSH release. Even though free $\mathrm{T} 4$ serum levels may also be decreased in some of the patients at the surmit of their illness, the metabolic response to thyroid hormone deficiency is to be expected with considerable delay.

Although the finding of decreased thyroid hormone levels is not rare in intensive care patients, it represents an index of poor prognosis. Differentiation between this "low-T4 syndrome" and true hypothyroidism depends essentially on clinical symptoms and course of disease. If there is no clinical evidence of hypothyroidism, thyroid hormone substitution may not only lack a rational basis, but due to their cardiotropic action could also endanger some of these patients.
53

METABOLIC TREATMENT OF CARDIOVASCULAR FAILURE: A REASSESSMENT OF THE INSULIN CONCEPT. M. J. ELLIOTT, F.R.C.S., FREEMAN HOSPITAL, HIGH HEATON, NEWCASTLE-UPON-TYNE, U.K.

Insulin has been used in the treatment of heart failure almost since its discovery. Such intervention has always been controversial. Insulin therapy has, of course, been combined with glucose and potassium (as GIK) to prevent hypoglycaemia and hypokalaemia. Such combination has led, pari passu, to difficulties in defining the exact mode of action of the therapy since each constituent has potentially beneficial effects in the failing heart. Sporadic reports of clinical benefit from the use of GIK led to therapeutic trials of the treatment in a wide variety of clinical situations - ranging from its use after myocardial infarction to its use before open-heart surgery. Unfortunately, highly varied doses of $G, I$ and $K$ have been used, and it is not surprising that clinical results have been equivocal. Further, the responses sought by the various workers have also differed markedly, ranging from suppression of dysrhythmias to increased cardiac output. Few reports exist which relate dose to response, yet it is exactly this information which is needed by the clinician planning therapy. There is, however, a noticeable trend in recent reports to increase the doses of insulin used, and results appear encouraging, particularly: after myocardial infarction and in relation to myocardial failure following open-heart surgery. In the latter case enormous bolus doses of insulin have been employed.

This presentation reassesses the evidence for the use of insulin in mocardial failure, discusses the logistics of its use, and emphasises the need for the establishment of a dose:response relationship. 
54

BEDSIDE MEASUREMENTS OF RQ - METHODS AND THERAPEUTIC IMPLICATIONS. J . Eckart, Augsburg,FRG

Indirect calorimetry is the method in use today for providing data on total energy expenditure and on the amount and composition of the oxidized fuel. The metabolic rate can be calculated by multiplying oxygen uptake by the oxygen caloric equivalent corresponding to the $\mathrm{RQ}$. The respiratory quotient is the ratio of the volume of carbon dioxide produced to the volume of oxygen consumed over a given interval of time. Whereas fats and carbohydrates are completely oxidized proteins are not. Each gram of urinary nitrogen signifies a respiratory exchange of 4.7 liters $\mathrm{CO}_{2}$ and 5.9 liters $\mathrm{O}_{2}$. Using this figures we can calculate the nomprotein $R Q$. This ratio indicates the relative amounts of fat and carbohydrate katabolized. For measuring metabolic rate traditional techniques - Douglas-bag technique, closedcircuit spirometry have been replaced by automated systems - Beckman Metabolic Measurement Cart, CanopySpirometer-Computer System (Kinney et al), Engström Metabolic Computer - usable for mechanically ventilated and spontaneously breathing patients. By means of indirect calorimetry and calculations of nonprotein RQ new insights were gained in recent years into the metabolism and nourishment of critically ill patients. It could be demonstrated for instance that administration of large glucose load to hypermetabolic patients does not totally suppress the net fat oxidation as it does in depleted patients and that excess carbohydrate intake may be a critical factor in weaning of a patient with mechanical ventilatory support. By using the same technique other authors have shown that after an oral glucose tolerance test lipid oxidation rates were completely different in maturity-onset and in juveniletype diabetics.

\section{5}

WATER AND ELECTROLYTE BALANCE DURING MECHANICAL VENTILA TION.P.il. Suter, Hôpital cantonal universitaire, Genẽve Handling of water and electrolytes results under physiological circumstances from neural, humoral, cardiovascular and renal mechanisms. Mechanical ventilation interferes with several of these regulatory circles, causing generally water and sodium retention(1). The changes are more marked when positive end-expiratory pressure(PEEP) is applied, and in most studies PEEP was used to amplify the underlying mechanisms. The following factors are involved: 1) Increased intrathoracic pressures elevates central venous pressure, decreases venous return and cardiac output. 2) Renal function is impaired by changes in intrarenal perfusion(2) leading to water and salt retention.3) Antidiuretic hormone secretion is increased during both short(5) and long term positive pressure ventilation(4).4) P7asma renin activity and plasma aldosterone are increased(6).

Most of these mechanisms are more important during controlled or intermittent mandatory ventilation than during spontaneous breathing with positive airway pressure $(8)$. The application of dopamine or dopamine with dobutamine improves water and sodium excretion in ventilated patients $(3,7)$. It is not clear if water retention during mechanical ventilation is part of an adaptive mechanism to the decreased cardiac filling or simply due to a dysregulation of the mentionned circulatory and neurohumoral factors.

References:

1)S7aden,Laver,Pontoppidan,N Eng1 J Med 279:448,1968

2) Priebe,Heyman,Hedley-Whyte;J app] Phys 50:643,1981

3) Henmer, Suter; Anesthesiology 50:399,1979

4) Hemmer, Viquerat, Suter, Val lotton; Anesth 52:395,1980

5) Kumar, Pontoppidan, Baratz, Laver; Anesth 40:215,1974

6)Annat, Viale,Bui Xuan, Hadj Aissa,Benzoni, Vincent, Gharib, Motin;Anes thesiology $58: 136,1983$

7) Brandl,Pasch, Kamp, Grinm; Int Care :1ed 8:69, 1982

8) Steinhoff,Falke,Schwarzhoff, Int Care Med $8: 69,1982$ 


\section{Early Management of the Trauma Patient}

56

PRIMARY FLUID LOSS AND REPLACEMENT THERAPY K. MeBmer, Dept.Exp. Surgery, University of Heidelberg/FRG

Primary fluid loss in trauma patients means first of all loss of both red blood cells and their colloidal suspension fluid. Depending upon severity and duration of hypovolemia, hypovolemia-induced activation of the sympathetic nervous system and deterioration of the fluidity of blood, the microvascular perfusion becomes impaired with the final result of tissue hypoxia and depletion of the extravascular fluid compartments. The length of time, a trauma patient has remained hypovolemic is critical for survival due to promotion of multiorgan failure with duration of hypovolemia and shock, respectively. Primary therapy should replace the colloidal fluid actually lost. The aim of initial volume substitution, however, is not only to restore circulating volume and central haemodynamics but to counteract at the same time the secondary impairment of the microcirculation. By virtue of their oncotic power and capacity to retain water within the circulation, red cell free colloid solutions should preferably be used for primary volume replacement in trauma patients. From the artificial colloids, Dextran 70 is considered most suitable due to its.long lasting volume and blood fluidity improving effect. Cristalloids have proven satisfactory, however, intravascular refill requires 2.5 - 4 times the volume loss and intensive haemodynamic monitoring. Iridependent upon the initial fluid used, a fall of haemoglobin to $10-8 \mathrm{~g} / 100 \mathrm{mI}$ calls for red cells. RBC-concentrates/FFP and fresh whole blood are both efficient to control deficits of oxygen carriers and plasmatic clotting factors.

\section{7}

\section{CIRCULATORY FAILURE AND PHARMACOLOGIC SUPPORT}

B. E. Strauex, Department of Medicine, University of Múnich, Klinikum Großhadern.

Cardiac failure may be due to abnormal alterations in preload, afterload, contractility and heart rate. Therapy and management of the failing heart therefore has to consider positive inotropic drugs as well as vasodilating and antiarrhythmic management.

Pharmacologic report embraces positive inotropic drugs (dopamin, dobutamin, prenalterol, amrinone etc.), reduction in preload (enddiastolic wall stress) by vasodilators (diuretics, nitroglycerine, isosorbiddinitrate) and reduction in afterload (systolic wall stress) by vasodilators with arterial action (dihydralazine, prazosine, nifedipine etc.).

The use of inotropic drugs has to consider the inotropic related increase in oxygen consumption of the heart, which may be compensated by afterload reduction. Thus, contractile enhancement as well as simultaneous preload and/or afterload reduction is discussed with regara to the management of cardiac and circulatory failure in the critically ill patient.
58

CHEST TRAUMA AND SURGICAL TREATEMEHT W. Giinz, Surgical Cinic B, University Hospital Hospital, Zürich.

Apart of intercostal tube drainage, which is the basic therapeutic procedure in all severe chest injuries, operative intervention is seldom necessary in blunt thoracic trauma. We performed thoracotomy in $8 \%$ of such hospitalized patients. There are clearly defined indications for surgery: Massive and persistent bleeding, acute cardiac tamponade, rupture of trachea, bronchi, aorta, supraartic branches, and diaphragm.

Operative stabilization of the chest wall should be considered in exceptional cases. Many restricting factors are involved in such an operation, and in many cases it is just not necessary.

Conditions are similar in the case of penetrating injuries. Here too, thoracotomy is reserved for precisely defined indications. Many cases can be treated by conservative management, which does not mean being inactive. Immediate. thoracotomy, however, is the key to success in all penetrating heart injuries, and this applies particularly to situations that are apparently hopeless.

Thoracotomy was performed in 49 out of 155 penetrating thoracic injuries (48\% of which were gunshot wounds). In this series, 36 heart injuries are included. Hortality was $5.5 \%$.

\section{9}

EARLY RESPIRATORY FAILURE AND MANAGFNENT. G.WOIfE, Division of Cardiothoracic Surgery, University of Basel, CH 4031 BASET.

Acute respiratory failure (ARF) means increase of $\mathrm{P}_{a} \mathrm{CO}_{2}$ and/or low $\mathrm{P}_{2} \mathrm{O}_{2}$ compared to $\mathrm{F}_{\mathrm{O}} \mathrm{O}_{2}$. After trauma a number of pathological conditions may cause these symptoms. Hypoxia/hypercapnia are produced by a reduction in ventilation and/or by disturbance of gas exchange. 1.Ventilation may be limited mechanically (blocked airways, Pneumothorax, flail chest), by central nervous depression (coma) or by pain (rib fractures). If causal therapy is not effective inmediately, mechanical ventilation has to be installed without delay. High frequency ventilation may be adequate in selected cases. 2. Gas Exchange may be disturbed by localised pulmonary lesions preventing ventilation in areas still perfused (puImonary contusion, aspiration pneumonitis) or in a diffuse change of pulmonary parenchyma beginning as interstitial edema progressing to alveolar edema and later on to interstitial fibrosis (ARDS). Although biochemical mediators may initiate ARDS, the first clinical manifestation is a capillary leak associated with and partially due to hypoxic pulmonary vasoconstriction. Therapy cannot focus on the primary lesions but must (1) increase pulmonary gas volume (mechanical ventilation with PEEP ) to raise $\mathrm{P} \mathrm{O}$ and to reduce hypoxic pulmonary vasoconstriction, pullionary hypertension and capillary leakage, and (2) increase cardiac output to reduce pulmonary vascular resistance and right ventricular failure. Intravascular volume must be optimised and vaso-active pharmacotherapy may be necessary. However, the important goal is difficult to reach : to get ventilation in match with perfusion. Early prophylactic steps are more effective than late therapeutic attemps. Corticostheroids, Heparin, Trasylol, etc. are not proven to have any effect. 
60

EARLY MANAGEMENT OF SEVERE HEAD INJURY. D. G. McDowa11, Department of Anaesthesia, University of Leeds, England.

Head trauma is common but severe brain injury is rare. In a few patients an injury which at first sight seems minor leads to severe brain damage due to intracranial bleeding. The primary brain injury which occurs at the moment of trauma may be complicated by secondary brain injury if hypoxia, hypocapnia, hypo- and hyper-tension or cerebral venous congestion are allowed to occur. The main problems in early head injury management are, therefore, 1) triage and 2) prevention of secondary brain injury.

At the scene of the injury the first requirement is to control the airway. Regurgitation of vomitus can usually be prevented by correct positioning. Unskilled attempts at tracheal intubation may make the brain injury worse. The second requirement is the support of the circulation by controlling haemorrhage and/or infusing colloid. Once these primary resuscitative measures have been taken the level of coma should be assessed and recorded using the Glasgow Coma Score and the reaction of the pupils examined.

The patient should be transported to hospital and a skull $\mathrm{X}$-ray obtained. If he remains in coma as defined by Jennett as "Not obeying commands, not uttering any recognisable words and not opening the eyes" after correction of respiratory and circulatory inadequacy, then he should be transferred to a hospital able to provide CAT scanning. This should also occur immediately if there is any sign of worsening of the conscious level. If the CAT scan shows intracranial haemorrhage, craniotomy will usually be necessary and this should be followed by ICP monitoring. If there is no haematoma but the patient remains in coma, ICP recording should be initiated. Controlled ventilation is indicated for at least 12 hours following any surgical haematoma evacuation. In the absence of surgery, controlled ventilation is indicated if there is 1) no reaction to pain, 2) extensor posturing, 3) convulsions, or 4) ICP over $25 \mathrm{~mm} \mathrm{Hg}$. During controlled ventilation ICP should be kept below $25 \mathrm{~mm} \mathrm{Hg}$ by mannitol, frusemide and althesin, etomidate or thiopentone.

Many severe head injuries also have other major injuries. Necessary surgery should always be covered by adequate anaesthesia, using controlled ventilation and avoiding volatile anaesthetics. Chest injuries may require the use of positive airway pressure and this is acceptable providing the patient is nursed head up to reduce cerebral venous pressure. Limb fractures should be managed by methods which do not require traction in the head down position. Maxillo-facial injuries can usually wait 2448 hours before surgery. It is very necessary to be on guard for visceral intra-abdominal bleeding which can readily be missed during controlled ventilation of the head injured patient.
61

Anesthesia in trauma victims

petex, K. , Franke, N.

Institut für Anästhesiologie der LM-Univ. München, Klinikum GroBhadern

In anesthesia under conditions of trauma and shock due to volume dificiency the pathophysiological alterations caused by these conditions have to be taken into account. on principle, trauma and shock result in an acute disproportion between oxygen supply and oxygen demand of the organism. To the fore of the cardiovascular reaction there is the sympathico-adrenergic stimulation at an reduced cardiac output which leads to a derangement within the field of microcirculation. In a stage of compensated shock constriction of arterioles, precapillaries and venules causes an impairment of inflow and outflow. As a result microcirculatory blood flow is redistributed thus leading to a reduction in perfusion of nutritive capillaries as well as to tissue hypoxia and anoxia. The aim of therapy must therefore be an improvement of microcirculatory blood flow. The most important factor in this connection is a rapid and complete volume replacement by dextrane, crystalloids and blood or blood fractions. Adequate oxygenation and reduction of respiratory work must be ensured early and with somolent patients early intubation is needed in order to protect respiration. With patients in traumatic shock anesthesia should be induced with etomidate, ketamines or opioides because of the low negative inotropy and the modest influence on afterload of these agents. Subsequent to a complete volume replacement narcosis can be maintained by a combination of fentanyl, for instance, and volatile anesthetics (enflurane, halothane). In order to decrease the pressure in situation with circulatory hypertension the administration of nitroclycerine should be preferred, since sodium nitroprusside induces microcirculatory disorders. These necessary measure call for an invasive monitoring including recording of cardiac output and pulmonary pressures.

\section{2}

TRAUMA AND INFECTION. I.McA. Ledingham, r. Watt. University Department of Surgery, Western Infirmaxy, Glas gow G11 6NT.

The relationship between multiple trauma and infection has been studied in $\mathbf{4 2 8}$ patients admitted to an ITU between 1969 and 1982 . Until 1980 mortality was consistently around $25 \%$. $62 \%$ of the non-survivors died in less than 5 days from injury, decreasing from $86 \%$ during the first two years to $35 \%$ during the last two years. The majority of the remainder died with septic complications and/or multinle organ failure.

During 1981/82 the number of trauma referrals rose by $60 \%$. Mortality also increased (from $25 \%$ to $44 \%$ ) $33 \%$ of the non-survivors died in less than 5 days from injury.

There were no obvious changes in the pattern of referral, severity of injury, nature of bacterial infection or frequency of invasive procedures to explain the increase in mortality. Other factors influencing host defence both duxing early resuscitation and subsequent intensive care may adversely affect outcome. 
101

ROLE OF COMPLEMENT - C5 A ACTIVATTON AND STEROLDS IN ADULT RESPIRATORY DISTRESS SYNDROME, SEPTIC AND NON SEPTIC SHOCK Dedhia H, Schiebel F, Bowen R, Koss W, Crompton J, Beatty $\mathrm{J}$, Depts. of Anesthesia, Medicine and Pathology, West Virginia University Hospital and School of Medicine, Morgantown, WV 26506 USA

Use of high dose steroids in ARDS, septic and non septic shock remains controversial. Complement activation, sp. C5a may be important in those conditions. We are involved with a prospective study in humans, in hope to clarify the issues. 31 patients with ARDS, septic or non septic shock admitted to ICU have been studied. A11 patients were on respirators and PEEP. Serum for C5a were drawn initially at the time of diagnosis and then daily. 82 samples from 31 patients were collected and analyzed. Complement induced leukocyte aggregation was measured in vitro and graded from $1+$ to $4 t$. From 31 patients, 5 were negative, 9 showed $1+$ to $2+, 17$ demonstrated $3+$ to $4+$ and were considered positive. Solumedro $1^{\mathrm{R}}$ (Methylpredniso-Ione) $30 \mathrm{mg} / \mathrm{Kg}$ was given $\mathrm{q} 6 \mathrm{hr}$ for 4 or 8 doses in $10 \mathrm{pa}-$ tients. Classification of each group and results are shown below.

\begin{tabular}{|c|c|c|c|c|c|c|c|c|}
\hline \multirow[b]{2}{*}{ Group } & \multirow[b]{2}{*}{ Diagnosis } & \multirow{2}{*}{$\begin{array}{l}\text { No. of } \\
\text { Patient }\end{array}$} & \multirow{2}{*}{\multicolumn{2}{|c|}{$\begin{array}{l}\text { C5a } \\
\text { Activation }\end{array}$}} & \multirow{2}{*}{\multicolumn{2}{|c|}{ Steroids }} & \multicolumn{2}{|c|}{ Outcome } \\
\hline & & & & & & & & $\mathrm{D}$ \\
\hline$I$ & ARDS & 24 & 16 & - & $\begin{array}{l}4 \\
4\end{array}$ & $\begin{array}{r}12 \\
4\end{array}$ & $\begin{array}{l}7 \\
5\end{array}$ & $\begin{array}{l}9 \\
3\end{array}$ \\
\hline 2 & $\begin{array}{c}\text { Septic } \\
\text { Shock } \\
\end{array}$ & 2 & 1 & 1 & 1 & 1 & 2 & - \\
\hline 3 & $\begin{array}{l}\text { Non-Septic } \\
\text { Shock }\end{array}$ & 5 & 0 & 5 & 0 & 5 & I & 4 \\
\hline $\begin{array}{l}\text { (S) } 1 \\
\text { (D) } 3\end{array}$ & $\begin{array}{l}\text { dicates Sur } \\
\text { dicates Dea }\end{array}$ & $\begin{array}{l}\text { vival } \\
\text { th }\end{array}$ & & & $\begin{array}{l}\text { C5: } \\
\text { cer: }\end{array}$ & tĩ & atior & \\
\hline
\end{tabular}

*Preliminary data suggests

1) C5a activation occurs in a high percentage of patients with ARDS and carries high mortality.

2) C5a activation is absent in patients with non septic Shock.

\section{3}

THE ROLE OF PROSTACYCLIN (PGI ) AND THROMBOXANE A IN COMPLEMENT INDUCED PULMONARY INSUFFICIENCY. Michael $M$. Krausz, M.D., Takayoshi Ut sunomiya, M.D.,Ph.D., Herbert B. Hechtman, M.D., Dept of Surgery B, Hadassah University Hospital, Jerusalem, Israel, and Dept of Surgery, Brigham and Women's Hospital and Harvard Medical School, Boston MA, U.S.A.

Activation of the alternative pathway of the complement system leads to leukocyte aggregation, entrapment in the pulmonary microvasculature and release of vasotoxic agents which lead to increased physiologic shunting and permeability pulmonary edema. 31 sheep were infused with zymosan activated plasma (ZAP): group I $(n=11)$ were untreated controls. In group II $(n=10)$ imidazole, a thromboxane synthetase inhibitor, $25 \mathrm{mg} / \mathrm{kg}$. h was started $\frac{1}{2} \mathrm{~h}$ before ZAP infusion. In group III $(n=10), P G I_{2}$ in a dose of $100 \mathrm{ng} / \mathrm{kg}$. min was given $30 \mathrm{~min}$ before $\mathrm{ZAP}$ infusion. Within 5 min, ZAP led to a fall in leukocyte count to $2900 / \mathrm{mm}^{3}$ (p<0.001), rise in plasma thromboxane $B_{2} \quad\left(\mathrm{TxB}_{2}\right)$ from 14 to $246 \mathrm{pg} / \mathrm{ml}(\mathrm{p}<0.001)$ rise in $1 \mathrm{ymph}, \mathrm{TxB}_{2}$ from 24 to $609 \mathrm{pg} / \mathrm{ml}$ ( $\mathrm{pt0.001}$ ) rise in mean pulmonary artery pressure (MPA) from 17 to $43 \mathrm{mmHg}$ and $\mathrm{Q}_{\mathrm{s}} / \mathrm{Q}_{\mathrm{t}}$ from $13 \%$ to $31 \%$. Both imidazole and $\mathrm{PGI}_{2}$ prevented the rise in $\mathrm{TxB}_{2}$ and $\dot{Q}_{S} / \dot{Q}_{t}$ and limited the increase in MPA to 25 and $30 \mathrm{~mm}$ $\mathrm{Hg}$ respectively. Imidazole but not $\mathrm{PGI}_{2}$ prevented the increase in lymph flow which in controls increased from 2.8 to $8.5 \mathrm{mI} / 30 \mathrm{~min}(\mathrm{p}<0.01)$ and lymph albumin clearence which increased from 2.2 to $6.0 \mathrm{~m} 1 / 30 \mathrm{~min}(\mathrm{p}<0.01)$. The high lymph concentration of $\mathrm{TxA}_{2}$ suggests a pulmonary site of production and its brgnchoconstrictive action may account for the increased $Q_{s} / Q_{t}$. TxA 2 is only partly responsible for the pulmonary hypertension and apparently unrelated to changes in permeability. The protective action of infused imidazole against increased permeability appears to be independent of its inhibition of $\mathrm{Tx}$ synthetase.

\section{4}

HISTOMORPHOMETRY OF LUNG ELASTIC FIBERS DURING ARDS . EFFECTS OF DISEASE DURATION AND TYPE OF VENTIJATION. Y. Ozier, B. Franc, J.F. Prost, D. Barres, F. Jardin, A. Mignot. Hôpital Ambroise Paré, Boulogne, France.

Lung elastic fibers of 27 patients deceased during ARDS have been quantified in order to evaluate effects of disease duration and type of ventilation.

3 groups of 9 patients with comparable aetiology have been constituted according to the duration of the ventilation and the amount of PEEP appreciated with an index as follow : A - Prolonged ventilation (16j.) and low PEEP (index 3) $B$ - Prolonged ventilation ( $15 j$. ) and high PEEP (index 18) C-Short ventilation because of early death

D - Control group of deceased patients wi thout lung pathology Elastic fibers quantitation on randomly distributed prelevment of I ung parenchyma stained by orcein has been achieved using i) a point counting method to measure the volume fraction of elastic fibers and the boundary length fraction ; and ii) an automatic image analyser working on images by successive erosions.

The 3 groups $A B C$ show a significant decrease of elastic fibers volume fraction compared with group $D$. The smallest value is in group C. The 2 groups $B$ and $C$ show a significant decrease of elastic fibers boundary length fraction compared with groups $A$ and $D$ together. The elastic fibers boundary length fraction have been appreciated first by the ratio of the total boundary length on the volume fraction and secondly by the area of the 4 th and 8 th erosions given by the automatic device.

These his tomorphometric results confirm the visual impression of elastic fibers destruction during the early phase of ARDS. In case of prolonged evolution these results sugges $t$ a partial regeneration to occur the quality of which being under the dependance of the type of ventilation. Indeed PEEP seems to maintain the elastic fibers in a fragmentation state close to the state of the first day of the disease.

- In this group $\mathrm{A}$, where mean venous admixture $(40.9+10.4)$ was not different from group B $(41.2+8.1)$, a similar mean duration of ventilation was obtained despite the lack of consistant PEEP using membrane lung oxygenation in several cases. 
105

ANGIOTENSIN CONVERTING ENZYME (ACE), A PROGNOSTIC PARAMETER IN ADULT RESPIRATORY DISTRESS SYNDROME (ARDS)?H.Steppling, M.ReuB, W. Muller, V.Schulz, Universitätskliniken Mainz,Abtl.f.Pneumologie U.II.Med.Klinik, D-6500 Mainz ACE is present in high concentration in pinocytotic vesicles on the Iuminal surface of the pulmonary capillary endothelium. Because damage of the pulmonary vascular endothelium is believed to be a cardinal pathogenetic feature of ARDS it is the question, if serum ACE level can be used as a marker for development and prognosis of ARDS.

Until now we have investigated 9 patients with ARDS.ACE activity was measured spectophotometrically in progress of ARDS (range 8-32 days; method described by Cushman and Cheung) and was correlated to data of pulmonary gas exchange $\left(\mathrm{AaDO}_{2}, \mathrm{PaO}_{2}, \mathrm{PaCO}_{2}, \dot{\mathrm{Q}}_{\mathrm{sh}} / \mathrm{Q}_{t}\right.$ ) and thoraco-pulmonary compliance? 60 healthy persons in comparable age were used as contol group.

In patients with ARDS ACE activity in serum was found significantly lower ( $\left.\bar{x}_{ \pm x}=11,9 \pm 7,7\right)$ than in healthy controls $\left(x \pm x_{s}=32,0 \pm 7,8\right)$.

Patients with relatively higher mean ACE levels in progress of ARDS $(z=13,0-24,0 \mathrm{U} / \mathrm{ml})$ demonstrated finally before death a marked increase of ACE serum level (range 31,5-43,6 U/ml) corresponding to an extreme rise of pulmonary shunt perfusion. This final increase of serum ACE was not found in patients showing continuously very low ACE values during ARDS $(\bar{x}=3,3-9,3 \mathrm{U} / \mathrm{ml})$. These patients survived a shorter time on average $(x=9 d)$ than those with higher ACE levels ( $\bar{x}=25 d)$.

The final increase of serum ACE in ARDS could be a sign of terminal, massive damage of pulmonary vascular endothelium. If very low ACE values are measured in progress of ARDS an early, severe damage of endothelium could be supposed.

\section{6}

PROGNOSIS OF ARDS : INTEREST OF GAS EXCHANGES AND COMPLTANCE MONITORING UNDER CONTROLLED VENTILATION (CMV). C. Chopin, F. Fourrier, J. Mangalaboyi, M.C. Chambrin, A. Durocher, D. Dubois, F. Wattel - Hôpital Calmette - LILLE The aim of this study was to point out the interest of gas exchanges and compliance monitoring of the patients submitted to controlled ventilation during ARDS. 34 patients supported the study (Mendelson's syndrom 18 - Lung contusion 9 - Viral pneumonitis 4 - Fat embolism 3). The monitoring based upon the continuous measurement of expired C02, expired volume and airways pressure by the mean of an individual computerized device. The monitoring was realized all along the controlled ventilation $(4,5 \pm 1,8$ days) and allows to obtain the following functional data : VA/V ratio, partial ductances of $\mathrm{CO} 2$ (expired/alveolar $=$ DuVCO2 alveolar/arterial $=$ DucC02) $-\nabla \mathrm{CO} 2-$ static compliance (Cst). The therapeutic regimen included : CMV with PEEP, isovolemic deshydration, corticotherapy and heparin. 23 patients survived (group S). 1.1. patients ( $31 \%$ ) died, (group D). We compared the results (table) of functional data obtained at T6 (6th hour) - T24 - T48 between both groups (Student's $t$ test).

Discussion : at the early stage, DuCCO2 seems to be the more significant pronostic index. As for recovery the predictive value $(\mathrm{PV}+)$ at $\mathrm{T} 6$, reaches $85 \%$ when $\mathrm{DucCO} 2 \geqslant$ 0,70 . However, when DucCO2 $<0,70$, the predictive value of death is bad ( $P V=50 \%)$. So we tried to define a more accurate index : IEM $=$ DucC02 x Cst which has PV $+=94 \%$ (when IEM $\geqslant 20$ ) and PV $-=74 \%$ (when IEM $<20$ ).

Conclusion: So, IEM represents a compliance taking into account the functional qualities of the remaining lung areas. We propose to use it in further prospective studies

\begin{tabular}{|c|c|c|c|}
\hline$T 6$ & GROUP $S$ & GROUP D & $\mathrm{S}$ \\
\hline $\mathrm{PaO} 2\left(\right.$ FIO2 $\left.\overline{\bar{H}}_{\alpha} 1\right)$ & $153 \pm 1 \overline{12}$ & $154 \pm \overline{88}$ & NS \\
\hline $\mathrm{VA} / \mathrm{V} \quad \mathrm{mmHg}$ & $0,60 \pm 0,137$ & $0,45 \pm 0,110$ & $p<0,01$ \\
\hline DucCO2 & $0,68 \pm 0,120$ & $0,55 \div 0,11$ & $p<0,001$ \\
\hline Cst $\left(\mathrm{m}^{1} / \mathrm{cmH}_{2} \mathrm{o}\right)$ & $36 \pm 10,2$ & $27 \div 8,1$ & $\mathrm{p}<0,05$ \\
\hline IEM $\left(\mathrm{ml} / \mathrm{cmH}_{2}^{2} 0\right)$ & $25 \pm 8,4$ & $14 \pm 4,6$ & $p<0,001$ \\
\hline
\end{tabular}

RESULTS AT T6
107

ALTERATIONS OF PULMONARY GAS EXCHANGES AFTER ADULT RESPIRATORY DISTRESS SYNDROME FOLLOUING PROLINGED NEAR DROUNING.G.Domenighetti, E. Buchser ,L.Genoni, Ph.l.euenberger, Unità dí cure intense Ospedale La Carità,Locarno, Département d'Anesthésiologie and Division de Pneumologie, CHUV, Lausanne, switzerland.

Pulmonary edema following near drowning in fresh water is a frequent and severe early complica tion.Lung mechanics and pulmonary gas exchange studies were performed 6 and 12 , months after the accident in 2 survivors of adult respiratory distress syndrome(ARDS) following prolonged immer sion( 10 and 20 minutes)in fresh water. The patients were 25 and 29 years old and non smokers. Assisted ventilation was performed during 2.9 and 34 days respectively. Measurements included spirometry, lung compliance,distribution of ventilation, transfer factor of carbon monoxyde(DLCO), membrane factor(DM), pulmonary capillary volume, gas exchanges at rest and during exercise.Result indicate that lung mechanics returned to normal. within 6 months after the onset of ARDS. No alterations of OLCO OI changes of the distribution of ventilation were detected.Conversely, the ratio of dead space to tidal volume was significantly increased at rest and during exercise, and the ra tio of capillary volume to alveolar volume was decreased in both patients. It is concluded that AROS following prolonced near drowning in adults causes late abnormalities of gas exchange probably related to decreased pulmonary capillary volume. 


\section{Pulmonary Gas Exchange}

108

PEEP, VENOUS ADMIXIURE AND TRUE SHUNT IN ARF PATIENTS

A.Pesenti, A.Riboni, L.Gattinoni, M.L.Caspani

Istituto di Anestesiologia e Rianimazione, Università degli Studi di Milano, Via F.Sforza 33,20122, Milano

$Q \vee A / Q 0$, (venous admixture) and $Q \mathrm{~S} / Q \mathrm{tSF}$ (true shunt) were measured in 15 occasions on 10 ARF patients requiring positive airway pressure therapy. Measurements were done after 30 min stabilization at 5 col $\mathrm{H}_{2} \mathrm{O}$ below and repeated at $5 \mathrm{~cm} \mathrm{H}_{2} \mathrm{O}$ over the clinically chosen PEEP $(13 \pm 6.5 \mathrm{SD} \mathrm{cm} \mathrm{H} O)$ at maintenance $\mathrm{F}_{2} \mathrm{O}_{2}(0.57 \pm 0.18 \mathrm{SD})$.

QVA $/ Q 0$ was then divided into two components, one due to true shunt and one due to maldistribution, computed as $\left(Q \mathrm{QVO}_{2}-0 \mathrm{SSF}\right) / 0$. The study showed:

- QVA/QO and QS/QTSF decreased significantly increasing PEEP (from $0.36 \pm 0.12$ SD to $0.27 \pm 0.11$ and from $0.28 \pm 0.16$ so to $0.22 \pm$ 0.15 SD respectively)

- (QVAO ${ }_{2}$ QSSF $\left.{ }_{6}\right) / Q$ : no significant changes in spite of minor unpredictable variations in both directions $(0.08 \pm 0.05 \mathrm{SD}$ at -5 vs 0.06 \pm 0.05 S.D at +5 ) ;

- cardiac output was not significantly influenced by the PEEP levels $\left(6.67 \pm 1.981 \mathrm{~min}^{-1}\right.$ at -5 vs $6.52 \pm 1.971 \mathrm{nin}^{-1}$ at +5$)$; changes were not correlated with changes in QVA/Q0 or QS/QtSF;

- the fraction of the total $Q V A / Q O$ due to maldistribution

(QVAO $-Q \mathrm{SSF}) /\left(\mathrm{QVAO}_{0}\right)(y)$ showed $^{2}$ a significant negative correlation with $F_{2} 0\left(\begin{array}{l}6 \\ x\end{array}\right)(y=0.75-0.84 x ; r=-0.75)$.

Conclusions: higher PEEP improved oxygenation mainly through a decreased true shunt. As expected at high $F, 0$ the true shunt was very similar to $\mathrm{QVA} / \mathrm{QO}{ }_{2}$. In patients tolerating lower $\mathrm{F}_{\mathrm{I}_{2}} \mathrm{O}_{2}$ substantial amount of hypoxia was due to maldistribution.

\section{References:}

1) Pesenti A., Latini R., Riboni A., Gattinoni L.: Simple estinate of the true right to left shunt $(0 s / 0 t)$ at maintenance $F O_{2}$ by sulphur hexafluoride retention. Intensive Care Med. 8, 283, 1982.

\section{9}

VENTILATION-PERFUSION RELATIONSHIPS DURING ANAESTHESIA WITH VARYING INISPIRED OXYGEN CONCENTRATIONS. G. Hedenstierna, R. Lundh, Departments of Anesthesia and Clinical Physiolony, Huddinge University Hospital, Huddinge, Sweden.

Ventilation-perfusion relationships $\left(\dot{V}_{A} / \dot{Q}\right)$, assessed by a multiple inert as elimination technique, were studied during halothane anaesthesia and mechanical ventilation at different inspiratory oxygen fractions $\left(\mathrm{F}_{\mathrm{T}} \mathrm{O}_{2}\right)$. Hidened $V_{A} / 0$-distributions were observed in a 11 nine patients (mean age 61 years, 4 smokers) during anaesthesia, indicating increased mis-matching between ventilation and blood flow. The $V_{A} / Q$-distribution was unaltered when $\mathrm{F}_{\mathrm{O}} \mathrm{O}_{2}$ was increased from a mean of $29 \%$ to $53 \%$. A further increase in $\mathrm{F}_{\mathrm{I}} \mathrm{n}$ to a mean of $85 \%$ caused a further widenina of the $\dot{y}^{1} / Q$-distribution, and an increase in true shunt $\left(\dot{V}_{A} / \dot{Q}=0\right)$ from $7 \%$ to $10 \%$ of cardiac output ( $\mathrm{p}<$ $0.01)$. However, there was no fractional increase in "low" $\dot{V} / \hat{0}$, except for one patient. On the return to $\mathrm{F}_{-} \mathrm{O}_{2}$ of $29 \%$, the $\dot{V}_{A} / \dot{0}$-distribution resumed the same patter $r$ as seen prior to oxygen breathing, and true shunt was reduced to the initial level except for one patient (the one with an increase in "low" $\dot{V} / \dot{Q}$ during oxygen breathing). The findings may fit in with release of hypoxic vaso-constriction when $F_{T} 0$ is increased to $85 \%$, or the openinr up of a certain population of shunt vessels. only one patient displayed a change of the $\dot{V}_{A} / 0$-distribution during oxycen breathing that could be explained by resorption atelectasis.

\section{0}

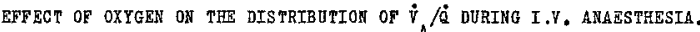

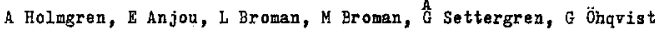
Dpt Anaesthesiology and Clinical Physiology, Thoracic clinics, Rarolinska Hospital. (Stockolm, Sweden).

I.7. anaesthesia is gonerally considered to be accompanied by impairad alveolar gasexchange with inpending hypoxemia. To elimixate this risk use of oxygen enriched inspired air is the role. The aim of the present investigation is to $s$ tudy the role of inspired oxygen fraction for the distribution of $\forall / A$ during 1.7 . anaes thesia in patients undergoing lung surgery. Methods. 14 patients ( $33-72$ years) were investigated before lung surgery because of lung tumour with the multiple inert gas elimination technique according to Wagner and West during 4 experinental settings: $1 /$ Before $1 . \gamma$. anaes thesia $\left(\mathrm{FIO}_{2}=0.21\right), 2 / 30$ ain after induction of ansesthesia (pentothal, diazepan, fentanyl, pancuronium and controllod ventilation) ( $\mathrm{FIO}_{2}$ $0.21), 3 / 30$ min after increasing $\mathrm{FIO}_{2}$ to $0.5,4 / 40$ min after change in body position from supine to lateral with $\mathrm{FIO}_{2}$ still $=0.5$.

Besults are presented in table 1 and 2 as means. $x$ ) indicated significance $=<0.05$ compared with proceeding measurement (paired t-test).

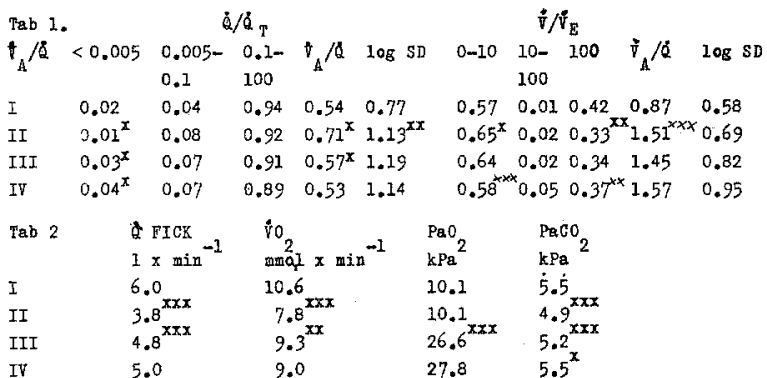

Conclusion. Induction of anaesthesia during air brosthing as wali as the increase of PIO fron 0.21 to 0.5 during anasthesia was only accompanied by minor changes in the distribution of perfusion. Ventilation ras redigtributed on the induction of anaesthesia to regions with less perfision as has been reported earlier.
111

EHFFECT OF VASODILATORS ON PULMONARY GAS. EXCHANGE TN ADULT RESPIRATORY DISTRESS SYNDRONE (ARDS). C. Mélot, N. Jaspar, R. Naeije, R. Hallemans, P. Mols, P. Lejeune Saint-Pierre University Hospital, B 1000 BRUSSELS (Belgium).

Vasodilators were given to 2 patients with ARDS and who were mechanically ventilated with positive end expiratory pressure (PHEP, cmH2O). Hemodynamic, gasometric and lung mechanic parameters and continuous distribution of ventilation-perfusion ratios $(\dot{V} A / Q)$ determined by the multiple inert gas elimination technique were measured at baseline and after diltiazem (DI $0.5 \mathrm{mg} / \mathrm{Kg}_{\mathrm{g}}$ IV) in the first patient and after sodium nitroprusside (NP $7 \mu \mathrm{g} / \mathrm{K}_{\mathrm{g}} / \mathrm{min} \mathrm{IV}$ ) in the second patient. In the two cases, pulmonary vasodilation was obtoined with a reduction in pulmonary arterial mean pressure (PAM, $\mathrm{mmHg}$ ) and in pulmonary vascular resistance index (PVRI, dyne.s.om-5.m2). Systemic vasodilation was observed with a drop in mean arterial pressure (MAP, $\mathrm{mmHg}^{\circ}$ ) and a slight increase in cardiac index (CI, I/ $\mathrm{min} / \mathrm{m} 2)$. A deterioration in pulmonary gas exchange was observed with a decrease in arterial $\mathrm{PO} 2\left(\mathrm{PaO}_{2}, \mathrm{mmHg}_{\mathrm{g}}\right)$ and increase in venous admixture (Qs/Qt, $\%$ of total blood flow). ViA/. distributions showed an increase in true shunt and in $\dot{V} A / \dot{Q}$ mismatching (Pat 1 fig)

\begin{tabular}{|c|c|c|c|c|c|c|c|c|c|}
\hline & & $\mathrm{Pa}_{\mathrm{a}} \mathrm{O2}$ & $\mathrm{Pr} 02$ & Qs $\delta t$ & CI MAP & IPAM & TVRI & $\mathrm{FiO}^{2}$ & FEEP \\
\hline $\begin{array}{l}\text { Pat } \\
1\end{array}$ & $\begin{array}{c}\text { Baseline } \\
\text { DI }\end{array}$ & $\begin{array}{l}58 \\
50\end{array}$ & $\begin{array}{l}30 \\
31\end{array}$ & $\begin{array}{l}29 \\
43\end{array}$ & \begin{tabular}{|l|l|}
3.7 & 67 \\
3.9 & 56 \\
\end{tabular} & $\begin{array}{l}37 \\
31\end{array}$ & $\begin{array}{l}473 \\
318\end{array}$ & 0.5 & \\
\hline $\begin{array}{c}\text { Pat } \\
2\end{array}$ & $\begin{array}{l}\text { Baseline } \\
\text { NP }\end{array}$ & $\begin{array}{l}80 \\
45\end{array}$ & $\begin{array}{l}39 \\
30\end{array}$ & $\begin{array}{l}24 \\
53\end{array}$ & \begin{tabular}{|l|l|}
2.3 & 96 \\
2.6 & 51 \\
\end{tabular} & $\begin{array}{l}37 \\
23\end{array}$ & $\begin{array}{l}771 \\
343\end{array}$ & 0.5 & \\
\hline
\end{tabular}

In ARDS pulmonary vascular tone improves VA/Q matching. 


\section{2}

DISTRIBUTION OF REGIONAL VENTILATION-PERFUSION RATIO $(\hat{V} / Q)$ WITH KRYPTON $81 M$ IN PULMONARY EMBOLISM. M. Meignan, G. Simonneau, L. Oliveira, A. Harf, L. Cinotti, J.F. Cavellier, P. Duraux, Intensive care unit, Hopital Antoine Béclère, Clamart, Department of nuclear medicine, Hôptial Henri Mondor, Créteil 94010, France.

The diagnosis of pulmonary embolism (P.E.) is difficult with ventilation-perfusion scanning in patients having a reduced ventilation in the region of the perfusion defects (matched defect) as in chronic obstructive lung disease (C.O.P.D.) Regional $V / Q$ шеге therefore computed in each region of a perfusion defect in 44 patients with angiographically confirmed P.E. and 40 patients vith C.O.P.D. by dividing ventilation scan by perfusion scan obtained with Krypton $81 \mathrm{~m}$ in tidal breathing with a gamma-camera linked to a computer. The regional ventilation-perfusion ratios vere computed in

each region of a perfusion defect. All the patients were studied supine in postérior viev. P.E. was characterized by mismatched defects (reduced perfusion and normal ventilation) with a high $V / .(1.96 \pm 0.1$ SD) due to vascular abstruction. A high $V / R(1.37 \pm 0.2 \mathrm{SD})$ was also found in the 25 out of 93 defects of perfusion which vere matched by a ventilation defect or a radioloqical opacity in these patients. Low $V / 0$ 's vere observed in the non embolic lung due to relative hyperperfusion. C.O.P.D. was characterized by matched defects with low $\dot{V} / Q$ in most of the cases $(.74+.1$ SD) and the turo groups (P.E. and C.O.P.D.) with matched defects differed significantly $(p<0.01)$. This regional quantitative analysis provides a simple mean to discriminate the defects of perfusion due to P.E. from those due to a reduced ventilation.
113

CORRECTION OF PULMONARY NON-GASEOUS FUNCTIONS METABOLISM IN THORACIC OPERATIONS - O.A.DOLINA, S.G.PTUSGHKINA, N.V.KUKUSCHKINA ist Medical Institute, Moscow, USSR

Studying of changes of lungs non-gaseous functions is great importance for the choice of intensive therapy. Complex investigations into the functions of respiration, circulation and metabolic changes were applied in dealing with 180 surgical patients undergone pulmonic operations. Use was made of polycardiography, rheography, capillaroscopy, of determining the acid-base aquilibrium, lipid metabolism, blood circulation volume. An analysis of these investigations enabled it to educe the initial specific disturbances of microcirculation, metabolic components caused by pulmonary non-gaseous metabolism. The data thus obtained served as a groundwork for elaborating differential indications for the cho ice of the method of general anaesthesia and pathogenetic therapy, a special complex treatment aimed at normalizing pulmonary ventilative-perfused correlation. Special attention in the prophylaxis of pulmonary complications is peid to the use of hypocoagulative and vasoactive agents, lipoconraining medicines and preventing the development of hyperhydration syndrome. 
114

HIGH FREOUENCY JET AND CONVENTIONAL MECHANICAL VENTILATION WILH PEEP: A COMPARISON OF AIRWAY PRESSURES AND CARDTORESPIRATORY FARAMETERS AT SIMILAR ALVEOLAR VENTILATION. A. Sladen, K. Guntupalli, M. Klain and R. Romano. Surgical Pittsburgh School of Medicine, Pittsburgh, PA 15213. USA High frequency jet ventilation with PEEP (HFJV) is used as an alternative to. conventional mechanical ventilation with PEEP (CPPV) for patients with acute respiratory failure. Comolications of CPPV include high peak airway pressures (FAP) and their sequelae, barotrauma to the lung and reduction in cardiac index. HFJV has been recommended to avoid high PAP. We observed when CPPV is changed to HFJV there is a temporary decrease in $\mathrm{FaO}_{2}$ which lasts about 60 studies of $P A P$, mean airway pressure (PaW) and cardiorespiratory parameters, initialIy with CPPV, and then with HFJV at similar alveolar ventilation, to determine the etiology of the decrease in $\mathrm{PaO}_{2}$ and the advantages, if any, of HFJV over CPPV.

Results:
CPPV: CI $2.54 \pm 0.14$ L.min.M ${ }^{-2} ;$ P $97 \pm 6 . \min ;$ SI $26.5 \pm 1.5$ ml.M-2; LVSWI $34.5 \pm 3.2$ gm.M.M-2; TPRI $2856 \pm 305$ dyne.sec.cm $-5 . \mathrm{M}^{-2} ;$ a-vo2 $4.4 \pm 0.2 \mathrm{ml} . \mathrm{dl} ; 02110.6+5.5 \mathrm{ml} . \mathrm{min} . \mathrm{M}^{-2} ; \mathrm{PaO}_{2}$ $2.7 \pm 0.2 \mathrm{mnHg} ;$ PAP $15.4 \pm 0.9 \mathrm{mmHg} ;$ PaW $4.41 \pm 0.29 \mathrm{mmHg}$

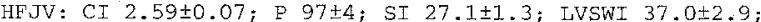

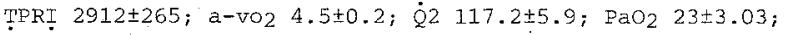

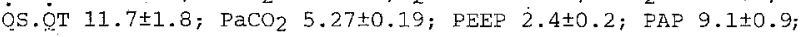
Paw $4.99 \pm 0.39$

This study demonstrated that there was no significant difference in CI, P, SI, LVSWI, TPRI, a-vo,$\dot{Q} 2$ and Paw between CPPV and $\mathrm{HFJV}$ at $100 . \mathrm{min}$ and at the same $\mathrm{PaCO}_{2}$ and PEEP. There was significant difference in $\mathrm{PaO}_{2}$ $\mathrm{P}<0.004$; $\dot{\mathrm{QS}}$. $\mathrm{T} \mathrm{P}<0.025$ and PAP $\mathrm{P}<0.001$. HEVV shoula reduce barotrauma because of the reduction in $P A P$. It is advisable to start with an $\mathrm{F}_{\mathrm{I}} \mathrm{O}_{2} 0.9$ and decrease $\mathrm{F}_{\mathrm{I}} \mathrm{O}_{2}$ as indicated by $\mathrm{PaO}_{2}$. Intensive Care Unit, Montefiore Hospital, University of min. Eleven patients admitted to the SICU had comparative $30.01 \pm 2.89 \mathrm{kPa}$; $\mathrm{QS} . \mathrm{QT}^{\mathrm{T}} 8.6 \pm 1.7 \%, \mathrm{PaCO}_{2} 5.24 \pm 0.2 \mathrm{kPa} ; \mathrm{PEEP}$

116

ACCUMULATIVE HIGH-FREQUENCY JET VENTILATION.M.D. Aochi, o Miyano, Fi.Mizuho-ku, Iagoya City University, Medical School, Nagoya City, Japan.

High-frequency jet ventilation (HFJV) in animals and humb - $n$-beengs with nomal lungs has been shown to provide adequate ventilation (V) and oxygenation (O) at lower airway pressure than IPPV without causing cardiac depression. However in those clinical cases with pulmonary disorders like ARDS, it is difficult to improve $V$ and 0 by HFJV alone, because of extremely diminished lung compliance and increased dead space.

So we have attempted the new method, accumulated highfrequency jet ventilation(Acc.-HFJV), in which the jet flow from HFJV generated by modified Bird Mark 3 has been accumulated by time-cycled regulation of the expiratory valve of $\mathrm{CV}-2000$ ventilator.

Acc-HFJV has improved $V$ and $O$ without compromising the characteristics of the jet flow, as compared with the superimposed mode. In addition, by using the technique of periodic interruption of the jet flow adjusted by respiratory cycles, it is possible to deliver accumulativ. e jet flow in the inspiratory phase, the expiratory phase or both. of them.

We have compared Acc-HFJV with CPPV and conventional HFJV in 40 patients with ARDS at same levels of PEEP. The results have indicated that adquate vand $O$ could be maintained more effectively by using Acc-HFJV than the other two modes of ventilation. No adverse circulatory effects have been observed.

117

HIGH FREQUENCY JET VENTILATION VERSUS INTERMITTENT POSITIVE PRESSURE VENTILATION IN'THE HYPOVOLEMIC DOG. M.Chiaranda, G.Fiore, E.Facco, G.P.Giron, Inst. of Anaesth. and Intensive Care, University of Padua, Italy.

The reduction observed in airway pressure when using high frequency jet ventilation (HFJV) instead of intermittent positive pressure ventilation (IPPV), could be advantageous in all conditions in which a minimal variation of intrathoracic pressure markedly modifies cardiovascular functions.

This study compares the cardiovascular effects of IPPV and HFJV in experimentally induced haemorrhagic shock.

Five heal thy Beagle dogs, $12 \div 15 \mathrm{~kg}$, were anaesthetized, paratized and intubated in the standard fashion. Sistemic, central venous and pulmonary arterial pressures, cardiac output via the thermodilution technique, arterial and mixed venous blood gases, airway pressure (Paw) at the end of the endothrachea t tube and oesophageal pressure were monitored. Cardiac and stroke indices (CI, SI), pulmonary and sistemic vascular resistances (PVR, SVR) and right and left ventricular stroke work indices (RVSWI, LVSWI) were calculated using standard equations. Ventilation was performed randomly with a volume-cycled ventilator (3100 Roche) at $15 \mathrm{~b} / \mathrm{m}$ and with an HFJV apparatus (VJP system) at 60,120 , $240,480 \mathrm{~b} / \mathrm{m}$, regulating tidal volume to maintain $\mathrm{PaCO}_{2}$ at $38 \pm 2 \mathrm{~mm} H \mathrm{Hg}$. Cardiorespiratory data were obtained for both modes of ventilation before and after lowering CI by inter mittent bleeding to about $50 \%$ of the initial value. Mean and peak airway pressures were significantly lower with HFJV at $60 \div 240 \mathrm{~b} / \mathrm{m}$; at $480 \mathrm{~b} / \mathrm{m}$, the end expiratory pressure was $3,7 \pm 1,2 \mathrm{mmHg}$, giving an increased mean Paw. Using HFJV at $60 \div 240 \mathrm{~b} / \mathrm{m}$ during haemorrhagic shock, CI, SI and LVSWI were signifjcantly enhanced, by respectively $+20 \%,+21 \%$ and $+38 \%$, in comparison to the control values in IPPV; a cardiovascular depression appeared at $480 \mathrm{~b} / \mathrm{m}$. These results confirm that when there is an haemodynamic impairment, as in the anaesthetized hypovolemic dog, HFJV reduces the deleterious cardiovascular effects of conven tional positive pressure ventilation.
$\mathrm{CO}_{2}$-EJIMINATION DURING HIGH FREQUENCY VENTIIATION WITH REGARD TO LING VOLIME. N.Mutz, M.Baum, H.Benzer, U. Losert Forschungsstelle für Intensivmedizin, Klinik für Anaesthesie, Wien, österreich

The influence of different lung volumes on various frequencies of high frequency ventilation was studied in 5 anesthetized mongrel dogs $(\bar{x}=28.9 \mathrm{~kg})$. After intubation, using a special developed endotracheal tube, dogs were placed in a rigid heat-exchanged pressure box (p.b.) with variable internal pressure (range: -10 to $+5 \mathrm{cmH}_{2} \mathrm{o}$ ). Ventilation was performed: $\mathrm{A}$. under conditions of IKPV ( $\mathrm{f}=$ $0.2 \mathrm{~Hz}), \mathrm{B}$. as "forced diffusion ventilation" (FDV), a modified high frequency jet ventilation ( $f=6 \mathrm{~Hz}, 50 \mathrm{~Hz}$, cont. =jet stream without any chopper frequency). By variing b.p. $\left(-10 / \mathrm{o} /+5 \mathrm{cmH}_{2} \mathrm{O}\right)$, different levels of lung volume were achieved. Particular combinations of b.p. and respirator settings were selected in random fashion. Blood gases, mixed expiratory $\mathrm{CO}_{2}\left(\mathrm{~F}_{\overline{\mathrm{F}}} \mathrm{CO}_{2}\right)$ and minute volume were measured $30 \mathrm{~min}$. after each setting was performed. At b.p. $-10 \mathrm{~cm} \mathrm{H}_{2} \mathrm{O}$ (=increased lung volume) $\mathrm{PaCO}_{2}$ rises statistically significant in comparison to b.p.o. In contrast, paCO decreases, if b.p. is elevated (lung volume diminished), ${ }^{2}$ as scheduled in table: Table (paCO $\bar{x} \mathrm{SD})$

\begin{tabular}{rllll} 
b.p. & $0.2 \mathrm{~Hz}$ (IPPV) & $6 \mathrm{~Hz}$ (FDV) & 5oHz (FDV) & cont. \\
\hline 0 & $36.2 \pm 5.5$ & $34.0 \pm 6.5$ & $49.6 \pm 7.6$ & $49.7 \pm 3.1$ \\
+5 & $35.2 \pm 5.7$ & $34.6 \pm 5.6$ & $44.8 \pm 5.6$ & $43.0 \pm 6.6$ \\
-10 & $41.4 \pm 3.5$ & $45.4 \pm 12.9$ & $62.2 \pm 5.2$ & $65.0 \pm 4.6$
\end{tabular}

$\mathrm{F}_{\overline{\mathrm{F}}} \mathrm{CO}$, shows an inverse proportional behaviour.

$\mathrm{Based}$ on our results, there is good evidence, that $\mathrm{CO}_{2}$ elimination is markedly diminished in existance of augmeted lung volume during FDV, especially using very high frequencies $(75 \mathrm{OHz})$ due to a decreasing $\mathrm{CO}_{2}$-elimination capacity of the jet. 
118

PHYSIOLOGICAL DEAD SPACE VERSUS TIDAL VOLUME DURING HIGH FREQUENCY JET VENTILATION IN THE DOG. M.Chiaranda, A.Rubi ni, R.Brigi, G.P.Giron, Inst. of Anaesthesiology and Inten sive Care, University of Padua, Italy.

The authors investigated the relationship between physiological dead space (Vd) and tidal volume (Vt) during high frequency jet ventilation (HFJV) at different positive end expiratory pressure (PEEP) leve $7 \mathrm{~s}(0-2.0 \mathrm{kPa})$.

Four healthy Beagle dogs, $11 \div 17 \mathrm{~kg}$, were anaesthetized, pa ralized and intubated in the standard fashion; ventilation was performed with intermittent (IPPV) or continuous (CPPV) positive pressure at $75 \mathrm{~b} / \mathrm{m}$ and $\mathrm{HFJV}$ at $60,120,240,480$ $\mathrm{b} / \mathrm{m}$, while minute volume $(\dot{V})$ was regulated to maintain $\mathrm{PaCO}_{2}$ at $38 \pm 2 \mathrm{mmHg}$. For each mode of ventilation arterial blood samples for gas analysis were taken after 10 min of stabilization. The volume of alveolar ventilation in a single breath ( $V a)$ and in a minute ( $\left.V_{a}\right)$ were calculated analyzing the values obtained with a pneumotachograph (Vt) and with Bohr's equation modified by Enghoff (Vd).

The results obtained show that there is a progressive redu ction in $V t, V a$ and $V d$ and a progressive: increase in $V d / V t$ ratio with increasing ventilatory frequency. The increase of PEEP values from 0 to $2.0 \mathrm{kPa}$ increases $\mathrm{Vd}$ and lowers the respiratory frequency value at which $V t$ falls below $V d$ measured at $15 \mathrm{~b} / \mathrm{m}$.

In conclusion, the authors stress that it is possible to maintain an adequate alveolar ventilation utilizing tidal volumes lower than the anatomical dead space volume. The $\dot{V}$ has to be increased with the increasing ventilatory frequen $c y$; this is due to an augmented wasted ventilation (Vd).
120

DIGITAL VENTILATION - A BRIDGE BETWEEN HFV AND CONVENTIONAL VENTILATION. M. Wend $t, L$. Freitag, F.Dankwart, J. Hansen, K1 injk für Anästhesiologie und op. Intensivmedizin, Universität Münster, W.-Germany

The enthusiasm about ventilation of patients with higher frequencies has changed a lot from the beginning. Two disadvantages are dominating, one is the impossibility of pressure measurement at alveolar level and the other is the difficulty of application at normal ICU-patients. So a new system has been developed, giving the chance of HFV (high frequency positive pressure ventila= tion), HFO (high frequency oscillation) and CMV (conventional mechanical ventilation) using normal endotracheal tubes with only one small ventilator. This system - nothing more than a small computer - gives the possibility to generate any new ventilatory pattern in future. We compared HFV,HFO and CMV generated with higher or lower frequencies. The research is done using two groups of ICU-patients, one, which does only need mechanically support and another, which has lung disease. In both groups similar hemody= namic data were found under similar airway pressures.Gas exchange may be better using generated frequencies under some circumstances.

HIGH FREQUENCY JET VENTILATION AND PEAK AIRWAY PRESSURE SYNCHRONIZATION WITH ECG. M.Chiaranda, A.Rubini, M.Trevi san, G.P.Giron, Inst. of Anaes thes iology and Intensive Care, University of Padua, Italy.

The use of ECG triggered jet ventilation is still controversial. The authors investigated the haemodynamic influence of high frequency jet ventilation (HFJV) with inspiratory peak synchronized with different phases of the cardiac cycle. Four healthy Beagle dogs, $17 \div 17 \mathrm{~kg}$, were anaesthetized, paralized and intubated in the standard fashion.Catheters were introduced for the measurement of sistemic, central venous and pulmonary arterial pressures, arterial and mixed venous blood gases; cardiac output was evaluated via the thermodilution technique. Cardiac and stroke indices (CI,SI), pulmonary vascular and total peripheral resistan ces (PVR, TPR) and right and left cardiac work indices (RCWI,LCWI) were calculated using standard equations. HFJV was performed at $120 \mathrm{~b} / \mathrm{m}$, with minute volume $(\dot{V})$ regulated to maintain $\mathrm{PaCO}_{2}$ at $38 \pm 2 \mathrm{mmHg}$ and a positive end expiratory pressure (PEEP) from 0 to $2.0 \mathrm{kPa}$. The haemodynamic influence of HFJV was evaluated when progres sively delaying the inspiratory peak corresponding to the onset of the ' $R$ ' wave on the ECG trace.

The mean pulmonary arterial pressure oscillations decrease as PEEP rises and their value reaches a maximum of $15 \%$ at zero PEEP. Lowest PVR and RCWI vaTues were observed when the inspiratory peak coincided with the protomesodiastolic phase of the cardiac cycle (that is at $30-70 \%$ of R-R inter val) and the highest values when the peak drops close to the $R$ wave $( \pm 20 \% R-R)$. This phenomenon occours independently from the PEEP level applied.

The results demonstrate the absence of significant haemodynamic effects due to ECG and inspiratory peak synchroni zation when HFJV is applied to anaesthetized dogs with a normal cardiovascular reserve and lung compliance. 
COPD, Embolism, Asthma

121

HEMODYNAMIC EFFECTS OF PIENTOLAMINE IN PULMONARY HYPERTENSION FOLIOWING ACUTE EXACERBATION OF CHRONIC OBSTRUCTIVE PULMONARY DISEASE. G. Damenighetti, Ph. Leuenberger, Cl. Perret. Institute of Pathophysiology and Intensive Care Unit, Dept of Medicine, C.H.U.V., Lausanne.

The usefulness of vasodilators in the treatment of pulmonary hypertension (PHT) following chronic obstructive pulmonery disease (COPD) has not yet been established, especially during acute exacerbation of the disease. Phentolamine (Ph), a potent systemic vasodilator drug, is known to act on the pulmonary circulation as well. The recognized spasmolytic action of ph on the bronchial smooth muscle could represent a further advantage in the management of COPD.

Seven patients ( 6 males, 1 female) with an acute exacerbation of COPD $\left(\mathrm{PaO}_{2} 49+3 \mathrm{~mm} \mathrm{Hg}, \mathrm{PaCO}_{2} 53+4 \mathrm{~nm} \mathrm{Hg}\right.$; mean $+S E M)$, aged 49-74, underwent hemodynamic investigation before and during $\mathrm{Ph}$ infusion $(10-15 \mathrm{mg} / \mathrm{h})$, without $\mathrm{O}_{2}$ therapy. Baseline hemodynamic data showed a moderate $\mathrm{PHT}\left(\mathrm{P}_{\overline{\mathrm{AP}}} 44,5 \pm 7 \mathrm{~mm} \mathrm{Hg}\right)$ with raised right atrial pressure and a nomal pulmonary wedge pressure ( $\mathrm{POD} 11+2$ $\mathrm{nm} \mathrm{Hg} ; \mathrm{P}_{\mathrm{VT}} 9 \pm 2 \mathrm{~mm} \mathrm{Hg}$ ). Ph produced a significant reduction in $\mathrm{P}_{\overline{\mathrm{AP}}}, \overline{\mathrm{P}}_{\overline{\mathrm{OD}}}$ and $\mathrm{P}_{\overline{\mathrm{WP}}}(\mathrm{p}<0,05 ; \mathrm{p}<0,01 ; \mathrm{p}<0,02)$. There was no change in cardiac index, $\mathrm{PaO}_{2}, \mathrm{PaCO}_{2}$ and mean systemic arterial pressure. $A$ further fall in $\mathrm{P}_{\overline{\mathrm{AP}}}$ following an initial reduction with $0_{2}$ therapy was observed in one patient.

In conclusion, in patients with an acute exacerbation of COPD, phentolamine has a beneficial effect on pulmonary hemodynamics without detrimental changes in $\mathrm{PaO}_{2}, \mathrm{PaCO}_{2}$ and $\mathrm{O}_{2}$ delivery. The mechanisms responsible for the decreased pressures in the pulmonary circulation induced by phentolamine are discussed.
123

EFFECTS OF KETANSERIN IN CHRONIC OBSTRUCTIVE PULMONARY DISEASE (COPD) Y. HUET, M. GERDEAUX, A. ABDEL RAZEK, D.PAYEN F. LEMAIRE, F. LHOSTE. Réanimation Médicale - HENRI MONDOR HOSPITAL - FRANCE -

Serotonin, recognized as a potent vasoactive agent is involved in pulmonary hypertension mechanism in patients with COPD. In order to validate this hypothesis, KETANSERIN (K) a specific $5 \mathrm{HTC}$ receptor antagonist, was used in COPD. METHODS : 9 patients (ranged 50 to 75 years old) with COPD (Medica1 Research Council Criteria) were studied during acute exacerbation of respiratory failure (4 breathing, spontaneousiy 5 mecanically ventilated). All were free of treatment except antibiotics. Haemodynamic parameters were systemic arterial pressure (MAP), pulmonary capillary wedge (PWP), pulmonary arterial (PAP), and right atrial pressure (RAP) (Swan-Ganz $7 F$ ), cardiac output (CI) (Thermodi lution technique), heart rate (HR). Simultaneous sampling or arterial (a) and venous (v) blood permitted measurement of oxygen and carbon dioxide tension, hemoglobin saturation leading to calculate venous admixture (Qs/Qt)

(Fi02 : .21). Then $10 \mathrm{mg}$ of $(\mathrm{K})$ were given intravenously followed by a continuous infusion of $4 \mathrm{mg} /$ hour. RESULTS: are summarised in the table (mean \pm SD)

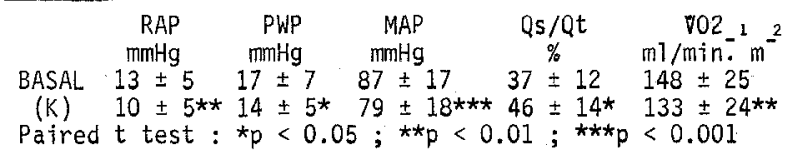

$C I, P a 02, P \bar{V} 02$, and $H R$ remains unchanged, No relationship was observed between $\mathrm{CI}$ and Qs/Qt and between PVOOZ and Qs/Qt.

CONCLUSION : 1) KETANSERIN acts as a balanced vasodilator drug. 2) The constant increase in venous admixture is not always related to CI changed so, when CI decrease lowers $P \bar{v} 02$, its variation may explain venous admixture increment 3) On the other hand, the constant decrease in 702 may be related to sympathetic blocking property of this drug.
122

ACUTE LIFE THREATENING PULMONARY HYPERTENSTON TREATED WITH IBUPROFEN. K.EIiasen, T.Mogensen, J.B.Andersen, L. Hasselstrøm, N.H.Jensen, I.Brynjolf, J.Godtfredsen. Department of Anesthesia and Department of Cardiology, Herlev Hospital, University of Copenhagen, Denmark. It has been shown, that the ratio between thromboxane and prostacyclin might be an important factor in acute pulmonary hypertension in sheep treated with E.coli endotoxin (1). On this basis we gave ibuprofen to two patients with acute pulmonary hypertension to convert the thromboxane/prostacyclin ratio in advantage of prostacyclin. One patient suffering from severe ARDS (effective compliance below $18 \mathrm{ml} / \mathrm{cm} \mathrm{H}_{2} \mathrm{O}$, pulmonary artery pressure (PAP) $56 / 38 \mathrm{~mm} \mathrm{Hg}, \mathrm{P}_{A} \mathrm{O}_{2} 10 \mathrm{kPa}, \mathrm{F}_{i} \mathrm{O}_{2} 0,6$, PEEP 10 $\mathrm{cm} \mathrm{H}_{2} \mathrm{O}$, balloon occlusion pulmonary angiogram showed pulmonary artery filling defects and thrombi) - and another patient suffering from multiple pulmonary embolism verified by ventilation-perfusion scintigraphy. In the first case a dose of $50 \mathrm{mg} / \mathrm{hour}$ of ibuprofen was given i.v., and in the second case a dose of $1200 \mathrm{mg}$ daily was given orally. In both cases PAP fell - in the first case from $56 / 38 \mathrm{~mm} \mathrm{Hg}$ to $40 / 15 \mathrm{~mm} \mathrm{Hg}$, and in the second case from $92 / 37 \mathrm{~mm}$ Hg to $25 / 12 \mathrm{~mm} \mathrm{Hg}$. $\mathrm{P} \mathrm{O}$ increased in the patient with ARDS with $4,9 \mathrm{kPa}$ with a constant $\mathrm{F}_{i} \mathrm{O}_{2}$ and constant PEEP. In the second case the $\mathrm{P}_{2} \mathrm{O}_{2}$ increased from $8,8 \mathrm{kPa}$ to $10,4 \mathrm{kPa}$. No adverse eftects were seen. These two cases suggest, that ibuprofen might be beneficial in the treatment of acute pulmonary hypertension. 1. W.D.Watkins, P.C.Hüttemeier, D.Kong and M.B.Peterson. Thromboxane and pulmonary hypertension following $\mathbf{E}$. coli endotoxin infusion in sheep: effect of an imidazole derivate. Prostaglandins 1982; $23: 273-85$.
124

OVER PERFUSION OF NON EMBOLIC LUNG AS A CAUSE OF HYPOXEMIA IN PULMONARY EMBOLISM (P.E.).

M. Meignan, A. Harf, L. Oliveira, G. Simonneau, L. Cinotti, P. Duroux, Intensive care unit, Hôpital Antoine Béclère, Clamart, Department of nuclear medicine, Hôpital Henri Mondor, Créteil 94010, France.

In order to validate the hypothesis that hypoxemia in P.E. can be related to the shift of perfusion. away from the embolic zone we have computed regional $\dot{V A} / \hat{Q}$ ratios and measured arterial $\mathrm{PO}_{2}$ in a group of 44 patients with P.E. proved by angiography. Distribution of $\dot{V} A / \dot{Q}$ was obtained with a minicomputer linked to a gammacamera from ventilation and perfusion lung scans with Krypton $81 \mathrm{~m}$ a short lived radionuclide (T1/2 = $13 \mathrm{sec}$ ) delivered by continuous inhalation and infusion in $t i-$ dal breathing. All 44 patients vere studied supine and the percentage of Iung field with $V A / Q$ less than 0.75 (VA/Q 0.75 ) was computer (The overall $\mathrm{VA} / \mathrm{V}_{\text {Uas }}$ normalized to 1). The mean values of $\mathrm{PaO}_{2}$ and $\mathrm{VA} / \mathrm{Q} 0.75$ vere respectively $67 \mathrm{mmHg} \pm 2.35 \mathrm{SD}$, and $21.6 \% \pm 9 \mathrm{SD}$. There was a significant inverse relation ship betveen individual $\mathrm{PaO}_{2}$ and $\mathrm{VA} / \dot{\mathrm{Q}} 0.75 \mathrm{PaO}_{2}=-2 \mathrm{VA} / \mathrm{Q} 0.75+$ $112.2, r=0.67 \mathrm{p}<0.01$.

Nine patients with unilateral embolism were also studied on lateral decubitus with the non embolic lung in dependent position in order to change the distribution of perfusion. In all cases the $V A / Q$ of this non embolic lung decreased due to the increase of perfusion (VA/G supine $0.83 \pm 0.1 \mathrm{SD}$, lateral decubitus $0.72 \pm$ $0.08 \mathrm{SO}^{\circ} \mathrm{p}<0.01$ ). This decrease was accompanied by a decrease of $\mathrm{PaO}_{2}$ without any change of $\mathrm{PaCO}_{2}$ (supine $77 \pm 12 \mathrm{~mm} / \mathrm{g}$, lateral decubitus $70 \pm 15 \mathrm{mmHg} \mathrm{p}<0.02)$. These results suggest that over perfusion of non embolic regions is involved in hypoxemia during P.E. 
125

THE OXYGEN COST OF BREATHING IN PATIENTS AFTER MITRAL VAIVE REPLACEMENT. A. Fournell, K. Falke, M. Zindler, H. Schulte, Institit of Anestheslology and Department of Surgery B, University of Duesseldorf, D-4000 Duesseldorf, West Germany The amount of oxygen consumed by the work of breathing can be calculated as the difference in total 02uptake (VO2) during controlled mechanical ventilation (CMV) and spontaneous breathing (SB). Whereas this difference is well known in normal sub jects (1 - $2 \%$ ) the oxygen cost of breathing in patients with mitral valve disease is still subject of discussion. In 8 patients Vo2 was measured continously according to the method of Neuhof (Crit.Care Med. 6:155,1978) during CMV after mftral valve replacement on the operative day and on the first postoperative day after weaning from the respirator during SB. In every patient mean V02 was increased during SB $(172,0 \pm 14$, m1 02/m2/min) in compariaion to CMV $(137,5 \pm 12, \overline{8}$ ml $02 / \mathrm{m} 2 / \mathrm{min}$, the mean difference was $25,5 \%$, with a range of $7,4 \%$ to $34,9 \%$. Other factors which might influence V02 (physical activity, body temperature, nutrition, and acid-base status) did not change significantly during both perlods of investigation. Because the cardiac Index did not vary $(2,73 \pm 0,76$ $1 / \mathrm{m} 2 / \mathrm{min}$ during $\mathrm{SB}, 2,68 \pm 0,791 / \mathrm{m} 2 / \mathrm{min}$ during $\mathrm{CNV}$ ) the greater 02-demand during SB could only be met by an increase in av-D02 $(6,50+1,22 \mathrm{ml} \mathrm{02/100} \mathrm{ml}$ during $\mathrm{SB}, 5,15 \pm 1,12 \mathrm{ml} 02 / 100 \mathrm{ml}$ during $\mathrm{CMV})$. The results confirm that the oxygen cost of breathing is a significant fraction of whole body V02 during the immediate postoperative period in patients after mitral valve replacement.

\section{7}

STATUS ASTHMATICUS : LETHALITY AND INTENSIVE THERAPY.A.S.Zarzar,R.A.Pavlova, Sh.A.Murtalibov, O.P.Khan, B. I . Makhkamov, Advanced Training Ins titute for Doctors, Tashkent, USSR

Lethality among status as thmaticus cases ranges between 7 and $16 \%$ at the peak of the attack.This necessitates a clinical analys is of each lethal case.Studies were conducted of 320 case histories of status asthmaticus with 38 deaths ( $11.9 \%)$. An analys is showed that 7 patients died of asthma ayyravated by cardiovascular insufficiency, 7 more patients died af ter entering hospital in irreversible hypoxia coma, 1 patiert developed an anaphylaxic shock from medication, yet another suffered from cerebral blood circulation disorder resulting $f$ rom the removal of a catheter from the central vein, 4 patierts developed irreversible hypoxia coma duriny couyh fits resulting from tracheal manipulation, 18 patients died as a result of incorrect treatment of the nronchial obturation syndrome or failure to administer treatment. This means that $65.8 \%$ of the lethal cases could have been avoided by timely and correct treatment. Prevention of lethality in status as thmaticus cases requires : urgent hospitalization of patients suffering from a prolonged attack of hronchial as thma; resuscitation treatment subdivided into 1) intensive the rapy when the patient is fully conscious (control of the coush reflex, restoration of sputum rheoloyy by microtracheostomia with follow-up bronchoscopy, and s) resuscitation when the patient is unconscious (artificial ventilation of the lunys, washiny, microtracheostomia or forced tracheostomia). In administering treatment the physician must foresee possible clinical state of the patient.

\section{6}

BEDSIDE EVALUATION OF BRONCHIAL OBSTRUCTION DURING STATUS ASTHMATICUS. M. Badan 1, F1. Depeursinge1, A.K. Boutaleb2, Ch. Depeursinge ${ }^{2}$, J.-C. Willemetz ${ }^{2}$; Cl. Perret 1 . Institute of Pathophysiology ${ }^{1}$, CHUV, and Federal Institute of Technology ${ }^{2}, E P F$, Lausanne (Switzerland).

Usual pulmonary function tests are not easily available for bedside evaluation of bronchial obstruction in patients with status asthmaticus. A global evaluation of lung function and degree of airway obstruction is made possible by the measurement of the high frequency respiratory impedance (HFRI) with the forced oscillations method. The purpose of this study was to assess the interest of HFRI in evaluating bronchial obstruction during status asthmaticus

Preliminary studies on asymptomatic asthmatics in the laboratory have shown a statistically identical percentage of good classification with the HFRT $(95,8 \%)$ as with the body plethysmography $(93,8 \%)$. Similarly, the method has given significant correlations between several derived mathematical parameters and usual function tests : Raw $\left(\frac{\circ}{6}\right): \mathrm{R}=0,73, \mathrm{FEF} 25-75$ (응 $: \mathrm{R}=0,74, \mathrm{RV} / \mathrm{TLC}\left(\frac{\circ}{6}\right):$ $\mathrm{R}=0,74, \mathrm{FEV} 1$ (ㅇ) $\mathrm{R}=0,82$ (in a11 $\mathrm{p}<0.001$ ).

Sixteen patients with status asthmaticus, aged 17-68 y., were investigated in the respiratory unit. Mean $\mathrm{PaO}_{2}$ and mean $\mathrm{PaCO}_{2}$ were respectively $66,4+19$ and $41,9+9,6 \mathrm{~mm}$ $\mathrm{Hg}$ at the time of the first evaluation. The HFRI proved to be able to assess bronchial obstruction and quantify its degree in terms of usual function tests. It allowed an adequate lung function monitoring, a reliable evaluation of arugs effectiveness and short term evolution. This method demonstrated a frequent discordance between the rapid clinical improvement and a persistant functional impaiment. The measurements are short (about one minute), easily performed at bedside and do not require any active cooperation. 
INSPIRATORY FLOW INFLUENCE ON PULMONARY GAS EXCHANGE: COMPARISON BETHEEN A MOUIfied Sine wave ano a SQuare curve yentilation. G. Damia, M. Solca, A. Pelizzola, A. Pesenti, M.L. Caspani, R. Marcolin, D. Mascheroni, P. Ausenda, P. Forlani. Istituto Anestesiologia e Rianimazione, Università Milano, and $R \& D$ Dept., Kontron Milano, Italy.

We studied pulmonary gas exchange under different inspiratory flow patterns in 5 lambs $(22.4 \pm 2.3 \mathrm{~kg})$, using a high performance ventilator prototype, which can be suitched from a modified sine wave (MSW) to a square $(S)$ inspiratory flow curve keeping all other parameters unchanged. The animals were tracheostomized, anesthetized and curarized; a $5 F$ Swan Ganz catheter was inserted in pulmonary artery, and a peripheral artery cannulated. Each animal was ventilated alternatively with $\mathrm{HSW}$ and s. At the end of each period $(20 \mathrm{~min})$ we recorded mean arterial, pulmonary artery and airkays pressures, and we measured arterial and pulmonary artery blood gases, tidal volune, mean expired $\mathrm{CO}_{2}$ fraction and end-tidal $\mathrm{CO}_{2}$. Venous adnixture $\left(\dot{Q}_{Y A} / \dot{Q}\right)$ and physiological dead space $\left(V_{D} / V_{T}\right)$ were coaputed; inspired 0 fraction was kept constant. After 5
periods with both curves we injected in the animals trachea $10 \mathrm{ml} \mathrm{kg}$ of HCl $0.01 \mathrm{M} \mathrm{to} \mathrm{produce} \mathrm{acute} \mathrm{respiratory} \mathrm{insufficiency,} \mathrm{and} \mathrm{we} \mathrm{repeated}$ 10 to 14 times our measurements varying the inspiratory flow pattern. ridal volume, mean airways pressure and total ventilation were identical in the two sets. $\mathrm{PaO}$ did not appreciably change with the different curves, nor $\dot{\theta} / \dot{0}$ did, both in physyological and pathological state; $P a C O$ during basal period was found significantly lower, by analysis of variance, with MSW $(33.7 \pm 3.8$ vs. $32.0 \pm 3.1$ torr, $p<0.02)$. At the contrary, $V / V$ was not significantly different; however, changing from HSW to $S D^{T}{ }^{T}$ consistently increased, and correspondingly decreased passing from $S$ to MSW. The variation was statistically significant $(P<0.05)$. After pulmonary lesions were established, both $P a C O$ and $V_{R} / V_{T}$ were significantly lower with HSW: $40.0 \pm 5.2$ vs. $41.8 \pm 5.1$ torr $\left(P^{D}<0.05\right)$, and $0.64 \pm 0.08$ vs. $0.67 \pm 0.08(\vec{P}<0.05)$. Ventilation with MSW, wutuated from spontaneous breathing, appears then to allow for better gas distribution within the lungs, at constant volume and airways pressure, particularly if those have altered mechanical properties.

DIFFERENTIAL VENTILATION DURING ROUTINE ANAESTHESIA IN THE LATERAL DECUBITAL POSITION. S. Baehrendtz, C. Klingstedt, G. Hedenstierna and J. Santesson. Dept of Medicine South Hospital, Stockholm, Sweden.

Differential ventilation (DV) in the lateral posture has shown to improve the gas-exchange in patients with severe acute respiratory failure due to bilateral lung disease. The mechanism is most certainly the countering of airway closure (AC) within the dependent lung. Also patients undergoing surgery in the lateral position have a preferential spread of AC towards the dependent lung. The present study was thus undertaken to evaluate the effect of DV during routine anaesthesia in the lateral position. Ten patients without history of cardio-pulmonary disease were investigated prior to major surgery. The patients were intubated by a double-lumen catheter. Ventilation was performed with ONE ventilator (i.e conventional ventilation) and by TWo ventilators with $50 \%$ of the tidal volume to each lung (DV). Anaesthesia was maintained with enflurane and the patients were kept in the lateral positione during the course of the study. Ventilation of each lung was determined by Argon dilution technique and a masspectrometer. Central heamodynamics was measured using a Swan-Ganz thermodilution catheter. In some of the patients, regional perfusion through each lung was studied by a gamma-camera.

Results: DV as compared to conventional ventilation resulted in a $26 \%$ decrease in venous admixture and a $23 \%$ increment of arterial oxygen tension $(p<0.01)$, while the cardiac output was not significantly altered. In the patients by which the regional distribution of pulmonary blood-flow was studied, it could be established that DV also resulted in a much more even distribution of pulmonary perfusion between the upper and the lower lung. It is concluded that differential ventilation with $50 \%$ of the tidal volume to each lung improves ventilation versus perfusion and thus oxygenation during routine anaesthesia in the lateral position.
INDEPENDENT LUNG VENTILATION (ILV) IN BILATERAL LUNG DISEASES.

A. Gasparetto, A. Candiani, G. Crimi. Istituto di Anestesiologia e Rianimazione. Universită degli Studi di Roma (Italia).

The purpose of this study was to demonstrate that in presence of bilateral. lung diseases leading to $A R F$, the finding of a difference in static compliance between the two lungs makes ILV preferable in order to differentiate the ventilatory support.

Six patients with ARF caused by bilateral pathology were studied. All of them showed marked difference in static compliance between the two lungs. They were first ventilated in a conventional way, using IMV-CPAP, IRV or HFV.Hemodinamic monitoring was instituted together with control of tissue $\mathrm{pH}$ and $\mathrm{PO}_{2}$. As their conditions did not show any improvement, they were switched to ILV, thus allowing the demonstration of a persisting gradient in static compliance and the subsequent modulation of the ventilatory techniques. The less compliant 1 ung was ventilated with $\mathrm{HFV}$, the other either with IMV-CPAP or with HFV.

The results are consistent with our hypotesis. All patients showed significative improvements of gaseous exchanges together with a normalization in peripheral oxygen transport and utilization.

It is concluded that in bilateral lung diseases refractory to conventional ventilatory therapy, a significant difference in compliance must be suspected between the two lungs, thus indicating the institution of ILV with selected ventilatory patterns.

131

IMPROVEMENT OF GAS EXCHANGE BY RROLONGED AND DIMINISHED EXPIRATORY FLOW DURING IPPV. W. van Rooyen, J.R.C. Jansen, H.A. Bruining, A. Versprilie, Dept. of pulmonary diseases, pathophysiological laboratory and Dept. of surgery, Erasmus University, P.O. Box 1738, 3000 DR Rotterdam, The Netherlands

IPPV, especially to patients with chronic obstructive pulmonary disease, may necessitate either a relatively high tidal volume or a positive end expiratory pressure to obtain sufficient gas exchange. The risks are barotrauma during peakinflation and airtrapping during deflation. To avoid these harmful effects we seaxched for another mode of ventilation, which improves gas exchange. The effects of prolonged and diminished expiratory flow during IPPV was studied on gas exchange in pigs. Under normal pulmonary conditions these animals were ventilated with a Servo-900 A ventilator at a mean tidal volume of $15 \mathrm{ml} \mathrm{kg}^{-1}$, and a rate of 10 $m^{-1}$. If spontaneous expiration was retarded to the total available expiratory time, a significant increase in $\mathrm{PaO}_{2}(10 \%)$ and decrease in $\mathrm{PaCO}_{2}$ (8.5\%) was observed. Physiological dead space. was decreased as well (28\%). These effects were compared to those of a PEEP which increased mean tracheal pressure to the same extent as the prolonged expiration. PEEP less improved a $\mathrm{PaO}_{2}$ $(+5 \%)$, but did not influence $\mathrm{PaCO}_{2}$ with respect to normal IPPV.

Cardiac output decreased under both circumstances to the same amount $(-18 \%)$.

We conclude that prolonged and diminished expiration flow has a rationale, when IPPV alone causes problems regarding gas exchange and PEEP is contraindicated. 
ECMO IN THE COMPLEX TREATMENT OF ACUTE RESPIRATORY INSUFFICIENCY. E.M.Nicoleyenko, A.A.Pigarevsky, B.S.Lazarev, A.B.Karasev, S.V.Grozdev.

Research Institute of Pransplantology and Artificial Organs, Moscow, U.S.S.R.

Intrapulmonary gas exchange, effective pulmonary blood Ilow, ventilation-perfusion matching ( $\mathrm{V} / \mathrm{Q})$, respiratory mechanics (in vivo oxyhemometry, mass spectrometry, pneumotachography ), systemic and pulmonary hemodynamics (SWAN - GANZ catheter, thermodilution)were studied in 300 patients with respiratory insufficiency (RI) who needed respiratory support.

ECMO ( Oxygenator MOST-122, USSR) was used in 11 patients with acute RI: in 5 patients as an extreme measure in the irreversible terminal state, and in 6 patients along with other measures of intensive care with mechanical ventilation (MV) in an extremely intensive regime (high PEEP, toxic $\mathrm{F}_{1} \mathrm{O}_{2}$ ) and progressively reducing $\mathrm{PrO}_{2} / \mathrm{F}_{\mathrm{T}} \mathrm{O}_{2}$. During $\mathrm{EC}$ ho $\mathrm{PaO}$ in all the patients increased and it became posaible to pass over to a less in tensive $M V$ regime. (One patient survived among 6 patients).

Venous-venoug ECMO effectively increases blood oxygenation and favourably influences the pulmonery tissue metabolism and $V / Q$. Venous-arterial ECMO is adviable in such cases with concomitant cardiac failure. The low frequency of favourable outlets after ECMO may be explained by limitation of indicationg for it, the retarded beginning, hematologic and technical problems. In the conditions of progressive reduction of $\mathrm{PaO}_{2} / \mathrm{F}_{2} \mathrm{O}_{2}$ $\left(\mathrm{F}_{\mathrm{O}} \mathrm{O}_{2}=1,0\right.$; high PEEP, dehydration, cardiac therapy It is advisable to apply ECMO before the development of critical hypoxia. 


\section{CARDIAC STRETCH RECEPTORS BLOCKADE DOES NOT ELIMINATE RENAL RESPONSES TO POSTTIVE AIRWAY} PRESSURE - IMV VERSUS CMV. H.H. Steinhoff, K.J. Falke, L.F. Samodeldor, Institut für Anaesthesiologie der Universität Düsseldorf, Germany.

An increase in intrathoracic pressure as a consequence of positive airway pressure leads to a depression of renal function. In the past this has been contributed to a rise in antidiuretic hormone secretion mediated by the cardiopulmonary stretch receptors. However, experiments interrupting afferent pathways of this reflex by cutting or cooling the vagus nerves, failed to eliminate the typical renal response to shifts in positive airway pressure.

The influence of changes in intrathoracic pressure by intermittent mandatory and controlled mechanical ventilation (IMV (CMV) on renal function without and with a specific blockade of cardiac stretch receptors using $2 \%$ procaine instillation in the pericardium (PLA) was studied in anaesthetized dogs. Institution of PLA during spontaneous breathing depressed all measured parameters of global circulatory and renal function such as urine flow, osmolar-, inulin-, and PAH-clearance. During mechanical ventilation (IMV/CMV) circulatory and renal function parameters further decreased and showed the most detrimental effects during CMV. However, IMV and CMV still caused similar changes in the kidney function as without the blockade of cardiac stretch receptors as described previously by us. Hence, although there is a marked influence of the stretch receptor volume regulating reflex on kidney function, this mechanism does not primarily govern the alteration in renal function induced by shifts in airway pressures.
THE USE OF MTLITARY ANTI-SHOCK TROUSERS (MAST) AS A REVERSIBLE FLUID CHALLENGE IN PATIENTS ON HIGH PEEP: $M$, JASTREMSKI, K. BENEY, H. MATTHIAS: CCM\&EM, Upstate Medical Center, Syracuse, New York, U.S.A. Fluid management in the critically ill patient on high levels of PEEP can be a difficult task. PEEP may cause the cardiac index to fall due to a decrease in left ventricular preload. However, the high interthoracic pressures produced by PEEP negate the usefulness of the PAo as a measure of left ventricular preload. Thus, one often has to give fluid challenges with the risk of worsening the acute respiratory failure for which the patient is being treated with PEEP. Inflation of the MAST compresses the venous capacitance reservoir and autotransfers 500-1000 cc's to the central circulation. This autotransfusion is fully reversible by deflating the MAST.

The MAST were used as a reversible predictor of the effect of fluids on 14 critically ill patients being maintained on PEEP greater than $10 \mathrm{~cm} \mathrm{H}_{2} \mathrm{O}$ with decreased cardiac index. Hemodynamic variables were measured before, during, and after the application and inflation of the trousers. After MAST inflation, fluids were given in a quantity sufficient to maintain the same PAo after MAST deflation as was achieved with the initial MAST inflation. The table below shows the results.

\begin{tabular}{lccc} 
& PAO & CI & QS/OT \\
\hline PREMAST & $16.14 \pm 4.05$ & $2.97 \pm .76$ & $.162 \pm .045$ \\
MAST & $20.00 \pm 3.96$ & $3.36 \pm .79$ & $.189 \pm .057$ \\
POST MAST & $20.64 \pm 2.94$ & $3.20 \pm .79$ & $.174 \pm .065$ \\
*Pearson $r$ & .91 & .62 & .82
\end{tabular}

Amount of fluids given $=1093 \mathrm{cc}+1046 \mathrm{cc}$

We conclude that in critical ill patients on high PEEP, application of MAST is a useful tool for predicting optimal fluid treatment by challenging the patient with a totally reversible volume load. This provides better physiologic criteria for important decisions in fluid management, predicting both hemodynamic responsiveness and gas exchange deterioration after fluid management.

EFFECT OF LUNG AND CHEST WALL COMPLIANCES ON THE HEMODYNAMIC RESPONSE TO PEEP. F. BONNET, M. FISCHLER, C. DUBOIS, D. BRODATY, G. VOURCH. Hôpi tauX LA PITIE FOCH - PARIS - FRANCE

Controlied ventilation with PEEP increases intrathoracic pressures and decreases cardiac output. In order to evaluate the influence of lung and thoracic compliances (C), $\mathrm{CCW}$ ) on the hemodynamic response to PEEP, we studied 11 patients following cardiac surgery. 5 patients had mi tral valve replacement (MV) and 6 patients aorto coronary graft (ACG). Static lung and tota 1 thoracic compliances were measured in patients sedated and curarised with 1.51 syringe and $\mathrm{C} C \mathrm{~W}$ was computed as

$1 / \mathrm{CWW}=1 / \mathrm{Ct}+1 / \mathrm{Cl}$. PEEP levels were increased fróm 0 to $20 \mathrm{~cm} \mathrm{H} \mathrm{H}_{2} \mathrm{O}$ with $5 \mathrm{~cm} \mathrm{H}_{2} \mathrm{O}$ steps. For each level, oesophagal, pleura ${ }^{2}$ and pericardia 1 pressures were measured using water filled catheters and hemodynamic data were recorded from a Swan-Ganz catheter.

\begin{tabular}{|c|c|c|c|}
\hline EEP $\left(\mathrm{cm} \mathrm{H} \mathrm{H}_{2} \mathrm{O}\right)$ & & 0 & 20 \\
\hline Pper (mm Hg) & $\begin{array}{l}A C G \\
M Y\end{array}$ & $\begin{array}{l}-0.5+1.7 \\
-2.8+1.6\end{array}$ & $8.9+2.1$ \\
\hline Paw - Ppl (m $\mathrm{Hg})$ & ACG & $1.2 \div 0.9$ & $9.2 \pm 1.5$ \\
\hline IC $\%$ & $\begin{array}{l}\text { ACG } \\
\text { PIV }\end{array}$ & & $\begin{array}{l}18.1 \mp 3.5 \\
13.6 \mp 4.3\end{array}$ \\
\hline
\end{tabular}

$\mathrm{Cl}$ and $\mathrm{CCW}$ were both decreased in MV patients (CT $32 \pm 6$; $\mathrm{CCW} 165 \pm 28 \mathrm{ml} / \mathrm{cm} \mathrm{H}, 0)$ compared to ACG patients (C1 : $65+6 ; \mathrm{CCW} 580+95$ ) and pericardial and pleural pressures increased in the same range in the two groups of patients while increasing PEEP. The decrease in cardiac output was significantiy more important in ACG patients. It is suggested that both $C$ and $\mathrm{CCW}$ could impair the hemodynamic response to PEEP by means of opposite effects on airway pressures transmission. 
137

THE EFFECT OF TRACHEAL SUCTIONING OVER TRANSCUTANEOUS PO2. E. Mesalles, S. Armengol, J. Vallés, A. Artigas. I.C.U. Hospital de la Santa Creu i Sant Pou. Barcelona. Spain. INTRODUCTION: The purpose was to analyze the effect of tra cheal suctioning (TS) in the gaseous interchonge and compa re different methods.

METHODS: The tronscutconeous PO2 (Ptc02) was monitored with transcutaneous sensor (Kontron-La Roche) with similtaneous measurements of $\mathrm{FaO2}$ in all patiente ( $p$ ).

When there was no correlation between the PtcO2 ond $\mathrm{PaO} 2$ the $p$ was excluded.

. We first studied two groups of ten patients: $G: 1=$ FiO2 $\leqslant$ $50 \%, P E E P=0$

G:2=FiO2 $50 \%$, PEEP $\geqslant 10 \mathrm{~cm} H 20$

Aspirations (2-4) of 10 seconds were made in alt patients.

..Secondly we comporatively studied two groups of $5 p$.

Grup 3= FiO2 $\leqslant 50 \%$, PEEP=O

Grup $4=F i O 2 \geqslant 50 \%$, PEEP $\geqslant 10 \mathrm{~cm}$ H2O

in whom 3 different methods of TS were applied.

Method A: 2 aspirations of $10 \mathrm{sec}$.

Method B: 2 aspirations of $10 \mathrm{sec}$ plus Ambu 100\%

between aspirations and 1 minut after.

Method C: the same as method $B$, plus 1 minut before.

There was a more marked descent of Pte02 in group 2 than in group $1(36 / 16 \mathrm{mmHg}, p<0.05)$ and stabilization time was also more prolonged in the former group.

There was a more marked descent of Ptco2 in group 4 than in group $3 .(20 / 10 \mathrm{mmHg})$ with all methods, and stabilization was also more prolonged in group 4.

In group 3 the methods copplying Ambri 100\% provoked hyperoxia (untit $200 \mathrm{mmHg}$ in some cases).

CONCLUSIONS: TS in ventilated patients provokes hypoxia, especially in patients with PEEP $\geqslant 10 \mathrm{~cm} \mathrm{H} 20$.

Application of Ambu $100 \%$ does not prevent hypoxia in $p$ with PEEP $\geqslant 10 \mathrm{~cm}$ H2O.

These methods provoke detrimental hyperoxia in patients without PEEP.
138

IMPAIRED PHAGOCYTIC FUNCTION OF LEUCOCYTES DURING INCREASED PHOSPHOLIPID SYNTHESIS IN ISOLATED TYPE II ALVEOLAR CELLS.

K. Geiger

Institut für Anästhesiologie und Reanimation an der Fakultät für klinische Medizin Mannheim der Universität. Heidelberg (Direktor: Prof. Dr. B. Lutz) D-6800 Mannheim 1

Polymorphonuclear leucocytes constitute a major line of defense for the lung against the dangers of acute bacterial infection by virtue of their ability to phagocytize and kill the invading organisms. Since phagocytosis is associated with an increased phospholipid synthesis presumably serving in renewal and modification of membranes required for phagocytic function we asked the question is this function impaired in situations where other cell types may compete for the same substrates of phospholipid metabolism as occurs in the lung where type II alveolar cells are known to have a high phospholipid turnover. We therefore studied the rate of phagocytosis during increased phospholipid synthesis in isolated type II alveolar cells.

Type II cells isolated from rabbit lungs were incubated in Krebs-Ringer phosphate (KRP) medium ( $\mathrm{pH} 7.4$ ) containing thyrotropin (TSH) for $1 \mathrm{hr}$ at $37^{\circ} \mathrm{C}$. The same volume of solvent was added to paixed control incubations. Type II cells were transferred into one of two compartments of a dialysis cell the other one harboring rabbit PMN-leucocytes in KRP-medium. After adding paraffin oil emulsion containing $O$ il Red $O$ incubation was continued for $10 \mathrm{~min}$. Metabolic activity of PMN-leucocytes was stopped with $1 \mathrm{mM}$ N-ethylmaleimide. Oil Red 0 was extracted from washed cel1 pellets with p-dioxane and the oD determined at $524 \mathrm{m \mu}$. TSH stimulated the uptake of ${ }^{3} \mathrm{~B}$-palmitic acid into type II cells by $60 \%$. $57 \% \pm 4.98$ (SE) of radioactivity was in lecithin. Particle uptake in leucocytes was $32.17 \% \pm 1.71$ (SE) less during increased phospholipid synthesis in type II cells. We conclude that phagocytic activity of PMN-leucocytes can be depressed during stimulated phospholipid metabolism of type II cells. 
SLOW AND RAPID VENTRICULAR TACHYCARDIA IN THE CCU - INCIDENCE, PROGNOSTIC AND THERAPEUTIC IMPLICATIONS. Johan HUlting and Mats-Erik Nygårds. Medical Intensive Care Unit, Södersjjukhuset, Stockholm and Department of Medical Informatics, Linköping University, Linköping, Sweden.

The occurence of slow (rate 121-180/min) and rapid (rate $\geqslant 181 / \mathrm{min}$ ) ventricular tachycardias (VT) has been studied in 1348 CCU pts with an automated monitoring system developed at our institutions. Acute myocardial infarction (AMI) was diagnosed in 548 pts.

The incidence of slow and rapid VT was 26 and $11 \%$, respectively, in AMI, and 9 and $4 \%$, respectively. in non-AMI pts. On admission, 3 pts with AMI, presented with VT (1 slow), a11 electroconverted. In non-AMI pts 75 (10 slow) had VT on admission (electroconversion in 11). Five pts with VT (rapid; $n=3$ ) after admission, were electroconverted. Thus most runs of rapid VT were short (less than 25 beats). About half of pts with rapid VT had their VT within $12 \mathrm{~h}$ after admission. Rapid VT usually developed before slow VT in pts with both forms.

In AMI, about $1 / 3$ of pts with rapid VT had their VT without prior signs of hypotension or left heart failure.Prognosis in this group was good. In AMI, rapid VT preceded ventricular fibrillation (VF) in 12 pts, in 5 of these first VT progressed to VF; in one pt VF preceded rapid VT.

In AMI, slow VT was associated with a hospital mortality of $14 \%$, not different from figure in pts without VT.

$(17 \%)$; however, mortality in rapid VT. was markedly raised $(53 \%)$ and $3 / 4$ of deaths occurred in the CCU.

In AMI, the incidence of rapid VT was strongly correlated to myocardial infarction size. In non-AMI, a history of myocardial infarction was related to the incidence of rapid VT. In the total material, a slight but statistically significant relationship between rapid VT and a serum potasium on admission below average was observed.

FFFECT OF AMRINONE ON METABOLIC AND HEMODYNAMIC PARAMETERS IN PATIENTS WITH CORONARY ARTERY DISEASE. F. Saborowski, R. Griebenow, W. Kaufmann, Dept. Internal Medicine II, University of Cologne, FRG

Amrinone (A) is a new non-glycoside and noncatechol positive inotropic agent which probably acts directly on the myocardium. In 10 male patients (mean age $=53.4 \mathrm{ys}$ ) with coronary artery disease (CAD) hemodynamic and metabolic measurements were done in the arterial (a) and coronary venous blood before and 15 min. after administration of $\mathrm{A}(1.5 \mathrm{mg} / \mathrm{kg}$ body weight $\left.i \cdot v_{0}\right)$.

Results $(\bar{x})$ :

$\mathrm{HR}$ (bpm)

IVSP (mm Hg)

LVEDP (mm Hg)

IV dp/dt max.

(mm $\mathrm{Hg} / \mathrm{sec}$ )

Lactate-Ex. (\%)

$\mathrm{Oxygen- \textrm {Ex }}$ (a) $(\mathrm{ng} / \mathrm{ml})$

$\mathrm{NE}(\mathrm{a})(\mathrm{ng} / \mathrm{ml})$

$\mathrm{I}=$ Epinephrine

significantly the contractility of ium in patients with CAD ( $19.2 \%$ ) cretion $(-93.8 \%)$.

\begin{tabular}{ccl} 
before & after A & \multicolumn{1}{c}{$\mathrm{p}$} \\
70.1 & 76.9 & 0.05 \\
153.5 & 129.6 & 0.0125 \\
15.0 & 6.4 & 0.0005 \\
2191 & 2612 & 0.01 \\
14.4 & 0.9 & 0.0005 \\
63.6 & 62.1 & n.s. \\
0.29 & 0.39 & n.s. \\
0.79 & 1.0 & n.s.
\end{tabular}

$\mathrm{NE}=$ Norepinephrine
140

RECORDING OF DELAYED POTENTIALS IN PATIENTS WITH ACUTE MYOCARDIAL INEARCTION.

J. Potratz, H. Djonlagic, K. B. Diederich Medical School of Iubeck, West Germany Ventricular arrhythmias very often represent an important problem in the treatment of acute myocardial infarction. Although the origin of cardiac arrhythmias is not yet understood the role of delayed potentials in ventricular arrhythmias in connection with myocardial infarction has been of increasing interest in recent years. In order to get further information about delayed electrical activity, we studied a group of 50 patients in the acute phase of myocardial infarction with ventricular arrhythmias. Intracardial recordings were obtained in these patients using an intracardial bipolar electrode and an amplifier with different filter frequencies. In 30 of these 50 patients we recorded delayed potentials $150-200 \mathrm{~ms}$ after the beginning of QRS. 14 patients showed delayed electrical activity in the diastole even after the T-wave. In several examples we could show that these delayed potentials initiated ventricular premature beats. 10 of the 50 patients suffered from ventricular tachycardia. These all showed delayed potentials after the T-wave. In 3 patients the onset of sustained ventricuIar tachycardia induced by delayed potentials were recorded. The same potentials obtained by intracardial recording techniques could also be recorded from the body surface by using a signal averaging technique. These delayed potentials can inhibit pacemakers. We found that the delayed potentials could be abolished by antiarrhythmic drugs. Thus there seems to be an important relationship between electrical activity and the occurence of ventricular arrhythmias. 
HIGH DOSE GLUCOSE THERAPY OF CARDIOGENIC SHOCK J. Schrezenmeir, J. Epping, M. Pfeiffer, S. Marcin, W.H. Hörl, Med. Univ.-Klinik, 8700 Würzburg, FRG

Glucose controlled infusion systems allow the treatment of cardiogenic shock with pharmacological doses of insulin.

Methods: 12 critically ill patients in prolonged cardiogenic shock after myocardial infarction with fatal prognosis and exhausted therapy received a $2000 \mathrm{IE}$ insulin bolus and $2000 \mathrm{IE}$ insulin per hour in the following. Blood glucose was automatically regulated with $70 \%$ glucose solution by a glucose controlled infusion system (Biostator GCIIS ). Prior to and 30, 60, 120, 180, 240 min. after the beginning of therapy and 2,4 and 10 hours after therapy the hemodynamic changes, insulin, glucagon, pyruvate, lactate, citrate, 2-oxogluturate, B-hydroxybuturate and acetoacetate were determined.

Results: Insulin therapy resulted in an increase of cardiac output, which was significant $(p<0,05)$ at all times of determination and amounted $11,3 \%$ after 30 minutes and $23 \%$ after 4 hours. Heart rate remained unchanged except for the first $30 \mathrm{~min}$. Where a significant increase of $5.6 \%$ was recorded; according to this stroke volume attained values after $1 \mathrm{~h}$ which were $20 \%$ higher than before therapy and remained at this elevated level during the four hours period of insulin treatment. Weiler index decreased significantly about $34 \%$ indicating increased myocardial contractility. Beyond this we found a significant increase of central venous oxygen saturation, a significant decrease of lactate and a tendency of decreasing of citrate and 2-oxogluturate levels. Glucose and potassium blood levels remained in the desired range after substitution. After disruption of insulin treatment the hemodynamic starting level was reattained.

Discussion: After exhausting conventional measures - including catecholamines - this therapy resulted in an improvement of cardiac index, myocardial contractility and chemical parameters in blood. The two receptor modell of insulin effects may explain, why high insulin doses can achieve effects, which cannot be found after lower insulin doses.

144

CHANGES IN HEMOSTASIS BY CONGESTIVE HEART FAILURE H.Straub, W.Schrege 1, H.D.Kuntz, C.Mül ler-Haake Med.Universitätsk Tinik Bergmannshei 1, Bochum, W. Germany

In the beginning of recompensation of congestive heart failure (CHF) it was possible to show that of 65 patients $9.2 \%$ had accompanying peripheral thrombos is of the deep veins of the legs (I-125 fibrinogen technique). Possible causes may be slowed blood flow or changes in hemostasis.

a) Swan-Ganz catheterisation, heart volume by $X$-rays,

liver enzymes, liver function (ICG- and BSP-half live), clotting tests (aPTT, Quick, TZ, fibrinogen) and antithromb in III (AT III, chromogene substrates) were determined in 43 patients with heart failure. AT III leve1s were compared with 20 healthy persons.

b) AT III was tested for 14 days during cardiac recompensation of 19 patients with CHF.

AT III was statistically significant reduced in the group of 43 patients with heart failure. In the subgroup ( $n=17)$ with right heart failure and peripheral edema AT III was 9.6 IU/ml, in the controlgroup of hea thy persons 13.2 . AT II showed a statistically significant correlation with right atrial pressure and liver congestion.

Group B showed AT II I reduced to 8.7 IU/m7. AT III was $11.5 \mathrm{IU} / \mathrm{m} 7$ after one week of treatment and $11.6 \mathrm{IU} / \mathrm{ml}$ after two weeks. The difference was significant.

These results show changes of hemostasis in CHF by changed liver functions. This could be the reason of the higher rate of peripherai thrombosis in CHF, so that the testing of AT III could be a possible early indicator to prevent thrombos is in CHF.
HEMODYNAMIC EFFECTS AND PHARMACOKINETIC PARAMETERS OF AR-L 115 BS IN PATIENTS WITH SEVERE HEART FAILURE. D. El Allaf, S. Cremers, V. D'Orio, A. Dresse, J. Carlier Institut de Médecine et Laboratoire de Pharmacologie, Université de Liège, Liège, Belgique.

AR-L 115 BS is a new positive inotropic agent, structurally not related to glycosides nor to catecholamines. AR-L 115 BS was infused at $1,4 \mathrm{mg} / \mathrm{min}$ for 6 hours, then discontinued, after another 6 hours the drug was readministered for 6 more hours in 11 patients with severe heart failure (NYHA class IV). Hemodynamic measurements and plasma level were obtained before admiriistration (C), hourly during both perfusions, and during the 6 hours following each perfusion period. The cardiac index (CI), the stroke volume index (SVI) and the left ventricular stroke work index (LVSWI) were significantly increased. The pulmonary artery wedge pressure (PWP) and the systemic vascular resistance (SVR) fell significantly. Heart rate and blood pressure remained unchanged $(*=p<0.005)$.

\begin{tabular}{|c|c|c|c|c|c|}
\hline & $\begin{array}{l}\text { PWP } \\
\text { mm Hg }\end{array}$ & 1. ${ }^{\mathrm{CI}} \mathrm{nin}^{-1} \cdot \mathrm{m}^{-2}$ & $\begin{array}{c}\text { SVI } \\
\mathrm{m} 1 / \text { beat } / \mathrm{m}^{2}\end{array}$ & $\begin{array}{l}\text { LVSWg } \\
\mathrm{g}-\mathrm{m} / \mathrm{m}^{2}\end{array}$ & $\begin{array}{l}\text { SVR } \\
\text { d.s.cm }\end{array}$ \\
\hline $\begin{array}{lr}r \\
\operatorname{mr} & 6 \\
\operatorname{mr} & 18\end{array}$ & $\begin{array}{l}23^{*} \\
13^{*} \\
14^{*}\end{array}$ & $\begin{array}{l}2,07 \\
2,99^{*} \\
2,89^{*}\end{array}$ & $\begin{array}{l}22 \\
31^{*} \\
30^{*}\end{array}$ & $\begin{array}{l}20 \\
32^{*} \\
31^{*}\end{array}$ & $\begin{array}{l}1759 \\
1263^{*} \\
1298^{*}\end{array}$ \\
\hline
\end{tabular}

Maximum plasma levels averaged $5,63 \pm 1,05 \mu \mathrm{g} / \mathrm{ml}$ after the first perfusion and $3,03 \pm 1,07 \mu \mathrm{g} / \mathrm{ml}$ after the second perfusion.

The plasma half-iife was $1,43 \pm 0,31 \mathrm{hr}$ after the first perfusion and $0,95 \pm 0,28 \mathrm{hr}$ after the second. The activation of hepatic metabolism may explain this difference. Thus AR-L 115 BS appears to be a promising inotropic agent in severe heart failure.

\section{6}

INFLUENCE OF BODY POSITION ON CARDIORESPTRATORY VARIABLES Luis Teba and Graziano C. Carlon, Department of Critical Care, Memorial Sloan-Kettering Cancer Center, 1275 York Avenue, New York, NY 10021 USA

The purpose of this investigation was to determine the effect of changing body position on arterial oxygenation and cardiac functions. The study included 28 patients admitted to an ICU. Initially; patients were placed in a supine position for one hour. Cardiac output ( $\mathrm{CO})$, systemic and pulmonary arterial pressures were measured at the end of the hour. Arterial and mixed venous blood samples were also obtained. Hemodynamic, oxygen transport $(02 \mathrm{De})$, and intrapulmonary shunt (Qs/Qt variables were measured. The patients were then placed in a sitting position at $45^{\circ}$ for one hour. All measurements were thereafter repeated. Only patients with stable cardiorespiratory functions were included in the study. The above results shown in the following table were compared.

\begin{tabular}{|c|c|c|c|}
\hline & C.o. & SVR & 02 De1 \\
\hline SUPINE & $7.2 \pm 1.7$ & $985 \pm 313$ & $1069+250$ \\
\hline SITTINC & $6.5 \pm 1.6$ & $1133 \mp 387$ & $995 \mp 268$ \\
\hline & $\mathrm{PaO} 2$ & A 02 Sat & Qs/Qt \\
\hline SUPINE & $78 \pm 15$ & $.94 \pm .02$ & $.25 \pm .09$ \\
\hline SITTTNC & $83 \mp 19$ & $.94+.02$ & $.23 \mp .09$ \\
\hline
\end{tabular}

None of the variables considered were significantly different in the two positions. Cardiac output, however, was higher in 20/28 patients while in the supine position. We conclude that the change in body position per se has no beneficial influence on respiratory functions and sitting may decrease cardiac output as a consequence of reduced venous return from lower extremities and increased systemic vascular resistance. 
EFFECTS OF FLUNITRAZEPAM (F) ON MYOCARDIAL PERFORMANCE AND CORONARY CIRCULATION. J. Marty, A. Nitenberg, F. Blanchet, S. Zouioueche, J.M. Desmonts, Hôpital Bichat, Paris, France

Sedation and anesthesia of patients with ischemic heart disease must use drugs which do not impair myocardial function and oxygenation. The present study was designed to evaluate the effects of $F$, a potent long acting benzodiazepine, on left ventricular (LV) performance, coronary circulation and myocardial metabolism in humans.

Methods. LV and aortic pressures (micromanometry), cardiac output, coronary sinus blood flow (CSBF), myocardial oxygen uptake (MVO,), myocardial lactate balance and their derivatives were studied before (C) and $2,5,10$ and $15 \mathrm{~min}$ after $F(15 \mathrm{mcg} / \mathrm{kg}, \mathrm{IV})$ in $g$ patients with coronary artery disease (Class 2-3 NYHA) undergoing heart catheterization.

Results. F administration produced a decrease of mean aortic pressure (MAP) (significant at 2, 5, 10 and 15 min) and of systemic vascular resistances (SVR) (significant at 5,10 and 15 min) with maximal changes from $C$ values observed at $15 \min (-16$ per cent for MAP) and at 5 min (- 16 per cent for SVR). No change in cardiac index was observed. The following changes in variables related to $\mathrm{LV}$ performance were observed: 1) a transient increase in heart rate at 2,5 , and $10 \mathrm{~min}$ and LV contractility (Vnax) at 2 min $(+16$ per cent and +9 per cent respectively) ; 2) a sustained $(2,5,10$ and 15 min) decrease of $\mathrm{LV}$ end diastolic pressure maximum at 15 min ( -35 per cent). MVO was decreased at 15 min (- 11 per cent), myocardial lactate uptake was increased (+ 37 per cent at $15 \mathrm{~min}$ ) but CSBF did not change while coronary vascular resistance was lowered at $2,5,10$ and 15 min with maximal change at $15 \min$ (- 18 per cent). Conclusion. These findings, i.e., no effect on $\mathrm{LV}$ contractility with arterial and coronary vasodilation and decreased $M V{ }_{2}$ suggest that $F$ may be useful for anesthesia of patients with coronary artery disease.

CONTINUOUS BLOOD GLUCOSE: (BG) MONITORING IN PATIENTS UNDERGOING HYPOTHERWIIC ( $28^{\circ} \mathrm{c}$ ) CARDIO-PULMONARY BYPASS (CPB) WITH DIFFERENT CRYSTALLOID BYPASS FOMP PRINING FLUIDS. C.K. McKnight, M.J. Elliott, Department of Cardiothoracic Anaesthesia and Surgery, University of Newcastle-upon-Tyne, Freeman Hospital, England. Dramatic alterations in blood glucose (BC) concentration during open-heart surgery haye been reported on the basis of intermittent sampling. There is a lack of controlled studies on the effect of different pump primes on glucose homeostasis. We report here the findings of a prospective, randomised study of hypothermic CPB with four different priming fluids, namely nom-glucose/ nonlactate, high-glucose/non-lactate, high-glucose/highlactate and non-glucosónon-lacta te utilising Biostator continuous blood glucose monitoring. Such monitoring allows changes in $B G$ concentration which are masked by intermittent sampling to be visualised. We have identified phases of the procedure which are associated with rapid and large changes.

A modest rise in BG occurred after skin incision in all patients $(1.3 \mathrm{mmol} / 1 \pm 0.3 \mathrm{SFH})$. Glucose containing primes resulted in a marked rise in $B C(25.5 \pm 0.5 \mathrm{mmol})$ 1) on institution of bypass followed by a sharp fall to $15 \mathrm{mmol} / 1 \pm 2.5$ which level was maintained during the hypothermic phase. With non-glucose containing primes there was a rapid, short-lived fall $(2 \pm 0.5 \mathrm{~mol} / 1)$ in $B G$ due to dilution on institution of bypass, followed by a steady rise during hypothermia. On rewarming there was a further rapid rise in $B G$ of $c .3 .0$ mmol $/ 1$ above $30^{\circ} \mathrm{C}$ with all primes. A marked rise ( $3 \pm 0.4$ mmol $/ 1$ ) in $B G$ was seen with all primes when sympathomimetic agents were infused.

Our results have clearly shown the magnitude and rapidity of changes in blood glucose during and after CPB. This new knowledge is of crucial importance in the management of diabetics requiring this type of surgery.
MYOCARDIAL PROTECTION BY HIGH INSULIN SUPPLY. S.Duma, I.Krisch, W.Schütz, C.Spiss, W.Haider. Clinic of Anaesthesia and General Intensive Medicine, University of Vienna, Austria.

A preventive accumulation of the myocardial glycogen stores should save the myocardial viability during hypoxia, since an anaerobic availability of energy is maintained. The therapeutic administration of high doses of insulin together with glucose and potassium achieves a shifting of metabolism to glycogenesis and glycolysis, providing an increased amount of energy rich phosphates. One half out of 16 patients undergoing mitral valve replacement received insulin $1 \mathrm{U} / \mathrm{kg} / \mathrm{h}$ together with glucose $0.5 \mathrm{~g} /$ $\mathrm{kg} / \mathrm{h}$ from onset of anaesthesia until aortic cross clamping. After a $26 \mathrm{~min}$ average time of ischaemia a cut-out papillary muscle-tip was immediately plunged into liquid nitrogen and the content of ATP, ADP and CP (creatine phosphate) was determined. In contrast to the control group (Ringer's lactate) the insulin group showed a significant $(p<0.01)$ higher myocardial content of ATP $17.98 \mathrm{\mu mol} / \mathrm{g}$ wet weight vs. $4.54 \mu \mathrm{mol} / \mathrm{g})$ and $\mathrm{CP}(6.78 \mu \mathrm{mol} / \mathrm{g}$ vs. $5.16 \mu \mathrm{mol} /$ g). Also the ATP/ADP-quotient ( 5.53 vs. 2.61) and the energy charge potential (ECP; ATKINSON) $(0.919$ vs. 0.857$)$ was significantly $(0<0.01)$ higher in the insulin group. It is concluded that the preventive application of high doses of insulin leads in fact to an increased myocardial energy provision during hypoxia and represents an enhanced ischaemic tolerance and an improved myocardial protection.

Mitral surgery and pulmonary arterial hypertension (mean PAP superior to $40 \mathrm{mH}(\mathrm{g})$ : post-operative hemodynamic study.

C.Isetta*, J.J. Armulf*, F.Mlonnot*, F.Prontiglio, C.Dusaintpere. Service du Pr V.Dor. Institurt A.Tzanck 06700 Saint Laurent du var. * D.A.R. Pr Piaestracci, Nice, France.

The postoperative hemodynamic effects of mitral valve replacenent are studied in patients with severe pulmonary arterial hypertension.

This herodynamic study turns on fifty patients, (mean age $53+12$ years) with a predominant mitral pathology without any associated coronaropathy. The preoperative status of these patients shows a cardiac index of $2,6+0,761 / \mathrm{m} / \mathrm{m} 2$; an ejection fraction $(E)$ of $0,57+0$, II ; pulmonary arterial pressures (PAP) : systolic : $79+$ 17, diastolic : $35+8$, mean $50+10 \mathrm{mhtg}$; a pulmonary capillary wedge pressure of $30^{-}+5 \mathrm{mmHg}$; a right atrial pressure (RAP) $: 9+5$ mith. The PAP, RAP, Teft atrial (LAP) and arterial pressures are continuously monitored in postoperative time. Measurements of cardiac output are carried out at the first, 12 th, 24 th hour. An hemodynaric control is made at the third postoperative week.

For these fifty patients : the pulmonary arterial (PA) pressures register a significant decrease of $42 \%$ at the first hour, $32 \%$ at the 12 hour, and $46 \%$ at the third week. The LAP register a significant decrease of $50 \%$ from the first hour and after doesn' $c$ change any longer. The RAP and the cardiac index don't differ from their preoperative values all along the first 24 hours.

Six patients die after the eight postoperative day : their PA pressures only register a decrease of $29 \%$ at the first hour and $23 \%$ at the 24 th one, their mean PA stays at a rate of $40 \mathrm{mitg}$. In the preoperative time, only a candiac index which is lower than two $1 / \mathrm{m} / \mathrm{mR}$, significantly differs. Five out of these patients present a preoperative tricuspid insufficiency (TI).

Seventy eight \% of patients presenting a TI linked with the mitral valvilopathy requiere the use of intravenous nitroglycerin and/or tonicardiac drug.

The PA pressures progress in two phases. The PA pressures values of the first postoperative hour and the third control ane the same. After mitral valve replacement, a mean PA pressure of $40 \mathrm{mmitg}$ has a poor prognosis.

Two criteria of seriousness are noted : a CI lower than two $1 / \mathrm{m} / \mathrm{mR}$ in the preoperative time and a TI linked with the mitral valvulopathy. 
POSTOPERATIVE MAINTENANCE OF PROPRANOLOL THERAPY BY CONTINUOUS I.V. INFUSION. D. VILLERS, M. PINAUD, B. ERISON, M. BOURIN, R. SOURON et F. NICOLAS, Départements de Réanimation, d'Anesthésiologie et de Pharmacologie Clinique, Hôte1-Dieu, C.H.U, Nantes, France.

Feasibility of propranolol ( $P$ ) infusion to maintain chronic $P$ therapy in the postoperative period was studied when patients cannot take drugs orally.

Methods : Seven coronary patients (angina grade III NYHA, $56 \pm 4$ yrs) undergoing intraabdominal surgery were selected. They received their last $P$ dose (60-120 mg daily) at 8 pul the day before surgery (Po). Postoperatively $P$ infusion started at about $2 \mathrm{pm}(\mathrm{B})$ (normothermia and normal blood gases) with a first iv dose $(0.2 \mathrm{mg} / \mathrm{kg}$ in 10 min) followed by a constant infusion ( $1 \mathrm{mg} / \mathrm{kg} / \mathrm{day}$ ) until oral $\mathrm{P}$ could be taken again $(24-66 \mathrm{hrs})$. Plasma $\mathrm{P}$ concentrations (C) were measured at $P 0, B$ and $5,10,60$ $\min , 4,6,12,18,24 \mathrm{hrs}$ after B. Haemodynamic data were simultaneously collected from radial artery and Swan Ganz catheters. Holter monitoring was performed before and after $P$ infusion.

Results : From 60 min to $24 \mathrm{hrs}$ mean $\mathrm{C}(58-80 \mathrm{ng} / \mathrm{ml})$ was in the therapeutic range (1). At $B$ there was a statistically significant increase in heart rate (HR), rate pressure product (RPP) and cardiac index (CI), when compared to Po data. Beneficial haemodynamic results (decrease $O f \mathrm{HR}$ and RPP compared to $B, \mathrm{P}<0.01$ ) without any adverse effects (PWP and CI unchanged compared to $\mathrm{PO}_{\mathrm{O}}$ ) were observed over the period ranging from 10 min to 24 hrs. Ecg traces showed no ischaemic or rhythmic change. Discussion : In this study expected activity of $P$ is achieved by this infusion way within 10 min over $24 \mathrm{hrs}$. As compared to a previous study (2) our method is able to achieve $P$ therapeutic level more rapidly because of its starter dose and is performed during a longer time.

(1) Pine $M$ et al. Circulation 1975 ; 52 : 886-93

(2) Wells Ph et al. Anesthesiology 1980; 53: S 128.
EXTRAVASGULAR LUNG WATER AND "ClOSING VOLUME" INPATIENTS AT THE EARLY PERIOD AFTER VALVE REPLACEMENT.E.M.NiCOlaYenko, Research Inst. Transplantology \& Artificial Organs. Moscow. USSR.

Closing volume" (CV), closing capacity (CC), FRC, extravascular lung water (ELW) and pulmonary hemodynamics have been measured by the methods based on mass-spectrometry, pneumotachography, Swan-Ganz catheterization and thermodilution in $47 \mathrm{pts}$ before and at the early period after valve replacement (VR). Postoperative changes in ELW were expressed by a ELW/FRC ratio because ELW depended on antropometric characteristics and effective alveolar volume even in healthy persons. The ELW/FRC increased almost twice during first postoperative hours compared with preoperational value and remained at the same level for $2-3$ p.o. days. Close correlation $(r=0,67)$ has been observed between ELW/FRC and CC/FRC. CC/FRC increased after VR and became more than $I, O$ in most cases. A more pronounced CC/FRC and ELW/FRC increase was observed in pts with $\mathrm{LV}$ cardiac failure. Hemodynamic improvement (isuprel, dopamine, nitroprussid) and lung ventilation optimization resulted in a ELW/FRC decrease, gas exchange improvement, and allowed adequate infusion therapy. No dependance of ELW elevation on quality and quantity of infused solutions and on pulmonary artery pressure was observed. An increase in plasma protein (from 45 to $75 \mathrm{~g} / 1$ ) by albumin infusion was found surprisingly low-effective for water recruitment from lung tissue,probably because of increased capillary wall permeability and elevated perivascular colloid-osmotic pressure. The ELW increase after open-heart surgery resulted in an increase of pulmonary tissue specific weight and gravitational lung gradient; obviously that contributed to a $\mathrm{CV}$ increase, $\mathrm{V} / \mathrm{Q}$ decrease and blood oxygenation disor-

ders.

\section{2}

COMPREHENSIVE PRE- AND POSTOPERATTVE EVALUATTON OF ASCENDING AORTIC DISSECTIONS (TYPE I AND II) BY ECHOAORTOGRAPHY. P.Bubenheimer, M.Schmuziger, Rehabilitationszentrum Bad Krozingen, West-Germany

From 1977 to 1982,22 patients underwent operative treatment for ascending aortic dissections (type I: $n=15$, type II: $\mathrm{n}=7$ ) by dacron graft replacement of the ascending aortaalone $(n=7)$ or combined with aortic valve replacement (composite graft) in 15 patients. For preoperative evaluation and postoperative follow-up of the disease, we prefered echographic imaging of the aorta and its major branches, using a system of multiple short and long axi cross-sections obtained from parasternal, suprasternal, paravertebral, subcostal and abdominal echowindows. In 17 patients the dissection was primarily defined by echography, in 5 patients by angiography prior to the echographic examination. In 14 patients the operation was based on echographic findings without angiography. In all cases the echoaortographic findings were confirmed. Preoperative echoaortography demonstrated ascending aortic aneurysms in 21 (diameter $5-9 \mathrm{~cm}$ ), aortic valve regurgitation in 15, pericardial effusion in 15, distal extension of the dissection to the aortic arch in 15, to arch branches - especially to the brachiocephalic artery - in 8 , to the descending aorta in 14, and down to the iliac arteries in 4 cases.

Serial postoperative follow-up (from 1 week to 5 years) of type I dissections ( $n=12$ survivors) which were corrected only partially by the ascending aortic graft, revealed occlusion of the distal dissection in 8 , persistence in 4, and progression in 1 patient. Descending aortic aneurysms developed within 2 years in 4 patients, leading to successful reoperation in 1 patient. Conclusion: Echoaortography is not only an excellent method for the diagnosis of aortic dissections, but may also improve the understanding of aortic pathology in chronic dissection by serial longtime follow-up. 
ALTERATION IN MYOCARDIAL O2 EXTRACTION (E $\mathrm{O} 2$ ) DURING MYOCARDIAL (M) DEPRESSION IN SEPTIC SHOCK: EFFECTS OF DOBUTAMINE (Db). J.F. Dhainaut, B. Schlemmer, M.F. Huyghebaert, $V$. Fourestié, 0. Salmon, A. Carli, J.F. Monsallier. Réa. Med. Hôp. COCHIN F 75674 PARIS.

Systemic 02 extraction $\left(E_{C}, 02\right)$ is impaired during severe sepsis, leading to a state of ischemia in muscles. To test the hypothesis that $\mathrm{E}_{\mathrm{M}} \mathrm{O2}$ may also be altered such 6 pts were studied Gasometric, metabolic (lactate) and hemodynamic investigations were performed using Swan-Ganz and Wilton-Webster catheters respectively for cardiac output (CO) and coronary sinus flow (CSF) by thermodilution technics. Systemic and $M 02$ consumption ( $\left.\nabla 02, M^{*} O 2\right)$ and $M$ lactate extraction $\left(E_{1} L\right)$ were calculated. The doses of $\mathrm{Db}$ were gradually increased until the vanishing of peripheral signs of shock. The pulmonary wedge pressure was maintained to $10 \mathrm{~mm} \mathrm{Hg}$ using volume expansion and dopamine (Dp) : $3 \mu \mathrm{g} / \mathrm{kg} / \mathrm{min}$ The doses of $\mathrm{Dp}$ were increased to $10 \mathrm{\mu g}$ when the doses of $\mathrm{Db}$ were higher than $20 \mu \mathrm{g}$, in relation to vasodilatator effects of $\mathrm{Db}$.

Results : ${ }^{*} \mathrm{p}<. \mathrm{Ol}$ C vs $\mathrm{Db}+\mathrm{Dp}$.

\begin{tabular}{|c|c|c|c|c|}
\hline & $\mathrm{CO}(1$, min $/ \mathrm{m} 2$ & $\operatorname{CSE}(\mathrm{ml} / \mathrm{mL})$ & MVO2 (ml $/ \mathrm{min}$ & $\mathrm{E}_{\mathrm{M}} \mathrm{O} 2$ \\
\hline Con & $2.2 \pm .4$ & $137 \pm 24$ & $9.8 \pm 3.3$ & $.50 \pm .10$ \\
\hline$D b+D p$ & $4.1 \pm .5 *$ & $192 \pm 53$ * & $15 \pm 4^{*}$ & $.49 \pm .10$ \\
\hline
\end{tabular}

$E_{1} O 2$ was very low despite profound $M$ ischemia in 2 cases $\left(E_{M} L<.20\right)$ and was closely related to $\mathrm{E}_{02}$ ( $\left.\mathrm{p}<\mathrm{M} . \mathrm{O}\right)$. Thus 02 supply became the majof determinant of $\mathrm{MVO} 2$ and closely related to MVO2 $(p<.01)$. Despite high levels of inotropic drugs, $M$ ischemia tended to decrease because the induced $\mathrm{M}$ O2 supply was higher than the induced $\mathrm{M} O 2$ demand.
EFFECTS OF PRENALTEROL ON CARDIAC PERFORMANCE AND TRANSMURAL MYOCARDIAL PERFUSION' IN PATIENTS WITH RENAL FAILURE. T. Pedersen, I. Brynjolf, $K$. Cleemann-Rasmussen, P.E. Nielsen, K. Rasmussen. Department of Anaesthesia and Department of $\mathrm{Ne}-$ phrology, Herlev Hospital, University of Copenhagen, Denmark.

The acute haemodynamic effects of a new beta-adrenoceptor agonist, prenalterol, were studied in 6 patients with renal failure. Using impedance cardiography and radionuclide angiocardiography, left ventricular function was investigated before and during increasing doses of prenalterol $0.8 \mathrm{mg}, 1.6 \mathrm{mg}$ and $3.2 \mathrm{mg}$ injected $i . v$. every 15. min.

Prenalterol induced a positive inotropic response. Stroke volume increased from $42.5 \pm 14.4$ to $51.3 \pm 13.6 \mathrm{ml} / \mathrm{beat} / \mathrm{m}^{2}(\mathrm{p}<0.05)$ and left ventricular ejection fraction increased from $69 \pm$ 7 음 to $77 \pm 7 \%(\mathrm{p}<0.05)$.

A dose dependent chronotropic effect was demonstrated as heart rate increased gradually from $74 \pm 5$ to $94 \pm 5$ beats/min $(p<0.05)$. The transmural myocardial perfusion (ratio of the flow from subendocardial to subepicardial layers) determined from the oxygen supply/demand ratio (DPTI/SPTI) decreased from 1.10 \% 0.08 to $0.86 \pm 0.06(p<0.05)$ signifying a transitory underperfusion of the subendocardium.

In conclusion, prenalterol increased cardiac performance in patients with renal failure reflected in increasing stroke volume and ejection fraction. A chronotropic effect was seen, which caused a greater incidence of myocardial underperfusion.

\section{5}

COMPARATIVE HEMODYNAMIC EFFECTS OF DOPAMINE, DOBUTAMINE AND ISOPROTERENOL IN ACUTE EXPERTMENTAL PULMONARY VASCULAR HYPERTENSTON. A.Artigas, R.Martinez, A.Rogtan, O.Bonnin. ICU. Hospital de la Santa Creu i Sant Pau. Barcelona. Spain. The present study was designed to compare the hemodynamic effects of dopamine (DP), dobutamine(DB). and isoproterenol (I) in acute pulmonary artery hypertension (PAH). METHODS: The hemodynamic response to different drugs was studied in 24 dogs. Anaesthesia was induced with pentobarbital and pancuronium. Animals were ventilated with VT 15 $\mathrm{ml} / \mathrm{Kg}$ and $\mathrm{FiO2}$ 1. Catheters were introduced into the left and right ventricles, pulmonary axtery and aorta. All hemo dynamic parameters and left and right ventricular dp/dt were measured at basal level, after inducing $P A H$ and follo wing infusing of $D P(4,8$ and $12 \mu \mathrm{g} / \mathrm{kg} / \mathrm{min}), D B(5,10$ and 20 $\mu \mathrm{g} / \mathrm{kg} / \mathrm{min})$ and $I(0.1,0.2$ and $0.4 \mu \mathrm{g} / \mathrm{kg} / \mathrm{min})$. The PAH $($ mean pulmonary artery pressure $E A m>25 \mathrm{mmHg}$ ) was obtained by pulmonary vascutar obstruction (OVP)

RESULTS: There was a progressive and statistically signifi cative increase of PAH after administration of the three drugs at equivalent doses. Following the administration of $D B$ and I there was an increase of cardiac index (CI) ( $p$ (0.001) and both left and right ventricular function with a decrease of pulmonary (PVRI) and systemic vascular (SVRI) resistence indexes.

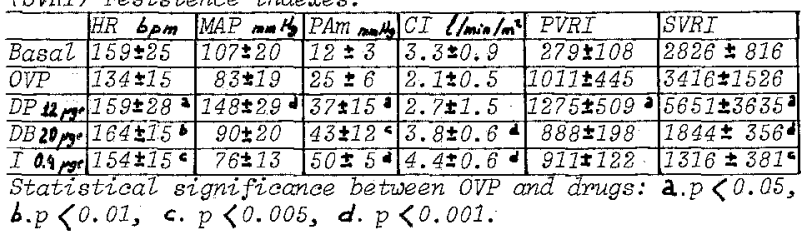

No significant increase of ventricular function was observed following administration of $D P$ due to an increase of PVRI and SVRI $(p<0.05)$. These data suggest that $D B$ and $I$ but not $D P$, may improve ventricular frmetion without increasing PVRI, and should be given preference in the treat ment of PAH.
159

\section{ADENOSINE TRIPIOSPHATE - A NEW VASODILATOR}

C. Anger, C. Puchstein, H. Van Aken, J. Thys, P. Lawin Klinik für Anästhesiologie und operative Intensivmedizin Minster

For a long time Adenosintriphosphate (ATP) has been known as a potent vasodilator. Purine nucleotides play a physiological role in regulating coronary blood flow. ATP may be released from intramural purinergic nerves, acting on purinoceptors in the vessel wall and therefore producing vasodilation. This study evaluates the possible role of ATP in producing deliberate hypotension in dogs. In 6 piritramide anaesthetized dogs, ventilated with 0 f $\mathrm{N}_{2} \mathrm{O}$, a femoral artery catheter and a Swan Ganz thermodilution catheter were introduced. Mean arterial pressure (MAP), mean right atrial pressure (RAP), mean pulmonary artery pressure (PAP), heart rate (IR), pulmonary wedge pressure (PCWP), cardiac output (CO), systemic vascular resistance (SVR), pulmonary vascular resistance (PVR) and stroke volume (SV) were estimated. A continous i.v. infusion of ATP was given, starting with a dose of $1 \mathrm{mg} /$ $\mathrm{kg} / \mathrm{min}$ and stepwise increasing it every five minutes to a maximum dose of $5 \mathrm{mg} / \mathrm{kg} / \mathrm{min}$. All data were analyzed by students' t-test. $p<0.05$ was considered significant. A dose dependent decrease in MAP, PAP, RAP, PCWP, SVR, PVR occured in all dogs immediately after ATP administration. The decrease in MAP was $55 \%+1-8 \%$ with $5 \mathrm{mg} / \mathrm{kg} / \mathrm{min}$. During the whole experiment $\mathrm{CO}$ and $\mathrm{HR}$ increased, SV remained unchanged. ATP seems to be a possible agent for deliberate hypotension. 
160

MITOCHONDRIAL SYSTEMS IN SHOCK STATES. G.C. Corbucci, A.Candiani,G.Crimi and A.Gasparetto, Istituto di Anestesiologia e Rianimazione, Università degli Studi di Roma. The source of our results is a group of ten patients with a diagnosis of shock based upon hemodynamic and metabolic criteria together with the monitoring of tissular P02.

The above shock states, either hypo or hyperdynamic, were studied with regard to the redox mitochondrial activity and the levels of some substrates of Krebs'Cycle in muscular needle biopsies. During the evolution of shock in the examined patients we have observed a significant reduction (one tenth of normal values) of the activity of cyt. oxydase (COx), of succynate cyt.c reductase (SCR) and of $\alpha$-oxoglutarate cyt.c reductase $(0 \mathrm{gCr})$. Moreover in all the hypodynamic shock states we have observed an irreversible "inhibition" of cyt.c oxydase. The tissue and plasma levels of some substrates of Krebs'Cycle (cytrate,

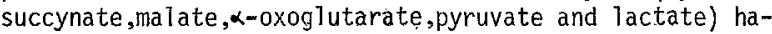
ve shown a close biofunctional relationship with the redox capacity of the electron transport chain (ETC). We could demonstrate a good correlation among tissue perfusion, intracellular 02 metabolization and mitochondrial oxydative capacity. Our resu?ts seem to open new and unexplored fields for the research on shock states in the human being. 


\section{Cardiovascular Monitoring}

161

CONTINUOUS MEASUREMENT OF DESCENDING AORTIC BLOOD FLOW BY OESOPILAGEAL ULTRASOUND PROBE (comparison with cardiac ontput by thermodilution technic). J.Motin’ R.Muchadał B.Bui Xuan, D.Cathignolle; B.Rousselet, M.Fauvet:

+ Département d'Anesthésie-Réanimation, Hôpital Edouard Herriot, 69374 LYON Cedex 08

- INSERM, SCR 2, 69500 LYON.

We have built a new display which measures the blood flow in the descending portion of the thoracic aorta with an oesophageal probe. The instrument consists of :

- a Doppler directional velocimeter of continuous frequency emission,

- an ultrasonic pulse echo system for measurement of aortic section.

This work compares measurements of thermodilution cardiac output (TDCo) with descending aortic blood flow (Ao DF 2) The cardiac output range was between 1.9 to $13.11 \times \mathrm{min}^{-1}$ The correlation between theses methods, based on $300 \mathrm{simu}^{-}$ 1 taneous determinations involving 21 patients is the following : TDco : $0,473=(1,110 \times \mathrm{xAoF})$

$$
r=0,977 \quad p<0,001
$$

The measurement of descending aortic blood flow by the ultrasound oesophageal probe here described is of easy realisation, non invasive and non traumatic for the unconscious patient.

The obtained values are well correlated with those of cardiac output obtained by thermodilution technic. The method has the advantage upon thermodilution of providing continuous recording, which is an important element in the prevention of haemodynamic complications occuring during surgery.

1. Chavez I: "Introduction générale" in "Haemodynamic changes in anaesthesia". Vth European Congress of Anaesthesiology, P 15-18, SNPM, Paris 1979.

2. Fourcade D, Cathignolle D, Muchada R, Chapelon JY, Bui Xuan B, Bouletreau P, Motin J : Validation de la débitmétrie aortique par capteur ultrasonore oesophagien dans la surveillance hémodynamique non sanglante. Agressologie, 21 (C) : 121-128, 1980.

NON INVASIVE ESTIMATION OF THE PULMONARY CAPILLARY WEDGE PRESSURE IN LEFT HEART FAПUURE.

F1. Depeursinge 1, F. Feihl1, M. Badan ${ }^{1}, \mathrm{Cl}$. Perret 1 , Ch. Depeursinge ${ }^{2}, \mathrm{~A} . \mathrm{K}$. Boutaleb2, J.-C. Willemetz ${ }^{2}$. Institute of Pathophysiology ${ }^{1}$, C.H.U.V., and Federal Institute of Technology ${ }^{2}$, EPF, Lausanne (Switzerland) .

Pulmonary function alterations induced by left heart failure (LHF) are known to be related to hemodynamic impairment. The purpose of this study was to assess the adequacy of high frequency acoustical respiratory impedance (HFRI) measurements by a forced oscillations method in evaluating pulmonary functional disturbances induced by an increased pulmonary capillary wedge pressure (PCW) in critically ill patients.

Repeated measurements of the HFRI and PCW have been performed in patients with acute LHF. Discriminant analysis on indices derived from the frequency dependence of the HFRI shows $96 \%$ of correct classification between PCW $\varangle 15$ and $\geqslant 20 \mathrm{~mm} \mathrm{Hg}$. Correlations between PCW and HFRI indices have been computed for patients with and without concommitant chronic obstructive pulmonary disease (COPD). Correlations as high as $R=0.9$ ( $p<0.001)$ have been obtained for non rapidly transient changes of $\mathrm{PCW}$ in both groups of patients. Repeated measurements of the HFRI yield a suitable monitoring of the trend of PCW.

In conclusion, the sensitivity of the HFRI measurements allows a non invasive estimation of the PCW at the bedside. The specificity of the HFRI is high enough to distinguish between LHF with and without concormitant COPD. The measurement is easily performed and does not require any active cooperation of the patient.
IMPROVEMENT OF CARDIAC OUTPUT ESTIMATION WITH THERMODILUTION IN CPPV BASED ON A TWO POINT AVERAGING METHOD. J.R.C. Jansen, A. Versprille, Dept. of pulmonary diseases, Pathophysiological laboratory, Erasmus University, P.O. Box 1738, 3000 DR Rotterdam, The Netherlands

The feasibility of cardiac output estimation with thermodilution was studied in anesthetized and artificially ventilated pigs. Fifty randomized measurements - equally spread over the ventilatory cycle - showed a maximal variation of 60-150\% from their mean, and demonstrated a cyclic modulation with the ventilatory cycle. When volemic load, positive end expiratory pressure (PEEP), ventilatory pattern or frequency were changed, a shift in the modulation with respect to the cyclic period was found. Due to this shift there was not one defined moment in the ventilatory cycle for all circumstances to estimate mean cardiac output.

To reduce the deviation of individual measurements from the mean we have averaged the paired measurements with a difference of half a vertilatory cycle, giving 25 new estimates for each series. These results were compared with the mean cardiac output obtained from all 50 measurements and Fick's method for oxygen respectively.

This averaging technique improved the estimation of cardiac output for the individual paired values $(n=1525)$ to a range between 80 and $120 \%$ of the mean. Moreover, a characteristic pair of points in the ventilatory cycle, at the end of insufflation and half a cycle later resp., could be selected. These selected estimates had a mean of $101 \%( \pm 6 \% \mathrm{SD}, \mathrm{n}=61)$ of the average of all measurements $(n=3050)$.

164

Calcium antagonists versus calcium in CPR.G.H.Meuret, HFO. Schindler, Anaesthesiol. Inst., Uni versität Freiburg i.Br. FRG This experimental study compares the effects of Calcium to that of Calcium antagonists in CPR, and advocates the thera peutic use of the latter. The following parameters were measured during (phase II) and after (phase III) resuscitation from asphyxial arrest: 1. haemodynamics 2. bloodgases and electrolytes 3 . variables of aerobic and anerobic meta bolism 4. histology and electron microscopy. (Elmi) at the end of the observation period $(2-4 h)$. The -32 dogs were divided into three groups: $E(n=11)$ : epinephrine $(50 \mathrm{~g} / \mathrm{kg}$ bw), Ca $(n=10): 20 \mathrm{mg} / \mathrm{kg}$ bw $\mathrm{CaCL}_{2} 30 \mathrm{sec}$ after E,D:Diltiazem (150 / $/ \mathrm{kg}$ bw bolus) $30 \mathrm{sec}$ after E, 25-50 / $/ \mathrm{kg}$ bw (infusion) after onset of spontaneous circulation. Results: 1. circulation restored : $E: 11 / 11,0: 11 / 11$, $\mathrm{Ca}: 7 / 10$ 2. Ventricular fibrillation (VF) : same incident rate in all groups in phase II, phase III : no VF in $D$, but in $\mathrm{E}$ and $\mathrm{Ca}$. With Ca VF was irreversible in two cases, myocardial contracture occured in one case. 3 . Haemodynamic parameters of myocardial $\mathrm{O}_{2}$ requirements were lowest in $\mathrm{D}$. 4. Coronary blood flow was higher and $\mathrm{O}_{2}$ consumption lower in $\mathrm{D}$ compared to $E$ and $C a$. 5. Elmi : highest rate of ultrastructural destruction with $\mathrm{Ca}$, lowest with $\mathrm{D}$. Conclusion : whereas Calcium has deleterious effects, calcium antagonists protect the heart in CPR. 


\section{5}

PROSPECTIVE CLINICAL AND RADIOLOGICAL STUDY ON THE RATE OF THROMBOSES OF CENTRAL VENOUS CATHETERS IN A MEDICAL INTENSIVE CARE UNIT: L.S. Weil lemann, M. Reuss, J. Majdandzic, H.P. Schuster, II. Medizinische Universitätsklinik Mainz.

Methods and patients: prospective clinical and $X$-ray examinations of 63 cases with central venous catheters (cvc) in situ for at least 12 hrs. X-ray control of the catheter position after insertion and /or correction of the catheter and every second day. Daily clinical control and assay of coagulation parameters.

Phlebography immediately after remoral of the $\mathrm{CVC}$.

Results: Radiological alteration in $27 / 63$ cases with complete thrombosis in 19 cases and incomplete thrombosis in 8 cases.. Only $21 / 27$ patients with incomplete or complete thrombosis had clinical signs or symptoms. Thromboses according to access vein: $v$. basilica $51 \%, v$. cephalica $55 \%$, v. subclavia $14 \%$. - Period of intravenous position of the CVC $319 \pm 158 \mathrm{hrs}$ in cases with - and $264 \pm 215$ hrs in cases without thrombosis $(p>0,05)$. Most of the thromboses $(71 \%)$ occurred 193 to $312 \mathrm{hrs}$ after insertion of the CVC. The dosage of heparin (low dose or therapeutic dose) had no influence upon the rate of thromboses. To sum-up: highest rate of thromboses in CVC positioned via arm veins. Heparin dosage and mean length of intravenous position had obviously no effect upon the rate of thromboses.
167

THE INFLUENCE OF ARTERIAL HYPEROXEMIA ON TISSUE $\mathrm{pO}_{2}$.

K.H.Kopp, E. Kammer, N. Krieg, Institut für Anaesthesiologie der Universitätskliniken Freiburg i.Br., BRD

Previous investigations indicate impaired peripheral oxygen supply of tissue under the influence of arterial hyperoxemia. Own results aroused suspicion. that these disturbances were dependant on cardiac output. Therefore muscle oxygen supply was investigated (using a $\mathrm{pO}_{2}$ multiwire surface electrode) in 46 ICU-patients under normoxemic and hyperoxemic conditions. The 246 patients were divided into 4 groups; I Ci-3.99 $1 / \mathrm{min} / \mathrm{m}$ BS $n=9$; II Ci-4.99 $\mathrm{n}=19$; III Ci-5.99 $\mathrm{n}=10 ;$ IV Ci> $6 \mathrm{n}=8$. Results: 1. A similar increase of pa0, from similar base Tine values could be observed under $\mathrm{FiO}_{2}=1$ in all of the 4 groups. 2. The 4 groups showed a decreasing $C i$ under hyperoxemia, the most pronounced decrease occured in group IV $(-13.68)$. 3. Under normexemia group I and II had similar mean muscle $\mathrm{pO}_{2}$ values $\left(\mathrm{pmO}_{2}\right)$, group III and IV however showed higher values (tab.1). 4. A increase of $\mathrm{pmO}_{2}$ under hyperoxemia was found only in group II, III and IV, slightly decreasing $\mathrm{pmO}_{2}$ values however could be seen in group I (tab.1).

Tab. 1

\begin{tabular}{ccc} 
Normexemia & Hyperoxemia & $\Delta$ \\
\hline 3.44 & 3.38 & -1.8 \\
3.38 & 5.22 & +54.4 \\
4.42 & 7.05 & +59.4 \\
4.96 & $7.66 \mathrm{kPa}$ & +54.4 \\
\hline
\end{tabular}

5. A disturbed muscle $\mathrm{pO}_{2}$ distribution under hyperoxemia was present in all of the 4 groups.

Conclusions: 1 . Under hyperoxemia microcirculatory disturbances of skeletal muscle occured in most of the ICUpatients.

2. The amount of $\mathrm{pmO}_{2}$ increase under $\mathrm{r}_{2}$ hyperoxemia seems to be dependant on $\mathrm{Ci}$. At $\mathrm{Ci}<4 \mathrm{1} / \mathrm{min} / \mathrm{m}$ BS no improved peripheral oxygen supply could be detected during arterial hyperoxemia.

\section{6}

BAROREFLEX FAILURE IN GUILLATN-BARRE SYNDROME (G.B.S.) J.C. RAPHAEL, D. PATTE, V. MORICE, Ph. GAJDOS, M. GOULON. Hopital Raymond Poincare. 92380.GARCHES. France.

Autonomic dysfunction can occure in the acute phase of G.B.S. In order to explain the mechanism of these anomalies hemodynamical and autonomic tests have been done in the acute phase of the disease (phase $A$ ) and during recovery (phase $R$ ). Methods. 31 patients were studied (average age $33+16$ years) without previous cardiovascular disease or complications, 24 required mechanical ventilation. The fol Iowing tests have been performed : measure of arterial pressure (A.P.), cardiac index (C.I.), total peripheric resistance (TPR) in supine position $(n=31)$ and after $30 \mathrm{mn}$ of $30^{\circ}$ tilt $(n=22)$, valsalva manoeuvre $(n=19)$, changes of AP after injection of phentolamine ( $5 \mathrm{mg})$, constant infusion of noradrenaline $(0,05 \mathrm{ug} / \mathrm{kg} / \mathrm{mn})$ and angiotensine $(0,01 \mathrm{ug} / \mathrm{kg} / \mathrm{mn})$, studies of urinary catecholamines, measuIe of blood volume (131 I Labeled albumine). Results. The comparison of tests during phase $A$ and $R$ ( $t$ test for matched series) demonstrate : 1) an increase in phase $A$ of supine mean A.P. $(p<0,001)$ and TPR (D<0.05). 2) Tilt test induces a greater fall in $A P$ during phase $A(p<0,01)$ explained by a lower increase of $T P R(p<0,03)$. No change in blood volume is observed. 3) Valsalva ratio is lower in phase $A(p<0,001)$. 4) urinary excretion of catecholamines is higher in phase $A(p<0,001)$. 5) phentolamine induces a greater fall in $A P$ during phase $A(p<0,001)$ Changes of AP after infusion of noradrenaline and angiotensine are identical in both phases. Conclusions. Impairment of baroreflex arc in the acute phase of $G_{*} B_{*}$. . $_{\text {. }}$ is proved by orthostatic hypotension and anomalies of the valsalva manoeuvre. This fact cannot be explained by a lesion of the autonomic efferent pathway. These results suggest an afferent block in the acute phase of G.B.S. 
PROPOSITIONS THERAPEUTIQUES DANS L'INTOXICATION CYANHYDRIQUE A PROPOS DE 24 CAS SANS MORTALITE. C. BISMUTH, F. BAUD, J. PRONGZUCK de GARBINO. Clinique Toxicologique, Hôpital F. WIDAL, 200 faubourg Saint-Denis 75010 PARIS - Université Paris VII.

Inhibiteurs de la cytochrome-oxydase, les cyanures entrainent une aroxie cellulaire rapidement mortelle et sont couramment considérés comme l'agent suicidaire le plus sûr de notre civilisation.

L'étude rétrospective de 24 cas d'intoxication cyanhydrique sans mortalité permet d'insister sur :

- la fréquence des arrêts cardiorespiratoires éventuellement inauguraux $(7 / 24)$,

- l'intensité de l'acidose (8/24) quí peut à elle-seule faire suspecter l'intoxication et évaluer son intensité,

- la possibilité d'intoxications asymptomatiques malgré la prise certaine suicidaire de sels de cyanure (par péremption de conditionnements vieillis).

Parmi les thérapeutiques classiques :

- les méthémoglobinisants apparaissent actuellement dépassés. - Te tétracémate dicobaltique, efficace mais dangereux en dehors de l'intoxication cyanhydrique, doit être réservé aux sujets présentant des signes objectifs (au minimum ébriété) d'intoxication.

- I'hydioxocobolamine, associée au thiosulfate de sodium, pratiquement sans effet secondaire, permet une neutralisation et une élimination rénale rapide des cyanures ; son efficacité est conditionnée par l'importance de la dose (au minimum $4 \mathrm{~g}$ ) - le traitement symptomatique reste essentiel, en particulier la ventilation en oxygène pur qui a permis a elle-seule la guérison d'intoxications cyanhydriques, connues ou méconnues, sans traitement antidotique associé, avec des taux de cyanure spontanément léthaux.

Cette série apporte la notion d'absence de taux sanguin mo: tel de cyanures chez le sujet pris en charge précocément en réanimation.

THE INFLUENCE OF THE KALLIKREIN-KININ SYSTEM ON PULMONARY MORPHOLOGICAL ALTERATIONS IN EXPERIMENTAL ACUTE HEMORRHAGIC PANCREATITIS (AHP). H.Kortmann, R.Bassermann Dep. of Surg. \& Inst. Respiratory insufficiency is a common severe complication in the course of AHP and often an ominous sign for a beginning shock with high mortality. The liberation of kinins is generally considered essential for the induction of pancreatic shock. - An AHP was induced in $15 \mathrm{pigs}$ by intraductal injection of taurocholic acid (TCA). The 6 controls were only sham operated. In another group of 5 pigs bradykinin (BK) was infused together with the kininase II inhibitor Captopril. Besides blood gas analysis lung biopsies were taken in the course and at the end of the experiments. - AIl pigs with AHP died of hypovolemic shock. The kallikrein levels increased immediately after the onset of AHP ( $\Delta \mathrm{x}$ : $+75 \%$ ). The total kininogen decreased about $70 \%$. Co and CVP decreased wherees PAP and TPR increased ( $\mathrm{p}<0.001)$. PCWP remained nearly constant. Lung biopsies taken early in the course of AHP showed interstitial edema and lateron intraalveolar hemorrhage, alveolar collaps, microthromboli, and in some animals hyaline membranes. By infusion of $\mathrm{BK}$ a marked interstitial pulmonary edema could be generated in healthy anaesthetized pigs. TCA induced AHP in pigs leads to a significant increase of kallikrein and a decrease of kininogen which means a high liberation of vasoactive kinis. By altering local capillary permeability they induce a high ascites production and contribute to a histologically proved respiratory distress syndrom.
PARENTERAL RANTTIDINE : ONSET AND DURATION OF ACTION. H.G. Dammann, P. Mijlier, B. Simon , Medizinische Universitätskliniken Hamburg und Heidelberg, F.R.G.

Pulmontry acid aspiration syndrame has been recognized as a major hazard in the practice of emergency anesthesia This rissk has been tightly correlated with a gastric fluid $\mathrm{pH}$ of less than 2.5 and a volume of more than $25 \mathrm{ml}$. This study was designed to investigate the onset and duration of action of the new $\mathrm{H}_{2}$-receptor antagonist ranitidine in man.

After an overnight fast a nasogastric tube was placed in the stomach of 12 healthy male subjects. The gastric contents were aspirated and the starting $\mathrm{pH}$ was determined. $50 \mathrm{mg}$ ranitidine as i.v. bolus or placebo $(0.98 \mathrm{pla}$ cebo) was given in a randamized fashion. Gastric juice was continuously aspirated over a test period of 6 hours, $\mathrm{pH}$ of the gastric aspirates and gastric volumes were determined in 1-hour fraction.

$50 \mathrm{mg}$ of ranitidine induced a rapic increase in gastric $\mathrm{pH} .45 \mathrm{~min}$ after ranitidine all 12 subjects had a gastric aspirate $\mathrm{pH}$ of more than 5 remaining at this level over the whole test period. By contrast, in the controls the $\mathrm{pH}$-values ranged between 1.30 and 1.90 over the whole 6 hour test period.

Gastric volume secretion in the ranitidine experiments was reduced from $60 \mathrm{ml} / \mathrm{hr}$ in the first collection period to volumes below $35 \mathrm{ml} / \mathrm{hr}$ (i.e. 45-50 응 inhibition), whereas in the placebo-experiments volume secretion remained almost unchanged.

Our data reveal that $50 \mathrm{mg}$ of ranitidine as i.v. bolus induces an immediater (within $30 \mathrm{~min}$ ) increase in gastric aspirate $\mathrm{pH}$ and a concomitant drastic reduction of volume secretion in all subjects. This rapid onset of action allows a short time interval between administration of this $\mathrm{H}_{2}$-blocker and induction of anesthesia. The prolonged activity of ranitidine (for more than 6 hours) may indicate that at time of extubation the $\mathrm{pH}$ of gastric con tents is still high. Premedication with ranitidine may, therefore, be helpful in patients at risks.

INTENSIVE THERAPY AND RESUSCITATION IN PATIENTS WITH ACUTE POISONING BY PHOSPHOORGANIC COMPOUNDS.

AA.Togaibaev, VI.Lapin, GD. Sheinin, LA.Badelbaeva, AIma-Ata, USSR, Kazakstan.

We studied 126 cases of acute poisoning by phosphoorganic substances. This kind of pathology was treated by a specific therapy consisting in combinated use of cholinolitics (atropin) and reactivators of cholinesterase (isonitrosine). We payed a special attention to symptomatic therapy aimed at decrease of hypoxia and its secondary effects, control of convulsious, prevention of inflammatory changes of the respiratory organs and control of pulmonary and brain edema. We used as obligatory the gastric and intestinal lavage, intensive ureapoiesis, hemoresorption, hemodialysis and blood transfusion. We noted a marked decrease in fatal outcome in this group of patients as a result of the treatment above described. 
172

CRITERION OF EFFECTIVENESS OF HEMOCARBOPERFUSION IN ACUTE EXOGENIC INTOXICATION, LV.USenko, VA KraUZ, EP.Litvin, Medical Institut, Dnepropetrovsk, USSR.

Despite the broad use of hemocarboperfusion method in a reanimation clinic many problems bound up with the reliable criterions of estimation of effectiveness of this method remain unsolved. We studied the effectiveness of a single and multiple hemocarboperfusions on the dynamics of clinical, biochemical, electrophysiological and psychophysiological indices of hemostasis. 200 patients and 65 dogs were observed in the condition of acute intoxication with phosphoroorganic insecticides, alcohol and psychotropic agents. It was shown that we can speak of effectiveness of hemocarboperfusion, that is, of its curable effect in case of intoxication according to complex estimation of different indices. The most informative characteris-

tics as well as clinical ones are bioelectrical brain activity, attention and memory function, indices of functional condition of sympathoadrenal, cholinergic, kallicreinekinin systems and acid-base.

Criterions of effectiveness of a single hemocarboperfusion operation as well as determination of a number of necessary operations in cases of exogenetic intoxication include overall the bioelectrical brain activity, and then the indices of attention and memory function. Neurophysiological mechanisms are analysed on the basis of experimental data. 
EFFECT OF CONTINUOUS POSITIVE PRESSURE VENTILATION ON THE SHUNT THROUGH THE FORAMEN OVALE. R. Spritzer, A. Versprille, W.J. Gussenhoven, Dept. of pulmonary diseases, pathophysiological laboratory, Dept. of pediatrics, subdivision of neonatology, Interuniversity Cardiology Institute, Erasmus University, P.O. Box 1738, 3000 DR Rotterdan, The Netherlands

Artificial ventilation has proven to be beneficial for many newborn infants. Little is known about the effects of continuous positive pressure ventilation (CPPV) on the neonatal circulation.

The effects of CPPV on the R-L shunt through the foramen ovale (FO) were studied in newborn pigs. Indicator dilution curves from the right atrium and the abdominal aorta after injection in the inferior caval vene were analysed. The shunt through the Fo appeared periodic and within the ventilatory cycle. This period was estimated from the shortest transit times, i.e. the time between arrival of indicator in right atrium and aorta. The period of shunting was dependent on the ventilatory pattern.

Non invasive detection of shortest transit time between right ventricular outflow tract and aorta by means of contrast echocardiography correlated closely to the invasive dilution method. We concluded that the cyclic changing shunt through the Fo during CPPV is mainly dependent on the cyclic differences in venous return to right and left atrium, and that the non invasive detection of transit time promises clinical application.
REIYAL VENOUS THROMBOSIS (RVT) IN INFANCY - THROMBOLYTIC TREATMENT IN 17 CASES. F. Beaufils, $\mathbb{N}$. Schlegel, G. Pillion, C. Loirat, J.C. Mercier, Hôpital BRETONNEAU, PARIS, We report our experience with 22 cases of RVT in infants (age 1 to 87 days). Etiologic factors were : hypertonic dehydration ( $n=11$ ) perinatal anoxia $(n=11)$. Diagnosis criteria were the following : clinical kidney enlargement gross hematuria, associated with non secreting kianey on intra verous pyelogram IVP and or anuria. RVT was unilateral in 10 cases and bilateral in 12 cases all with anuria.9 infants required peritoneal dialysis.Surgical thrombectomy was rejected, most of these RVT being mainly intrarenal. 5 infents were not treated ( 3 because of early death). 3 were treated by Heparin ( $H$ ) and streptokinase (SK) : loading dose $2000-2500 \mathrm{U} / \mathrm{kg} / 20$ minutes maintenance dose 750-1200 U/kg/hours 24-48 hours. 14 were treated by $\mathrm{H}$ and Urokinase (UK) : loading dose $4000 \mathrm{UCTA} / \mathrm{kg} / 20 \mathrm{minu}-$ tes maintenance dose $3000 \mathrm{UCTA} / \mathrm{kg} /$ hour $24-72 \mathrm{~h}$. 2 of them received plasminogen 6 hours before UK.

4 infants ( 3 not treated 1 SK) died at the acute phase. Bilateral RVT was found in the 3 autopsied eases. 1 infant (UK) died after 3 months of chronic peritoneal dialysis. 17 infants (2 not treated 2 SK $13 \mathrm{JK}$ ) survived. 1 (SK) kept end stage renal failure ( $R F)$ and hypertension and entered on hemodialysis programm at 6 years of age. 1 (UK) had mild RF (follow up 21 months). The 15 remaining patients (2 not treated 1 SK 12 UK) have normal glomerular filtration rate and blood pressure (follow up 5 to 48 months). Evolution of IVF was evaluated for surviving patients according to the overall number of kidneys which were altered in acute phase. 9 out of these $26 \mathrm{kid}-$ neys are normal. 9 are non secreting. 8 are atrophic. Finally 6 ( 1 non treated 5 UK) out of the 22 patients fully recovered (normal IVP and renal function). Poor factors of prognosis were bilaterality ( 5 deaths $2 \mathrm{RF}$ ) and dehydration ( 5 deaths $1 \mathrm{RF}$ ). The benefit of thrombolytic agents cannot be clearly evaluated because of the small number of patients. Further studies ean be performed with UK because of its small risk of bleeding $(0 / 14)$ if appropriate biological monitoring is performed.

LONG TERH RESULTS FOLLOWIIG REPAIR OF ESOPHAGEAL ATRESIA. c. Hercier, H. Cordier, ho Robert, A. Lacombe, F. Gold, J. Laugier, Centre de Pédiatrie, C.H.R. Tours, France.

We report our experience about 100 cases of esophageal atresia admitted to our unit from 1968 to 1900 . The aim of this study is to appreciate respiratory and esophageal complications. $52 \%$ of the infants were considered at high risk (in accordance with the French Society of Pediatric Surgery, classification 1969). $82 \%$ survived after the surgical management of the esophageal atresia. The long term survival rate was $74 \%$ : death occured as a result of cardiac or multiple malformations, 3 to 36 months after surgery. 74 children were followed up prospectively for periods between 3 and 6 months, then every year. Data were obtained from physical examination and esophagography (performed at one year). Other investigations, such esophagoscopy, tracheoscopy were performed in case of respiratory complication.

Results : The following diagnosis were established :

- chronic suppuration of the bronchus in $24 \%$

- esophageal stricture in $28 \%$

gastroesophageal reflux in $23 \%$

Correlation between respiratory and esophageal sequelae was noted.

Our results stress the need for an early and systematic detection of esophageal abnomalities, particularly when responsible for the recurrent respiratory problems, and for an antireflux procedure.
AN IMPROVED TECHNIQUE FOR NON-INVASIVE ICP MEASUREMENTS IN NEONATES. F.Fallenstein, A.Huch, R.Huch, Dept. of obstet.and Gyn., University Hospital, Zürich, Switzerland. We have reported on the possibility of continuous non invasive monitoring of ICP in neonates and its Clinical diagnostic relevance (1). It is our aim to develop a sensor which measures ICP with sufficient precision and which is inexpensive and easy to handle. Our latest developement uses a commercially available strain gauge pressure transducer with a flat surface which is in direct contact with the skin of the head above the fontanelle. This method requires the pressure transducer to be pressed against the head skin with a certain force. This is accomplished individually in each application by a step motor drive which can alter the depth of the transducer relatively to the sensor case. The action of the step motor is controlled by a microprocessor which also porvides an automatic routine to find the optimum position by analyzing the signal of the transducer in relation to its deflection. In order to investigate the influence of the skin membrane on the accuracy of pressure transmission between the intracranial system and the transducer, we applied membranes wi th various compliances to a water filled artificial head with a fontanelle opening. By varying the water pressure below these simulated "head skins" and recording the transducer signal, we found a linear function within the physiological range $(10-50 \mathrm{~cm}$ water) for all kinds of membranes. We averaged the various slpoes and found a maximum deviation of $6 \%$. For this reason, we assume the real head skin to have similar pressure transmission characteristics. Consequently a sensivity calibration is not necessary before in vivo application.

(1) A.Huch, F.Fallenstein, R.Huch and JL.Peabody (A new device for non-invasive measurement of intracranial pressure (ICP) in newborns), Med.Prog.Techno1. 6, 185-187, 1979. 
IS NASOTRACHEAL INTUBATION (NII) A PROCEDURE OF CHOICE IN THE MANAGEMENT OF SEVERE LARYNGOTRACHEOBRONCHITIS (ITB) ? Y. Bompard, S. Bobin, J.C. Mercier, P. Narcy, F. Beaufils Hôpital BRETONNEAU - PARIS - FRAINCE

Intubation has been proposed as an alternative of tracheostomy for the airway stabilization in LTB. But this procedure for some authors, might cause secondary subglottic stenosis. The purpose of this retrospective study is to analyze the immediate and secondary outcome of 40 LTB treated by NTI.

PATIENTS : 14 girls (32\%), 30 boys (68\%), age 6 weeks to 12 years. Etiology : 9 measles, 10 bacterial proved infections, 10 viral infections, 15 unknown. Tube size was : for 21 patients, 1 size $(0,5 \mathrm{~mm})$ smaller than the recommanded size for age ( 1 ), for 16 patients $\geqslant$ to the recommanded size for age and unknown for 3 patients. RESULTS : Mortality 0; good outcome 37; subglottic stenosis 3

- one intubation(average duration 84 hours) 24 patients

- prolonged intubation (mean duration 180 hours) 13 patients : 9 unique reintubation $\leqslant 9$ days, 3 multiple intubations, 1 tracheostomy at 24 hours

- delayed subglottic stenosis 3 patients needing 1 calibration which was successfuI and 2 tracheostomies ( 1 recovered after 6 months. 1 underwent a laryngoplasty after 12 months for failure to recover.

Finally $37(92,5 \%)$ out of the intubated LTB had a good outcome. Facilitating factors of subglottic stenosis appeared : measles $(2 / 3)$ and too large size tube $3 / 3$. CONCLUSION : Intubation is a safe and efficient procedure in the management of sever ITB. Subglottic stenosis does not seemed to occur if the tube is one size smaller than the recommanded size for age.

(1) HUAUTT, LABRUNE - Pédiatrie d'urgence FLAMMARTON PARIS - 1981, 1099.

ARRHYTHMIA MONITORING IN PEDIATRICS R. Frey, I. Bergmann, D.Widmann, G.Brueggemann, A.A. Schmaltz, J. Apitz

Dept. of Pediatric Cardiology, University

Children's Hospital, Tuebingen/FRG

With the rise in the number of heart operations and the improved accuracy of pediatric monitoring, arrhythmia and its detection has become an increasing problem in pediatric cardiology.

Our department provides preoperative, postoperative, and general cardiologic care for children with heart disease between the ages of one day and 16 years.

We adapted the alarm limits and conditions of an arrhythmia computer (HP-78525) to our intensive care and long-term ECG monitoring problems and to the field of pediatrics.

For quality control, statistical analys is was used to examine all stored QRS complexes of each patient after the control by the cardiologist and to assess sensitivity and specificity results in a 4-field table. Continuous storage makes possible the detection of false negative as well as false positive results. The control by the cardiologist occurs through the EDIT and RECALL system.

The results obtained over a 24-hour period for 10 patient were presented and compared with the interpretations acquired with Holter monitoring.

The accuracy of QRS analysis ranged between $80 \%-99 \%$ for good ECG quality but dropped to 5: for instable ECG qualitiy for the same patient.
PROGNOSIS FACTORS OF SEVERE INFECTIOUS PURPURAS

(90 cases from the French group of pediatric intensive care)

F. LECLERC, R. BEUSCART, B. GUILLOIS, J.F. DIEPENDAELE

G. KRIM, D. DEVICTOR, Y. BOMBART

Ca7mette Hospita7-59037 LILLE Cedex-FRANCE

The French group of pediatric intensive care has prospectively studied 90 cases of infectious purpuras which were hospitalized in 1981 ; the purpose of this study was to determine prognosis factors.

The statistic study ( $x^{2}$ test) of all these cases is in agreement with the litterature data and shows that the mortality is significantly higher when there is : a shock $(p<0,001)$, a coma $(p<0,05)$, an ecchymotic or necrotic purpura $(p<0,01)$, a temperature $<36 \mathrm{C}(p<0,05)$, no clinical meningism $(p<0,001)$, a white blood cells count $<10000(p<0,05)$, a thrombocytopenia $<100000(p<0,01)$, a fibrinogen $<1,5 \mathrm{~g} \quad(p<0,001)$ a kaliemia $>5 \mathrm{mEq}(p<0,01)$, a spinal fluid cells count $<20(p<0,01)$.

Because the shock is one of the main prognosis factors (23 deaths in 55 shocked patients, vs 2 in 35 non shocked) we have done an other statistic study (with the BENZECRI Method) to determine a pronosis index in shocked patients : for its determination five initial parameters are used :

- Age, kaliemia, white blood cells count, clinical meningism, platelets count.

is $87 \%$.

Its sensibility is $91 \%$, its specificity

\section{0}

RENAL EFFECTS OF CALCIUM CHLORIDE INFUSION IN OLIGURIC CHILDREN AFTER OPENHEART SURGERY. M.Dechaux, B.Marie, A. Dequirot, Y.Durandi, Mankikian, C. Sachs, Services de Physiologie et de Chirurgie Cardio-Vasculaires, Hôpital Laënnec, Paris France.

Renal dysfunction (oliguria, renal insufficiency a.s,o.) after cardiopulmonary by pass for open heart surgery is a frequent and sometimes severe complication, especially in infants and young children. $\mathrm{CaCl} 2$ infusion is known to reverse these urinary troubles. The aim of this study is to try and determine the exact nature of these desorders and the mechanism (s) of $\mathrm{CaCl} 2$ infusion action. Six children (weight range 8 to $15 \mathrm{~kg}$ ) with congenital heart diseases have beenistudied before (period I) and after (period II) infusion of $0.5 \mathrm{mEq} / \mathrm{kg} \mathrm{b} . \mathrm{w}$, of $\mathrm{CaCl} 2$. In one of the patients 2 subsequent studies have been performed. The following methods have been used: standard inulin clearance for glomerular filtration rate (G.F.R.),P.A.H. clearance for renal blood flow (R.B.F.) measurements. Plasma total and ionized calcium, plasma citrate, urinary sodium $\left(\mathrm{U}_{\mathrm{Na}}\right)$ and osmolality (Uosm) were also measured. Plasma filtration fraction (F.F.) and urinary flow (V) were calculated. Results are summarized in table I reporting mean values $\pm 1 \mathrm{SD}$.

\begin{tabular}{ccccccc}
\hline & GFR & RBF & FF & $\dot{v}$ & Uosm & Ca+* \\
I & $123^{+}-50$ & $386^{+}-154$ & $33 \%^{+}-7$ & $0.7^{+}-0,3$ & $736^{+}-145$ & $2,39^{+}-0,32$ \\
II & $123^{+}-45$ & $470^{+}-154$ & $26 \%^{+}-3,5$ & $2,2^{+}-2,1$ & $557^{+}-150$ & $3,1^{+}-0,42$ \\
T & n.s. & n.s. & $*$ & $*$ & $*$ & $*$ \\
\hline \multicolumn{7}{c}{ Citrate } \\
values and GFR were in normal range and unchanged before
\end{tabular}
and after $\mathrm{CaCl} 2$ infusion. Initial values for R.B.F, were low with increased F.F., and urinary osmolarity was elevated $\mathrm{CaCl} 2$ infusion produced an increase of $\dot{V}$ with a decrease of $\mathrm{U} \mathrm{osm} \mathrm{Ca}^{++}$,initially in the normal-low range, increased dramatically. Alt these changes were statistically significant as estatished by a non parametric test (WH COXON) follow : - low PAH clearance with elevated FF suggest an insufficient RBF - the initial oliguria with elevated Uosm suggest a vasopressin hypersecretion - infusion produced hypercalcemia might induce a stimufation of $P G E 2$. The latter is known to increase RBF, $U_{N a}$ and antagonize vasopressin tubular action - hypercalcaemia might also have a direct inhibitory effect on vasopressin release. 
HYDROCHLORIC ACID INFUSTON FOR TREATMENT OF HYPERCAPNIA. $S$ Brimioulle, JL Vincent, $J$ Berré, $P$ Dufaye and RJ Kahn. Department of Intensive Care, Erasme University Hospital, Free University of Brussels, Belgium.

Hypercapnia is commonly associated with surimposed metabolic alkalosis (SMA), defined as an excessive increase in bicarbonate concentration, which can itself contribute to further increase the $\mathrm{PaCO}_{2}$. We tested the hypothesis that correction of SMA by HCl infusion could decrease $\mathrm{PaCO}_{2}$ in patients with acute ventilatory failure associated with SMA. Concentrated HCl (.25 N) was infused in 15 critically ill patients who presented either with a pH of 7.40-7.45 and a $\mathrm{PaCO}_{2}>45$ torr (group $\mathrm{A}, \mathrm{n}=9$ ), or with a $\mathrm{pH}$ of $7.35-7.40$ and a $\mathrm{PaCO}_{2}>55$ torr (group $\mathrm{B}, \mathrm{n}=6$ ). Ten patients had been treated by mechanical ventilation (MV). NaCl administration was either contra-indicated or ineffective to correct SMA. Serum potassium was $4.2 \pm .4 \mathrm{mM} / \mathrm{L}$. Reduction of $\mathrm{FiO}_{2}$ had not resulted in any decrease in $\mathrm{PaCO}_{2}$. $\mathrm{HCl}$ was infused into the superior vena cava at the rate of $100 \mathrm{ml} /$ hour until the bicarbonate concentration was below $26 \mathrm{mM} / \mathrm{L}$, or the $\mathrm{pH}$ below 7.35 (group A) or 7.30 (group B).

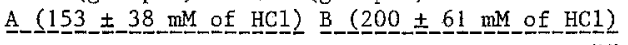

$\mathrm{pH} \quad 7.43 \pm .02 \rightarrow 7.36 \pm .03_{* *}^{* * 37 \pm .01 \rightarrow 7.30 \pm .03_{* *}^{* *}}$ $\mathrm{HCO}_{3}-\mathrm{mM} / \mathrm{L} \quad 32 \pm 2 \rightarrow 24 \pm 1^{* *} 36 \pm 3 \rightarrow 26 \pm 3^{* *}$ $\mathrm{PaCO}_{2}$ torr $49 \pm 3 \rightarrow 43 \pm 2^{* *} 63 \pm 6 \rightarrow 55 \pm 6^{*}$ $\mathrm{PaO}_{2}$ turr $77 \pm 19 \rightarrow 96 \pm 25^{* * *} \quad 77 \pm 22 \rightarrow 91 \pm 24^{*}$ * $\mathrm{p}<.01$ $* * \mathrm{p}<.001$

The decrease in $\mathrm{PaCO}_{2}$ was still significant 12 hours after the end of the HCl infusion. In our opinion, these effects on $\mathrm{PaCO}_{2}$ contributed to the successfull weaning in 7 of the 10 patients treated by $\mathrm{MV}$, and to a brisk clinical improvement in the other 5 patients. No hematological or vascular complication due to HCI was observed.

We conclude that $\mathrm{HCl}$ infusion can significantly improve ventilation and oxygenation in patients who present with hypercapnia and SMA. Aggressive correction of SMA should be actively considered in the management of acute ventilatory failure in critically ill patients.

182

SOME UNKNOWN EFFECTS OF $\mathrm{NH}$ Cl AND ARGININE-HCl. THERAPY. K.F. Rothe, Dept. of Anaesthesiology, University of Tübingen, D 7400 Tübingen, Calwerstr. 7, FRG

Though agents for correction of metabolic acidbase disturbances are widely used in the daily practice of intensive care medicine, there is only little information about their effects on the intracellular acid-base status. In this study the effects of $\mathrm{NH}_{4} \mathrm{Cl}$ and arginine-HCl on intra- and extracellular acid-base equilibria of rats were examined. The "mean whole body pHi", an overall estimate of the intraceltular $\mathrm{pH}$, as complementary to the in vivo determined extraceliular plasma $\mathrm{pH}$, was determined with ${ }^{14} \mathrm{C}$ labeled DMO ( 5,5-dimethyl-2,4-oxazolidinedione). For evaluation of buffering, extra- and intracellular bicarbonate was calculated from the Henderson-Hasselbalch equation. For treatment of metabolic alkalosis therapeutic agents are given to reduce intracellular $\mathrm{pH}$ and intracellular bicarbonate concentration. "It was found ou.t. that after application of the agents extracellular bicarbonate was reduced but there was only little influence on intracellular bicarbonate concentration. In addition it could be demonstra ted that both agents cause a significant increase of intracellular $\mathrm{pH}$ which cannot be detected by blood-gas measurements. The intracellular $\mathrm{pH}$ increase that was observed following application of $\mathrm{NH}_{4} \mathrm{Cl}$ or arginine-HCl application may have adverse consequences for patients and raises objections to the use of both agents in the treatment of metabolic alkalosis.
IACTTC ACID METABOLISM IN ALKALOSIS

W. Druml , A. Laggner , K. Lenz, W. Base, G.Kleinberger ; I Med. Univ.Klinik/Intensivstation, University Vienna, Austria

Alkalosis may induce hyperlactemia representing a mechanism of metabolic compensation of the alkalotic state. It is however not known whether alkalosis per se or hypocapnia and whether an increased production or a decreased hepatic utilisation of lactic acid causes the rise of plasma lactate concentration (=LAC). We therefore investigated the influence of alkalosis on the elimination of parenterally infused L-lactic acid-

Patients and methods: 6 patients ( 30,3 o, mean age 57.5 a) with respiratory failure were evaluated. 1 mol $/ \mathrm{kg} \mathrm{b} . \mathrm{w}$. L-lactic acid was infused in $10 \mathrm{~min}$. LAC and blood gas status was determined before, $2,3,10,20,30,60$ and $90 \mathrm{~min}$ after the infusion. The study was performed in a basal condition with normal pH (7.44+o.02) and a pCO of $39.2+$ 6.33 ) and during controlled mechanical hyperventilation and respiratory alkalosis ( $\mathrm{pH} 7.59+0.03$ ) and hypocapnia $(\mathrm{pCO}, 29.3+4.1)$.

Results:Basal IAC was $1.87+0.37$ at normal $\mathrm{pH}$ and $2.6+$ $0.37 \mathrm{mmol} / I$ in alkalosis $(f \overline{4} 0 \%$ ). The elimination half time was $2.55+0.25 \mathrm{~min}$ at normal $\mathrm{pH}$ and $11.04+3.34 \mathrm{~min}$ in alkalosis $(+320 \%)$. The clearance rate decreased from $64.23+$ $38.4 \mathrm{mI} / \mathrm{kg}$ b.w. $/ \mathrm{min}$ to $25.7+5.01$ in alkalosis $(-60 \%)$. Despite constant $\mathrm{pH}$ and $\mathrm{pCO}_{2}^{-} \mathrm{LAC}$ decreased below basal values after $90 \mathrm{~min} 0.37 \mathrm{mmol} / 1$ in normal $\mathrm{pH}(=20 \%)$ and $0.4 \mathrm{mmol} / 1$ in alkalosis (=-15\%)

Conclusion:Hyperlactemia in alkalosis is caused mainly by a decreased utilisation and is mediated by the pH value and not $\mathrm{pCO}_{2}$. The $\mathrm{pH}$ optimum for lactate metabolisation seems to be below pH 7.44.As a clinical implication alkalisation therapy in post-shock states should be performed carefully since the induction of alkalosis may result in an impairment of lactate removal.-
184

\section{THE USE OF THE ARTIFICIAL PANCREAS FOR TPN IN} CRIMCAL METABOLIC STATES.

J. Schrezenmeir, J. Epping, S. Barthel, W.H. Hörl, Med. Univ.Klinik, 8700 Würzburg, FRG

In acute disease, catabolism, a negative nitrogen balance and the loss of funtional proteins remain problems facing parenteral nutrition. When sugar substitutes are used instead of glucose, metabolic disorders can only be detected by an increase in secondary metabolites. The problems of high dose glucose therapy such as variations in osmolarity, alterations in hemoglobin- $\mathrm{O}_{2}$-dissociation and impaired substrate utilization, may be avoided by using the artificial pancreas (AP).

24 critically ill patients who received high dose parenteral glucose therapy and who had blood glucose concentrations of more than $500 \mathrm{mg} \%$ and daily variations of more than $300 \mathrm{mg} \%$ inspite of insulin per infusion, were placed on the AP. The insulin infusion rate was set to maintain blood glucose values between $150-200 \mathrm{mg} \%$. With the AP mean blood glucose levels of $198+79 \mathrm{mg} \%$ were obtained, compared to $332+149 \mathrm{mg} \%$ ( $p<0,01)$ with conventional therapy. Although more glucose was infused, the maximal serum glucose amplitude per day was significantly reduced $(115 \pm 97 \mathrm{mg} \%$ compared to $262 \pm 131$ $\mathrm{mg} \% ; \mathrm{p}<0,0 \mathrm{l})$ and a significant fall $(\mathrm{p}<0,05)$ of lactate blood levels from $2,45+1,15$ to $1,25+0,24 \mathrm{mg} / \mathrm{l}$ with unchanged lactate-pyruvate ratio and a decrease of citrate and oxoglutarate concentrations indicated a better fuel consumption. After attaining a dynamic equilibrium, insulin glucose ratio was $13.2+21.1$ IE insulin/g glucose and could be used for further therapy without the AP. This parameter of insulin resistance correlated with insulin levels at equilibrium but not with proteolytic activity (digestion of azocasein and phosphorylase kinase; titration of protease inhibitor capacity of plasma, $\alpha-2$-macroglobulin, $\alpha$-l-antitrypsin). Thus the marked resistance in sepsis could not be explained by immunologically detectable insulin degradation or by alteration of the proteolytic activities and protease inhibitors we determined in plasma.

The AP enables us to administer high caloric parenteral nutrition to critically ill patients without the hazards of conventional therapy and to study the mechanisms of insulin resistance in these patients. 
185

USE OF THE ARTIFICIAL PANCREAS (BIOSTATOR GCIIS) DURING AND AFTER TOTAL PANCREATECTOMY. S.De] Prato, F.Giunta,U. Baccaglini, M.Calabrò,E.Pizzinari, C.Tremolada, G.P.Giron A. Tiengo. Università di Padova Italy.

Hypo- and hyperglycemic events and acute metabolic derangement are common comp 1 ications in patients undergoing total pancreatectomy. We evaluated the effect of glucose control with Biostator on intermediary metabolism. 5 non diabetic patients affected by pancreatic adenocarcinoma (age $58 \pm 6 y r$, ideal body weight $93 \pm 2 \%$ ) were studied throu ghout operation (S) and $24 \mathrm{H}$ post operative period (PS). 3 patients (PXB) were put under Biostator control, while 2 patients ( $P X C)$ were treated according to a conventional protocol. Arterial blood samples were frequently taken for hormone and metabolite determination. In PXB glycemia during $S$ and PS was $110 \pm 33 \mathrm{mg} / \mathrm{d} 1$ and $290_{ \pm} 15$ in PXC. C-peptide became undetectable in a $71 \mathrm{PX}\left(3.9_{ \pm}+1.1\right.$ to $\langle 0.2 \mathrm{ng} / \mathrm{m} 1)$. Insulin levels were maintained appropiate in $\mathrm{PXB}\left(76_{ \pm} 12\right.$ $\mu \mathrm{U} / \mathrm{ml}$ in respect to PXC $10 \pm 3$ ). During $S$ lactate and pyruvate increased similarly in both groups (PXB 2612 \pm 420 ; PXC 2534 $700 \mu \mathrm{mol} / 1)$, but a marked peak was observed in a PXC (1actate 7169 ; pyruvate $293 \mu \mathrm{mol} / 1$ ) at the beginning of PS. Alanine was similar in both groups during S (PXB $204 \pm 19$, PXC 249 $25 \mu \mathrm{mol} / 1)$. During PS alanine was higher

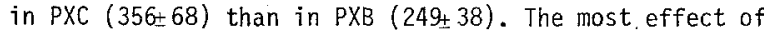
insulin replacement was observed on glycerol (PXB 69. 14 , PXC $218 \pm 8 \mu \mathrm{mol} / 1$ ) and ketone bodies (PXB $87 \pm 14$, PXC 567 $\pm 82 \mu \mathrm{mol} / 1)$. In conclusion: Biostator maintained physiologic glycemia without hypo- and hyperglycemia. Normoglycemia was related to metabolic control avoiding ketoacidosis and hyperlactacidemic risk. Futhermore, reduced levels of alanine in PXB may suggest reduced proteolisis. 
ACUTE RENAL FAILURE IN A MEDICO-SURGICAL INTENSIVE CARE UNIT. V. Ninane, M. Marcha 7, J.L. Vanherweghem, J.P. Degaute, R.J. Kahn. Erasme Hospital, University of Brussels, Brusse1s, Belgium.

Among 2319 patients admitted in a medico-surgical intensive care unit in 1980 and 1981,101 developed acute renal failure (ARF : blood urea $>100 \mathrm{mg} / \mathrm{dl}$, blood creatinine $>2.5 \mathrm{mg} / \mathrm{d} 1)$. ARF was related to surgery $(n=33)$, to one of the following medical insults : hypovolemia, cardiac failure, sepsis, rhabdomyolysis, exposure to nephrotoxic agents $(n=36)$ or to several of these factors $(n=32)$. Median age was 62 years (range, 19-89). The management of these patients included fluid challenge and/or furosemide $(n=85)$, mechanical ventilation $(n=73)$, parenteral nutrition $(n=36)$, hemodialysis $(n=32)$ and peritoneal dialysis $(n=2)$. 01 iguria (urine flow $<400 \mathrm{~m} 1 /$ day for 3 days) was present in 38 patients. Sixty-nine of the 101 patients died. Mortality was not significantly affected by the association of several etiological factors and by the medical or the surgical setting of the patient. Incidence of non oliguric renal failure was not influenced by fluid challenge or diuretic administration: Dialysed and non dialysed patients have a similar mortality rate. Patients who presented with a blood urea $>200 \mathrm{mg} / \mathrm{d}$ l during hospitalisation have a comparable mortality to other patients.

\begin{tabular}{|c|c|c|c|c|c|c|}
\hline Age & Mechan. & vent. & & ria & Dialys is & Urea \\
\hline & $t$ & - & + & - & + & $<200>200$ \\
\hline 40 & 73 & 28 & 38 & 53 & 34 & 40 \\
\hline $1913^{*}$ & 18 & $14^{* * *}$ & 7 & $23^{*}$ & 22 & 16 \\
\hline
\end{tabular}

$\mathrm{S}=$ survivors. $\mathrm{N}=$ number of patients. ${ }^{*} \mathrm{p}<.05-{ }^{*}{ }_{\mathrm{p}}<.01$

Increased survival was associated with younger age, non oliguric ARF and the absence of mechanical ventilation. Our data suggest that the mortality of ARF in critically $i 11$ patients is more related to the general status of patients than to the severity and management of uremia.

\section{7}

NUTRITIONAL STATUS AND IMMUNOLOGIC FEATURES IN PATIENTS WITH ACUTE RENAI FAILURE (ARF).

M. Garré, J.M. Boles, P. Youinou, P. Miossec. Hôpital Morvan 29200 Brest, France.

31 patients with ARF (creatininemia $\geqslant 200 \mathrm{micromo} / 1$ ) due to acute tubular necrosis were assessed for nutritional status and cellular immunity. The series comprised $15 \mathrm{M}$, $16 \mathrm{~F}$, mean age 54.3 years, range $19-83$. The nutritional evaluation included : mid arm muscle circumference (MAMC); serum albumin (A1b), thyroxin binding prealbumin (TBP), transferrin (Tr). The immunologic assessment included : total Iymphocyte (Ly) count, $T$ Ly count, active (act) $T$ Ly count ; skin tests using PPD, mumps and streptokinasestreptodornase antigens.

Most of the nutritional values were lower than those of 40 healthy controls : MAMC males $22.9 \pm 3.5$ vs $25.3 \pm 2.5$ cm $(P<0.002)$, Alb $2.91 \pm 0.78$ vs $3.55 \pm 0.53 \mathrm{~g} / \mathrm{d}]$ (P<0.001), TBP $11 \pm 10$ vs $29 \pm 5 \mathrm{mg} / \mathrm{d} 1(\mathrm{P}<0.001)$, Tr $148 \pm 68$ vs $253 \pm 43 \mathrm{mg} / \mathrm{dl}(\mathrm{P}<0.001)$. On the othef hand, cellular immunity was greatly depressed; Ly $1400-490$ vs $2384 \pm 627$ per $\mathrm{q} \operatorname{mm}(\mathrm{P}<0.001)$, T Ly $540 \pm 480$ vs $1924 \pm$ 598 per $q$ mo $(P<0.001)$, act $T$ Ly $223 \pm 119$ vs $649 \pm 170$ per $q \mathrm{~mm}(P<0.001) .15$ patients were classified as anergic. Nutritional and immunologic status were equivalent whatever the level of renal failure. Alb, TBP, Tr, T Ly and Act T Ly were significantly lower in patients who died. Anergy was more frequent in patients with at least 3 nutritional parameters below $25 \mathrm{D}$ from the values of the controls. Besides a positive correlation was demonstrated between $\mathrm{T}$ Ly and $\mathrm{TBP}(\mathrm{r}=0.36, \mathrm{P}<0.05)$ and act $\mathrm{T}$ Ly and TBP $(\mathrm{r}=0.48, \mathrm{P}<0.001)$.

We therefore suggest that impairment of cell immediated immunity associated with $\mathrm{ARF}$ is at least partly due to protein malnutrition. TBP, simple to assess, seems to be a useful tool as it is correlated with some immunologic values.
UNCOVERED T-ANTIGEN AS PATHOGENETIC FACTOR OF ACUTE RENAL FAILURE.G.Lenz, H.Junger, U.Goes, D.Baron, and U.Sugg. Institute of anesthesiology, University of Tübingen. F.R.G.

The enzyme neuraminidase produced by some viruses and many bacteriae unmasks a cryptantigen(Thomsen-FriedenreichAntigen, T-antigen). on the membrane of red cells and other cells. The T-antigen react with T-agglutinins present in all human sera resulting in a damage of these cells. Increasing attention has been focused on the in vivo action of neuraminidase as pathogenetic agent for the hemolytic uremic syndrome (HUS) in children, Therefore, T-activation of red cells was investigated in 60 surgical ICU patients with suspected septicemia and positive culture results. T-activated red cells were detected by apositive agglutination reaction with peanut agglutinin anti-T (lecitinof Arachis hypogea) and by an indirect hemagglutination Ah test using rabbit antiserum against anti-T. In $17 \mathrm{pa}-$ tients a significant uncovering of T-antigens on red Ah cells was detected in vitro. In 5 of these patients an acute renal failure developped, whereas only 2 of 43 T-negative patients had renal problems. There is strong evidence that the unmasking of T-antigens is not only $1 \mathrm{imi-}$ ted to red cells but also does take place in the renal capillary endothelium. According to these results the neuraminidase induced activation of T-antigens may be an important factor in the etiology of acute renal failure in adult septic patients.

\section{9}

HIGH-BLEEDING RISK IN ACUTE RENAL FAILURE : HEMODIALYSIS WITH DIPVRIDAMOLE AS THE SOLE ANTITHROMBOTIC AGENT. Y. PAGE, J.J.LEHOT, B. ROUSSELET, B. BUI-XUAN, J.P. HOEN J. MOTIN - Département d'Anesthésie-Réanimation - Pr J. MOTIN - Hôpital Edouard Herriot - 69374 LYON CEDEX 08.

A feasibility study of the efficiency of Dipyridamole (DPM) was made to find out how to prevent clotting of the extra-corporeal circuit during hemodialysis (HD) in 13 high-bleeding risk patients (pts). The bleeding risk factors were active gastro-intestinal bleeding ( $7 \mathrm{pts}$ ), acute head trauma ( $3 \mathrm{pts}$ ), haemopericardium ( $2 \mathrm{pts}$ ), others $(3 \mathrm{pts})$. There were 2 bleeding factors in 2 pts. DPM was infused $(25 \mathrm{mg} / \mathrm{h}$ ) in the "arterial" line of a unipuncture HD circuit filled with normal saline. Four benign bleeding complications $(6 \%)$ and no neurological deterioration were noticed among 66 courses of HD. A clotting of the circuit (C.C.) needing to stop HD. (without any dangerous consequence) occured in 12 courses (18.2\%). A platelet count above $100 \mathrm{000} / \mathrm{mm} 3$ was assooiated with a $23.3 \%$ occurence of C.C. , whereas there was none if the count was below 100.000. However, this difference is not statistically significant $(0.05 \mathrm{P} \quad 0.10)$ Bleeding time before HD, the prerinsing of the circuit with heparin and infused doses of saline were not linked with frequency of C.C.

CONCLUSION : 1) HD with DPM is feasible. 2) we observed a higher occurence of C.C. than with previously reported methods using either regular saline wash-out or prostacyclin. 3) This increased occurence may, in part, be due to our circuit (unipuncture, low blood-flow rates). 4) so DPM deserves a comparative trial against other methods of HD without heparin. 
191

THERAPY RESISTANT BRONCHIAL ASTHMA SUCCESSFULLY TREATED WITH PLASMA EXCHANGE. R. Bambauer ${ }^{+}$, M. Austgen ${ }^{++}, K$. Mickat+, P. Sch1 immert+ und $F$. Trendelenburg ${ }^{++}$

+ ) Department for Nephrology, +t) Department for Pneumology at the Medical University Hospital, D-6650 Homburg/Saar, W-Germany

Therapeutic plasma exchange (TPE) experienced rapid world wide dissemination on the introduction of hollow fibre membranes. New areas of application where TPE combined with conservative therapy appear very promising as a symptomatic treatment procedure are increasingly reported.

In 1978 GARTMANN (Lancet 1978) reported for the first time on the successful use of TPE for bronchial asthma. We were able to considerably improve the condition of 2 patients with therapy resistant bronchial asthma using a technically simplified TPE system. A 33 year old patient with medication dependent, therapy resistant bronchia? asthma suffered no further attack after only 1 exchange treatment. The condition of the patient improved so much that she was discharged after 7 further treatments. The extremely high level of IgE decreased under plasma exchange and the pulmonary function also considera'bly improved. A 52 year old patient with therapy resistant bronchial asthma also showed a distinct improvement after only 3 treatments.

The technique, the exchange method of plasma filtration and the course of the diseases treated are reported.
192

PLASMAPHERESIS: COMTROL OF VOLUME-SUBSTITUTION BY MEASURE MENT OF COLLOID-OSMOTIC PPESSURE? A. Laganer, H. Druml, K. Lenz, W. Base, G. Kleinberger, 1. Dent. Medicine(Head: Prof.Dr.Dr.h.c.E.Deutsch)Vienna University, Austria.

The role of colloid-osmotic pressure (COP) in determining intravascular forces in health and disease is generally accepted. In plasmapheresis the plasma is separated and has to be replaced by volume-substitution. This therany has to be iso-colloid-osmotic to prevent patients from renal failure or pulmonary edema.

Materiat and Methods: 9 patients underwent therapeutic plasmapheresis for various reasons. 25 plasmaseparations were performed. COP, albumin(ALB), total protein(TP) and hematocrit(HK) were determined before and after Dlasmapheresis and calculated as \% increase $(+)$ or decrease $(-)$. In group A 10 plasmaseparations were replaced by $5 \%$ human a1bumin, group $B: 8$ plasmaseparations received 10 or less backs of fresh-frozen $D$ lasma(FFP) and in aroup $C$ received 7 Dlasmasenarations more than 10 packs of FFP.

\begin{tabular}{|c|c|c|c|}
\hline Results: & $\begin{array}{l}\text { Group } \bar{A} \\
n=10 \\
\bar{x} \pm s d\end{array}$ & $\begin{array}{l}\text { Group B } \\
n=8 \\
\bar{x} \pm s d\end{array}$ & $\begin{array}{l}\text { Group C } \\
n=7 \\
\bar{x}+5 d\end{array}$ \\
\hline $\begin{array}{l}\text { Volume separated } 1 \\
\text { Volume infused } 1 \\
\text { COP } \% \\
\text { ALB } \% \\
\text { TP } \% \\
\text { HK \% }\end{array}$ & $\begin{array}{rr}3.17 & 0.46 \\
3.36 & 0.53 \\
+0.90 & 18.12 \\
+12.95 & 10.67 \\
+8.75 & 7.94 \\
-9.48 & 13.48\end{array}$ & $\begin{array}{rr}3.48 & 0.51 \\
3.54 & 0.63 \\
-1.23 & 12.54 \\
+16.00 & 29.00 \\
+5.82 & 17.81 \\
+2.88 & 14.49\end{array}$ & $\begin{array}{rr}3.54 & 0.61 \\
4.11 & 0.41 \\
+1.48 & 7.72 \\
+3.31 & 9.24 \\
-0.20 & 6.92 \\
0.00 & 10.38\end{array}$ \\
\hline
\end{tabular}

Discussion: After volume-substitution in plasmapheres is no significant change in volume infused, volume separated COP, ALB, TP, HK could be documented between the 3 arouns. OnTy ALB increased sliahtly in arouns $A$ and B. Measurement of COP seems to be a reliable parameter for quiding volume-substitution therapy in plasmanheresis. Furthermore it is easy performable and cuickly obtainable in modern intensive care units. 
MANAGEMENT OF PATIENTS UITH RAISED INTRACRANIAL PRESSURE AND ACUTE RESPIRATORY FAILURE, L.Holzapfel, P.L. Blanc, L.Thomas, A. Mercate110, M. Gérard, D. Robert, A.Bertoye. Hôpital de la Croix-Rousse, Lyon, France.

Patients with raised intracranial pressure (ICP) may require ventilation with positive end expiratory pressure (PEEP) if acute respiratory failure (ARF) is associated. But PEEP can increase ICP and reduce arterial pressure (AP) ; these changes could critically reduce cerebral perfusion pressure (CPP) and initiate neurological deterioration.

10 patients with coma and raised ICP were studied;age was $37 \pm 18 y ; 3$ had meningitis, 3 encephalitis, 4 head trauma. During $5.6 \pm 3.1$ days, PEEP was $12.4 \pm 3.2 \mathrm{cmli20}$, FI02.47 \pm 5 , Pa02 $83 \pm 19 \mathrm{~mm} \mathrm{H} \cdot \mathrm{g}$, body temperature $37.9 \pm 1.3^{\circ}$ $\mathrm{C}$ and body weight was increased by $5.2+2.3 \mathrm{kn}$ due to fluid therapy far hemodynamic support. ICP was monitored in 8 patients with an epidural pressure-transducer (Philips) and in 2 with an intraventricular catheter. Technics for reducing ICP were : - hyperventilation ( $\mathrm{PaCO} 230+4$ $\mathrm{mm} \mathrm{Hg})-$ adaptation to the respirator with pancuronium bromide - drugs given on a regular basis or on an emergency basis when ICP was $\geqslant 25 \mathrm{~mm} \mathrm{Hig}:$ Mannitol: $.87^{+}=.33 \mathrm{~g} / \mathrm{kg} /$ day and Pentobarbital $(P) 35 \pm 10 \mathrm{mg} / \mathrm{kg} /$ day; serum $P$ level was $75 \pm 55 \mu \mathrm{m} / 1$ (2.2 measurements per patient). In 2 patients ventricular drainage was performed $(112 \pm 47 \mathrm{ml} /$ day and $335-261 \mathrm{~m} 7 /$ day). 5 patients needed Dopamine $13.4 \pm 2.5 \gamma / \mathrm{kg} / \mathrm{mn}$ to maintain MAP $\geqslant 80 \mathrm{~mm} \mathrm{Hg}$. PEEP was briefly discontinued in 8 patients $(10 \pm 8$ times per patient) when CPP was $\leqslant 35 \mathrm{~mm} \mathrm{Hig}$ and promptly restored after action of adequate therapeutic procedure.

Results (base line values) :ICP was $21.8 \pm 4.7 \mathrm{~mm} \mathrm{Fig}$, MAP : $86 \pm 11 \mathrm{~mm} \mathrm{Hg}$ and CPP (MAP-ICP): $64 \pm 9 \mathrm{~mm} \mathrm{Hg} .7 \mathrm{pa}-$ tients survived ( 2 with neurological deficit), 3 eventually died, but pulmonary and neurological lesions were not directly responsible for the death.

Conclusion : patients with raised ICP and ARF can be treated with PEEP and fluid infusion provided that ICP 论 monjtored and adequate therapeutic procedures are taken

\section{4}

AUDITORY BRAINSTEM RESPONSES IN POST-TRAUMATIC COMATOSE PATIENTS: ASSESSMENT OF BRAINSTEMI DAMAGE AND PROGNOSTIC IMPLICATIONS. E.Facco, A. Martini ${ }^{\circ}$, M. Zuccarellot, 11. Chiaranda, G. Trinciat, C.Ori,G.P. Giron. Institute of. Anaesthesiology and Intensive Care, Dept. of 0tolaryngo logy-sect. of Audiology ${ }^{\circ}$ and Dept. of Neurosurgery ${ }^{+}$, University of Padua, Italy.

Auditory brainstem responses (ABRs) were recorded and ana lyzed in 35 patients with severe head injuries, who were admitted to the intensive care unit: of the university of Padua over the last 12 months. The patients were selected as follows: a) age range from 15 to 60 years; b) presence of a supratentorial post-traumatic lesion and absence of primary brainstem damage at the CT scan; c) absence of temporal bone fracture at the X-ray skul1 films; ) absence of an anamnestic otologic pathology; e) normal canal otomicroscopy with normal tympanogram.

The level of consciousness was defined using the Glasgow Coma Score evaluation and the brainstem disfunction with a clinical assessment of brainstem reflexes and posture. The CT scan findings were classified in four grades, rela ting to the onset of descending transtentorial herniation The ABRS were recorded and analyzed many times according to the clinical evolution from the moment of admission to the final outcome. Patients who died from causes unrelated to the brain were excluded from the analysis.

The results show that a severe braintem disfunction, as defined by ABRs, is closely correlated with high mortality while a normal brainstem function is indicative of a good prognosis. ABR seems to provide more reliable information about brainstem damage than the neurological signs and is closely correlated with CT scan findings. Information from these techniques may thus supplement that obtained from clinical examinatior, allowing early prediction of final outcome.
PROGNOSTIC VALUE OF EARLY SOMATOSENSORY EVOKED POTENTIALS IN THE ACUTE STAGE OF POSTANOXIC AND TRAUMATIC COMA. D. Zegers de Bey $1^{1}$, S. Borenstein ${ }^{12}$, E. Brunko ${ }^{2}$. Dpt of Neurology', Hôpital' Erasme and Brain Research Unit ${ }^{2}$, University of Brussels, Belgium.

The prognostic value of somatosensory evoked potentials (SEPS) was evaluated soon after onset of coma secondary to brain anoxia, brain ischemia after cardiac arrest or head trauma. The SEPS were correlated with neurological state and SEPs were followed over several weeks in surviving patients. SEPs were elicited by unilateral stimulation of the median nerve at the wrist. SEPs were recorded at the wrist, Erb's point (N10), the neck (N15) and the contralateral parietal (P15 -N20-P25 complex) and frontal scalp regions using a Pathfinder II (8 channels) from Nicolet Biomedical. The analysis time was $50 \mathrm{msec}$. Our group of 30 patients with acute anoxic-ischemic brain injury showed that no patient with major abnormality of the N20-P25 complex recovered; they remained in a vegetative state and SEPS remained grossly abnormal. This predictive value of the abnormality of the N20-P25 complex is not found in the group of patients with acute head trauma. Major abnormality of the N20-P25 complex bi7aterally hours after trauma did not exclude recovery of higher cortical function after several weeks.

\section{6}

SHORT LATENCY MEDIAN NERVE SOMATOSENSORY EVOKED POTENTIALS AND EEG IN ACUTE ANOXIC COMA H. WALSER, H.M. KELLER, NEUROLOGISCHE KLINIK, UNTVERSITAETSSPITAL ZUERICH

21 patients in acute anoxic coma after cardiac surgery with cardiopulmonary bypass ( 9 patients), after cardiac infarction (7 patients), accidental anoxia during anesthesia (2 patients), hemorrhagic shock (1 patient), drowning ( 1 patient) and poising by furnes (1 patient) were examined with short-latency median nerve somatosensory evoked potentials (SEP) and EEG.

For the SEPs, the amplitude ratio $(R)$ between the first negative response recorded from the contralateral parietal scalp (N2O - P25) and the negative response from the neck at the level of C2 (N14), and the latency difference between the contralateral scalp response and the cervikal response (Central Conduction Time, CCT) were used as parameters. For the EEG, visual inspection was perfarmed only.

A significant difference of the mean value of $R$ was observed in the group of patients with anoxic coma with a measurable response, as compared to an age- and sexmatched group of healthy volunteers $(p<0.005$, T-test of the means). No significant difference of the CCT was found between the two groups. Furthermore a significant relation betwen the mean value of $R$ of the 2 hemispheres and the clinical outcome was also found $(p<0.002$, Fisher's exact probability test).

The only EEG pattern with a clearly dismal prognostic significance - other than the pattern of electrocerebral silence - were suppression bursts. Amplitude of the cortical SEP is therefore considered as the most promising prognostic parameter in acute anoxic coma. 
197

URAPIDIL VERSUS PROPRANOLOL IN THE MANAGEMENT OF POSTHYPOTENSIVE HYPERTENSION IN NEUROSURGICAL PATIENTS.

D.Heuser, H. Guggenberger, R. Schneble, J.Ebeling; Department of Anaesthesia, University of Tübingen, Tübingen, FRG

It is well known that rebound. hypertension following discontinuation of Sodiumnitroprusside can be hazardous and possibly outweigh the benefits of deliberate hypotension, mainly at neurosurgical interventions, thus emphasizing the necessity of an adequate posthypotensive therapeutic management. In a controlled clinical study we compared the effectiveness of Propranolol with that of a new antihypertensive drug Urapidil on 36 patients subjected to controlled hypotension in the course of neurosurgical interventions. In 24 patients intracranial interventions were performed, whereas 12 patients (volunteers) with lumbar disc operations served as controls. One half of each group was treated with either Propranolol or Urapidil pre- and intraoperatively, the desired hypotensive level was $66 \%$ of the control value. At certain intervals we neasured Flasma Renin activity, Catecholamines, free fatty acids, arterial blood gas tensions, electrolytes, hemoglobin, P.C.V., whereas MABP and endtidal $\mathrm{CO}_{2}$ were continuously recorded.

Results: 1. Posthypotensive hypertension following discontinuation of SNP may be due to increased levels of P.R.A. and Catecholamines. 2. In the control group Urapidil was more effective than Propranolol in prevention of hypertension. 3. Urapidil considerably reduces the required amount of SNP. 4. Drug intracranial interventions both drugs were equally effective and prevented hypertensive reactions in $65 \%$ of all cases.
198

CEREBRAL TISSUE ACIDOSIS DURING SODIUMNIIROPRUSSIDF-INDUCED HYPOTENSION AND ITS PREVENTION BY THIOSULPHATE.

H.Guggenberger, D.Heuser, P.J. Morris* , Departments of Anaesthesia, Universities of Tübingen (FRG) and Leeds* (UK)

Sodiumnitroprusside (SNP) may be regarded as drug of choice to electively induce arterial hypotension, especially when very low levels of systemic blood pressure (MABP) are desirable. However recent animal studies have indicated a progressive development of cerebral e.c.f. acidosis during administration of the drug even when normal CBF values are maintained and the critical dosage of SNP is not exceeded. In order to elucidate whether this acidosis is due to cerebral cyanide intoxication, we tried to prevent development of e.c.f. acidosis by simultaneous administration of thiosulphate in 8 cats out of 19 animals subjected to controlled hypotension with SNP. E.C.F. $\mathrm{pH}$ was measured continuously with $\mathrm{pH}$ microelectrodes implanted in the cerebral cortex of the animals. In both groups of animals MABP was lowered to $30 \mathrm{mmHg}$ for 30 minutes, followed by a period of 15 minutes with 28 mmHg. The results indicate that at SNP dosage of $<1 \mathrm{mg} / \mathrm{kg}$ severe e.c.f. acidosis develops directly after the onset of SNP administration which can be prevented completely by thiosulphate treatment. In the thiosulphate group development of e.c.f. acidosis did not start before MABP was lowered to $50 \mathrm{mmHg}$. We conclude that during SNP administration to electively induce arterial hypotension the simultaneous administration of thiosulphate is necessary to prevent cerebral lactacidosis, even when the "critical"SNP dosage is not exceeded. 
NDSDCDMIAL INFECTIONS IN PATIENTS WITH SEVERE HEAD INJURY. Margaret HEMMER \& Rabert HEMMER, Departments of Surgical Intensive Care and of Infectious Diseases. Centre Hospitalier Luxembourg - LUXEMEDURG.

We studied retrospectively 91 consecutive patients with severe head injury (Glasgow coma scale 3 to $B$, most under 6 ) to determine the incidence and the autcome of infection and the value of prophylactic antibiotics. Mean age was 32 years ( range 1-76); all patients had corticosteraid treatment and 45 were induced to barbiturate coma far ICP control. 57\% received prophylactic antibiotics, mostly Penicillin G, sometimes in association with Gentamicin. 45 patients ( 32 with prophylactic antibiotics and 13 without) had one or more episades of infection. Types of infection were: 27 Septicemias, 22 urinary tract infections, 14 Sinusitis, 11 early Pneumonias, 3 late Pneumonias, 3 Meningitis, 3 otitis, 2 Wound infections. Microorganisms responsible for severe infections (i.e. septicemia, pneumania and meningitis) were: 9 S.epidermidis; 6 Streptococcus faecalis; 6 E.coli; 5 S,aureus; 5 Pseudomonas sp. (among them one P.maltophilia); 5 Proteus sp.; 1 Bacteraides fragilis; I Acinetobacter calcoaceticus var. anitratus; I Flavobacterium sp.; 1 Corynebacterium "group J K "; 1 Candida albicans. In 12 patients infection was leading to death. All microorganisms responsible for severe infection were resistant to the prophylactic antibiotics administered.

we conclude (1) Nosocomial infection occured in $49 \%$ of our patients with severe head injury. (2) Prophylactic antibiatics did not prevent infection. (3) The high proportion of opportunistic and often multiresistant microorganisms ( S.epidermidis, P. maltophilia, Acinetobacter sp., Flavobacterium sp., Corynebacterium " group J K ", Candida albicans) suggest that severe head trauma patients are compromised hasts at high risk far nosacomial infections.

PULMONARY ARTERY CAIHETER-RELATED SEPSIS. W. Kaye, M. Wheaton, G. Potter-Bynoe. Brown. University-The Miriam Hospital, Providence, Rhode Island, U.S.A.

Several reports have documented that the risk of catheter (cath)-related sepsis for intravenous caths increases after 3 or 4 days (d) of cannulation. However, there is a paucity of data examining the relationship between duration of cannulation and cath-sepsis from pulmonary artery (PA) caths. The purpose of this study was to determine the overall incidence of PA cath-related bacteremia and the relationship between length of time in place and incidence of infection. From March through August, 1982, $239 \mathrm{PA}$ caths were inserted. All were followed prospectively, but complete data were available for $120 \mathrm{PA}$ caths (in 107 patients) which were inserted percutanecusly into internal jugular or subclavian vein. A rigid protocol was followed to provide aseptic technique for PA cath insertion, inspection and care of insertion site every 48 hours, and removal. After removal, the excised cath tip was rolled across a blood agar plate which was then incubated at $37^{\circ}$. All colony types were enumerated and identified. Following the criteria of Maki et al, 15 or more colonies (pos cult) were considered to signify infection. Cath-related bacteremia was determined by isolating the same organism from the blood.

The incidence of pos cult was $9 \%(11 / 120)$. Non-fatal bacteremia occurred in $2.5 \%(3 / 120)$ overall or in $27 \%$ (3/11) pos cult. The incidence of pos cult relative to duration of cannulation was: $1 \mathrm{~d}, 2.5 \%(1 / 40) ; 2 \mathrm{~d}, 2.9 \%$ $(1 / 35) ; 3 \mathrm{~d}, 21 \%(4 / 19) ; 4 \mathrm{~d}, 0(0 / 8) ; 5 \mathrm{~d}, 11 \%(1 / 9)$; $6 \mathrm{~d}, 40 \%(2 / 5)$; more than $6 \mathrm{~d}, 50 \%(2 / 4)$. The incidence of pos cult for 2 days or less was $2.7 \%$ (2/75) vs. $20 \%$ (9/45) for three days or longer.

We conclude: (1) there is a real risk of infection (9\%) and bacteremia (2.5\%) for pulmonary artery catheters;

(2) after 2 days in place, the risk of infection

increases sevenfold.
SEVERE ACUTE PNEUMONIAS AND CYTOMEGALOVIRUS (CISV)

J.J.Lehot, Y.Page, D.Perrot, B.Delafosse, C.Guil taume, J.C.Tardy, B.Bui Xuan, J.Motin - Service de Réanimation Hôpital E.HERRIOT - F 69374 LYON CEDEX 2

We studied, between october 1980 and august 1982, 18 cases of pneumonia which required mechanical respiration and in which CMV was involved. Antibody titers were deter mined by complement fixation, immunofluorescence and ELISA (IgG and IgM for the last two methods). In most of the patients, a check-1ist for pneumonia in immunocompromised patients was realised by means of bronchic endoscopy (bacteriology, Myco-bacterias, Pneumocystis, Mycoplasma, Chlamydia, Legione1la, mycology, virus). Cliv were isolated on human embryonic lung diploid cells.

Nearly all the patients had underlying diseases (hematologic diseases, marrow transplantations, Tung or heart transplantation, plasmocytom, systemic lupus erythematosus, great obesities, chronic respiratory failures, carci nologic or vascular surgery, intestinal amibiasis). The chest x-ray often showed a bilateral alveolar pattern, an intersticial pattern was seen in 28 per cent. Pulmonary pathologic findings showed cytomegalic inclusions cells in 2 of 3 cases, and once in myocard. ELISA method had the best sensitivity, but 6 of 11 patients in which CMV was isolated in the lungs presented no seroconversion. Other infecticias diseases were associated in 10 patients. 11 patients finally died. The average duration of mechanical respiration was 5 weeks in the survivors. This study emphasizes the role of CIV in severe pneumonias, often associated with other pathogens. We underline the usual absence of specific symptoms and frequent negative serologies in immunocompromised hosts.

THE RELATION BETWEEN BUCCO-PHARYNGEAL FLORA AND INFECTIOUS PNEUMONIA DURING MECHANICAL VENTILATION IN I.C.U. PATIENTS

C. GRANTHIL, S. VALERO, T. FOSSE, J.L. BLANC, M. ALAZIA, Dep. Anesth. Réa. (Pr.G. FRANCOIS) G.H. La Timone, 13385 Marseille, France.

Bronchopulmonary infection is known as being the most frequent complication of mechanica? ventilation. The predisposing factors for superinfection are numerous and well documented. However the initial localisation of these germs cannot always be determined. Seventeen tracheotomized patients were studied in order to examine the relationship between cro-pharyngeal flora and broncho-puimonary secondary infections. All the patients were mechanically ventilated for reasons other than pulmonary infection. Buccal, pharyngeal and bronchial samples were collected with in 24 hours of tracheotomy. During the study-period 9 patients developed secondary pneumonia as defined by clinical, biological and radiological criteria. The results show: 1) a colonisation of the buccopharyngea 1 cavity with a high prevalence of negative gram bacilli 2) an early tracheo-bronchial colonisation by at least one the oro-pharyngeal germs in 16 out of 17 patients.

3 ) that the germ held responsible for the superinfection in the 9 cases of secondary pneumonia was always present in the initial buccopharyngea? samples Proteus: 3 ; Klebsiella: 2 ; E. coli: 1; pseudomonas Aer.: 1 ; enterobacter: 1 , Serratia: 1 ). Given the above circumstances, it is reasonable to perform an initial clinical exam as well as systematic bucco-dental and nasopharyngeal care in order to reduce local bacterial growth. 
VALUE OF EARLY BACTERIOLOGICAL EXAMINATIONS FOR THE MANAGEMENT OF SYNERGISTIC BACTERIAL GANGRENES. Fichelle A., Mourlon M., Scardin A., Orsoni J.L., Desmonts J.M. Synergistic bacterial infections are involved in most ex tensive cellulitis occuring in patients treated by routine antibiotherapy. This study was performed to evaluate the value of early bacteriological diagnosis and adequate anti biotherapy $(A B)$, on the prognosis.

Patients and methods. Eighteen patients with extensive gan grene were studied ( 12 men 6 vomen). Mean age was 57 years (24-82). Eleven patients had signs of systemic toxicity ; mecchanical ventilation was required in 11 patients. Anuric renal failure observed in 1 patient was treated with hemodialysis. According to the location of gangrene, patients vere divided in 4 groups : perineal (8), abdominal wall (2), limb (6), neck (2) cellulitis.

Results. Eleven of 18 patients had been treated before ad mission with penicilline $G$ associated with imidazole deri vate $(n=9)$ and aminosides $(n=6)$. Four patients developped cellulitis despite treatment with ampicillin. Bacteriolo gical examinations on admission was negative in 3 patients; only gram negative stains (GNS) vere isolated in patients having antianaerabic prophylaxis $(n=4)$; GNS were associated with different types of streptococci $(n=6)$. Staphyloco cci were observed in association with different types of streptococei $(n=3)$, GNS $(n=1)$; in one patient, D. Strept. was associated to $\mathrm{Cl}$. perfingens. Specific antibiotics according to bacteriological results stopped gangrene ex tension in all patients. Four patients died; the death was related to the septic shock in two patients and to other cause in two patients.

Conclusions. Early identification of microbial agents involved in synergistic-bacterial gangrene has likely played a major role in the management of these severe infections. Specific antibiotherapy associated with surge ry may improve significantly the prognosis of these infec tions.
THE USEFILNESS OF SKIN TESTS IN AN INTENSIVE CARE UNIT. P. DAlAAS, Dnt of Anesthesia, Hosp.Baviēre, University of Liège, Bèlgium.

One hundred and six traumatized or post suraical patients admitted to our intensive care unit were followed weekly by skin tests with three types of antiaens (PPD, candidin, varidase). Anergy is defined as no reaction to any of the three antigens while reactivity is defined as one or more nositive reactions. The factors related to anergy are : older age, renal failure, major sentic complications, lenght of hospital stay and death. More interesting the outcome of the batients according to their skin test reactivity : of the 56 reactive natients at the beginning of the study, 61 remained nositive and 4 of them died; among the 5 natients who became anergic 4 died. Of the 40 anergic natients, 26 remained anergic during all the study and there were 17 deaths; among the 14 natients who became reactive only 2 died.

66 reactive 61 reactive; 4 deaths $(6 \%)$

5 anergic; 4 deaths $(80 \%) \quad p<0.01$

40 anergic 25 anergic; 17 deaths $(65 \%) \quad 0<0.01$

Those anergic who became reactive, had a good outcome comnared to those who stayed nositive during all their $i$ Thess Among the factors which influence the skin tests reactivity, we retain the caloric intake : the anergic patient had a mean caloric intake of $25.5 \mathrm{kca} / \mathrm{kg}$ day, combared to a mean of $41.2 \mathrm{kcal} / \mathrm{kg}$ day for those who recovered a nositive reaction. Other factor will be discussed.

In conclusion, the repetition of skintests allowed us to evaluate the efficacy of treatment particularly caloric intake and to pick un the high risk natients in the intensive care unit.

\section{4}

ELECTROMYOGRAM (EMG) AS DIAGNOSTIC AID IN TETANuS. H.P. Ludin, F. Roth, University Hospital, Berne, Switzerland

In developing countries tetanus is still a real problem in respect to both occurence and mortality rate. In all countries with high medical standard it has become an uncommon disease. In our own hospital the number of tetanus cases per year has decreased from $10-12$ in the sixties to $2-3$ in the last three years. Because of this relative rarity, very few clinicians see more than an occasional case. The diagnosis is therefore often missed or recognized quite late as it is still based on clinical observation only. Till now no laboratory or other test is accepted, although various suggestions have been made. The problem of diagnosis is further complicated because cases of pseudotetanus are occasionally seen. Since 1978 we have taken EMGs in all patients who were suspect for tetanus but whose case history or clinical symptoms left some doubt. In 6 cases the EMGs were typical for tetanus with a shortening or absence of the silent period after a stretch reflex or after supramaximal stimulation and with a continuous activity of motor units which could not be influenced voluntarily. In two patients we found a normal EMG. In all 8 cases the acuracy of the electromyographic diagnosis of tetanus was confirmed by the further development of the disease. Therefore we think that Electromyography is a very useful and reliable tool either to confirm or to rule out the diagnosis of tetanus.

\section{6}

IMMUNOLOGICAL ASPECTS IIN SERTOUSLY TRAUMATIZED PATIENTS. F. Murillo, M.A. Munoz, A. Nunez, C. Ortiz-Leyba, Ciudad Sanitaria Virgen del Rocio, Seville, Spain.

Immunodeficiency has proved to play an important role in the outcome of critical patients. The present communication will investigate, in a prospective manner, the sensitivity and precocity of the different parameters measuring the immunological competence, as well as its changes as an indez of septic risk.

Nineteen patients were studied. All of them were seriously traumatized (multiple trauma or head injury). Within the first 24 hours, they were submitted to the following: Skin testing (ST), T lymphocytes, B lymphocytes, total lymphocyte count, and total hemolytic comolement (CH50). In a sub-group of seven patients, the same study was repeated a week later.

The results showed that $\mathrm{T}$-rosettes was an useful method for prediction on septic risk $(p 0,05)$ as ST were, but with more promptness and statistic significance $(p 0,01$ versus 0,05$)$. CH50, B lymphocytes and total lymphocvte count were not specific as an index of evolution nor of septic death or complications.

As a conslusion, the determination of T-rosettes has proved to be, in this group of patients, a valuable test, higher than $\mathrm{ST}$, as a prognosis of septic complications and as a rapid checking of immuno-competence state associated to high risk. 


\section{Infection in the ICU}

207

BACTERIOLOGIC DIAGNOSIS OF NOSOCOMIAL PNEUMONIA IN VENTILATED PATIENTS. A. Bouchama, A. Akesbi, J. Plerre, P. Brun, F. Viau, J. Chastre and C. Gibert. Réanimation Médicale, Hôpital Bichat, Paris, France

To determine the relative cultural accuracy of protected nosocomial pneumenia of ventilated patients, we compared this method with histological and bacteriological examination of pulmonary specimen. The procedures were made just after death when ventilatory supply was still in place. Samples via the PSB were taken into a branch of the anterior basal bronchus of the left lower lobe. Immediate left thoracotomy was performed to obtain 6 peripheral specimens from the corresponding segment. Bacteriological specimens were eventually crushed, vortexed vigorously in $1 \mathrm{~mL}$ of medium and quantitative cultures performed. pneumonia was associated with pulmonary culfure $>10^{4}$ cfu per g. A correlation between PSB and lung cuttures was showed $(r=0.57 ; p<0.01)$. For patients ventilated less than 10 days, a better correlation was found $(r=0.71 ; p<0.001)$. With a threshold of $10^{3}$ cfu per $\mathrm{mL}$ for PSB cuantitative cultures, no false negative results were observed for the 26 patients and for the 55 microorganisms. With a threshold of $10^{4}$ cfu per $\mathrm{ml}$, false positives were only $25 \%$, but false negatives were observed (17\%). We conclude that culture results obtained by PSB should be useful in differentiating bacterial colonization of the airways from pneumonia in ventilated patients in the presence of diffuse pulmonary infiltrates. specimen brush (PSB) through a flexible bronchoscope in

26 patients were studied. Histologic evidence of

\section{9}

PREDICTION OF SEPTIC SHOCK UNEAVOURABIE OUTCONE V.A.Gologorsky, B.R.Gelfand, V.E. Bagdatjer, A.J. Schichov, I.J.Lapschina. 2-nd Moscow Medical Institute, Moscow, USSR.

A comparative analysis of different physiological parameters was made for prediction of outcome in 116 patients with septic shock due to peritonitis.

Indicator dilution method, intravascular pressure measurements, blood gas analysis and policardiogram were used to investigate hemodynamic and oxygen transport parameters. Cardiac performance was estimated by rolume loading and drawing starling curves.

Blood volume and arterial pressure did not vary in survived and nonsurvived patients during intensive care.There was significant difference in pulmonary arterial pressure and resistance which increased in nonsurvived patients and remained higher than normal up to the lethal outcome. The most considerable difference was marked in cardiac output, left and right cardiac work, and heart performance index. These parameters are considerable lower in nonsurvi vers at all stages of the investigation. Accorm ding to received date unfavourable outcome prediction or death risk indices were as fgllom wing: cardiac index less than $4 \mathrm{~L} / \mathrm{min}$. $/ \mathrm{m}^{2}$; left cardiac work less than $6 \mathrm{kgm} / \mathrm{min}$; right cardiac work less than $1,2 \mathrm{kgm} / \mathrm{min}$; total rascular resistance higher than 2000 dynes $/ \mathrm{cm}^{2} / \mathrm{sec}^{5}$; pulmonary vascular resistance higher than 200dynes/ $\mathrm{cm}^{2} / \mathrm{sec} 5 ;$ slope of ventricular performance curve less than $0,15 \mathrm{~L} / \mathrm{min} . / \mathrm{m}^{2} /$ topr; arterial $\mathrm{pO}_{2}$ less than $70 \mathrm{~mm} \mathrm{Hg}$; arterial-venous gradient of oxygen content higher than $5 \mathrm{ml} / 100 \mathrm{ml}$; oxygen availability less than $400 \mathrm{ml} / \mathrm{min} . / \mathrm{m}^{2}$; oxygen extraction higher $\tan 40 \%$.

211

MICROBIOLOGICAL VALUE OF SELECTIVE STERILE BRUSH CULTURE IN ACUTE RESPTRATORY FAILURE. E. Quintana, A. Roglan, J. Vazzés, S. Amengol, J. Castezla, C. Puzo, V. Ausina, A. Artigas. I.C.U. Hospital de La Santa Creu i Sant Pau. Barcelona. Spain.

Due to controversy in the miarobiological diagnosis of pulmonary infection (PI), the following prospective study was made.

METHODS: 30 selective bronchofiberscopic aspirations with double zumen Barlett catheter (BAB), were made in 28 mechanically ventilated patients with clinically demonstrated respiratory infection. Bacterial cultures of lower respiratory tract samples with $B A B$ and tracheal aspirates (TA) were compored. Blood, urine and respirator-air oultures were made simultaneousty. Studies were repited every 4 days when PI persisted.

RESULTS: Mean number of microorgonisms par sample was $0,83 \pm 0,65$ in $B A B$ and $1,73 \pm 0,37$ in $T A$. (p < 0.001$)$. The microbiological culture of $B A B$ scomples was positive in 70\% of cases, with monobacteriat culture in 66,6\%. Microbiological results of $B A B$ and TA were identical in $33,3 \%$ and partialty coincided in $52,3 \%$; a total difference was observed in 3 cases. The Grommegative microorganisms predomined (84,6\%: Pseudomonas spp and Serratia). Only. $11,5 \%$ were Grom positive and 3,8\% Candida spp. The biood cultures were negative in all cases and respiratory-air cultures were positive en 3 cases. These date were related to duration of mechanical ventilation and radilogic pattern.

CONCLUSTONS: BAB is a more selective technique in the diagnosis of $P I$ in patients with acute pulmonary faizure.
INTENSIVE THERAPY AND RESUSCITATION OF SEPTIC SHOCK. I.F.KOsonogov, V.N.Rodionov, Medical Institute, Voronezh, USSR. The efficiency of hemosorption and subsidiary circulation with extracorporal oxygenation was studied in 32 patients with septic shock. Signs of the liver and kidneys diaseases, high plasma toxicity, homeostatic disorders were revealed by clinical and laboratory findings. Before bemosorption sanative operations were performed to all the patients, and they received conventional intensive therapy without positive results. Hemosorption gave a marked cinical and laboratory effect in alI observations. In 12 patients with marked hemodynamic disorders hemosorption was carried out by subsidiary circulation with blood oxygenation from the vein into the artery. Stabilization of the general state normalization of the functions of the liver and kidneys sharp decrease of plasma toxicity were clearly observed after the given therapy. 30 patients out of 32 recovered. Hemosorption has a great detoxicologic effect with intensive therapy of septic shock. 
ENDOCRINOLOGY OF THE CRITICALLY ILL . A. Luger, H.Graf, R. Prager, it.K.Stummoll, M. Weissel Departement of MedicineII, University of Vienna Vienna, Austria

Hormonal status of prior untreated patients admitted to the intensive care unit were evaluated

Stress hormones (cortisol, prolactin, growth hormone), thyroidal hormones (T4,ETR, TSH) and the renin-angiotensin-aldosterone system were studied by RIA in 15 pts with various underlying acute diseases.Patients with abnormal serum-elec trolytes or blood glucose were excluded.

Stress hormones: As anticipated cortisol and prolactin levels were elevated(cortisol 40,97士 $20,39 \mathrm{ug} / \mathrm{dl}($ (normal 6-19 ug/d1)) prolactin 59,6+ $32,4 \mathrm{ng} / \mathrm{ml}$ ( (normal range1-25 ng/dl)). Growth hormone levels were not elevated in our pts $(1,43 \pm 1,02 \mathrm{ng} / \mathrm{ml}$, normal range $1-5 \mathrm{ng} / \mathrm{ml})$. Thyroidal hormones:T4, ETR, TSH were normal in all pts. (T̄ $\overline{4}, \overline{3} \overline{5} \pm \overline{3}, 57$, normal $4,4-14,4$ ug/dl;ETR $0,98 \pm 0,14$, normal $0,87-1,13$; TSH $4,57 \pm 1,03$, normal -6uU/mi) Thus at adnittance the pts did not show the well known "lowT3, T4-syndrom"

Renin-angiotensin-aldosterone.system: All levels of this system were in the normal range (renin $1,7 \pm 0,91 \mathrm{ng} / \mathrm{ml} / \mathrm{h}$, normal $0,1-2,62 \mathrm{ng} / \mathrm{ml} / \mathrm{h}$; angiotensin II 17,23+ 5,71 og/ml;normal $8-25 \mathrm{pg} / \mathrm{ml}$; aldosteron $143 \mp 80,7 \mathrm{pg} / \mathrm{ml}$, normal $30-150 \mathrm{pg} / \mathrm{ml}$ ). Thus the prior described state of hyperreninemic hypoaldosteronismus was not present in our pts at admittance to the intensive care unit.

Abnormalities in stress hormones are an early finding in intensive care unit patients, whereas changes in thyroidal hormones and the renin-angi otensin-aldosterone system either develop later in the course of severe illness or are the consequence of therapeutic interventions.

\section{3}

HYPUADRENALISM IN ACUTE STRESS. W.E.I.Finlay, J.I.McKee. Western Infirmary, Glasgow, U.K.

Adrenocortical hypofunction is not uncommon in critically ill patients and daliy serum cortisol measurements may have prognostic importance. ${ }^{1}$ In a previous study of 132 patients 34 who had cortisol levels remaining $<350 \mathrm{nmol} / 1$ all died. This report refers to a trial of replacement therapy in cortisol deficient patients. Using a radioimmuno assay (Corning], daily $08.00 \mathrm{~h}$ serum cortisol measurements were made an 70 consecutive patients, who were allocated randomly to one of 2 groups. 18 (25.7\%) patients had cortisol values below the critical level of $350 \mathrm{nmol} / \mathrm{l} .1212$ of these had 1-hour adrenal stimulation tests using synthetic corticotrophin. All tests were negative. All patients received treatment appropriate to their conditions but additionally patients in group 2 received hydrocortisone replacement while group 1 acted as controls.

Results: 18 patients 08.00n cortisol $<350 \mathrm{nmol} / 1$.

$\begin{array}{cccc} & \text { No. of patients } & \text { Hydrocortisone } & \text { Died } \\ \text { Group 1 } & 10 & \text { No } & 9 \\ \text { Group 2 } & 8 & \text { Yes } & 1\end{array}$

Difference between outcome $P<0.002$

It is concluded that cartisol replacement therapy may be beneficial in some severely stressed patients. The duration course and aetiology of the observed adrenocortical insufficiency will be discussed.

1. FINLAY, W.E.I. MCKEE, J.I. Serum cortisol levels in severely stressed patients. Lancet 1982 i 1414.
Acute Poisoning.A comparison of experiences in 1971 and 1981. D.GILLMANN, M.REUSS, L.S.WEILEMANN, H.P.SCHUSTER II. Medizinische Universitätsk linik Mainz.

Methods and patients: 330 cases of acute poisoning were treated in 1971 and 340 in 1981 . Patients were compared in respect to biosocial data, incorporated poisons, severety of intoxication and treatment.

Results: The ratio of female to male pat. varied from $1.25: 1(1971)$ to $0,8: 1(1978)(p<0,01)$. Alcohol intoxication increased significantly in $1981(p<0,01)$ wheras clinically treated hypnotic drug intoxications decreased. Severety of intoxication was judged by 7 parameters: loss of consciousness, loss of pain reaction, circulatory arrest and/or respiratory faiTure, areflexia, arterial hypotension $\operatorname{SAP}<90 \mathrm{~mm} \mathrm{Hg}$, hyperglycemia $>200 \mathrm{mg} / \mathrm{dl}$, artificial respiration. 2 or more of theses parameters were present in 27 (1971) and 33 (1981) pat. and the numier of pat. with more than 3 parameters increased significantly. of the most severe intoxicatians $9 / 27$ (1971) resp. 15/33 (1981) were due to barbiturates. In $197139 \%$ of pat. were treated in the ICU, in 1981 only $15 \%(p<0,01)$. There was no significant difference in frequence of unconsciousness, loss of pain reaction, areflexia, light reaction of pupils, arterial hypotension and hypothermia, but pat. with heart rate $<80 / \mathrm{min}$, circulatory arrest, respiratory failure, artificial respiration were more frequent in 1981 ( $p<$ $0,01)$. Gastric lavage was performed in $80 \%$ in both periods, forced diureses decreased from $48 \%(1971)$ to $13 \%$ (1981) $(p<0,01)$. Extracorporeal hemodialys is and hemoperfusion was performed in 11 pat. in 1981. Globale mortality was less than $1 \%$, mortality in the ICU was $2 \%$ (1971) resp. $6 \%$ (1981) (n.s.). The mean duration of stay in the ICU increased from $2.2 \pm 3.1$ (1971) to $5.5 \pm 8.1$ days (1981) $(p<0,01)$. Conclusions:The poputation of clinically treated pat. with acut poisoning varied in resp. to an increased rate of alcohol intoxication and of very severe intoxications with cardio-respiratory-metabolic failure with a high rate of barbiturates, a decrease of forced diureses, a stronger selection of pat. for the ICU. Mortality re-

\section{5}

HEMOFILTRATION IN ACUTE RENAL FALLURE (ARF).J.Feret, N.Simon, J.Verrier, $O$.Simons, D. Duruy and $F$. Nouail hat. Réanimation et Urgences médicales, CHI POISSY, 78303 , France.

Twenty-two courses of hemofiltration( $\mathrm{HF}^{\mathrm{l}}$ ) were assessed in ten patients with ARF(mean age 65 years; range 38-79). The initial affection was peritonitis in 3 , pancreatitis in?, ARDS in 2 and septicemia in 2 patients. The rotation speed of the three pumps used during $\mathrm{HF}$ was either electronical1y monitored or manuelly adjusted according to lost and reinjected volumes. Thirteen hollow-fiber polyacrilonitrile filters were used (ASAHI Pan 20). Post-dilution reinjection fluid was buffered with lactate $(35.75 \mathrm{mM} / \mathrm{I})$ in 18 courses and alternate lactate/acetate in 4. The vascular access was femoro-femoral ( 16 courses), subclavian-femorel( 4 ) and a double-lumen venous catheter in 2 patients.Through. high. blood-flow $21.5 \pm 5.41$ were exchanged in a mean time of $229 \pm 70 \mathrm{~min}$ and with a mean filtration rate of $95.5 \pm 24 \mathrm{ml} / \mathrm{mn}$. Table 1 reports weight loss $(W)$ and extraction of urea(U) creatinine $(C)$, aminosides $(A)$, mezlocillin $(M)$ and vancomycin $(V)$

\begin{tabular}{|c|c|c|c|c|c|c|}
\hline & $\mathrm{W}(\mathrm{kg})$ & $\mathrm{J}(\mathrm{mM})$ & $\mathrm{C}(\mathrm{mM})$ & $\mathrm{A}(\mathrm{mg})$ & $\mathrm{M}(\mathrm{g})$ & $\mathrm{V}(\mathrm{mg})$ \\
\hline $\mathbf{n}$ & 22 & 19 & 13 & 5 & 4 & 1 \\
\hline $\mathbf{\mathrm { m }} \pm \mathrm{SD}$ & $3.05 \pm 2$ & $655 \pm 270$ & $9 \pm 5$ & $24 \pm 4$ & $3.56 \pm 2.64$ & 200 \\
\hline
\end{tabular}

Table 2 shows plasma values measured before $\left(T_{0}\right)$ and after $\left(\mathrm{T}_{1}\right) \mathrm{HF}$.

\begin{tabular}{|c|c|c|c|c|c|c|c|}
\hline & $\mathrm{Na} \mathrm{mM} / \mathrm{l}$ & $\mathrm{K} \mathrm{mM/1}$ & $\mathrm{Ca} \mathrm{mM/1}$ & $\mathrm{P} \mathrm{mM} / 1$ & $\bar{U} \operatorname{ms} / 1$ & C. $\mu \mathrm{M} / \mathrm{l}$ & Prot 1 \\
\hline$T_{0}$ & $132 \pm 6$ & $4.5 \pm 08$ & $2 \pm 0.4$ & $15 \pm 08$ & $39 \pm 8$ & $420 \pm 217$ & $56 \pm 7$ \\
\hline $\mathrm{T}_{1}$ & $134 \pm 5.5$ & $3.6 \pm 0.7$ & $2.3 \pm 0.3$ & $1,08 \pm 0$. & $25 \pm 5$ & $257 \pm 127$ & $64 \pm 7.5$ \\
\hline
\end{tabular}

Conclusion:HF with high blood-flow is adequate for metabolic adjustment and water depletion in $A R F$ in intensive care patients. Antibiotics removal was high even for vancomycin, a non-dialysable substance 
USE OF TAUROLINE AND DOPAMINE OR DOBUTAMINE IN DHOCKED HYPOVOLEMIC RATS. PG.WASER, E.SIBLER, Pharmakologisches Institut, Universität Zürich.

Tauroline is applied intravenously as a chemotherapeutic in infections and septic cases. A hypothetic interaction of injected tauroline on the hypertensive effect of dopamine or dobutamine was tested in hypovolemic rats and compared with an injection of saline instead of taurolidine. The blood pressure was lowered in WISTARrats by reducing the blood volume by $1 \mathrm{ml}$ within 1 minute. The blood pressure was continuously measured with a Statham biood pressure transducer connected to a cannula in the carotid artery and recorded on a Beckman Dyonograph. 4 rats received 3 minutes after the artificial blood pressure decrease $0,6 \times 10^{-6}$ mol dopamine, followed by an infusion of $2 \mathrm{~m} 1$ Taurolin $\mathrm{B} N \mathrm{NaCl}$ or $2 \mathrm{ml}$ saline within 7 minptes. 4 rats received an infusion of $0,6 \times 10^{-5}$ mol and 2 ml Taurolin (2) $2 \%$ or saline simultaneously. These procedures were repeated several times with the same rats. In a 11 experiments, there was no significant difference in the sympathomimetic effect of dopamine. 2 hypovolemic rats reveived $0,7 \times 10^{-6}$ mol dobutamine, followed by $2 \mathrm{ml}$ Taurolin $(\mathbb{Q}$ NaCl or saline. 2 rats received an infusion of $0,7 \times 10^{-6}$ mol dobutamine and $2 \mathrm{ml}$ Taurolin 8 . $2 \%$ or saline simultaneously. In these experiments, taurolidine even increased the pressure action of dobutamine when injected simultaneously. Therefore it must be concluded that taurolidine has no depressive effect on the vasopressive action of dopamine and shock cases. It was also shown in previous experiments, that there are no interactions of taurolidine with some other biogenic amines as epinephrine, noradrenaline or histamine.

\section{7}

THE TNFLUTHCE OF TAUROLIN ON THE HAFMODYNAVIC EF'FECTS OF DOPAMINE. M.K. Browne, Monklands District General Hospital, Airdrie, Glasgow, Scotland.

Taurolin is a chemotherapeutic agent with antiendotoxin properties which can be administered intravenously (IV) or intraperitoneally (IP). It is specially indicated in the treatment of peritonitis and septic shock. In vitro, it reacts with Dopamine to inactivate it. It has been recommended that the two drugs should be used al ternately in two hour cycles. This sequence is not appropriate in the clinical care situation. Experimentaliy this has been tested by studying nine dogs anaesthetised and ventilated. Measurement of pressure was by a transducer placed in the right femoral artery, renal blood flow was measured by a Stathan guage in the left renal artery and urinary output by a catheter in the bladder. These were recorded simul taneously on a Polygraph (Gould ES 1000). Dopamine was infused in a dose of $6.25 \mathrm{Ug}$. $\mathrm{Kg}^{-1}$ min $^{-1}$ for 8 hours. Taurolin $2 \%$ in Nafl $0.45 \%$ was infused in a dose of $15.37 \pm 1.58 \mathrm{mg} . \mathrm{Kg}^{-1}$ $\mathrm{b}^{-1}$ for 6 hours commencing one hour after the Dopamine infusion. A control group was given a saline infusion in place of Thurolin. Taurolin did not significantly alter the pressor effects of Dopamine or its effects on the kidney. Clinically five patients with septic shock who were requiring Dopamine infusions were given Taurolin in addition. Two patients received $200 \mathrm{~m}$ ? of $2 \%$ Taurolin b.d. intraperitoneally while three received $250 \mathrm{ml}$ of $2 \%$ Taurolin intravenously over 2 hours twice daily. In none of these cases was there any loss of the alpha or beta adveregic action of the Dopamine.

From these animal and clinical results it is concluded that there is no contra-indication to the simulaneous administration of these two valuable drugs in the intensive care situation.
INTENSIVE CARE IN DEVELOPING COUNTRIES: "CUI PRODEST"? A.Gasperi, Maputo Central Hospital, Maputo, Peoples' Republic of Mozambique.

Intensive Care Medicine still represents a "novelty" in most developing countries, because other priorities have to be dealt with by local health authorities, and because of the need of very expensive investments. Nevertless, within the frame of projects of technical cooperation between industrialized and developing countries, some attempts have been made to establish and, where already existing, to ameliorate projects in the field of intensive care medicine. The Author, after a five years service, spent as responsible of projects of technical assistance in intensive care and anaesthesiology, in african developing countries, comments in the present paper the following points:

- definition of intensive care: possibilities and limits in developing countries.

- practical aspects linked with the speciality, such as teaching, training, type of technology needed.

- priorities which should be taken in consideration when planning projects of technical aid. - costs versus benefits analysis.

Finally, on the basis of previous experience, the Author presents some suggestions to those, (institutions, aid organisms)who might be interested in projects of technical cooperation with developing countries in intensive care medicine.
219

Antipyretic therapy with Diclofenac Sodium in ICU patients. Effects and side effects of $100 \mathrm{mg}$ suppository versus $0.2 \mathrm{mg} / \mathrm{kg} . \mathrm{m}$. Zandstra D.F., Stoutenbeek Ch., Miranda D.R. ICU University Hospital, Groningen, The Netherlands.

Diclofenac sodium $100 \mathrm{mg}$ suppository proved to be a potent antipyretic drug. However severe side effects: oligo-anuria and protractive shock necessitating increasing amounts of i.v, fluids and dopamine, make this drug in this dosage unsuitable for use in ICU patients. Whether these effects were dose related or not we studied the effect of $0,2 \mathrm{mg} / \mathrm{kg} \mathrm{bw} \mathrm{i.m.} \mathrm{in} 8 \mathrm{ICU}$ patients. Antipyretic effect, as were bloodpressure diuresis and therpeutic measures of both groups were compared.

In both groups this drug proved to be a potent antipyretic drug. However dose related effects could be observed. Significant decrease in bloodpressure was observed up to $6 \mathrm{hrs}$ in the suppository group, as in the $0,2 \mathrm{mg} / \mathrm{kg}$ group only in the first 2 hrs this was seen. In both groups we observed a significant decrease in diuresis.

Therapeutic measures to maintain adequate circulation and diuresis were the same in both groups on $3 \mathrm{hrs}$ after application; additional l.v. fluids $(600 \pm 75 \mathrm{ml})$ and a $100 \%$ increase of the dose dopamine administered.

Conclusion:

Serious side effects; acute oligo-anuria and severe fall in bloodpressure necessitating the administration of increasing amounts of dopamine and $i_{i} v$, fluids makes diclofenac sodium even in a small dose of $0,2 \mathrm{mg} / \mathrm{kg} \mathrm{l}, \mathrm{m}$. unsuitable for use in ICU patients, as an antipyretic agent. 
IS PURE HIGH FREQUENCY VENTILATION A MISCONCEPTION? REPORT ON CLINICAL APPLICATION OF SUPERIMPOSED HIGH FREQUENCY JET. K. Czech, Unfallkrankenhaus Lorenz Boehler, Vienna, Austria

High frequency ventilation offers some advantages over IPPV (oxygenation, removal of secretions

etc.) but it is difficult to handle and adequate $\mathrm{CO}_{2}$ elimination is not always easily achieved. By superimposing $\mathrm{HF}$ Jet impulses on conventional ventilation or even spontaneous breathing the following effects could be observed.

1. Clearing of atelectatic areas that have been refractory to conventional therapy (bronchoscopic suctioning, CPPV, external vibration).

2. Improvement of blood gas values in ARDS

( $\mathrm{FiO} 2$ reduced from 1.0 to 0.5 within 8 hours)

3. In patients breathing oxygen by face mask $\mathrm{PaO}_{2}$ could be raised from. less than 60, torr $=$ $8 \mathrm{kPa}$ (in one case 34 torr $=4.5 \mathrm{kPa}$ ) to levels between 90 and 100 torr $(12$ and $13.5 . \mathrm{kPa})$. This was achieved by repeated 5 -min treatment sessions with oral HF-Jet, mechanical ventilation or CPAP was not necessary.

4. It has been successfully used to prevent posttraumatic ARDS.

Detailed case histories and $\mathrm{x}$-ray-photos will be presented.

Conclusion: With the exception of a few clearcut indications (eg. large bronchopleural fistulae) many clinical effects seen in HF-ventilation could be achieved by superimposed HF-Jet technique. The new method is easier, safer and cheaper than sophisticated $\mathrm{HF}$ ventilation techniques. 
PROGNOSIS OF POLYTRAUMATIZED PATIENTS IPP] IN A MULTI DISCIPLINARY I C U (M.I.C.U.).- C. GRANTHIL, J. FORGET, M. ALAZIA, A. CALDERON, G. FRANCOIS - Dept. Anesth,Réanimation Pr.G. FRANCOIS, G.H. La Timone, 13385, Marseille, France.

A $31 / 2$ year retrospective study on the prognosis of $\mathrm{PP}$ was performed in a M.I.C.U.. The Injury Severity Score (I.S.S.), a reliable index of seriousness, was calculated for 96 consecutive admissions and correlated with age and final prognosis. The I.S.S. values were from 20 (3 PP) to 66 (10 PP) points ( $\bar{m}=43+13$ ), according to trauma severity. The ages ranged from 16 to $77(\overline{\mathrm{m}}=35+17)$, and hospitalization from 1 to 173 days $(\bar{m}=17,4 \pm 25)$. The statistical resuits show :

$\left.1^{\circ}\right)$ a significant correlation between overall mortality and I.S.S vaTues (Mann-Whitney test, $p<0,05$ ). However, contrary to various studies, no I.S.S. values is $100 \%$ lethal : in 22 PP with an I.S.S. of 50 or more points, the survical rate was $50 \%(1.2 .3$.

$2^{\circ}$ ) a very significant correlation between mortality and age, showing the importance of the latter (Mann-Whitney test, $p<0,01$ ). However, contrary to previously published results the mortality rate is identical in both age groups (below and above age 45) as long as the I.S.S. is below 38 points (1.2)

$\left.3^{\circ}\right)$ a highly significant correlation between the length of hospitalization in I CU and I.S.S. in the discharged group (Spearman test, $p<0,001$ ). But, in opposition to previous data, there is not a negative correlation between length of survival and I.S.S. in the group of patients who died (3).

In conclusion, the above results are different from previous studies. The reasons for the differences are analysed: population characteristics, quality of care, length of time before admission into ICU, and transport conditions.

(1) BAKER: J. of Trauma,1976, 16: 882-885

(2) BULL: Acc. Ana 1. Prev. 1975, 7: 249-255

(3) SEMMLOW: Health Serv. Research, 1976,11: 45-52.

\section{2}

SEVERITY SCORES ON MULTITRAUMATIZED PATIENTS: A PROGNOSIS APPROACF. N. Dufeu, A. Margenet, p. Huguenard., Département d'Anésthésie Réanimation, Hopital Henri Mondor F 94010 Créteil France.

On 570 multitraumatized patients hospitalized in a traumatologic intensive care unit, severity scores have been established, and compared to clinical evolution.

Three types of severity scores were performed at the patient's admission:

- the Injury Severity Score ( ISS ), summarizing the victim's injuries ( based on the Abreviated Injury Scale),

- the Respiratory Index ( RI ) integrating PaO2 and its corresponding FiO2,

- the C.H.O.P. ( using Creatinine, Hematocrit, Osmolarity, and first systolic blood pressure).

Added and compared to these, classical cutaneous immunity tests (tuberculin, candidine, varidase) were realized, having only a value on patients hospitalized more than 48 hours.

The results show out, first, a very significant difference of Severity Scores Values in the two series individualized:" cured " and " deceased ".

Secondly, comparing severity scores values together and one to another, by including them into differents tables, an idea on the patient's prognosis can be given in chances of survival.

Concerning immunity response, prognosis interest is maximum in the non reactive group ( nearly 60 of of the patients which stay in the unit was over 48 hours). Based on a two years experience, and on a population of 570 patients, correlating severity scores to clinica] evolution can allow an early theoritical prognosis approach of the matitramatized patient survival.
FIBRONECTIN PLASMA LEVEL (FPL) IN PATIENTS WITH MULTIPLE INJURIES: ITS RELATIONSHIP WTTH SEVERITY. OF THE CLINICAL CONDITION. A. Salgado, S. Ro dríguez, C. Miquel, M.A. León, J. Ordi y M.C. Vázquez-Prada. C. Sa Valle de Hebrón. Barcelona. The administration of exogenous fibronectin gea red to avoid some complications in critically. ill traumatic patients (sepsis, ARDS) relates to the important role played by this glycoprotein in the inespecific opsonization of the reticuloendothelial system. The change in the FPL in these patients and its dependence on the severity of the trauma were investigated. The FPL was measured by immunoelectrophoresis in 29 patients with multiple injuries and they were related to an injury severity score (ISS). The me an value for the FPL was $58,6+18 \%$ as compared to the $98,5 \pm 20,6 \%$ of the control group of healthy human beings ( 0,001$)$. There was no statistical significance in the correlation between the FPL and the ISS in aIl the patients studied. Patients with only head trauma (with an ISS $=25,5 \pm 0,3)$ however had a higher FPL $(68,5$ $\pm 20 \%)$ than the rest of patients with multiple injuries ( ISS $=35,3 \pm 10$ and FPL $=54,8 \pm 16 \%$ ). These results demostrate that the FPL is reduced in patients with multiple injuries. This $1 \mathrm{e}$ vel, however, is better correlated with the volume of tissue involved than with the possible injury of vital organs (head trauma). This is to be taken into account when facing a possible the rapeutic infusion of this protein.

\section{4}

BEDSIDE PREDICTION OF OUTCOME OF SEVERE HEAD INJURIES DURING CONTROLLED VENTILATION S. Firm, Pinderfields Hospital, Wakefield; A. Z. Keller Post-Graduate School of Studies in Industrial Technology, University of Bradford

Predicting the outcome in severe Head Injuries (H.I.) is notoriously difficult. The "Glasgow Coma Scale", which is widely used can be a valuable indicator of H.I. outcome in patients breathing spontaneously, but is of little practical use if Controlled Ventilation is required as part of the patient's overall management, especially if relaxant and sedative drugs are used. A Ventilation Observation Chart in use at Pinderfields Hospital appeared to of fer a prediction of ultimate prognosis. It was besed on a simple scoring system of 15 parameters routinely monitored in such patients.

When these charts were subjected to a Discriminant Analysis Package 8 of the 15 parameters were identified as being of significance in predicting outcome and were arranged in order of importance by their weighting factor. Prediction of outcome was calculated using the formula of Sayles et al (1982).

100\% Separation into survival and fatality groups was obtained. A pocket computor was programmed with the Prediction Formula allowing rapid day to day Outcome Predictions.

\section{Reference}

Sayles et al (1982) Proceedings 7th Advances in Reliability Technology Symposium 
CHANGES IN CARDIORESPIRATORY PROF ILES TO INDUCED TOTAL BODY HYPERTHERMIA. A. Sladen; K. Guntupalli, R. Selker, E. Weinstock, D. Wilks and M. Klain. Surgical Intensive Care Unit, Montefiore Hospital, University of Pittsburgh School of Medicine, Pittsburgh, PA 15213 U.S.A.

Clinical trails currently are being undertaken to study the enhancement of radiation and chemotherapy with total body hyperthermia (TBH), to $41^{\circ} \mathrm{C}$, for patients with advanced malianant disease. The objectives of this study were to compare chances in cardiorespiratory profiles, pre, intra and nost TBH to determine the appropriate therapeutic maneuvers which are required to maintain hemodynamic and respiratory stability during TBH. Sixteen treatments, each of 4 hours, were given with the following results.

Pre Intra Post

CVP minkrg

$6.2 \pm .7$

$13.2 \pm 1.6^{*} \quad 8.2 \pm 1.1$

MAP $\mathrm{mmHG}$

CI L.min. MP

P.min

$88.2 \pm 3.5 \quad 69.3 \pm 3.7^{\circ} \quad 85.8 \pm 3.2$

$\begin{array}{lll}7.5 \pm 0.9 & 13.2 \pm .9^{*} & 11.2 \pm .2^{\circ}\end{array}$

$3.1 \pm .2 \quad 7.7 \pm .4^{*} \quad 3.8 \pm .2^{\circ}$

$92 \pm 4 \quad 139 \pm 3^{*} \quad 90 \pm 3$

LVSWI gm.M.M $20131.7 \pm 3.1 \quad 51.9 \pm 3.3 \quad 49.5 \pm 4.1$

TPRI dyne.sec. $\mathrm{cm}^{-5} \cdot \mathrm{M}^{2} \quad 2167 \pm 122 \quad 613 \pm 50^{*} \quad 1765 \pm 176$

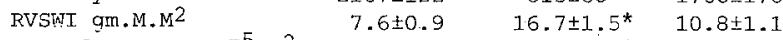

PVRI dyne.sec. cm ${ }^{-5} \cdot \mathrm{M}^{2} \quad 203 \pm 19 \quad 86.4 \pm 6.4^{*} \quad 143.3 \pm 15^{\circ}$

$\mathrm{nO}_{2} \mathrm{ml} . \mathrm{M}^{2} \quad 126.5 \pm 7 \quad 168.9 \pm 10.3^{\circ} 129.3 \pm 8.8$

Qsp. QT

$\begin{array}{llll}\text { Lactate } \mathrm{mg} \% & 8.8 \pm 1.5 & 26.9 \pm 2.9^{*} & 12.9 \pm 2.1\end{array}$

$7.4 \pm 0.007 \quad 7.31 \pm 0.01^{\circ} \quad 7.41 \pm 0.01$

$\begin{array}{llll}C O P \\ \text { IMnHg } & 20.4 \pm .7 & 14.9 \pm .5^{*} & 17.5 \pm .7^{\circ}\end{array}$

COP-PANP mmHg $\quad 13.0 \pm 1.2 \quad 1.6 \pm 0.9 * 6.78 \pm 1.4^{\circ}$ statistical analysis comparing pre with intra and pre with past TBH revealed a significance of $*_{\mathrm{P}}<0.0001$ and ${ }^{\circ} \mathrm{P}<0.05$. During TBH CI increased by $>100 \%$, TPR decreased by $>70 \%$ and MRP by $>20 \%$. To maintain an adequate MAP with these hemodynamic changes, crystalloid was infused to a positive mean fluid balance of $4814 \pm 323 \mathrm{ml}$. Post hyperthermia, pulmonary edema was demonstrated in 30\% of treatments and was

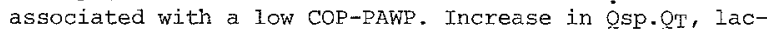
tate and a mild metabolic acidosis also occurred during $\mathrm{TBH}$. 


\section{Nutrition}

226

EFFECT OF NAFTIDROFURYL ON PROTEIN METABOLISM AFTER INJURY. H. Burns, C. Porteous, D. Galloway, I. MicA. Ledingham, G. Beastall, Departments of Surgery and Biochemistry, University of Glasgow, Scotland.

Naftidrofuryl (Praxilene) reduces lactate levels and increases ATP content of ischaemic tissue apparently by stimulating aerobic metabolism. We have examined the metabolic effects of this drug in injured patients. In a randomised study of 90 patients undergoing surgery of moderate severity, 46 received infusions of naftidrofuryl $400 \mathrm{mg} /$ day for three days after operation. A11 patients, including 44 controls, received a standard dextrose/saline fluid regimen providing $400 \mathrm{keal} / \mathrm{day}$. Both groups were similar in severity of operation, nutritional state, age and sex. Results three days after operation are in the table. (mean $\pm 2 \mathrm{SEM}$ )

Cumulated $N$ Naftidrofuryl Controls

Balance (g)

Serum total

$-23.09+3.8$ $-30.95 \pm 2.7 p<0.001$

proteins $\mathrm{g} / 1$

$62.0 \pm 1.6$

$54.7+4.9 p<0.05$

Serum

$35.5 \pm 1.9$

$31.7+2.2 \mathrm{p}<0.05$

There was no significant difference at any time between the two groups in plasma insulin, glucose, lactate, pyruvate or ketone levels. This study suggests that pharmacological treatment of post injury metabolism can produce significant protein sparing effects. Additional animal data suggest naftidrofuryl may act by stimulating glucose oxidation and reducing amino acid oxidation in the Krebs cycle.
CONTINUOUS ENTERAL HYPERALIMENTATION IN THE TREA TMENT OF SEVERE ACUTE PANCREATITIS. EFFECT ON NUTRITION, COURSE AND PROGNOSIS (65 CASES) E.Lévy, L. Hannoun, P. Fril eux, C. Huguet, J. Loygue, Centre de Chirurgie Digestive USI. INSERM. Hôpital Saint-Antoine.Paris.France.

Continuous enteral hyperalimentation can reduce the deaths rate associated with severe acute pancreatitis by atleast one-third. 85 patients while in an intensive care unit after digestive tract surgery are reviewed. In any case, destructive changes are seen in part or in all of the glande at operation or at autopsy; $46 \%$ of the patient had diffuse necrotic hemorrhagic involvement.

Acute pancreatitis in these patients was the result of biliary 1 ithiasis $(53 \%)$, alcoholism, trauma, sphincterotomy, gastrectomy or colecto my.Symptoms or consequences of the pancreatitis included encephalopathy, collapse, renal organic insufficiency, digestive hemorrhage, icterus, intraperitoneal abscess, septicemia, respiratory distress severe enough to require assistance. Every patient is in a critical condition with an average of 2.9 criteria of severity.

20 patients died during the first week. 65 surviving patients were started on continuous enteral feeding between the $3 \mathrm{rd}$ and 12 th day after resection or drainage of Pancreas: 17 died (26\%). The continuous feeding was administered by means of a jejunostony and was mixed with increasing amounts of carbohydrate and protein until an optimal level was reached of $75 \mathrm{KCal}$ per Kg b;w.per day.The total mortality rate is 42. $4 \%$. This is a obvious improvement over the mortality of $72 \%$ observed in a previous comparabie series of 68 patients underwent a conven tional treatment without enteral hyperaliment.

"ALL IN ONE" VERSUS CONVENTIONAL TOTAL PARENTERAL NUTRITION IN SURGICAL ICU-PATIENIS. A. Teutenegger, M. Buchmann, A. Frutiger. Department of Suxgery, Kantonsspital, Chur, Switzerland.

In 10 randomly selected surgical ICU-patients a new regimen of total parenteral nutrition (TPN) using a so-called all in one (AIO) solution was tested prospectively. Another 10 patients receiving conventional TPN served as control group. For a minimum of 7 days the patients were given either an AIO solution containing $40 \mathrm{~g}$ of crystalline I-aminoacids, $38 \mathrm{~g}$ fat, $75 \mathrm{~g}$ Sorbit and $45 \mathrm{~g}$ Xylite (4180 Joules/1, 600 Joules/gN, fat: carbohydrates $=4: 6$ ) or a conventional TPN with glucose and aminoacids. The regimens were identical regarding caloric intake ano Joule/N ratio. Amounts of infused solutions were adjusted according to patient weight. Both regimens were well tolerated and side effects urging us to interrupt the protocol did not occur. A set of 23 laboratory parameters taken each day underwent different statistical analysis. Efficiency of both regimens to improve nutritional status could be documented. In both groups values for albumin, protein and nitrogen balance improved significantly from day 1 to day 7 . Comparing the two groups, we found only two significant differences: glucose levels in the AIO group were significantly lower than in the control group $(6.87-8.97 \mathrm{mmol} / 1$ and $10.28-13.09 \mathrm{mmol} / \mathrm{l}, \mathrm{p}<0.001)$. The bilirubin increase observed in both groups, probably a sign of cholostasis, was significantly higher in AIO patients $(p<0.05)$.

Conclusions: Inmediate postoperative or posttraumatic nutrition with an AlO solution was safe and its handling simple. Because glucose metabolism is only minimally strained, AIO compares favorably with conventional ITPN and is a promising alternative; when stress induced glucose intolerance occurs. However, the influence of AIO on hepatic function deserves further investigation.
EFFECTS OF LEUCINE VS. KETOLEUCINE ON NITROGEN (N) M. Blanc, A. Calderon, F. Rosé, Dept. of Anesthesia and Intensive Care, G.H. La Timone, Marseille, France. early fasting while leucine does not. In vitro KIC has been reported to inhibit muscle protein breakdown while leucine stimulated protein synthesis. Surgery is followed by increased muscle protein breakdown. Thirty patients undergoing gynecologic surgery (hysterectomy with or without 1 ymphadenectomy) were randomized to receive for the first post-operative 3 days one of the following I.V. solution per $\mathrm{kg}$ and per day: $3 \mathrm{gm}$ glucose (G), $3 \mathrm{gm}$ glucose $+89 \mathrm{mg}$ leucine (L) or $3 \mathrm{gm}$ glucose $+104 \mathrm{mg}$ $\operatorname{NaKIC}(K)$. The output of 3 methylhistidine (3MH), total $\mathrm{N}$ and creatinine were measured daily. Values are expressed per $\mathrm{kg} \mathrm{B.W.} \mathrm{and} \mathrm{per} \mathrm{day.} \mathrm{(table)}$

\begin{tabular}{c|c|c|c|c}
\hline Group & $\begin{array}{c}\text { Creat.mmol } \\
*\end{array}$ & $\begin{array}{c}N \mathrm{~g} \\
*\end{array}$ & $3 \mathrm{MH}$ (mol & 3MH/Creat. \\
\hline $\begin{array}{c}\mathrm{A}=30 \\
\mathrm{~B}=30\end{array}$ & $0,167 \pm 0,025$ & $0,106 \pm 0,015$ & $5,25 \pm 0,75$ & 32,1 \\
\hline $\begin{array}{c}\mathrm{C} \\
n=30\end{array}$ & $0,165 \pm 0,013$ & $0,114 \pm 0,013$ & $4,67 \pm 0,41$ & 28,4 \\
\hline * mean \pm confidence Timits.
\end{tabular}
the Kruskal Wallis test. Urinary creatinine and tota? $N$ did not differ significantly in $G, L$ and $K$. Muscle protein breakdown measured as urinary $3 \mathrm{MH} / \mathrm{creatinine}$ was significantly reduced in $K$ as compared with $G$ or $L$. not reduce total nitrogen excretion. Leucine administered under the same conditions did not. METABOL ISM FOLLOWING GYNECOLOGIC SURGERY. G. François,

It has been shown that ketoleucine (KIC) spares $N$ during

The values were tested for statistical difference using Thus, I.V. KIC reduced muscle protein breakdown but did 
THE EFFECT OF BRANCH-CHAIN AMINO ACIDS ON SYSTOLIC PROPERTIES OF THE NORMAL AND SEPTIC ISOLATED RAT HEART.

H. R. Freund, E.J. Dann, Y. Hassin, Hadassah University Hospita1, Jerusalem, Israel.

We investigated the effect of different amino acid formulations on systolic properties of the isolated normal \& septic heart in 59 rats $(220-310 \mathrm{gm})$. Hearts were rapidly removed \& perfused as Langendorff preparations with Krebs solution $+8.5 \mathrm{mM}$ glucose, or Krebs $+5 \mathrm{mM}$ glucose $+3.5 \mathrm{mM}$ amino acids containing: $15 \%, 42 \%$, or $100 \%$ branch-chain amino acids (BCAA). Developed force (F) \& force velocity (df/dt) were measured for 1.5 hours at paced rates of $100,200,300$ $\& 400$ beats/minute. Sepsis was induced by cecal ligation \& perforation, animals being studied 12-24 (19+5) hours after induction of sepsis.

TAB: Percent change in developed force (F) \& force velocity $(\mathrm{df} / \mathrm{dt})$ over 1.5 hours.

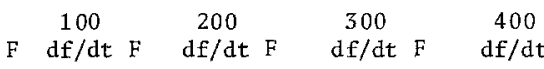

Krebs - Normal $-20+4-20+4-13+3-23+4$ Krebs - Sepsis $+21+34+6+10 \quad-10 \quad-5 \quad-17 \quad-20$ $\begin{array}{lllllllll}\text { BCAA } 15 \%-N & -28 & -18 & -37 & -23 & -42 & -32 & -49 & -39\end{array}$

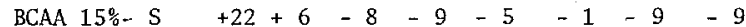

$\begin{array}{lllllllll}\text { BCAA } 42 \%-N & -11 & -12 & -26 & -21 & -28 & -1 & -33 & -28\end{array}$

BCAA $42 \%-5+94+106+106+90+28+41-4 \quad+19$

$\begin{array}{lllllllll}\text { BCAA } 100 \%-\mathrm{N} & -32 & -21 & -44 & -30 & -52 & -33 & -54 & -46\end{array}$

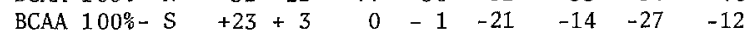

In normals: both Krebs and the $42 \%$ BCAA maintained near normal $\mathrm{F}$ and $\mathrm{df} / \mathrm{dt}$ while the $15 \%$ or $100 \%$ BCAA resulted in a significant decrease of both $\mathrm{F}$ and $\mathrm{df} / \mathrm{dt}$. In sepsis all four solutions improved $\mathrm{F}$ and $\mathrm{df} / \mathrm{dt}$ compared to normal

hearts, pointing towards different nutritional requirements of the septic heart. Exceptionaly good improvement was achieved by the $42 \%$ BCAA formulation. 
301

ORGANIZATION OF A CENTER FOR ACUTE RESPIRATORY DISTRESS SYMDROME (ARDS) TREATMENT: PROBLEMS ABOUT COMMUNICAIIONS AND SANITARY TRANSFER SYSTEM. G. Bordone, G.P. Rossi, F. Scarani, W. Zuliani, A. Pesenti, A. Pelizzola, G.C. Fontana. Ist. Anestesiologia e Rianimazione, Università di Hàlano, Italy.

In the last three years we organized the transfer of $3^{2}$ ARDS patients refractory to conventional therapy, from other hospitals to our Institution as candidates for treatment with Low Frequency Positive Pressure ventilation with Extracorporeal CO Removal (LFPPV-ECCO R). Our managing strategy develops as follows: $3^{2}$ a network of comaunications with peripheral hospitals to collect detailed informations about clinical condition and evolution of the patient; 2) cooperation with private and pubblic Institutions in order to obtain the nost suitable means of transport (air and ground); 3) continuous training of a medical tean; 4) the availability of sanitary equipment of smallest size, rationally arranged in standard kits and battery operated. Our criteria for sanitary transfer of these patients can be summarized: use of the most suitable mean of transport (sanitary flight, helicopter, anbulance); patient assessenent and preparation before leaving; sedation and curarization of the patients, artificial ventilation with positive end expiratory pressure, possible infusion of sympathomimetic agents; continuous monitoring of respiratory and hemodynamic paramethers; travel performed as fast as possible. We transferred 32 patients from as far as $1.200 \mathrm{~km}$ using ambulance (84\%), helicopter (3\%) and sanitary flight (12.5\%). Mean $\mathrm{PaO}$ on leaving was $51.02 \mathrm{~mm} \mathrm{Hg}$ (ranging from 95 to $23 \mathrm{~mm} \mathrm{Hg}$ ); on arrival was $63.83 \mathrm{~mm} \mathrm{Hg}$ (ranging from 147.5 to 27.5 mil $\mathrm{Hg}$ ). Mean PaCO on leaving was 47.12 (ranging froll 63 to $27 \mathrm{mill} \mathrm{Hg}$ ); on arrival was 43.9 (ranging from 79.3 to $24.5 \mathrm{~nm} \mathrm{Hg}$ ). 17 of our patients were treated with conventional respiratory therapy. 15 of therl underwent LFPPV-ECCO $R_{i}$, none of them died during the transport.Being our Institution, at present, the only center in Italy where LFPPV-ECCO ${ }^{R}$ is carried out the transfer of patients with AROS may be considered an integral part in this type of life saving procedure.

302

Neurogenic ARDS - its frequency and relevance to outcome in patients with isolated head injury. G. Singbartl, G. Cunitz, Dept. Anaesthesiology and Intensive Care Medicine, Ruhr-University of Bochum, D - 4630 Bochum 7

Though ARDS following sepsis, trauma or coagulation disturbances is well known, the same does not hold true for centally-initiated impaired pulmonary gas-exchange or neurogenic ARDS, respectively. Therefore, in a prospective clinical study in 129 patients with isolated head injury frequency of ARDS, its relation to severity of cerebral trauma and its relevance to clinical outcome were examined. Severity of head injury was graded by means of the Glasgow-Coma-Scale (GCS) and pulmonary gas-exchange was expressed by the quotient $A-a D O, / P O,(Q)$. Patients with

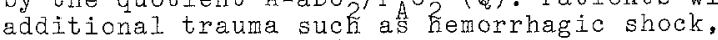
fractures of the large bones, direct chest-trauma or aspiration were excluded. Our results demonstrate a relationship between the severity of head injury and impaired pulmonary gas-exchange. $22.5 \%$ of all patients suffer from a severe neurogenic ARDS(Q>0.6) while in additional 26.3 \% pulmonary gas-exchange was moderately impaired $(Q>0.4<0.6)$. With increasing severity of neurogenic ARDS survival rate decreased from $58.3 \%$ (severe head injury but without ARDS ) and $55.3 \%$ (severe head injury with a moderate degree of ARDS) down to $24.1 \%$ (severe head injury with severe ARDS) despite an increase of controlled ventilation from 66.6 to $89.1 \%$. Moreover, neuro logical outcome is significantly worse in the latter group than in the former ones.
303

BIOLOGICAL ALTERATIONS OF BLOOD COAGULATION IN ADULT RESPIRATORY DISTRESS SYNDROME. J. Fontcuberta, S. Benito, A. Artigas, J. Castella, J. Vallês, S. Armengol, M. Rut1 lant. Servicio Cuidados Intensivos. Hospital de la Santa Creu i Sant Pau. Barcelona. Spain.

The alterations of blood coagulation were studied in 16 patients with adult respiratory distress syndrome (ARDS). A11 patients required mechanical ventilation $10 \pm 7$ days, Fi02 $0.8 \pm 0.2$, PEEP max. $10 \pm 5 \mathrm{~cm} \mathrm{H2O}$ with a $P(A-a) 02 / P A 02$ $0.74 \pm 0.13$ and 0 s $/$ Qtot $38 \pm 6 \%$. The following parameters were analized in plasma and bronchoalveolar lavage fluid (BLF) at $0,24,72$ hours and 10 days: fibrinogen ( $F$, Von Claus), fibrin degradation products (PDF, Merskey), factor VIII antigen ( $F$, VIII ag, Laure 11), platelet factor 4 (PF4 Ria) and beta-tromboglobul in ( $\beta T G, R i a)$. A control group of 10 patients was included.

RESULTS: Mean values of the first 3 days are shown in the table:

\begin{tabular}{lc|c}
\hline & PLASMA & BLF \\
\hline F g $/ \mathrm{T}$ & $6.08 \pm 1.9$ & 0 \\
\hline PDF $\mu \mathrm{g} / \mathrm{m}$ & $25.58 \pm 27,1$ & $10.7 \pm 18.98$ \\
\hline F. VIII ag\% & $583 \pm 312$ & 0 \\
\hline PF4 $\mathrm{ng} / \mathrm{ml}$ & $49.22 \pm 28.42$ & $24 \pm 25.7$ \\
BTG $\mathrm{ng} / \mathrm{ml}$ & $89.38 \pm 46.31$ & $46.94 \pm 50.9$ \\
\hline
\end{tabular}

In a 11 cases a 11 parameters analized were higher than normal values and an increase of PDF, PFA and BTG in BLF was observed.

These data suggest an endothelial vascular lesion together with an increase of fibrin deposits and platelet aggregation in the pulmonary microcirculation.

\section{4}

ALVEOLAR-CAPILLAR DUCTANCE FOR CARBON MONOXYDE AS A RELIABLE INDEX OF SEVERITY IN PULMONARY EMBOLISM. J.F. Prost,

P. Des fonds, P. Lacombe, M. Leroy, Y. Ozier, F. Jardin. Hôpi tal Ambroise Paré, Boulogne, France.

Alveolo-capillar ductance for carbon monoxyde (defined by a mathematical expression [(PI - PA)/PI] identical to efficient alveolar ventilation) represents the pulmonary blood volume close to ventilated alveolar space.

With an original informatic me thod, it's measurment in steady state conditions can be performed at bed side and in mechanica$1 \mathrm{y}$ ventilated patients.

A prospective study has been conducted in order to assess the diagnostic and pronostic value of DuACCO in pulmonary embolism. This day 12 patients were entered in the study.

on the first day following the admission in the intensive care unit, blood gases and DuACCO were measured and a pulmonary angiography was performed. A Iong term follow up was obtained by repeated measurments of DuACCO.

On day 1 , DuACCO reached a mean of 0.43 (i.e. $61 \%$ of the theoretical value) wi th a minimum of 0.24 and a maximum of $0.60, \mathrm{PaO}_{2}$ reached a mean of $53 \mathrm{mmH} g$ with a minimum of $35 \mathrm{mmHg}$ and a maximum of $70 \mathrm{mmHg}$. The pulmonary hypoperfusion degree, as it can be evaluated on pulmonary angiograms according to WALSH index, reached a mean of 10 wi th a minimum of 2 and a maximum of 15 . A closed correlation is observed between Walsh Index and DuACCO $(r=-0.78, p<0.01)$. In one case of massive pulmonary embolism (Walsh index $=20$ ) with slight hypoxemia $\left(\mathrm{PaO}_{2}=62 \mathrm{~mm} \mathrm{Hg}\right.$ ) DuACCO remained dramatically lowered (DuACCO $=37$, i.e. $53 \%$ of the theoretical value).

On day 40 , DuACCO reached a mean of 0.59 (i.e. $84 \%$ of the theoretical value) in 6 patients despite the lack of thrombolytic therapy .

We conclude that DuACCO is a non invasive reliable measurment allowing severity evaluation and longterm follow up of pulmonary embolism. 
305

REGIONAL LUNG PROTETN TRANSCAPILLARY ESCAPE RATE (TCER) IN CHRONIC LEFT VENTRICULAR FAILURE (CLVF). MEASUREMENT BY A SCINTTLLATION CAMERA. F.A. Grimbert, F. Dubois, J.C. Peyrin, J.P. Caravel, P. Gelas, Département d'Anesthésiologie et Service de Médecine Nucléaire. C.H.U. de GRENOBLE F-38700 LA TRONCHE We measured regional lung TCER of $111^{1 n-t r a n s f e r-~}$ rin (mol wt 76000 ) in 5 normal volunteers and in 5 patients with CIVF studied before left heart valvular surgery. All subjects were studjed semirecumbent. The equilibration process of 111 Intransfexrin -diffusible label-and $99 \mathrm{~m}_{\mathrm{Tc}-1 \mathrm{abeled}}$ red blood cells - nondiffusible label- in lung was followed by a scintillation camera for 60 minutes after intravenous administration of tracers. The proportion of diffusible and nondiffusible labels in venous blood samples was used to partition count rates made over the lung into contributions from an intravascular and an extravascular compartment. Protein TCER in lung of CLVF patients, $4.8 \pm 3.2 \times 10^{-3} \mathrm{~min}-1$ (t \pm s.d.), was within the normal range. However time to half-equilibrium concentration (t1/2) of transferrin in the pulmonary interstitium was $24 \mathrm{mi-}$ nutes in CLVF compared to 65 minutes in normals. These results confirm those of A.B. GORIN et al (Microvasc. Res. 17 : $\$ 116,1979$ ). In addition we observed that compared to normals, the lung protein TCER in CLVF patients was highex in the upper part of the lung than in the lower part. These results suggest that in CLVF patient lung 1 - vascular permeability is normal 2-vascular surface area is increased ard/or interstitial protein mass is cecreased 3-vascular permeability is relatively increased in the upper part of the lung. We conclude that this non-invasive method is suitable to study regional lung protein TCER in intensive care patients.

306

EFFECTS OF ESCHERICHIA COLI ENDOTOXIN ON DISTRIBUTION OF CARDIAC OUTPUT IN ANESTHETIIED PIGS. A.Mercate110,A.Bonmartin, B.Bui-Xan, M.Lièvre, J.J.Mailet, J.Motin.

Laboratoires de biophysique (Pr. J.0 Peyrin) et de pharmacologie (Pr. G.Faucon) ; Faculté de Médecine Grange Blanche, Université Lyon I, Lyon, France.

The experiments were performed in 10 pigs ( 5 for controls and 5 animals received $1,5 \mathrm{mg}$ of escherichia coli endotoxin). The animals were tracheotomised and anesthetized with Halothane $(0,5 \%)$. the cardiac output (C.O) was measured by thermodilution. The distribution of $C .0$ was measured by injection nuclide labeled radioactive microspheres (15 $\mu \mathrm{m}$ in diameter) (New England nuclear) into the left ventricule. Particles were injected before $(57 \mathrm{Co})$ and at 5. (113 Sn) and $60 \mathrm{mn}(46 \mathrm{Sc})$ after administration of endotoxin. After the pigs were killed, 50 samples of the organs were dissected, weighed and counted in a camma scintillation counter. The $15 \mu m$ microspheres measured only the capillary blood flow (nutrient bjood flow). Particles shunted through the systemic circulation (arteriovenous anastomoses) were stopped in the lungs.

3 groups of organ blood flow were individualized (for $100 \mathrm{~g}$ of tissue, percentage of $\mathrm{C.0}$, before and at 5 and $50 \mathrm{mn}$ after infusion).

- coronary $\left(2.32,4.18,6.31^{*}\right)$ pancreas $\left(0.46,1.03,1.49^{*}\right)$ aorta $(0.12,0.21,0,33)$ blood flow were increased. - Tiver $\left(0.98,0.63^{*}, 0.64^{*}\right)$ adrenals $(2.57,4.49,2.48)$ muscle $(0.11,015,0.11)$ and total gastro-intestinal tract blood flow were well maintained.

-spleen $\left(3.71,1.85^{*}, 2.32^{*}\right)$ brain $(1.94,2.97,0.81)$ kidneys $\left(4.16,4.58^{\ddagger}, 2.65^{*}\right)$ and ears $(0.042,0.025,0.019)$ blood flow were decreased. During early endotoxemia the ears and spleen blood flow were decreased in contrast the kidney and brain blood flow were maintained. The pancreas $(0.45$, $\left.1.03,1.49^{*}\right)$ adrenals $(2.57,4.49,2.48)$ and pituitary $(1.95$, $1.80,2.00)$ blood flow were maintained.

The fraction of cardiac output passing to the lung (arteriovenous anastomoses and bronchial arteries) was significantly decreased $\left(5.68,5.5^{*}, 2.21^{*}\right) . \quad * P \leqslant 0.05$
307

RIGHT VENTRICULAR PERIPHERIC BLOCK INI ACUTE EXPERIMENTAL PULMONARY ARTERY HYPERTENSION. R. Martinez, A. RogLan, JO. Bonnin, A. Bayés, R. Oter. I.C.U. Hospital de la Santa Creu i.Sant Pau. Barcelone. Spain.

The present study was designed to determine the changes of electrophysiological patterns in acute pulmonary hypertension $(P A H)$.

METHODS: Using intracardiac recording techiques, His bund Le (H) and right ventricular apical (RVA) electrograms were recorded simittaneously with I, II and VI leads in 10 dogs anaes thetized with pentobarbital $(15 \mathrm{mg} / \mathrm{Kg})$ and voncuronium $(0.10 \mathrm{mg} / \mathrm{Kg})$, ventilated with $15 \mathrm{ml} / \mathrm{Kg}$ and FiO2 1. Catheters were introduced into the right ventricle (RV) and pulmonary artery. Pulmonary arteries were dissected by billateral thoracotomy and two epicardial bipolar electrodes were placed on the postero-inferior (PI) and antero-superion (AS) wall of the RV. $P A H$ was obtained by pulmonary vascular obstruction. The His (H), RVA, I, II, and V1 leads, RVA-IP and RVA-AS were recorded simultaneous ly at basal level and following induced PAII (mean pulmonary artery pressure $>27 \mathrm{mHg}$ ).

RESULTS: Mo significative differences were seen in $P$ wave, $P R$ intemal or AQRS. Yhere was no $r^{\prime}$ wave in V1 following $P A H$. There was significative increase of the H-RVA $(p<0,01$ and $R V A-A S(p<0,001)$ intervals.

These findings suggest that there is a delay in the right bundle bronch between RVA-IP and RVA-AS, indicating the presence of a peripheric block on the RV associated with a $R B B$ block without significant changes in $V_{1}$.

308

STUDY OF TRANSCUTANEOUS POZ IN SHOCK. E. MesalZes, S. Armengol, J. Vallés, A. Artigas. Servicio de Cuidados Inten sivos. Hospital de la Santa Creu $i$ Sant Eau. Barcelona. Spain.

The purpose of this study is to evaluate the transoutaneous POR (Ptc02) in different hemodynomic patterns and. its relationship with paor.

Twenty-six patients (p) in shock with clinical signs of peripherat underperfusion and needing inotropic dmigs (or fluids) were studied.

Fulmonary and radial arteries were catheterized and cardiac output was determined by thermodizution. Ptcol was measured with transcutaneous sensor (Kontron-ta Roche) with simultaneous measurements of PaO2 and alt hemodynamic parcameters.

Patients were divided in three groups:

A: 7 p. with low CI $(<2,5$ l/mixm2)-MAP: $75,8 \pm 8 \mathrm{mmH}$. B: $14 \mathrm{p}$. with normal CI $(2,5-4 \mathrm{~L} / \mathrm{mixm})-M A P \quad 87 \pm 17 \mathrm{mmHg}$. C: $7 \mathrm{p}$. with increased CI (>4 I/mixm2)-MAP $77,6 \geq 14 \mathrm{mmHg}$ Forty studies were analysed with student $T$ and linear regression tests.

RESULTS: Sumarized in the tabie.

$\begin{array}{lccc} & A & B & C \\ \text { No data/no } p & C I<2,5 & 2,5<C I<4 & 4<C I \\ \text { PaO2 ve Pteo2 } & 10 / 7 & 21 / 14 & 10 / 7 \\ \text { Linear regression } & & & \\ \text { r=value } & 0,43 & 0,95 & 0,77 \\ \Delta_{\text {PO2 }} & 7,8 \pm 14 & 7,05 \pm 12 & 12,8 \pm 12 \\ \text { Ptco2/pao2 } & 0,9 \pm 0,14 & 0,95 \pm 0,11 & 0,88 \pm 0,12\end{array}$

The relationship was not dependent on different levels of $C(a-v) 02$, iv 02 and systemic vascular resistances.

CONCLUSION : PtCO2 and PaO2 were equivalent at normat CI but not in low output shock ond hyperdynamie shock. 


\section{Mechanical Ventilation: Techniques and Complications}

309

SHPARATFD ARTIFICIAL, IUNG VENTIILATION. A. Margenet, C. Hervé, Y. Morin, P. Huguenard, Département D'Anesthésie Réanimation, Hopital Henri Mondor - F 94010 Créteil France

The technic, largely used in bronchopulmonary surgery may find a more recent indication concerning intensive care patients.

This type of ventilation has been performed on 17 patients of a traumatologic and surgical intensive care unit, using:

- P.V.C. endatracheal tubes (Bronchocath TD ), without ergot,

- Two ventilators making possible a totaly asynchronous ventilation. Asynchronism seens to be one of the necessary conditions to the efficiency of the technic; and this is shown by its positive effects on:

- hematosis : arterial ( $106+45$ versus $351+106 \mathrm{mmHg}$ in $\mathrm{FiO}=1$ ) and venous blood gases. - the haemodynamic parameters:cardiac index $(2.8+1.6 \mathrm{v} .3 .2+1.6)$, arterial pulmonary resistance, arterial pulmonary pressure $(17+6$ versus $13+1.5 \mathrm{mmHg}$ ) and pulmary capillary wedge pressure $(9+5 \mathrm{v} \cdot 4+6 \mathrm{mmHg})$.

Iocal tolerance to the double lumen endotracheal tube, has been appreciated on fiberoptic bronchoscopic criteria.

Instead of waiting for the advent of a severe hypoxemia, a precocious indication of such technic can be discussed in the following situations :

- after an unilateral aspiration,

- when different PFFP levels are requested for each lung,

- to finish haemodynamic tolerance during high PEEP levels is largely improved by the separated artificial lung ventilation.

CONTINUOUS POSITIVE AIRHAY PRESSURE IN HEALTHY VOLUNTEERS: EFFECTS ON RESPIRATORY PATTERN AND FUNCTIONAL RESIDUAL CAPACITY.

P. Constantin, A. Forster, D. Morel and P.M. Suter. Départment of Anes thesiology, Surgical ICU, Hôpital Cantonal, 1211 Genève 4, Suisse.

Continuous positive airway pressure (CPAP) has been shown to increase functional residual capacity (FRC) in healthy volunteers proportionally to the level of positive pressure (1).

The purpose of this study was to evaluate the changes in respiratory pattern and the duration of increase in FRC induced by CPAP $(10 \mathrm{~cm} \mathrm{H} \mathrm{H})$ in nine heal thy volunteers. Before and after CPAP, FRC was measured by multiple breath nitrogen washout. During CPAP, changes in FRC and respiratory pattern were continuousiy monitored with pre-calibrated bellows pneumographs.

Results : The increase in FRC ( $+22 \%$ of control level) observed under CPAP varied with time (range: $+17 \%$ to $+41 \%$ of control level) and disappeared within the first minute after discontinuation of CPAP. Tidal volume increased significantly during CPAP while minute ventilation remained stable.

Conclusions : In patients with normal lungs, the effect of CPAP on FRC ends with the removal of the positive pressure. The mean increase in FRC observed with bellows pneumographs during $10 \mathrm{~cm} \mathrm{H}_{2} 0$ CPAP is similar to the one measured with the helium difution method (1) but varies greatly breath by breath and thus may give additional information to the results of former studies where only intermittent measurements of FRC were performed.

1. Gherini S, et al., Chest 76: 257-256, 1979.
311

FNIPAINMENT DURTNG HTGH FREOUENCY JET VENTILATTON: CLINICAL IMPLICATIONS FROM STUDIES VITH A MODEI LUNG. A.J. Mortimer, J-L. Bourgain, Nuffield Department of Anaesthetics, Radcliffe Infinmary, Oxford, U.K.

The purpose of this study was to investigate the occurrence of ambient gas entrairment during jet ventilation at different respiratory frequencies and $I: E$ ratios. $A$ model lung (Manley B.O.C. of ${ }_{1}$ conpliance $50 \mathrm{ml} \mathrm{cm.} \mathrm{H}_{2} \mathrm{O}^{-1}$ and resistance $5 \mathrm{~cm} \mathrm{H} \mathrm{O} \mathrm{I}^{-1} \mathrm{sec}^{-1}$ was ventilated in a closod plethysmograph by a solenoid-operated jet ventilator. The ventilator output was directed into the lung through a $1.8 \mathrm{rm}$ nozzle in a T-piece connected to a $9 \mathrm{rm}$ EI tube. At a driving pressure of $45 \mathrm{psi}$ the degree of entrairment was measured with $I: E$ ratios of $1: 2$ and $1: 4$ at frequencies of $1,3,5$ and 10 hertz. The tidal volume delivered to the lung (VI LUNG) was derived from the pressure swings of the plethysmograph, and the tidal volume delivered from the jet (VI VEMI) was obtained by dividing the minute volume of the ventilator by the frequency under observation. The ratio of VI IUNG to VT VENT gave a measure of the entrainment.

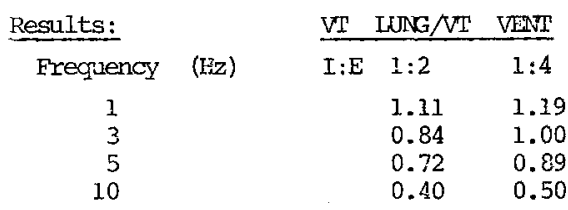

Clinical Irmplications:

1. The $F_{1} \mathrm{O}_{2}$ and humidity of the inspired gas are largely deternined by the gas delivered fram the jet.

2. The minute volume of the ventilator is not a useful guide in assessing the minute volume of the patient.

\section{2}

HIGH FREQUENCY JET VENTILATION DURING BRONCHOSCOPY, SURVEILLANCE BY TRANSCUTANEOUS $\mathrm{PCO}_{2}$ MEASUREMENTS. M. FISCHLER F. MICHON, J.C. MELCHIOR, F. SEIGNEUR, G. VOURC'H, HOpital FOCH, SURESNES, FRANCE.

High frequency jet ventilation (HFJV) has been widely used during bronchoscopy ; the main problem during $\mathrm{HFJV}$ is $\mathrm{CO}_{2}$ elimination. The accuracy of a cutaneous capnometer (Roche Kontron) was evaluated in this clinical situation. 6 patients were investigated under general anesthesia. Different methods of ventilation were used successively over a 10 mn period : manual jet ventilation, HFJV at rates of $150 / \mathrm{mn}, 300 / \mathrm{mn}$ and $500 / \mathrm{mn}$. The jet ventilator MR 800 (Acutronic medical system) was used with a driving pressure of 5 bar and a 16 gauge injector. Measurements of arterial and transcutaneous $\mathrm{PCO}_{2}$ were made simultaneously before anesthesia and at the end of each period of ventilation.

Satisfactory correlation was found betweer transcutaneous $\mathrm{PCO}_{2}$ and arterial $\mathrm{PCO}_{2}$. Thus it appears transcutaneous $\mathrm{PCO}_{2}$ measurement $\mathrm{can}$ be used for evaluating $\mathrm{CO}_{2}$ elimination during $\mathrm{HFJV}$ in such procedures as bronchoscopy where no important hemiodynamic changes are expected.

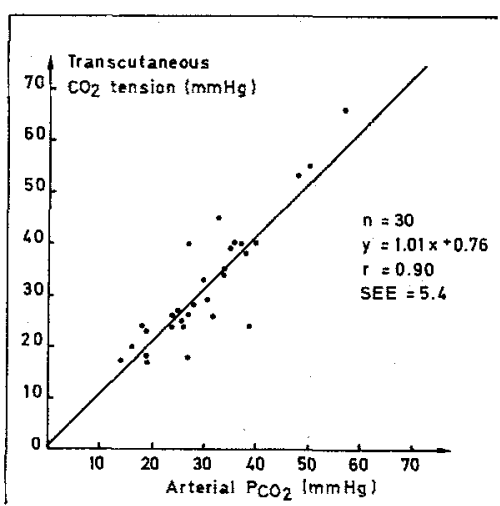


313

MANUAL JET VENTILATION (JV) OR HIGH FREQUENCY JET VENTILATION (HFJV) DURING LASER RESECTION OF TRACHEOBRONCHIAL STENOSIS. M. FISCHLER, G. VOURC'H, F. MICHON, J.C. MELCHIOR, F. SEIGNEUR. Hopital FOCH, SURESNES, FRANCE

HFJV has been proved to be satisfactory during bronchoscopy at a frequency of $60 / \mathrm{mn}$. We compared JV with HFJV during laser resection of severe tracheo-bronchial stenosis under general anesthesia, JV using the Sanders technique, HFJV the Jet ventilator MK 800 (Acutronic medical system). During both methods $\mathrm{FiO}_{2}$ of the injected gases was 0.5 , the driving pressure was 5 bar. Ventilatory rate was $20 / \mathrm{mn}$ for JV and $300 / \mathrm{mn}$ for HFJV with an $\mathrm{I} / \mathrm{E}$ ratio of 0.25 . A 16 gauge tube welded on the bronchoscope permitted ventilation. Arterial blood was withdrawn before anesthesia (A) and at the tenth minute of surgery (B). Results (mmg) are expressed as mean \pm SD, statistical analysis used t test.

The results are summarized in the table.

$$
\text { JV (20 patients) }
$$

$$
\mathrm{PaO}_{2} \quad \mathrm{PaCO}_{2}
$$

$$
67.2 \pm 11.6 \quad 36.3 \pm 5.1
$$

HFJV (20 patients)

(B)

$$
\begin{aligned}
& 126.8 \pm 39.1 \quad 32.6 \pm 6.8^{*} \quad 112.3 \pm 49.6 \quad 40.8 \pm 13.2^{*} \\
& \approx p<0.02
\end{aligned}
$$

$\mathrm{PaCO}_{2}$ is significantly highet under HFJV. In cases with tracheal stenosis this difference does not occur; on the other hand in cases with bronchial stenosis $\mathrm{PaCO}_{2}$ was $31.9 \pm 5.2$ under JV and 44.1 \pm 12.1 under HFJV ( $\mathrm{p} 0.02$ ). The location of the stenosis and so the location of the tip of the injector influence gas exchanges under HFJV. This method can be used for tracheal stenosis. JV will be preferable for treatment of bronchial stenosis.

\section{4}

CLINICAL VALIDATION OF A NEW DEVICE FOR STATIC THORACOPULMONARY COMPLIANCE COMPUTERISATION DURING MECHANICAL VENTILATION. J.P. Viale, B. Bui Xuan, G. Annat, Y. Khater J.Motin; Hôpital Edouard Herriot, 69374 LYON CEDEX 08 The optimal management of critically ill ventilated patients of ten requires repeted measurements of static thoracopulmonary compliance $\left(\mathrm{C}_{S T}\right)$. However the conventional methods which are.used for this measurement are generally laborious and request a possibly dangerous interruption of the ventilation. The new device Spirolog IIR Drägger which takes into account cycle by cycle informations of expired flow and pressure from the nasotracheal tube calculates continuously $\mathrm{C}_{S T}$ in ventilated patients. The aim of the present study was :

1) to compare the values of $\mathrm{C}_{\mathrm{ST}}$ calculated by the Spirolog II (CST-SP) with those measured by the syringe method (HARF 1975) during inspiration ( $\mathrm{C}_{\mathrm{ST}}$-insp) and expiration $\left(\mathrm{C}_{\mathrm{ST}}-\exp \right)$,

2) to determine the normal values of $\mathrm{C}_{\mathrm{ST}}$-SP by measuring, this parameter in anesthetized surgical patients with clinically normal respiratory function and normal $\mathrm{x}$ ray chest.

3) to test the usefulness of this calculator for the estimation of the "best-PEEP" level (SUTER 1975).

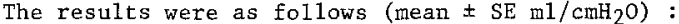
1) $\mathrm{C}_{\mathrm{ST}}$-SP $(46,9 \pm 5,6, \mathrm{n}=15)$ was well correlated (p 0,001$)$ with $c_{S T}{ }^{-i n s}(64,9 \pm 6,5, \mathrm{n}=15)$ and with $\mathrm{C}_{\mathrm{ST}}-\exp (49,1 \pm 4,6, \mathrm{n}=15) . \mathrm{C}_{\mathrm{ST}}-\mathrm{SP}$ was lower than $\mathrm{C}_{\mathrm{ST}}-$ ins $\left(\mathrm{p}\langle 0,001)\right.$, but was the same as $\mathrm{C}_{\mathrm{ST}}$-exp

2) $\mathrm{C}_{S T}-\mathrm{SP}$ in normal anesthetized patients was found to be $57,5 \pm 1,9, \mathrm{n}=47$, a value which is within the normal range of the already published data.

3) The levels of "best PEEP" estimated with the Spirolog were well correlated with those estimated by the syringe method $(\mathrm{p}<0,05)$

We conclude that Spirolog II is suitable for the clinical management of intensive care ventilated patients.

HARF (A.) and A1. Bul1. Physiopath. Resp. 1975, i 1:709-728

SUTER P. and A1. N. Engl. J. Med. 1975, 292 : 284-289
A NEW RESPIRATOR BASED ON HIGHLY ACCURATE FLOWCONTROL AND FLOW-MEASUREMENT. A. Meier. Hamilton lhedical, Bonaduz, Switzerland.

The desirability of changing, the behaviour of a Respirator, according to the differing and changing needs of the critically ill patient, can only have a meaning if precise control and measurement of relevant data can be achieved.

Our way to comply with these clinical specifications has been the construction of a simple proportional valve with extremely few movable parts but designed specifically to interact with the advanced and reliable microprocessor technology. This combination has provided us. a highly versatile operational Respirator, which allows the clinician a very broad range of operationality, concerning any ventilatory mode or function.

The device is conceived with clear and precise settings; identified patient alarms; patient monitoring with trends, and warning for erroneous settings.

\section{6}

A.BIDIRECTIONAL PEEP VAIVE AND ITS POSSIBLE APPLICATIONS A.Frutiger, M.D.Surgical ICU Kantonsspital Chur, Switzerland

Currently available Peep valves work unidirectionally,i.e. gas flow through them is only possible in one direction. Peep is produced by preloading these valves, which pernits gas flow only from a set opening pressure. Once the opening pressure is overcome, ideally gas flow should occur unobstructed. No gas flow is possible in the opposite direction. There are many techniques to produce Peep, they involve water columns, springs, magnets, counterpressure, balls, etc..; but one feature common to all currently used valves is their unidirectional function. We present a bidirectional Peep valve which not only exerts Peep in one direction, but also permits unobstructed flow in the opposite direction. The Peep ranges between 3 and 20 mbar. Its resistance is 0.8 mbar at a gas flow of $0.5 \mathrm{~L} / \mathrm{sec}$ and 2.45 mbar at $1 \mathrm{~L} / \mathrm{sec}$ respectively. Two ports allow suctionning and airway pressure measurements.

The suggested clinical application of the described valve is to produce differential peep in artificially ventilated patients with assymmetrical lung disease or patients in lateral position during chest surgery. The valve is simply placed on line into the selected branch of a double lumen endotracheal tube. Peep is applied to the less compliant lung in unilateral lung disease or to the dependent lung in lateral position during chest surgery. The technique of differential peep is thus much simplified. More. complicated techniques like $\mathrm{x}$-piece systems or the use of two ventilators are avoided. Of course the bidirectional Peep valve may also be used in any other kind of Peep therapy. The valve has then to be placed between the $\mathrm{Y}-$ or T-piece of the chosen gas delivery system.

Conclusion:

A bidirectional Peep valve is presented. We suggest its use together with a double lumen endotracheal tube to produce differential Peep in patients with unilateral lung affections. 
COMPLICATIONS ASSOCIATED WITH PROLONGED HIGH FREQUENCY VENTILATION. J. Berré, A.M. Ros, J.L. Vincent, P.Dufaye, R.J. Kahn. Department of Intensive Care, Erasme University Hospital, Free University of Brussels, Belgiuii.

The type and the incidence of complications during treatment with high frequency ventilation (HFV) were evaluat,ed in 7 patients (age 17 to 74 ) who presented with acute respiratory failure. HFV was used for 6 to 34 (median 9) days for management of bronchopleural fistulas (5), associated in one case with tracheo-esophageal fistula, tracheal rupture (1) or voluminous lung abcesses (1). Four of the 7 patients died from multisystem failure. HFV was delivered using a ventilator ACUTRONIC ${ }^{\mathrm{h}}$ VS $600(3)$ or MK $800(4)$, at rates $100-250 \mathrm{cycles} / \mathrm{min}$. Inspiratory time was $30-40 \%$ and driving pressure 2-4.5 bar $\mathrm{FiO}_{2}$ ranged from 0.3 to 0.9 . Jet injector (DESERET ${ }^{2}-14^{2}$ GA-8.3 cm with 2 side-holes) was secured in the endotracheal tube. Inspiratory gases were carefully humidified. We identified technical complications associated with insufficient humidification, leading to viscous secretions ( 3 cases), desiccation of the tracheobronchial tree (2 cases) and total obstruction of the endotracheal tube (one case). Disconnection or kinking of the catheter were not rare events. One case of severe hypothermia was attributed to humidification with a cold solution. Ventilator noise was sometimes hardly tolerated and two patients developped acute confusional state. Sleep disturbances were variable. On the other hand, abrupt disconnection of the noise could give rise to panic. Acceptation of HFV by nursing staff was directly proportional to their knowledge of the device. Technical problems occured more commonly during nights or week-ends. Inadequate alarms were generally incriminated. Easy, practical solutions can be suggested to improve humidification and monitoring of $\mathrm{HFV}$, and thereby limit the incidence and the severity of complications.
ACUTE COLONTC DILATATION WITH MECHANICAL, VENTILATION:POTENTIAL PHENOPERIDINE INVOLVEMENT ?:F. LEMOINE, JL. RICÖME C. RICHARD, D. KHAYAT, A. RIMAILHO, Ph. AUZEPY - Hôpital de Bicetre - 94270 LE KREMLIN-BICETRE (France).

Acute colonic dilatation ( $A C D$ ) were one of the most deleterious side effects of mechanical ventilation. The aim of this work was to assess.

1) etiologic factors of $A C D$

2) $A C D$ treatment.

Patients and methods.

9 patients with radiologically proved $A C D$ (ie coecal diameter $>7 \mathrm{~cm}$ ) were selected. The four following etiologic features were studied : a) ventilation modalities (naso-tracheal tube, tracheotomy), b) hypokalemia, c) cirrhosis, d) patients sedation with phenoperidine. Used treatment were : 1) symptomatic medical therapy (enteral nutrition and eventually phenoperidine withdrawal, nasogastric suction), 2) surgical therapy (decompression and local resection).

Results :

6 patients were ventilated by nasotracheal tube, 3 by tracheotomy. As other etiologic factors we found 2 hypokalemia, 3 cirrhosis and 5 patients treated by phenoperidine. None patient were dead during ACD period. High risk of colonic perforation, in spite of initial medical treatment was the reason for surgery in 5 patients.

Conclusion :

Multiple factors inducing ACD with mechanical ventilation were discussed, but we would emphasize the potential phenoperidine involvement. In fact, for three patients ACD resolution followed phenoperidine withdrawal. In one patient a threefold phenoperidine using had induced a threefold $A C D$. In patients submitted to mechanical ventilation phenoperidine will be used with dramatic carefulness. High risk of colonic perforation due to medical treatment inefficacy allowed surgical therapy.

\section{8}

HIGH FREOUENCY JET VENTILATION-A PROSPECTIVE REVIEW OF 100 PATIENTS. A. Sladen, K. Guntupalii, J. Marquez, M. Klain, anä C. McConaha. Surgical Intensive care Unit, Montefiore Hosoital, University of Pittsburgh School of Medicine, Pittsburgh, PA 15213 U.S.A.

High frectuency jet ventilation (HFJV) has been recomnended for treatment of acute respiratory failure (ARF) in critically ill vatients during the postoperative period. The goals of this study were to assess the feasibility and practicality of HFJV for a heterogeneous group of critically ill patients, with ARF, during the postoperative period, to define optimal initial HFJV settings and to observe the concurrent effects of HFJV with PEEP, endotracheal suctioning and weaning. One hundred patients admitted to the SICU and NICU were ventilated with HFJV. The age group ranged from $10-92$ years with $75 \geq 65$ years. The operations included craniotomies and thoracic, abdominal and major vascular procedures. Optimum initial settings were driving pressure $35 \mathrm{psi}$, frequency $100 \mathrm{~min}$, IE ratio $30: 70, \mathrm{FIO}_{2} 0.90$ and PEEP $3-4$ mmHg. The ariving pressure proved to be the primary mode of $\mathrm{CO}_{2}$ elimination, initial mean $\mathrm{PaCO}_{2}$ 35.8. $\mathrm{FIO}_{2}$ and $\mathrm{PEEP}$ were adjusted to provide the desired $\mathrm{PaO}_{2}$ and optimum $2 \mathrm{sp} \cdot 2 \mathrm{~T}$. Cardiorespiratory profiles indicated that QsP.QT would be reduced a mean of $30 \%$ by the adaition of PEEP 10 mming but was associated with a simultaneous decrease in mean CI from 3.39 to 2.81 L.M2 . Endotracheal suctioning with HFJV resulted in a $\triangle$ $\mathrm{PaO}_{2}$ of 15 mmHg compared to 90 mimHg without HFJV. Weaning was achieved by progressively decreasing the driving pressure. Patients subsequently reported that they were comfortable spontaneously breathing at a rate of $10-20$.min while HFJV continued at 100 .min. ICU physicians and nurses found the patients were easy to wean using HFJV. Eightyfive of the 100 patients were extubated within a 24 hour period; fifteen demonstrated criteria consistent with continued ARF and required HFJV for $<14$ days.

HFJV offers a new and improved technique for patients with $A R F$ in the postoperative period.

\section{0}

COMPARISON OF THE CARDIOVASCULAR EFFECTS OF HIGH FREQUENCY JET VENTILATION AND CONTINUOUS POSITIVE PRESSURE. VENTILATION IN THE NORMOVOLEMIC DOG. M.Chiaranda, E.Facco, G.Fiore, G. Pittoni, G.P.Giron, Inst. of Anaesthesiology and Intensive Care, University of Padua, Italy.

High frequency jet ventilation (HFJV) has proved to ensure an adequate alveolar ventilation with low peak airway pressure and small tidal volume (Vt). This may be advantageous in situations when the $V t$ at conventional intermittent (IPPV) or continuous (CPPV) positive pressure ventilation encroaches on the horizontal portion of the lung $P-V$ curve.

Six healthy Beagle dogs, $11 \div 17 \mathrm{~kg}$, were anaesthetized, paralized and intubated in the standard fashion. Sistemic, central venous and pulmonary arterial blood pressure, cardiac output via the thermodilution technique, arterial and mixed venous blood gases, airway pressure (Paw) at the end of the endotracheal tube and oesophageal pressure were monitored. The cardiac (CI), stroke (SI) and other cardiorespiratory indices were calculated using the standard equations. Ventilation with air was performed randomly alternating a volume-cycled ventilator at $15 \mathrm{~b} / \mathrm{m}$ with an HFJV apparatus (VJP system) at $60,120,240,480 \mathrm{~b} / \mathrm{m}$. Vt was regulated to maintain $\mathrm{PaCO}_{2}$ at $38^{+2} \mathrm{mmHg}$. Cardiorespiratory values were obtained after stabilization for both modes of ventilation increasing positive end expiratory pressure (PEEP) progress $i$ vely from 0 to $2.0 \mathrm{kPa}$.

The use of PEEP significantly decreased the $\mathrm{CI}$ in all modes of ventilation. The transition from IPPV or CPPV to HFJV at 60 and $120 \mathrm{~b} / \mathrm{m}$, wi th PEEP held constant, led to a significant reduction of the inspiratory peak and an improvement of $\mathrm{Cl}$ and SI due to the reduction of mean Paw. This improvement was more evident at PEEP $2.0 \mathrm{kPa}$. At frequencies of $480 \mathrm{~b} / \mathrm{m}$ the increase of intrathoracic volume and of mean Paw markedly increased haemodynamic depression.

The results confirm the efficacy of HFJV, at adequate frequencies, when the reduction of $V t$ brings about $a$ reduction of the cardiovascular depression and reduces the risk of 'barotrauma'. 
421

SUPPRESSION OF SPONTANEOUS BREATHING DURING HIGH FREQUENCY VENTILATION. A.J. van Vught, A.

Versprille, J.R.C. Jansen, Pathophysiological lab., dept. of pulmonary diseases, Erasmus University, P.O. Box 1738, 3000 DR Rotterdam, and the Pediatric Intensive Care Unit, University Children's Hospital Het Wilhelmina kinderziekenhuis, P.o. Box 18009, 3501 CA Utrecht, The Netherlands

We investigatea whether and under which circumstances suppression of spontaneous breathing occurs during high frequency ventilation. Yorkshire piglets were ventilated with a high frequency jet ventilator under pentobarbital anaesthesia. The highest $\mathrm{PaCO}_{2}$ at which the animals did not breath against the ventilator $\left(\mathrm{PaCO}_{2}{ }^{-}\right.$ apnea) was established during different patterns of ventilation. Where necessary for compensation of hyperventilation this was done by adding $\mathrm{CO}_{2}$ to the respiratory gases. Arterial oxygen tension was kept above $100 \mathrm{mmHg}$.

Suppression of spontaneous breathing activity could be obtained during ventilation with higher frequencies, irrespective the tidal volume and the insufflatory flow velocity. So, the mode of dynamic activation of the stretch receptors was rejected as a causal mechanism. Positive end expiratory pressure (PEEP), increasing with higher frequencies, suppressed the spontaneous breathing activity, also at a constant ventilatory rate. However, a hysteresis effect in the relation $\mathrm{PaCO}_{2}$-apnea versus PEEP was found, which suggests that the suppression of spontaneous breathing during high frequency ventilation depends on the end expiratory volume rather than the end expiratory pressure.
CORRELATION OF END-TIDAL TO ARTERIAL CARBON DIOXIDE TENSION IN ADULTS ON CONTROLLED VENTILATION

A. Vuori and P. Jaakkola, Department of Anaesthesiology, University of Turku, Turku, FinTand.

Alveolar carbon dioxide tension is in balance with the pulmonary capiliary and arterial blood carbon dioxide tension. Thus, end-tidal carbon dioxide tension $\left(\mathrm{P}_{\mathrm{ET}} \mathrm{CO}_{2}\right)$ can offer usefut information concerning the adequacy of ventilation. In order to find out the correlation between $\mathrm{P}_{\mathrm{ETCO}}$ and the arterial carbon dioxide tension $\left(\mathrm{P}_{2} \mathrm{CO}_{2}\right)$, linear rearession analysis was performed between 250 values of $\mathrm{PETCO}_{2}$ and simultaneous Ty obtained $\mathrm{P}_{a} \mathrm{CO}_{2}$ values. The $\mathrm{P}_{\mathrm{ET}} \mathrm{CO}_{2}$ was determined using an infrared carbon dioxide analyser (Datex Normocap).

The correlation was found good in patients on controlled mechanical ventilation (CMV) after open-heart surgery. The correlation coefficient $(r)$ was 0.858 for a volumecycled ventilator (Servo 900B; $n=176$ ) and the $r$ was 0.722 for a ventilator using a continuous fresh gas flow via the T-piece (IMV Bird; $n=29$ ). The aas samples were obtained from a sampling adapter interposed between the intubation tube and the T-piece. Thus, with the sampling method used, fresh gas flow via the T-piece may mix with the respiratory gases and affect the reliability of $\mathrm{PETCO}_{2}$ monitoring. In another series of samples, obtained from patients on CMV using the Servo 900B ventilators, the $r$ was 0.898 for samples drawn directly from the intubation tube at the mouth level $(n=26)$, while the $r$ was 0.792 for samples drawn from the aforementioned adapter $(n=19)$. Both samples correlate well with the $\mathrm{P}_{2} \mathrm{CO}_{2}$, but it may be concluded that for best precision it is advantageous to draw the expiratory gas sample directly from the intubation tube.

\section{4}

PULMONARY EMBOLISM (P.E.) IN ACUTE RESPIRATORY FAILURE (ARE) OF CHRONIC OBSTRUCTIVE LUNG DISEASE (COLD) : INTEREST OF THE MAXIMUM EXPIRED PARTIAL PRESSURE OF $\mathrm{CO}_{2}$ $\left(\mathrm{PEMCO}_{2}\right), C$. Chopin, J. Mangalaboyi, F. Fourrier, $A$. Durocher, D. Dubois, $F$. Watter, Service de Reanimation, Hopital Calmette, C.H.U. Lille, FRANCE. In the patient, without any previous lung disease, the measurement of the difference between $\mathrm{PaCO}_{2}$ and end expiratory $\mathrm{PCO}_{2}$. $\left.P(a-E T) \mathrm{CO}_{2}\right)$ may be an aid for diagnosis of pulmonary embolism (PE). On the contrary $(a-E T) \mathrm{CO}_{2}$ in COLD patients, is increased whatever be the cause of the ARF. Then the difference is linked with the ventilation/perfusion ratio mismatching and is due to both alveolar mixing defect (ventilatory mechanism) and dead space effect (circulatory mechanism). We speculate that the ventilatory part of the difference could be cancelled by forced expiration. 18 COLD patients with suspicious $P E$ support our study. Pulmonary angiography and $\mathrm{PEMCO}_{2}$ are performed the same day. $\mathrm{PEMCO}_{2}$ is calculated by continuous recording of forced expired $\mathrm{CO}_{2}$ and simultaneous determination of $\mathrm{RaCO}_{2} . \triangle P(a-P E M) \mathrm{CO}_{2}$ is then computed, and also the ratio $D=\triangle P(a-P E M) C_{2} / P E M C O_{2}$. The diagnosis of $P E$ was supported when $D \geqslant 5 \%$ and excluded when $D<5 \%$. It was confirmed by pulmonary angiography. The results are reported on the table.

We concluded that the determination of $\mathrm{PEMCO}_{2}$ is an easily, quickly performed test and is an accurate eriteria for angiography indication during ARF in COLD patients.

\begin{tabular}{l|c|c|c|}
\multicolumn{1}{c}{} & \multicolumn{3}{c}{ ANCIOGRAPHY } \\
\cline { 2 - 4 } \multicolumn{1}{c|}{} & $P E+$ & $P E-$ \\
\hline$E$ & $D \geqslant 5 \%$ & 9 & 2 \\
\hline$M$ & $D$ & \\
\cline { 2 - 4 }$O_{2}$ & $D<5 \%$ & 0 & 7 \\
\cline { 2 - 4 } & &
\end{tabular}

Chi square test with Yates correction $p<0,01$ lar highrisk patients, should be intubated and given respiratory theraoy already at the place of accident even if their consciousness has been maintained. 
DTAZEPAM: HAZARDOUS SEDATION OF VENTILATED PATIENTS.

H.J.Rapold, F.Follath, G.Scollo, R.Ritz (Basle)

Diazepam is among the most widely used drugs for the sedation of ventilated patients. However, it does not appear to be generally recognised that this kind of treatment might be responsible for a prolonged depression of the central nervous system and therefore a delay in extubation for many days.

Analysing two cases with massive accumulation of Diazepam and persistent coma the problem of Benzodiazepine-intoxication during sedation of ventilated patients is demonstrated on the basis of measured plasmaconcentrations and the diagnostic and therapeutic use of a new Benzodiazepine-antagonist (Ro 15-1788): 1. a previously healthy 70 year old female with respixatory insufficiency following pulmonary embolism remained comatous duxing 12 days following administration of a total dose of $260 \mathrm{mg}$ Diazepam within the first 3 days. Plasmaconcentrations of Diazepam and Desmethyldiazepam were 437 and $483 \mathrm{ng} / \mathrm{ml}, 150$ hours after the last medication; the calculated elimination-halflifes of the two substances were 109 and 403 hours. 2. a 63 year old man with preexisting liver disease had to be ventilated because of severe bacterial pneumonia; following sedation during 16 days with a total dose of $245 \mathrm{mg}$ Diazepam he remained comatous for edditional 6 days. The semiquantitative urinary test for Diazepam was still positive 10 days after discontinuation of the drug. In both cases the Diazepam-induced depression of the central nervous system could be demonstrated and reversed under EEG-controlled conditions by the new Benzodiazepine-antagonist Ro 1.5-1788.

We conclude that Diazepan is not an appropriate drug for long-term sedation because of its pharmacokinetic characteristics; the new Benzodiazepine-antagonist Ro 151788 seems to be a valuable tool in the diagnostic and therapeutic management of Benzodiazepine-intoxications.
DETECTION OF C5A IN ACUTE RESPIRATORY FAILURE BY CHEMILUMINESCENCE.*J.M. Coulaud,*J. Labrousse ${ }^{* *}$ B. Descamps;*Ph. Lesavre,*A. Boudjadja,*J. Lissac *Hôpital Boucicaut**Hôpital Necker - F 75730 PARIS (France).

An increase of $\mathrm{C} 5 \mathrm{a}$ measured by in vitro aggregation of polymorphonuclear granulocytes (PMN) has been detected in plasma of adult respiratory distress syndrome (ARDS) by Hammerschmidt et a1 (Lancet, 1980, 1, 947-949). To assess this phenomenon $\mathrm{C} 5$ a activity was measured by chemiluminescence (CL) in control $A B$ serum before (CS) and after zymosan activation (CSA) and in serum of patients with acute respiratory failure : ARDS, cardiogenic pulmonary edema (CPE), chronic obstructive pulmonary disease (COPD). C5a triggered the production by PMN of free radicals $\mathrm{CO}^{-}$, $\mathrm{H} 202,-02, \mathrm{OH})$ which were assessed by CL (at the 1st mn). The results were first measured in relative light units (RLU), then a CL index was calculated :

$$
\text { CLI } \%=100 \times \frac{\text { RLU (test serum) - RLU (CS). }}{\text { RII (CS) }}
$$

C5a activity was measured in whole serum and in serum fractionated with sephadex 675 , fraction $<20000$ daltons. Results in CLI \% are given on the table ( $\bar{x} \pm \mathrm{SE})$.

$\begin{array}{lcccc}\text { Whole } & \text { CSA } & \text { ARDS } & \text { CPE } & \text { COPD } \\ \text { serum } & \begin{array}{c}246 \pm 80 \\ (\mathrm{n}=10)\end{array} & \begin{array}{c}6 \pm 11 \\ (\mathrm{n}=15)\end{array} & \begin{array}{c}23 \pm 16 \\ (\mathrm{n}=7)\end{array} & \begin{array}{c}41 \pm 15 \\ (\mathrm{n}=7)\end{array} \\ \begin{array}{cccc}\text { Fractionated } \\ \text { serum }\end{array} & \begin{array}{c}277 \pm 91 \\ (\mathrm{n}=7)\end{array} & \begin{array}{l}128 \pm 36 \\ (\mathrm{n}=7)\end{array} & \begin{array}{l}-18 \pm 9 \\ (\mathrm{n}=5)\end{array} & \begin{array}{c}4 \pm 37 \\ (\mathrm{n}=6)\end{array}\end{array}$

The present study shows that low molecular weight fractions of ARDS serums are able to induce a CL response, suggesting the presence of $\mathrm{C5a}$. The non activation of PMN by whole serum is probably due to C5a inhibitors. By detecting the production of oxygen radicals, only with ARDS serums, our results contribute to the pathogenesis of this syndrome.

\section{6}

COLLOID OSMOTIC-PULMONARY ARTERY WEDGE PRESSURE GRADIENT IN ACUTE RESPIRATORY FAILURE. A. Brienza, F.Bruno, G. Belpiede and M.P.Cecere. Institute of Anesthesiology, University of Bari, Italy.

To evaluate the relationship between different colloid osmotic-pulmonary artery wedge pressure gradients(COP-PAPW) and gas exchange, COP-PAPIN values (Group A: $>9$ torr; B:9-5; $C: 5-3 ; D<3$ )were correlated with shunt (Qs/Qt) and alveolar arterial oxygen difference $\left(A-a D_{2}\right)$ in 15 septic patients (12. died) in Acute Respiratory Failure (ARF). ARF was characterized by: $\mathrm{A}-\mathrm{aDO}=313 \pm 115 ; \mathrm{Qs} / \mathrm{Qt}=22 \pm 9 \%$; Cardiac Index $(\mathrm{CI})=$ $4 \pm 1.3$ (mean $\$$ sd) and radiological findings of oedema. The mean $\pm \mathrm{s} d$ values of pressures were: $\mathrm{COP}=16 \pm 3.6$ torr, $\mathrm{PAPW}$ $=13 \pm 4$ tarr, $\mathrm{COP}-\mathrm{PAPT}=3.3 \pm 5$ torr. Data were obtained by oncometer and Swan-Ganz thermodilution catheters.

Results. Different COP-PAP $\mathrm{did}$ not correlate with Qs/Ot and $\mathrm{A}-\mathrm{aDO}{ }_{2}$ (see Table).

\begin{tabular}{|c|c|c|c|c|}
\hline & Group & $\mathrm{n}^{*}$ & $r$ & $p$ \\
\hline$(\mathrm{COP}-\mathrm{PAPN})-\mathrm{Qs} / \mathrm{Qt}$ & A & 16 & -0.41 & - \\
\hline$" 1 "$ & $B$ & 23 & 0.01 & - \\
\hline \multirow{3}{*}{ " } & C & 9 & -0.53 & - \\
\hline & $\mathrm{D}$ & 52 & -0.35 & $<0.01$ \\
\hline & & 100 & -0.30 & $<0.01$ \\
\hline \multirow{2}{*}{$\begin{array}{cc}(\mathrm{COP}-\mathrm{PAPW})-\mathrm{A}-\mathrm{aDO} \\
"\end{array}$} & $\mathrm{~A}$ & 16 & -0.49 & - \\
\hline & B & 23 & -0.18 & - \\
\hline$"$ & $\mathrm{c}$ & 9 & -0.66 & - \\
\hline$"$ & D & 52 & -0.33 & $<0.05$ \\
\hline " & & 100 & -0.24 & $<0.05$ \\
\hline
\end{tabular}

$\mathrm{n}^{*}=$ number of measurements

Conclusions. In ARF different COP-PAPIV values do not influence the gas exchange

\section{8}

INCREASED WORK OF BREATHING WITH DEMAND FLOWCPAP-SYSTEMS. W.R. Thies, P. Härter, K.J. Falke Universitätsklinik Düsseldorf, FRG Patients receiving CPAP-therapy frequently develop signs of respiratory distress, especially infants, when a demand flow type of ventilator is employed. We compared several demand flow systems with a continuous flow system in respect of the inspiratory work of breathing using a mechanical lung model. The continuous flow system consisted of a reservoir of 15 land a gas flow of $70 \mathrm{l} / \mathrm{min}$. Endotracheal tubes of $4.5,6.5$, and $8.5 \mathrm{mmID}$, various tidal volumes, and different respiratory frequencies were used. Pressurevolume-, pressure-flow-, and flow-volume-curves were recorded. A strong dependency between work of breathing and tube diameters became evident. A typical example is demonstrated below, simulating conditions in an infant: tube diameter $4.5 \mathrm{~mm}, V_{\mathrm{T}} 80 \mathrm{ml}$, RF $24 / \mathrm{min}, \mathrm{PEEP} 0$. The total inspiratory work of breathing increased with the demand flow system by $20 \%$ and the inspiratory flow resistive work by $100 \%$. During the first third of the breathing cycle those values were $240 \%$ and $400 \%$ respectively. That enlights the strong efforts which were necessary just for opening the demand valve. We have established evidence that demand flow systems may not be suitable in situations with increased respiratory resistances

continuous flow CPAP

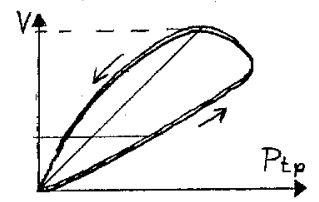

demand flow CPAP

$\checkmark 4$

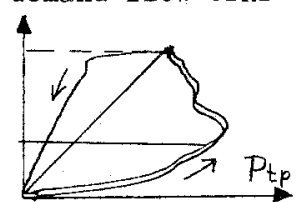


429

MONITORING OF GAS EXCHANGE AND ENERGY EXPENDITURE IN RESPIRATOR PATIENTS. P Kri11, B Högman, Engström Medical AB, Box 20109, S-16120 Bromma, Sweden

Information regarding $\mathrm{O}_{2}$-uptake, $\mathrm{CO}_{2}$-el imination, respiratory quotient and metabolic rate is important for the determination of both certain haemodynamic parameters and relevant supply of parentera] nutrition. Unti] recently, the most commonly used method of getting these pieces of information involved using a Douglas bag and mass spectrometry. Drawbacks with this method are:

- the equipment is huge and expensive.

- the operation of the equipment is time consuming and requires special education.

In order to avoid those drawbacks we have designed a device based on indirect calorimetry and intended for measurements on patients connected to an Engström Erica respirator. Inspired and expired gas samples are analysed by an electrochemical $\mathrm{O}_{2}$-sensor and an external $\mathrm{CO}_{2}-$ analyser. Tidal volume information is retrieved from the ventilator. From values measured every 30 seconds, the $0_{2}$-uptake, $\mathrm{CO}_{2}$-elimination, respiratory quotient and metabolic rate are calculated. The results are available both as one-minute mean and as trend values.

The difficulties associated with al1 the methods used consist in that

- the gas samples are taken at different humidity, temperature and pressure levels.

- inspired and expired volumes differ.

- the small concentration differences to be measured. The influence of these factors has been minimized with the aid of automatic $0_{2}$-sensor calibration, microprocessor-based numerical compensations and gas sample adaptation in a special tubing.

Comparison tests with a mass spectrometer using a test model show a difference of less than 8 percent between the two methods. Clinical evaluation on patients is in progress.

\section{1}

NITROGLYCERIN INFUSION EFFECTS IN PATIENTS WITH CHRONIC OBSTRUCTIVE LUNG DISEASE UNDER CONTROLLED VENTLATION. B. Stimmesse, A. Boillot, F. Barele. Service de Réanimation, C.H.U. Saint-Jacques, Besanço:, France.

The aim of this research was to determine the effects of $\mathrm{Ni}$ troglycerine (NG) infusion on pulmonary circulation in patients with chronic obstructive lung disease (C.O.L.D.).

In 26 patients with severe C.O.L.D. under controlled ventilation, we have studied, after insertion of right heart and arterial radial catheters, haemodynamic effects and blood gas changes for an infusion rate of $\mathrm{NG}$ of $1 \mathrm{O}, 20,40 \mu \mathrm{g} \cdot \mathrm{mn}^{-1}$. In addition, 10 of the 26 patients had a volume loading with $N G_{\text {, }}$ and without NG after return to control values.

Before NG infusion, we observed, in all cases, an increase of mean pulmonary pressures (PAP), an increase of pulmonary resistances, and an increase of right systolic work index. None of the patients had features of left heart failure. After NG infusion, we noted a significant decrease in the systolic cardiac index producing a reduction of PAP, without any changes in pulmonary or peripheral resistances. Left and right systolic work decreased. All these haemodynamic changes were in direct proportion with NG rate. There were no significant changes in $\mathrm{PaO} 2, \mathrm{PaCO} 2$ except an increase in 2, 3 Diphosphoglycerate with NG. In addition, volume loading, resulted in an increase of right and left pre-loads and after loads, with and without NG. Cardiac out put and the systolic index increased with volume loading with NG, while they did not change with volume loading without NG.

These results suggest that, during the acute course of respiratory failure in patients with C.O.L.D. under controlled ventilation, NG, may be useful particularly on right overlaod allowing the patient to leave the artificial respirator more quickly.

\section{2}

PNEUMONIA COMPLICATING SELF POISONING WITH PSYCHDACTIVE DRUGS.Offenstadt $G$, Gabillet $G$, Héricord $P$, Pinta $P$, Tembely $A$, Amstutz P - Hôpital Saint-Antoine - 75012 Paris France.

474 patients admitted in ICU between 1976 and 1981 were retrospectively analysed. Pneumonia $(P)$ was assessed by condensation on chest $X$ ray.

- $P$ developped in 67 patients (group I). In group I mean age $(40,4 \pm 18$ years) was higher than in patients without $P$ (group II) $p<0,001$. In group I, $P$ was present at admission in 53,7 p.cent of the cases. 24 hours after admission 77,6 p.cent of $P$ had appeared.

- Initial location was unilateral in 79,4 p.cent with predilection to the inferior half of the right lung (72p.cent). Fever was more frequent in group I ( 89,5 p.cent) than in group II $(37,7$ p.cent $) p<0,001$.

- Promoting factors were observed :

- Delay between ingestion and admission was much longer in group I $27,6 \pm 37,4 \mathrm{~h}$ than in group II $7,7 \div 9,4(p<0,001)$.

- Vomiting and tracheobronchial embarassment were more frequent in group I, respectively 17,7 p.cent and $63,2 \mathrm{p}$.cent than in group II 3,7 p.cent and 20,7 p.cent $(p<0,00.1)$.

- Coma was deeper in group I $(2,3 \pm 0,8)$ than in group II $(1,4-0,9)$ p $<0,001$. Quantifications of depth was obtained by giving to comas values from 0 to 4 .

- Evolution was most of ten favarable :

- recovery was simple in 83,8 p.cent of cases in less than 4 days ( 50 p.cent) and with antibiotics in 83,4 p.cent.

- Abcedation appeared in 3 cases.

- The overall mortality was 2,8 p.cent (14 patients); 6 died because only of $P$, in 4 others, $P$ was aggravating.

- At last duration in ICU was much longer in group I $(9 \pm 8,1$ days $)$ than in II $(2,5 \pm 2,1)$ p $<0,001$

- $P$ is major complication of self poisoning with psychoactive drugs. Prevention must be a main objectif. 
433

PROCOLLAGEN-III-PEPTIDE IN PROGRESSIVE RESPIRATORY FAILURE AFTER PARAQUAT INTOXICATION. J.LOhmann, G.Pott, H.P.Bertram, U.Gerlach, Medizinische Universitätsklinik, Münster, W-Germany Patients with severe paraquat poisoning often died because of respiratory failure.Changes in pulmonary function are due to a progressive pulmonary fibrosis 8 to 10 days after intoxication. Procollagen-III-peptide (P-III-P) was measured enhanced by radioimmuno assay in patients with fibrosis of the liver. We determined P-III-P in serum of 4 patients who died after ingestion of paraquat and in 2 patients who survived. In case of the non-survivors P-III-P increased to 4 fold of normal values. In case of the survivors P-III-P slightly increased then no further progression was. seen. Our data suggest that estimation of P-III-P in serum of patients with para quat intoxications may represent paraquat-induced pulmonary complications.
434

PULMONARY FUNCTION WITH ACUTE LOSS OF EXCESS LUNG WATER BY HEMODYALISIS IN PATIENTS WITH CHRONIC UREMIA. A. Artigas, S. Benito, J. Sanchis, M. Rodá. Hospital de Ia Santa Creu $i$ Sant Pau. Barcetone. Spain.

Lung function in 12 patients with advanced renal faiture on chronic hemodialysis progrom was studied. With de patients in the seated position, both before and after hemodyalisis lung volumes, flow rates, diffusing lung copacity (DLco) by the single breath technic and anteriat blood gases were measured. The $\mathrm{P}(A-a) 02$ and $\mathrm{Q}$ s/Qtot were measured with a FiO2 1. Before dialysis a restmictive pattern was observed, with nomal EEF $25-75 \%$ and reduced lung vozumes. With removal of body fluid ( $\Delta$ weight $4,2 \pm 1,0.1 \%$ ) the residuat volume decreased $(p<0,01)$ further with a concomittant increase in vital capacity and EEF $25-75 \%$

$(p<0,01)$ with an increase in the bronchoditator test ( $p<0,05)$. Dialysis resulted in no significant change in TLC, F'RC or DLCo. P(A-a) 02 (76 $\pm 25 \mathrm{mmHg}$ before diatysis) imorovised in 8 patients after dialysis (mean value $64 \pm 15$ motig, $p(0,05)$. These results reflected reversible airway closure and gas trapping due to accumulation of edema around smali airways with improvement of ventilation-perfusion ratio. 
INVASIVENESS SCORING SYSTEM (ISS): STUDY ON THE PROCEDURERELATED INFECTIONS IN INTENSIVE CARE PATIENTS. P.Geraci, R.V. Dionigi, L.Carnevale, A.Pernigotti, M.Maure11i, G.Lorenzon Vos, A.Mapelli, Rianimazione II, Policlinico, Pavia, Italia Invasive procedures that are potential vehicles of infection were scored according to seat, technique and during of application, using a scoring system (ISS) ${ }^{1}$, in order to value the relation among nosocomial infections, extent of invasion and other risk factors in Intensive Care (ICU) patients (pts). 100 pts (9-82 years, mean 50.7), admitted to ICU for 3 days at least because of different ailments, were sorted in 4 groups $(A-D)$ according to the aggregate score of ISS (IS), growing from $A$ to $D$, during their stay in $104(15.5 \pm 9.3$ days $)$.

The mean infection rate was $60 \%: 18.5 \%$ in group $A, 100 \%$ in $D$. Significative correlation was found between IS and number of infectious episodes per patient $(n i / p)(p<0.001)$ and between $\mathrm{ni} / \mathrm{p}$ and during of stay $(\mathrm{p}<0.002)$. Infection rate resulted more significantly related to IS $(p<0.01)$ than to during of stay $(p<0.05)$. No significative correlation was found between infection rate and patient's age and between infection rate and immunodeficiency from corticosteroid therapy. A moderate invasiveness have not a predominant roll for infection's rise in comparison to the during of stay, the immunodeficiency and the age; it is dangerous when it gets over a medium leve1; then, it seems to increase any other risk factor. The ISS proved to be usefull for studying comparatively heterageneous pts and it could have a clinical application, if calculated at the beginning of the stay in ICU, in order to identificate pts with high risk of procedure-related infection.

${ }^{1}$ Geraci P. et al., Atti $34^{\circ}$ Congresso SIAARTI, 1982; in press.
MICROBIAL SPECTRUM AND RESISTANCE TO ANTIBIOTICS IN A MEDICAL IHTENSIVE GARE UHIT DURIHG THE COUR SE OF 4 YEARS.J.Majdandzic, H.P. Schuster, M.ReuB, L.S. Weilemann. II.Med.Clinic of the University, D-6500 Mainz,FPG.

In a retrospective study we compared routinely performed done microbiological analyses of tracheal secretions (TS) and catheter urine (CU) in the period of $1976 / 77$ to $1978 / 79$. The percentage of sterile TS-specimen remained constant (17\%) while mixed cultures decreased from $47 \%$ to $39 \%$ of positive cultures. The relative frequency of different bacterias found in TS changed remarkably:1976/77 Klebsiellae were found most often $(36 \%)$ followed by Pseudomonas aeruginosa (34\%) and E.coli (18\%).1978/79 Pseudomonas aer. remained equally frequent ( $35 \%$ ), Klebsiellae fell back to third place (21\%), but Staphylococcus aureus was second $(33 \%)$. In 1976/77 Staph. aureus had not been found in one single patient.

$1976 / 7760 \%$ of all catheter urines (CU) were sterile,1978/79 even $73 \%$. In both groups Candida species were in first place with $16 \%$. Klebsiellae made up $11 \%$ in $1976 / 77$, in $1978 / 79$ they were not found.Klebsiellae showed reduction in number of resistant strains against cephalosporines from $67 \%$ to $2 \%$. Similar reduction of reistance was seen in E.coli with $59 \%$ to $5 \%$ and Pseudomonas aeruginosa from $77 \%$ to $9 \%$. In $1976 / 7784 \%$ of the samples with Enterobacter cloacae were resistant to cephalosporines, $1978 / 79$ only $52 \%$.P seudomonas aeruginosa got increasingly resistant to aminoglycosides.

\section{2}

SPECTRUM OF NOSOCOMIAL MICROORGANISMS IN AN ORIGINALLY OPEN AND LATER ON STRICTLY CLOSED NEUROSURGICAL INTENSIVE CARE. UNIT (DAILY MICROBIOLOGICAL SURVEILLANCE OF 601 PATIENTS).

A. Karimi und K.P. Schaal; Neurochirurgische Klinik und Hygiene-Institut der Universität zu Köln.

Before reconstruction and air-conditioning of two neurosurgical operating-theatres and an adjacent, completely open intensive care unit, tracheobronchial secretions and urine samples from 100 patients attended in this unit were daily examined for nosocomial and other microorganisms. After the reconstruction project including installation of an air-conditioning system with highperformance filters and strict structural and organizational separation of the unit from other parts of the hospital had beed completed, the daily microbiological surveiliance was continued for two years and provided data from 500 patients.

A comparison of frequency, species distribution and clinical significance of the microbes obtained from the unit which was run all the time with the same personnel, before and after reconstruction revealed the specific problems associated with a strictly isolated ward. In addition, the changes observed in the spectrum of the nosocomial bacteria, thein antibiotic susceptibility patterns and their clinical significance could be used to evaluate the therapeutic measures employed and to establish more appropriate therapeutic schemes if necessary.

\section{4}

ICU ACQUIRED PNEUNONIA: A PROSPECTIVE STUDY. M.LAnEeT, S.Vesconi, MoSolca, A.Graziina. Istituto di Anestesiologia e Rianirazione, Ospedale Policlinico, Milan/Italy Incidence, time of onset, and mortality of ICU acquired pulmonary infection was evaluated in 96 pts from 2 Units (general and neurosurgical) in a period of 6 months. Pts with an ICU stay less than $48 \mathrm{~h}$, preexisting pulmonary infection and irreversible brain damage were excluded. In the 96 study. the mean value of therapentic Index Score System (CULLN) was 33.9 $13.68 \mathrm{pts}$ (71\%) requi red continuous mechanical ventilation for longer than $24 \mathrm{~h}$ (median 8 days). Pts were considered to have eitherpespira tory tract infection if they had persistent fever and consistent clinical data, or pneumonia if a persistend infiltrate on chest $X$-ray film was also present. Overall mortality was $25 / 96$ pts $(26 \%) .46 \mathrm{pts}$ had pulmonarylinfection, 25 pneumonia (mortality $=60 \%$ ), 21 respirata ry|tract infection without infiltrate (iontelity $=28.5 \%$ ); $50 \mathrm{pts}$ (mortality $=8 \%$ ) did not develop pulmonary infection. Mortality rates observed in the 3 groups are significantly different $(p<0.0005)$.

Among pta with pneumonia, the onset of infection was sur prisingly early in over $50 \%$ f cases. ( $t$ able)

$\begin{array}{lrrr}\text { pneumonia onset(ICU day) } & 1-3 & 4-7 & 8 \\ \text { INo pts/expired } & 14 / 5 & 6 / 5 & 6 / 6 \\ \text { \% of ICU acquired pneumonias } & 56 & 24 & 20\end{array}$

Pneumonia with later onset was associated with a significantly higher mortality $(p<0.025)$.

Beside the well known high mortality rate associated with pulmonary infection in ICU pts, this strdy emphasizes the high incidence of early onset pneumonias. 
IEGIONEITA INFECTION IN AN INTENSIVE CARE UNIT FROM 1977 To 1.982. W. Donald Munro, City Hospital the University of Nottingham, England.

Tegionaires disease first appeared in an identifiable form in the Nottingham area in 1977. Initially identification of the disease was difficult and early blood specimens had to be sent to the National Centre for Disease Control in Atlanta, Georgia, USA, for identification of antibodies. This did not help early diagnosis; even when immunological identification became available locally the delay of fourteen days for a sienificant antibody response precluded the rapid recognition of the disease by that means. Fortunately distinctive radiological, biochemical and haematological changes came to be recognised. Patients could therefore be treated early on the basis of these findings alone with Erythromycin, which appears to be almost the only available effective antibiotic which is effective in this disease.

Almost all the patients referred to the intensive care unit required prolonged lung ventilation with (at times) very high levels of inspired oxygen. Intravenous nutrition was often required for long periods although naso gastric feeding was preferred when ever this was possible. Renal failure, when it occurred required dialysis.

A review of the incidence of pneumonia cases since 1973 suggests that there is now a cyclical legionalla factor occurring every two years in those patients requiring mechanical respiratory support.
STAPHYLOCOCCUS COAGULASE NEgATIVE (STAF-) IN BLOOD SAMPLES. EVALUATION AND CLINICAL IMPLICATIONS. E, Dominguez de Villota, JM Mosquera, A. Algora, JJ Rubio, M. Roig, P. Galdos. Intensive Care Unit. Clínica Puerta de Hierro. San Martin de Porres 4. Madrid 35. SPAlN

The STAF- isolated in blood may be dismissed as contami nants. However, STAF- septicaemias (SEPT) are well recognized in patients with intravascular foreing bodies (cardiac prostheses, ventricular-atrial shunts, vascular grafts) Intravascular catheters (VASCATH) are very commonly used in critically ill patients and they may favour the presen ce of STAF- SEPT. in them

CRITERIA to diagnose a STAF- SEPT in this study were: $1 /$ clinical septic condition, $2 /$ isolation of STAF- in at least two blood culture bottles and $3 /$ presen ce of VASCATH whether or not the STAF - was isolated from tem.

RESULTS.- Among the 1141 admissions to our ICU, 504 had blood cultures taken and they were positive in 210 patients ( $15 \%$ incidence).

In 44 ( $9 \%$ of all blood cultures) STAF- was isolated. However, in $32(73 \%)$ was considered as contaminant and only

in $12 .(27 \%)$ as pathogenic for the above criteria were met. The STAF - was isolated in 4 patients in the course of a "multiple species septicaemia" and in 8 was the only organism isolated (mean of 3.6 bottles). One patient with endocarditis in a valvular prostes is was excluded. Hence in 7 patients the STAF- was thought to be the responsible of a "primary STAF- SEPT".

Their mean age was 68.3 years (range $51-73$ years). All patients had VASCATH (mean 1.9/per patient) with a mean duration of catheterization $(n=6)$ of 7.2 days (range 2-15 days). In 5 STAF- was cultivated from the catheter's tip. One patient developped shock during the SEPT.

CONCLUSIONS STAF- appears frequently in blood samples, but usually represents a contamination. However, the repetitive isolation of STAF- in blood samples in patients with VASCATH must be considered as a relevant finding concerning the posibility of a STAF - SEPT.

ACUTE GENERALIZED PERITONITIS (AGP) DEVELOPMENT IN INTEN= SIVE CARE UNIT (ICU). F. Bobbio Pallavicini,A.Braschi,V. Emmi , G. Negri, C. Reposi, G. Iotti, F. Raimondi, M. Fischetti, P. Tosi, M.Ferrera, D.Carbonera. Rianimazione I0, Ospedale San Matteo, Università di Pavia, Italia.

According to literature, mortality of patients suffering from AGP is higher than $50 \%$ (in some cases, higher than $90 \%$ ). In 115 patients (68 primary AGP, 47 secondary AGP) ob= served over 20 months, admitted in ICU for a stay over 5 days, were investigated some factors of probable prognostic meaning: pathogenesis (primary, secondary), source of in= fection (supra- or infra-mesocolic), interval between cli= nical onset and operation, interval between operation and admittance in ICU, stay in ICU, percentage of complica= tions. Total mortality was $40.9 \%$ (39.7\% in primary AGP, $42.6 \%$ in secondary AGP), while mortality in infra-mesoco= lic AGP was significantly lower. The interval between ope= ration and admittance in ICU was nearly the some in the patients who recovered $(1.0-2.6$ days $)$ and in those who died $(0.6-1.4$ days). The interval between clinical onset and operation was remarkably longer for the patients who died. In this last group, the percentage of complications was significantly higher too. According to literature, the investigation confirmed a higher mortality in secondary AGP, a clear connection between operation delay, complica= tions percentage and mortality. In opposition to literatu= re, it showed a mortality significantly higher in the su= pra-mesocolic versus infra-mesocolic peritonitis. The low total mortality percentage is probably due to the early admission to ICU, immediately after the operation, before the onset of haemodynamic, respiratory and/or renal com= plications:
$P$ AND 2-3 DPG. IN SEPSIS.Pinta P,Tran-Minh T, FrancoMontoya ML, Offenstadt G,Clair B,Cannone C, Hatzfeld D. Hôpital Saint-Antoine - 75571 PARIS Cedex 12.

Nineteen patients (A) admitted in ICU for a severe sepsis extensive cellulitis ( 1 ). There were 10 men and 9 vomen. The mean age was 57 years. Deati rate was $79 \%$.

On arterial blood ve measured:blood gas, hemoglobin ( $\mathrm{Hb}$ ), 2-3 diphosphoglycerate (2-3 DPG), standard $P 50$ ( $P 50$ std) from the axyhemoglobin dissociation curve (OCD) (dynamic method). 49 samples vere performed, Il patients have had daily studies.12 healthy subjects (B) vere also studied.

\begin{tabular}{|c|c|c|c|c|c|}
\hline & A & $B$ & & 2-3 DPG & P5O Std \\
\hline \begin{tabular}{|l|} 
Pa 02 \\
Torr \\
\end{tabular} & $\begin{array}{r}71,4 \\
+26,4 \\
\end{array}$ & $\begin{array}{r}89,6 \\
\pm 6,6 \\
\end{array}$ & P5O Std & $r=0,80^{* *}$ & \\
\hline $\mathrm{pH}$ & $\begin{array}{r}7,42 \\
\pm \quad 0,09 \\
\end{array}$ & $\begin{array}{r}7,41 \\
-0,02 \\
\end{array}$ & $\mathrm{pH}$ & $r=0,51^{* *}$ & $r=0,38^{*}$ \\
\hline $\begin{array}{l}\text { P50 Std } \\
\text { Torr }\end{array}$ & $\begin{array}{r}28,7^{*} \\
\pm \quad 1,9 \\
\end{array}$ & $\begin{array}{l}27,2 \\
\pm 0,3 \\
\end{array}$ & $\mathrm{~Pa} 02$ & NS & NS \\
\hline $\begin{array}{l}2-3 \mathrm{DPG} \\
\mathrm{mol} / \mathrm{g} \mathrm{Hb}\end{array}$ & $\begin{array}{r}18,5^{*} \\
\pm 4,2 \\
\end{array}$ & $\begin{array}{l}14,8 \\
\pm 1,1 \\
\end{array}$ & $H b$ & NS & NS \\
\hline $\begin{array}{l}\mathrm{Hb} \\
\mathrm{mg} / 100 \mathrm{ml}\end{array}$ & $\begin{array}{r}10,3 \\
\pm \quad 1,45 \\
\end{array}$ & $\begin{array}{l}13 \\
\pm 1 \\
-1\end{array}$ & & *** & \\
\hline
\end{tabular}

Large and unforeseeable variations of P50 Std and 2-3 DPG were observed. There was a stricking right shift of the ODC. We found no definite explanation to this shift. Hypoxemia and anemia are theorical causes, but in our study there was no correlation between $\mathrm{P} 50$ Std and $\mathrm{Pa} 02$ or $\mathrm{Hb}$, either between 2-3 DPG and $\mathrm{Pa} \mathrm{O} 2$ or $\mathrm{Hb}$.

In current practice, blood oxygenation should be assessed by simultaneous measurement of oxygen arterial pressure and oxyhemoglobin saturation. were studied:septicemia (7), pneumonia (6), peritonitis (5), 
CIMETIDINE VERSUS CIMETIDINE PLUS PIRENZEPINE IN PREVENTING UPPER GASTROINTESTINAL TRACT BLEEDING IN PATIENIS OF AN INTENSIVE CARE UNIT - A RANDOMISED, PROSPECTIVE, CONTROLLED CLINICAL TRIAL -

R.-D. Hanrath, B.K. Bouillon, W.-P. Fritsch, T. Scholten, Med. Kliniken, Universität Düsseldorf, FRG

Introduction: The combination of cimetidine and pirenzepine results in a stronger and longer lasting suppression of gastric acid secretion than cimetidine alone. Therefore cimetidine plus pirenzepine should be more effective in the prevention of upper GI-tract bleeding than cimetidine alone. Methods: Patients admitted to the medical intensive care unit of the University of Dusseldorf from May 1982 to November 1982 were included in the study. Upon admission all patients were randomized into one of the two treatment groups $A$ or $B$ by a table of random numbers. Patients with upper GI-tract bleeding, recent GI-tract operations etc. were excluded from the protocol. Those in group A received $200 \mathrm{mgs}$ cimetidine iv every 3 hours during the entire stay in the intensive care unit. Those in group $B$ additionally received $40 \mathrm{mgs}$ of pirenzepine/day by continuous infusion. Results: 95 patients of group $A$ and 105 patients of group $B$ met the criteria. The distribution of patients with regard to sex, age, and severity of illness were comparable for both treatment groups. There was only 1 patient with acute upper GI-tract bleeding and 1 with chronic bleeding in group B. No bleeding was observed in group $A$. Conclusions: In patients of a medical intensive care unit the prophylaxis of upper GI-tract bleeding by cimetidine alone proved to be effective. Therefore no additional positive effect of a combined treatment with cimetidine plus pirenzepine could be shown.
COMPUTER-ASSISTED METHOD FOR EVALUATION AND DOCUMENTATION OF DATA FROM GLUCOSE CONTROLLED INSULIN INFUSION SYSTEMS IN CRITICALLY ILL PATIENTS. G.Miiller-Esch, A. Peters, M. Göhl, M. Mewes, P. C. Scriba, Klinik für Innere Medizin, Medizinische Hochschule Liübeck, Liubeck, Genmany.

Glucose controlled insulin infusion systems (GCIIS) seem to be a valuable tool in the metabolic treatment of critically ill patients. The incidence of 4320 measurements from the GCIIS during a 24-hour control period is the main reason for developing this method, which permits a comfortable handling of a vast number of data. The procedure is based on a BASIC computer programme, that will be demonstratea.

Inputmode: An interface between the GCIIS and the microcomputer PC 800 (MAGIRUS DATENIECHEIK) has been erployed to transfer all data directly at one minute intervals. Further, corments concerning actual therapy can be inserted manually.

Calculations: The following parameters, characterizing the state of carbohydrate metabolism, may be calculated:

- MBG = mean blood glucose

- $M$-value $=$ a measure for the duration and the degree of pathological blood glucose levels (1)

- MAGE = mean amplitude of glycemic excursions (2)

- an index, indicating the sensitivity to insulin. Record:Blood glucose, insulin rate and dextrose rate are plotted continuously. Corments will be printed, too. Documentation: All recorded data are stored on a 5 inch floppy $d \overline{i s k}$.

Conclusion: The method permits complete processing of GCIIS-data, which is almost impossible when confined to manual computation. Its usefulness in the treatment of critically ill patients, especially during metabolic therapy with glucose-insulin-potassium in acute myocar dial infarction, will be demonstrated (Supported by the Federico Foundation).

1. Schlichtkrull, J. et al.:Acta med.Scand.177(1965), 95

2. Service, F. J. et al.: Diabetes $19(1970), 644$ 
ARE PROSTAGLANDINS INVOLVED IN THE DEVELOPEMENT OF ARTERIAL HYPOXIS? R. SCHERER, H. VAN AKEN, P. IAWIN Klinik f.Anaesthesiologie u.operat.Intensivmedizin Jungeblodtplatz 1,D4L00 Minster, West Germany Persistance of blood flow through atelectatic areas of the lung cause hypoxia by increased venous admixture. Hypoxic pulmonary vasoconstriction (HPV) should reduce ventilation perfusion-mismatching.One-lung-anaesthesia is an example of massive atelectasis and a suitable model to study the influence of prostaglandins( $\mathrm{PG}$ ) on intrapulmonary shunting and HPV.

Nine patients were studied during esophageal surgery under two- and one-lung ventilation (TLV,OLV) with $66 \% \mathrm{O}_{2}$ in $\mathrm{N}_{2} \mathrm{O}$ and neurolept anaesthesia.systemic and pulmonary arterial pressures and blood gases and cardiac output were measured.During TLV and OLV arterial and mixed venous levels of PGE and $P G F$ were determined.

Cardiac output and $\mathrm{pCO}_{2}$ did not change significant$1 \mathrm{y}, \mathrm{pO}$ decreased from $219+42 \mathrm{mmHg}(\mathrm{TLV})$ to $74+1.8$ $m m H g(6 L V)(p \leqslant 0,01)$ and $Q 7 Q_{1}$ increased from $14+4 \%$ (TLV) to $43+10 \%$ (OLV) ( $0 \leqslant 8$ P.01).PGE increased from $2.83+1,59 \mathrm{ng} / \mathrm{ml}$ (TLV) to $3,06 \pm 2,21 \mathrm{ng} / \mathrm{ml}$ (OLV) (n.s.) and $\bar{P} G F$ decreased from $0,3 \overline{5}+0,53 \mathrm{ng} / \mathrm{mI}(\mathrm{TLV})$ to

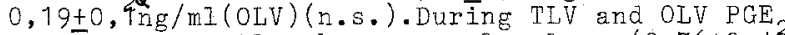
was significantly above normal values $(0,76 \pm 0,47$ ng/ml), while PGF was below normal level $(\overline{0}, 87 \pm$ $0,2 \mathrm{ng} / \mathrm{ml}$ ). Mixed venous PG Ievels were generally below the arterial levels.

These findings indicate a clear prevalence of vasodilating $P G E$ during mechanical ventilation even if massive attelectasis is present. PGE may have partly off'set HPV in the presence of atelectasis.other metabolites of arachidonic acid like prostacyclin could also be inverved.
NEUROGENIC ETIOLOGY OF RESPIRATORY INSUFFICIENCY. I.M. Popova, Institute of Neurology of the USSR Academy of Mecical Sciences, Moscow, USSR The purpose of the study was a quantitative determination of functional pulmonary tests in disturbances of cerebral control of breathing and in paralysis of respiratory muscles. Spirometry was made by means of the "POoL" apparatus (USSR). Gas composition of the blood and acid-base balance were determined by using the equipment of the "Radiometer" Company (Denmark). Disturbance of cerebral control of breathing occurs in lesions of the corticospinal and corticonuclear connexions: a) Unilateral destruction of these systems in the right hemisphere causes the syndrome of partial loss of cerebral control. Spirometry indicated restrictive form of respiratory insufficiency. b) Bilateral destruction of the corticonuclear and corticobulbar connexions in the brain stem leads to complete loss of cerebral control and consequently of voluntary breathing and cough. Automatic control provides gas exchange under condition of free airways (tracheostomy, suction from the tracheobronchial tree). Respiratory insufficiency was referred to obstructive type.

Diseases of peripheral neuron (paralysis of respiratory muscles and bulbar palsy) are followed by respiratory insufficiency of restrictive-obstructive type. Restoration of pulmonary functions occurs within 8 to 12 months from the development of paralyses in acute polyradiculoneuritis. In severe form of myasthenia gravis this type of respiratory insufficiency has been observed for many years.
ACIDIC PHOSPHOLIPIDS IN BRONCHOALVEOLAR LAVAGE DURING RESPIRATORY FAILURE OF THE ADULT.

J.Tahvanainen, M.Hallman, P.Nikki, Department of Anaesthesia, Helsinki University Central Hospital, and Children's Hospital, University of Helsinki, SF-00290 Helsinki 29, Finland

Normal lung surfactant contains prominent phosphatidylglycerol. (PG), or phosphatidylinositol (PI), but only trace of phosphatidylserine (PS). These phospholipids were investigated in lung effluent from 14 adult patients with acute respiratory failure.

31 samples were obtained by bronchoalveolar lavage using a $70 \mathrm{~cm}$ silicone catheter. PG, PI and PS were measured as percentages of total phospholipids in lavage return. Prior to sampling pulmonary venous admixture (Q́s/Q்t) and lung thoracic compliance $(C, m$ ) were measured. $C_{L T}$ correlated significantly with PG $(r=0.61$, $p<.001)$ and PS $(r=-0.62, p<.001)$, but not with PI. No correlation between any of the phospholipids and Qs/Qt was found.

Patients who died of respiratory failure $(n=6)$ had higher PS than those who survived $(n=8)$, i.e. $8.4 \pm 1.2 \%$ vs $3.8 \pm 1.1 \%(\mathrm{p}<.05)$. $\mathrm{C}_{\mathrm{LT}}$ was $30+3 \mathrm{mI} / \mathrm{cm} \mathrm{H}_{2} \mathrm{O}$ in the former group and $4 \overline{6} \pm 8$ $\mathrm{ml} / \mathrm{cm} \mathrm{H}_{3} \mathrm{O}$ in the latter one $(\mathrm{p}<.05)$. $\mathrm{PG}, \mathrm{PI}$ or ós/Q́t values did not differ significantly between these two groups.

Our data suggest that deficient surfactant phospholipids are at least partly responsible of reduced lung elasticity in acute respiratory failure of the adult. Furthermore, a patient with deteriorated lung nechanics and a prominent PS has poor prognosis.

Supported by the Academy of Finland.
NEW SAMPLING TECHNIQUE FOR RESPIRATORY GAS MEASUREMENTS. A.Gedeon ${ }^{+}$, K.Hamilton ${ }^{+}$, S.Häggmark, S.Reiz ${ }^{+}$Engsträm Medica 1, Bromma, Regionsjukhuset Umeå, Umea, Sweden In order to simplify the clinical handing and to improve the response time of medical gas analyzers a new sampiing line has been developed that eliminates water fall out from the sampled gas by acting as a selective permeable membrane for water vapor.

Results: As the gas is drawn into a $\mathrm{CO}_{2}$ or an $0_{2}$ analyzer it passes along the samping tube and by diffusion is gradually equilibrated with the ambient air as regards temperature and relative humidity.

At a flow of $100 \mathrm{ml} / \mathrm{min}$ a $98 \%$ equilibration is achieved in a $30 \mathrm{~cm}$ long tube of diameter $1 \mathrm{~mm}$. For a similar effect to occur at a flow of $400 \mathrm{ml} / \mathrm{min}$ an $80 \mathrm{~cm}$ long tube is needed.

Conclusion: Since no dead space in the form of water traps needs to be introduced in the sampling system -the response time of an instrument is improved by a factor of 3-4 compared to current sytems. In measuring $\mathrm{O}_{2}$ uptake the source of error due to the variable moisture content of inspired and expired gas is effectively eliminated using the present sampling technique. In addition, all units can run continuously and unattended with no risk to the sensors or sampling systems of the instruments. 


\section{5}

LABORATORY EVALUATION OF AN EQUIPMENT FOR CONTINUOUS DXYGEN CONSUMPTION MO NITORING IN MECHANICALLY VENTILATED PATIENTS M. Carlsson, E. Forsberg, A. Thörne, J. Nordenström, G. Hedenstierna, Departments of Anaestesiology, Surgery and Clinical Physiology, Karolinska Institute at Huddinge University Hospital, Sweden.

Continuous measurement of energy expenditure by methods of indirect calorimetry in ventilatory assisted intensive care patients has therapeutic as well as prognostic implications. The ventilator Erika (Engström Medical AB, Sweden) has been supplemented with a device for oxygen uptake measurement and energy expenditure calculation, the Engström Metabolic Computer (EMC). In the EMC, inspiratory and expiratory 02 corcentrations are determined by an electrochemical $\mathrm{O}_{2}$ sensor(Catalyst Research). The inspiratory flow ( $\left.\vec{V}_{I}\right)$ measured by a pneumotachygraph, is used in the calculation of oxygen consumption. This study examines the influence of different $\mathrm{O}_{2}$ concentrations $\left(\mathrm{FO}_{2}\right)$, ventilatory frequencies $(f)$, tidal ${ }^{2}$ volumes(vt) and PEEP on the EMC.

Oxygen concentrations (21-100\%) measured by the EMC were compared with values from a masspectrometer (Centronic 200). The inspiratory flow signal was compared with values from a Bernstein mechanical spirometer at different ventilator settings.

Results and conclusion

Ttest analysis gave no difference at $\mathrm{FO}_{2}=21 \%$, but significant difrerences $(\mathrm{p}<\mathrm{0}, 001)$ for $\mathrm{FO}_{2}>21 \%$

The coefficient of variation at $F 0{ }_{2} 21-100 \%$ was $0,03-0,10 \%$

$\mathrm{O}_{2}$ for the EMC and $0,04-0,10_{\%}^{\text {or }} 0$, for the masspectrometer. The inspiratory flow meter was dependant on $\mathrm{FO}_{2}, \mathrm{f}$, vt and PEEP. Thus, increasing $\mathrm{FO}_{2}$ from 21 to $100 \%$ decreased $\hat{V}_{\mathrm{I}}$ by $6 \%$; increasing vt from 0,3 to 1,1 l increased $\dot{V}_{\text {T }}$ by $6 \%$; increasing f from 10 to $20 \mathrm{bpm}$ increased $\dot{V}_{\mathrm{f}}$ by 7. sing PEEP from 0 to $20 \mathrm{~cm} \mathrm{H}_{2} \mathrm{O}$ decreased $V_{\mathrm{I}}$ by $3 \%$. In most. clinical situations $\left(F_{10}, 21-60 \%\right.$, f 10-20 bpm, vt 0,5-0,9 I PEEP $0-20 \mathrm{~cm} \mathrm{H}_{2} \mathrm{O}$ ), the oxygen and flow meter of the EMC will yield an error in the calculation of oxygen consumption of less than $\pm 5 \%$
336

THE SIGNIFICANCE OF HYPOXEMIA ON LOWERING FIO2 BEFORE EXTUBATION. P.Nikki and J.Tahvanainen, Department of Anaesthesia, Helsinki University Central Hospital, Haartmaninkatu 4, 00290 Helsinki 29, Finland

In order to evaluate the significance of hypoxemia arising from ventilation to perfusion $\left(\dot{V}_{A}(\dot{Q})\right.$ abnormalities, $\mathrm{PaO}_{2}$, arterial $\mathrm{O}_{2}$ saturation $\left(\mathrm{SaO}_{2}\right)$, and transcutaneous $\mathrm{O}_{2}$ tension $\left(\mathrm{PtCO}_{2}\right)$ were measured on lowering $\mathrm{FIO}_{2}$ in 47 patients before extubation. All patients had been weaned from mechanical ventilation and CPAP after respirator treatment of at least 36 hours.

The patients entered the study on the following extubation criteria: no mechanical breaths, CPAP of $5 \mathrm{~cm} \mathrm{H} \mathrm{H}_{2} \mathrm{O}, \mathrm{FTO}_{2}$ of $0.35, \mathrm{PaO}_{2} 60 \mathrm{mmHg}$ and $\mathrm{PaCO}_{2} 45 \mathrm{mmHg}$. In the study, $\mathrm{FTO}_{2}$ was lowered in the following order: $0.40,0.35,0.30,0.25$ and 0.21 .

No significant difference was found in $\mathrm{PaO}_{2}$ or $\mathrm{SaO}_{2}$ with any $\mathrm{FTO}_{2}$ between those who were successfully extubated (group $S, n=38$ ) and those who required reintabation within 24 hours (group $\mathrm{R}, \mathrm{n}=9$ ). On the other hand, $\mathrm{PtcO}_{2} / \mathrm{PaO}_{2}$ ratios decreased from 0.82 to 0.66 in group $R$ whereas those remained above 0.8 in group $\bar{S}$. $\mathrm{Hb}$ concentrations and $P_{50}$ values were lower and septic hypermetabolism more frequent in group $R$.

Theșe data indicate that hypoxemia arising from $\dot{V}_{A} / \dot{Q}$ abnormalities do not solely predict succesful extubation in patients with compromized oxygenation. The safe lower limit of $\mathrm{PaO}_{2}$ depends on extrapulmonary factors, such as $\mathrm{Hb}, \mathrm{P}_{50}$ and metabolic state. $\mathrm{PtcO}_{2} / \mathrm{PaO}_{2}$ ratio seems to be a valuable criteria of weaning, because it probably reflects peripheral tissue oxygenation. Supported by the Academy of Finland. 


\section{Cardiac Intensive Care, Resources, Metabolism}

338

QUANTITATIVE DEIERMINATITON OF DYNAMIC PRETOAD IN A NORMAL IEFT VENTRICTE DURING REST AN EXERCISE. H.Tauboeck, Zentrale Anaesthesieabteilung, Bergmannsheil, Ruhnuniversität Bochum, BRD.

The term "preload" usually denotes the force that must be supported by the ventricles of the heart at the end of the diastolic phase: the maximum of diastolic filling pressure, volume an muscle fiber tension ( as given by Iaplace relation) is reached; rising ventricular pressure crosses atrial pressure, atrioventricular valve closes. In contrast to this the dynamic point of view leads to quite different conclusions. The prupose of the present investigation is to describe the dymamic relationship between pressure and flow across the mitral valve. Due to inertia of mitral blood flow, valve clasure is delayed for a certain time after the atrioventricular pressure crossover. This delay has been investigated by means of dimensional analysis. A nondimensional number occurring in this analysis has been "taken from the report of an experiment with dogs and then used to determine the conditions of mitral valve closure (i.e. the magnitude of dynamic preload) in man. Results: rather high ( $\Delta \mathrm{p} 80$ Torr) pressure are obtained during exercise( heart rate $172 / \mathrm{min}$.) and about 10 \% of the stroke volume enters the ventricle and increases its volume before the mitral valve closes. The theoretical prediction is then verified by echocardiography of the isovolumetric period (IP) . Mitral valve closure and aortic valve opening are picked up simultaneously with two echocardiographic apparatus. Thus

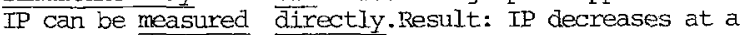
rate greater than that of the increase in heart rate resulting from exercise and even disappears altogether when the heart rate reaches a sufficiently high level $(140 / \mathrm{min}$.$) . It is possible for the dynamic preload to$ overlap with the beginning of the afterload period, as indicated by aortic valve opening.

\section{9}

ACUTE MYOCARDIAL INFARCTION COMPLICATED BY RESPIRATORY FAILURE: THE EFFECTS OF MECHANICA¿ VENTILATION. J.Räsänen and P. Nikki, Department of Anesthesiology, Helsinki Unjversity Central Hospital, Helsinki, Finland Controlled mechanical ventilation (CMV), intermittent mandatory ventilation (IMV) and spontaneous breathing with continuous positive airway pressure (CPAP) were compared in 9 patients with acute myocaraial infarction complicated by respiratory failure. Cardiopulmonary function was assessed by measuring thermodilution cardiac output, circulatory pressures, blood gases and the sum of the ST-segment deviations in a 12-Lead ECG $(\Delta \Sigma S T)$. The ventilator frequency was altered to deliver $100 \%$ (CMV), $50 \%$ (IMV) and $0 \%$ (CPAP) of the patient's minute ventilation with a tidal volurne of $12 \mathrm{ml} / \mathrm{kg}$. The end-expiratory pressure (range 5-10 $\mathrm{cmH}_{2} \mathrm{O}$ ) and the inspired oxycen concentration were kept unchanged. The arterial blood oxygen saturation was $>90 \%$ at all times. The respiratory rate during CPAP was 10-24 breaths/min; no $\mathrm{CO}_{2}$ retention was seen. The essential results were as follows:

\begin{tabular}{|c|c|c|c|c|}
\hline & & CMV & IMV & CPAP \\
\hline MAF & $(\mathrm{mmHg})$ & $77 \pm 16$ & $86 \pm 19^{*}$ & $90 \pm 22^{*}$ \\
\hline $\mathrm{HR}$ & (bpm) & $93 \pm 18$ & $91 \pm 16$ & $94 \pm 14$ \\
\hline CI & $\left(1 / \mathrm{min} / \mathrm{m}^{2}\right)$ & $2.9 \pm 1.3$ & $3.1 \pm 1.3$ & $2.9 \pm 1.0$ \\
\hline $\mathrm{C}(\mathrm{a}-\overline{\mathrm{v}}) \mathrm{O}_{2}$ & $(\mathrm{ml} / \mathrm{dI})$ & $5.8 \pm 1.7$ & $5.3 \pm 1.6^{*}$ & $5.3 \pm 1.7^{\star}$ \\
\hline SVR & $\left(d y n \cdot \sec \cdot \mathrm{cm}^{-5}\right)$ & $1193 \pm 449$ & $1189 \pm 421$ & $1344 \pm 479 * *$ \\
\hline PVR & $\left(\right.$ dyn $\left.\cdot \mathrm{sec} \cdot \mathrm{cm}^{-5}\right)$ & $171 \pm 101$ & $130 \pm 69$ & $139 \pm 92$ \\
\hline$\Delta \Sigma S T$ & $(\mathrm{~mm})$ & $12 \pm 7$ & $13 \pm 8$ & $15 \pm 9 *$ \\
\hline$Q_{s} / Q_{t}$ & $\left(\frac{8}{6}\right)$ & $8 \pm 7$ & $8 \pm 6$ & $13 \pm 7$ \\
\hline PCWP & (mmHg) & $14 \pm 6$ & $18 \pm 6 *$ & $19 \pm 6 * *$ \\
\hline
\end{tabular}

we conclude: 1) when used with PEEP, CMV impairs cardiac function by reducing venous return even in patients with acute myocardial infarction and high filling pressures. 2) The withdrawal of ventilatory support is associated with an increase in systemic vascular resistance and may cause myocardial ischemia with reduced cardiac performance even when the blood gases and the respiratory rate are normal.
340

PARADUXICAL EMEOL ISM: HEMEOYNAMIE, ANGIDGRAPHID AND ECHOCARDIOGRAPHIC FEATURES-THERAPEUTIC APPRDACH.J.d'Enfert,T.Deliere, D.Dubourg, Ch.Conseiller, J-[.Patel, J-P.Bqurdarias. Hôpital Ambroice Paré. 92100 . Baulogne. France.

In two patients who were admitted for systemic arterial embolism, the development of clinical radiographic and electracardiagraphic signs of pulmonary embalism suggested paradoxical embolism (PE).Bloud gases showed maderate to severe arterial hypoxemia and pulmanary angiography demanstrated bilateral pulmanary embolism. Twodimensional cantrast echocardiography visualized right-ta-left shunt thrqugh a patent faramen ovale (PFB). Fight heart catheterizatian canfirmed the PFu and excluded ar atrial seatal defect. Leg: deep veiri thrombosis was confirmed by phlebacavography. (case1) and pathological studies (ase 2 ).

In these two patients, treatment of PE associated 1-heparinotherapy 2-embolectomy fallowing peripheral arterial angiography 3 -partial interruption of the inferior vena cava using Adam de Weese clip or Greenfield filter 4-lang term anticaagulatian.

With a follow-up of mare than one year, there was no reccurence of pulmonary or arterial embolism despite the persistence of PFo. In canclusion, 1-cantrast echocardiagraphy should be performed whenever PE is suspected 2 -interruptian of the inferior vena cava proved useful in preventing reccurent pulmonary and systemic arterial embolism.

"TORSADES DE POINTES" AND POTASSIUM DEFICIENCY : A. Rimailho, J. Litwin, JL. Ricome, C. Richard, Ph. AuzépyHôpital de Bicêtre - Service de Réanimation Médicale 94270 LE KREMLIN BICETRE (France).

Within a period of one year, in our intensive care unit five patients developed "torsades de pointes" (TP) with production of syncopes. In all patients E.C.G. revealed QT prolongation longer than $0,55 \mathrm{sec}$ and mild bradycardia just before the onset of TP; at the same time, in three patients a markedly hypokaliemia $(<3$ meq/1) was noted, but in two others, kaliemia was normal $(4,6$ and 4,7 meq/1). These two ones, 74 and 79-year-old women, presented no congestive heart failure, cirrhosis, dentutrition, diarrhea, renal or surrenal dysfunction ; calcemia, magnesemia, protidemia and blood $\mathrm{pH}$ were normal ; no antiarythmic, diuretic, mineralocorticoïd or laxative drugs were given ; daily urinary potassium was in both cases about $50 \mathrm{meq}$, balancing imputs ; a measurement of total exchangeable potassium by $\mathrm{K}^{42}$ revealed a significant depression of $30 \%$ and $28 \%$. In all our patients ventricular pacing was safely rapidly and temporary used, and at the same time large daily amounts of parenteral potassium were given. In the two normokaliemic patients kaliemia and kaliuresis were without appreciable change, OT returned to normal within three and four days, and under daily potassium supplements, none episode of TP occured later without any other treatment. It seems thus that some patients present unexplained potassium deficiency without hypokaliemia and that potassium chronic supply should be an appropriate measure to prevent dramatic episodes of $T$. 
RETENTION OF CARDIOPULMONARY RESUSCITATION (CPR) SKILLS AFTER INITIAL OVERTRAINING.

J.L. Blache, B. Laurent, C. Soler, C. Chail101, F. Dubouloz, Dept. d'Anesthêsie Réanimation (Pr.G. François) G.H. La Timone, 13385, Marsei11e, France.

The authors have examined CPR skills retention in a Medicine University. 150 pregraduate medical students received a 8 hours course of Basic Cardiac Life Support as defined by American Heart Association with recording manikins.

Each training session was followed by a written test and a performance test on the recording manikin (post-test). 105 of them reached the instructor's leve] tape criteria as defined by the standard.

12 to 18 months later, the 105 students who had reached this high level performance were retested of cognitive knowledge and performance skills in a similar test situation ( $r e$ test).

The first min of one-man CPR on the two tapes was compared. Retention was expressed as a percentage i.e. re test score / post test score $\times 100$. Statistical comparison was made by a student's $t$ test for paired samples.

\begin{tabular}{l|c|c|c|c}
\hline & $\begin{array}{c}\text { Post test } \\
\text { score }\end{array}$ & $\begin{array}{c}\text { Re test } \\
\text { score }\end{array}$ & $\begin{array}{c}\text { Retention } \\
(\%)\end{array}$ & $P$ \\
\cline { 2 - 5 } & $80 \%$ & $84 \%$ & $>100 \%$ & \\
\hline $\begin{array}{l}\text { Written test } \\
\text { ventiladequate }\end{array}$ & 7,7 & 4 & $52 \%$ & $<0,001$ \\
\hline $\begin{array}{l}\text { Nof adequate } \\
\text { compress }\end{array}$ & 59,2 & 36 & $60 \%$ & $<0,001$ \\
\hline
\end{tabular}

With the effort and cost devoted to CPR training there is an evident need for more research in teaching methodology and skills retention. The present study demonstrates that. even overtraining of medical basic rescuers results in unsatisfactory psychomotor skills retention for a year but satisfactory knowledge retention.

\section{3}

CARDIAC PACING DURING CPR BY MEANS OF AN EXTERNAL MECHANICAL STIMULATIQN. DEVICE. L. Binner A. Schmidt, $W$, Nechwatal, H. Heinrich ${ }^{2}, 0$. Wess ${ }^{3}$ and M. Stauch . Division of Cardiology(1) and Department of Anesthesia(2), University of Ulm Germany. Dornier System GmbH Friedrichshafen(3) Germany.

Electrical intracardiac stimulation during drug resistant cardiac arrest usually is not available in the ambulance; furthermore correct positioning of the endocardial lead may be difficult and time-consuming during CPR. Therefore we have employed an external mechanical device for cardiac stimulation during the lag period until definitive placement of the endocardial lead. Pressure waves are applied in the 4 th intercostal space, using a $2.5 \mathrm{~cm}$ diameter thumper with variable rate and adjustable mechanical energy. With proper angulation and sufficient energy, electrical cardiac potentials are induced with subsequent contraction of the heart. In 8 patients with cardiac arrest we used this device during CPR. In 4 of these patients it was possible to obtain a sufficient circulatory function without cardiac massage until stable endocardial electrical pacing could be established. As could be expected, in cases of electromechanical dissociation no effective circulation was obtained. In these 4 patients no mechanical response followed the induced cardiac potentials. This was Confirmed by subsequent electrical stimulation. These preliminary results indicate, that external pacing with a mechanical pressure wave device may be useful in the emergency treatment of patients with cardiac arrest, while endocardial pacing is accomplished.
$\alpha$-OR. B-SYMPATHOMIMETIC STIMULANTS IN CPR ? G.H. Meuret, H.G. Lenders, H.F.O. Schindler

The effects of orciprenaline [0] (B-stimuIant) and norfenefrine [N] ( -stimulant) to those of epinephrine [E] ( $\alpha$ - and B-stimulant) in CPR was compared in this experimental study in dogs.

After five minutes of anoxial cardiac arrest we measured continuosly the following parameters: hemodynamics, blood gases and electrolytes,biochemic parameters of aerobic and anerobic metabolism.

Left ventriculär and central aortic pressure was significantly higher in the $E-(n=11)$ and $N$ group $(n=8)$ than in the 0 -group $(n=8)$ during internal cardiac massage. Incidence of fibrillation was equal in all three groups. The pressures after defibrillation were significantly higher with E than with $\mathrm{N}$ and 0 ( $\mathrm{p} 0.001$ ). Consequently the coronary blood flow was better with $E$ as well. This was strongly correlated with survival. (E: $11 / 11, N: 5 / 8,0: 2 / 8$ ) We conclude that epinephrine is superior to $\mathrm{N}$ and 0 to restard spontaneous circulation because of its combined $\alpha$ - and $\beta$-stimulating activity. But epinephrine is not yet the ideal drug in CPR.

\section{5}

BEDSIDE COMPUTER FOR PATIENT SAFETY, DATA COLLECTION AND DATA PROCESSING. U. Frucht, P. KunOw, Th. Kersting, K. Reinhart and R. Dennhard, Dept. of Anesthesiology and Operative Intensive Care, Free University, Berlin, FRG

Introduction: In applying vasoactive substances, false dosages can lead to dangerous cardiovascular alterations. The prevention of blood pressure crises resulting from sudden changes in systemic vascular resistance (SVR) and cardiac output (CO) signifies an advance in therapy with these substances.

Methods: We have developed a computer the size of a standard clinical monitor, which, as part of a control system, safely doses vasoactive substances. The advantages of this system (monitor, computer and metering pump) consist in its safety and variability. After input of the applied substance, the maximal dose and a code for the direction of the blood pressure change, the program functions automatically. Fixed limits (dose, blood pressure) are maintained; an alarm is set off when they are reached. In addition, important calculations (hemodynamic profile, pulmonary shunt volume and $\mathrm{P} 50$ ) can be made with a separate computer program (1) and a data logger.

Conclusion: The computer stores the dose of the vasoactive substance, the changes in the hemodynamic parameters and the calculated parameters for further statistical evaluation.

References:

1. Th. Kersting, K. Reinhart, G. Gasschütz and $K$. Eyrich: Easy-to-operate computing system for haemodynamic parameters, pulmonary shunt and P50: Anaesthesia. 6th European Congress of Anaesthesiology, 1982, Academic Press, Inc.., London 1982, p. 263. 
COMPUTER EVALUATION OF HEMODYNAMICS IN POSTOPERATIVE INTENSIVE CARE UNIT.PrOf.R.H. Lebedeva, A.A. Yeriomenko, V.V. Abbacumov. Intensive Care Unit, National Research Center of Surgery, Moscow, USSR

Hemodynamic parameters obtained by heart chambers and major vessels catheterization are registered automatically with the help of computer based monitoring system. Oxygen palance and acid base status data input to assess the adequacy of circulation is performed with the use of bedside microcomputer key board. The algorythm is based on clarification of images. Normal type of hemodynamics, hyperkinetic, hypokinetic type / hypovolemia, compensated and decompensated heart failure and shock / are defined. Left ventricular and right ventricular pump function are estimated seperately.By the experts' assessment $93 \%$ of computer conclusions appeared to be correct.

\section{7}

COMPUTER-ASSISTED THERAPY IN I. C. U. : DOPAMINE INFUSION.

G. Pelosi, R. Proietti, F. Lorinio, L.. Cristaldi, V. Perilli, V. Perottj, A. Arcangeli,

Istituto Anestesiologia e Rlanimazione - Università Cattolica del Sacro Cuore - Roma

Several and complex problems associated to the hemodynamic conditions and the peculiar pharmacology of dopamine, are frequently met by clinlcians treating shock syndrome.

The following report is a preliminary attempt to design a system of physician-computer interaction in the management of shock syndrome and in particular in the adjustment of an optimal pharmacological (dopamine) intervention.

The report describes a system of dopamine infusion automatic control as well as the general procedure ado pted. Clinical application of the system allows to specify the following advantages:

- proper collection and organisation of specific data;

- rapid computation of hemodynamic data and est $i-$ mation of optimal dopamine infusion which is constantly adjusted;

- computer-aided measurements and calculations;

- data storage;

- educational and training capabilities.
VVI-STIMULATION TIN IDIOPATHIC STBBAORTIC

STENOSIS. (IHSS) - A TFERAPEUTIC ALTERNATIVE. J.Bücking, H.Feigel, M.Schwartau, H.Voss, AK St. Georg, Hamburg, W.-Germany.

A 48 year old patient (pt.) with IHSS having been under medical control for 12 years ran into clinical state IV NYHA. She was treated by means of right ventricular stimulation in VVI-mode only. The preexisting tachyarrhythmia was suppressed by $50 \mathrm{mg}$ Atenolol. Heart rate fel] from 110 to 80 . A stimulation rate of 90 was high enough to provide only pacemaker stimulation. Thus the pt. recovered to such an extend that we decided to implant a permanent pacemaker.

The following criteria proved benefit from this procedure at the moment of changing from spontaneous rhythm to pacemaker rhythm:

1. Arterial blood pressure raised from 80 to $110 \mathrm{mmHg}$

2. Left ventricular high pressure (apex) fell from 230 to $140 \mathrm{mmHg}$.

3. Echocardiography showed remarkable reduction of SAM.

Conclusion. The "false" way of excitation of the myocardium causes the apex parts of the heart to contract prior to the septal parts. Therefore the typical trapping phenomenon of IHSS coula be diminished.
349

DESCENDING AORTIC DISSECTION : PREOPERATIVE AND INTRAOPERATIVE ASSESSSMENT. M. Dan ${ }_{+}^{+}$A. Milano ${ }_{++}^{++}$, C. Sorbarat, F.M. Cir $110^{+}$, P. Cantele , G.M. Aru ${ }^{+}$, G.P. Giron ${ }^{+}$, V. Gallucci

${ }^{+}$Cattedra di Anestesia e Rianimazione, ${ }^{++}$Cattedra di Chirurgia Cardiovascolare, Universita di Padova, Italy.

In order to improve the surgical treatment of patients (pts) with Type III aortic dissection we reviewed the records of 36 consecutive pts operated on by our surgical group between march 1971 and november 1982 .

Sixteen pts required an operation on emergency basis

(group A) because of signs of impending aortic rupture (12) oliguria (1), development of neurologic defict (2), failure to control hypertension (1). Twenty pts had uncomplicated dissection and the operation was performed after stabilization with medical treatment (group B). The overall mortality rate was $33 \%$ with 10 hospital deaths in group A (62\%) and 2 in group $B(10 \%)$.

We performed 15 operations using femoro-femoral by-pass with 7 deaths (46\%), 16 using Gott shunt with 4 deaths (25\%), 4 using simple cross-clamping technique with I death (25\%). Only in one patient we used successfully left atrial-femoral artery bypass.

The main complications were spinal cord injury in 5 pts, renal insufficiency in 5 , left ventricular falure in 4 , hemorrhage in 3 .

We concluded that the operative survival rate is significant1y higher $(\mathrm{p}<0.05)$ in stabilized patients; the spinal cord injury is unpredictable and probably not related to perfusion techniques; renal failure seems to be related to low perfusion; the Gott procedure is more satisfactory in providing proximal decompression. 
RESULTS OF SURGICAL THERAPY. OF DESCENDING AORTIC ANEURYSMS (DAA), J.LAAS, E.STRUCK, F.GRIESBECK, H. MEISNER, P.SCHMIDT-HABELMANN, F.SEBENING GERMAN HEART CENTER, MUNICH, W.-GERMANY

F The optimum treatment of DAA- surgical or solely medicalremains uncertain. Since there is little information about long term results this study persues prognosis of operative therapy of DAA over a 7-year period. Since 1974, an unselected cohort of 32 patients had surgical therapy of DAA. All patients were followed up until July 1982, datas were analyzed retrospectively $(76.8$ pat.yrs, max.surv. 7.2 yrs). 27 aneurysms were dissected (84\%). There were 17 traumatic(53\%) and 13 arteriosclerotic (41\%) DAA. In either 16 patients $(50 \%)$ clinical course was acute or chronic. 30 patients had replacement of DAA by vascular graft, 2 had local correction. All but 1 patient were operated with ECC or temporary shunt. overal1 operative mortality (OM) was $37.5 \%$, in dissecting DAA $41 \%(11 / 24)$. OM in traumatic DAA was $18 \%(3 / 17), 2 / 3$ patients died in table due to acute rupture. OM in arteriosclerotic DAA was 54\% (7/13). Postop. no patient had paraplegia; 4 patients (13\%) required hemodialysis because of temporary renal failure. 1 patient with replacement of DAA died 3 months postop., all other patients were alive on control key date, 61\% resuming their professional activities. We conclude that best operative results can be achieved in traumatic DAA. However, the high incidence of intraop. rupture in this group emphasizes the need of rapid diagnosis and surgery. Patients with arteriosclerotic DAA have the highest oM due to poor quality of aortic tissue and to the elevated morbidity of these patients. Although none of our patients suffered paraplegia the incidence of renal dysfunction underlines the importance of ECC or sufficient shunt. Late mortality after surgical therapy of DAA is low, patients generally resume normal private and professional activities.

\section{1}

COMPLTCATTONS POST-OPERATOTRES DES DISSECTIONS ATCUES DE L'AORTE ASCENDANTE : INTERET DE LA, COLLE GELATINE-RESORCINE-FORMOL (G.R.F.)

DUBOTS C., BRODATY D., SCHLUMBERGER S., BACHET J., GOUDOT B., GUTLMET D.; P.LOIRAT.

Entre Janvier I970 et Décembre I980, 74 patients ont été opérés d'une dissection aigüe de $1^{\prime}$ aorte ascendante. De I970 à 1976, 25 patients ont été opérês avec des techniques classiques (groupe I). Entre Janvier I977 et Décembre I98I, la colle GRF a été utilisée chez 49 patients pour renforcer les tissus disséqués (groupe II). Il n'y a aucune différence significative entre les deux groupes concernant 1 'àge, le sexe, l'état pré-opératoire et le type anatomique. L'aorte ascendante a été remplacée chez tous l'es patients, la valve aortique a été remplacée dans 12 cas du groupe I (48\%) et dans 8 cas du groupe II $(16 \%)$. Le volume moyen de transfusion per-opératoire a été de 5800 ml pour le groupe I et de 2980 pour le groupe II. 4 patients du groupe I (16\%) sont décédés en salle d'opération pour 0 dans le groupe II. Les complications post-opératoires sont significativement moins importantes en gravité et en fréquence dans le groupe II que dans le groupe $\mathrm{I}$.

$\begin{array}{lrr} & \text { Groupe I } & \text { Groupe II } \\ \text { Insuffisances rếnales aigües } & 14(66,5 \%) & 12(24 \%) \\ \text { Ventilation assistée de + 48 H } & 17(80,9 \%) & 18(40 \%) \\ \text { Ischémies périphériques } & 2(9 \%) & 0 \\ \text { Troubles neurologiques } & 6(28,5 \%) & 9(18 \%) \\ \text { Hêmorragies digestives } & 2(9 \%) & 6(12 \%) \\ \text { Médiastinites } & 3(14,2 \%) & 2\end{array}$

Ces complications ont étê responsables de 8 morts dans chaque groupe. La mortalité hospitalière globale a donc été réduite de 48 à $16 \%$.

Au total, 1'utilisation de la colle GRF au cours de 1 a réparation chirurgicale en réduisant les problèmes hémorragiques per-opératoires diminue la fréquence et la sévérité des complications post-opératoires.
Comparison of metabolic and endocrine changes produced by balanced anesthesia vs narconeuroleptanalgesia during cardiac surgery.

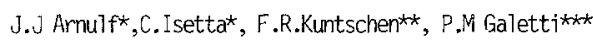

Service Pr V.Dor. Institut A. Tzanck 06700 Saint Laurent du Var - F-

* D.A.R. Nice Pr P.Maestracci

** Fondation organes articiels. Clinique de Genolier. Pr $\mathrm{CH}$. Hahn - $\mathrm{CH}-$

*** Artificiel organ laboratory Brom university RI - USA -

To compare the degree of metabolic protection afforded during cardiopulmonary bypass (CPBP) by the two most widely used technicues of anesthesia, I5 patients (I4 mens and I women) undergoing elective coronary surgery (II) or cardiac valve replacement (4) had their blood glucose levels continously monitored by means of the Biostator glucose controller. The patients received no exogenous dextrose and no insuline from either the anesthesiolocist or the priming fluid of the heart lung machine. Blood samples for metabolic and endocrine determinations were obtained before induction of anesthesia, before CPBP, after 30 min of CPBP, at the end of CPBP and $50^{\prime}$ after discontinuation of CPBP. Eight patients were operated under balanced analgesia using enflurane, flumitrazepam, fentanyl, pancuronium and nitrous oxide, whereas 7 patients received narconeurolept analgesia using thiopenthal, droperido?, phenoperidine, pancuronium and nitrous oxide.

Starting from the same fasting blood glucose level as the balanced anesthesia group, the patients under narconeuroleptanaigesia exhibited a lower hyperglycemic response to non pulsatiTe CPBP with the same levels of circulation insulin. This was coupled with lower blood levels of cortisol, and highter levels of glucacon. The narconeuroleptanalgesia group also showed sionificantly laver levels of alanine and 3 - hydroxybutyrate compared to the balanced analgesia group. Lactate, pyruvate, epinephrine, norepinephrine, growth hormone, free fatty acids, glycerol, triglycerides and cholesterol levels did not differ significantly between the two groups. $\mathrm{NA}, \mathrm{K}, \mathrm{mg}, \mathrm{Ca}$ and $\mathrm{P}$ remanied within normal limits.

These observations suggest that during narconeuroleptanalgesia, there is an increased glucose utilization by peripheral tissues, coupled with reduced proteolysis and glyconeogenesis as compared with balaniced anesthesia. Lipolysis is not affected by the type of anesthesia used for cardiac surgery.

\section{3}

ELECTROCARDIOGRAPHIC AND ENZYMATIC CHANGES FOLLOWING AORTO CORONARY BYPASS SURGERY. R. Martinez, D. Obradon, J. Gómez, A. Aris, R. Fort, F. Oca, E. Trizia, A. Bayés, A. Artigos. S. Cuidados Intensivos. Hospital de la Santa Creu $i$ Sant Pau. Barcelona. Spain.

Fifty-six patients were studied following coronary revascu larisation (CR). Five ECG's (preoperative, inmediately postoperative, at 24 and 48 hrs and on discharge) and 5 isoenzime CK-MB (u/L) determinations (preoperative, 6,12,24 and $48 \mathrm{hrs}$ ) were made. Pre and postoperative VCG's were ma de in only 40 patients. Patients were classified accoraing to appearance of postoperative electrocardiogrophic changes. Group A $(23,2 \%)$ with ECG or VCG eriteria of myocar dial infarction; group $B(12,5 \%)$ with introventricular con duction disturbance (IVCD) and severe repolarization disturbance (SRD) defined as $2 \mathrm{~mm}$ ST ascent or depression or $5 \mathrm{~mm}$ negative $T$ wave; group $C(17 ; 8 \%)$ with $S R D$ on $2 y$; group $D(46,4 \%)$ without ECG changes (IVCD not associated to SRD were inciuded).

RESULTS: Enzimatic results (moximum value) were: group $A=$ $119 \pm 70$; group $B=136 \pm 77$; group $C=61 \pm 31$ and group $D=$ 51 28. No significative difference was found between $A / B$ and $C / D$. Enzymatic level $C K-M B$ in group $A$ and $B$ was higer than group $C$ and $D: A / C(p<0.05), A / D(p<0.001), B / C$ $(p<0.05), B / D(p<0.01)$.

ConCLUSTONS: There were no differences between $C$ and $D$ groups. Group B presented the some level at $C H-M B$ as grou A although there was no necrotic image. These enzymatic results suggest further studies cre needed to define the incidence of postoperative myocardiat infaretion following coronary revascularisation. 
HOW TO WEAN IN THE POST OPEN-HEART SURCERY PERIOD (CPAP VERSUS $\mathrm{O}_{2}$-INSUFFLATION). U.Fina, Ch.Spiss, W.Koller, H.Benzer, Research Center for Intensive Care, Clinic of Anaesthesia, Spitalgasse 23, A-109o Vienna, Austria.

The pulmonary lesion produced by ECC causes a decrease in FRC and in arterial oxygenation. In the irmediate postoperative period the addition of PEEP can reverse this effect. 64 patients $(42$ male, 22 female, mean age 55 years) who had undergone CABG $(n=40)$ or valve replacement $(n=24)$ were included in this study. Group I $(n=34)$ were weaned with CPAP 7, group II $(n=30)$ were weaned with $\mathrm{O}_{2}$-insufflation. Weaning was started $9.25 \pm 6.25$ hours after ending operation. The patients did not receive any narcotic or sedative, nor were they on any vasopressor agents. Blood gases and respiratory rate (RR) were documented and $\mathrm{P}_{\mathrm{A}} \mathrm{O}_{2}-\mathrm{P}_{\mathrm{a}} \mathrm{O}_{2} / \mathrm{P}_{\mathrm{A}} \mathrm{O}_{2} \quad\left(\mathrm{AaDO} \mathrm{O}_{2}\right.$ quotient) was calculated in each of these 3 conditions: 1. CMV, both grouns PEEP 7; 2. Intubated, spontaneous breathing PEEP 7 (group I), ZEEP (group II) ; 3. 1 hour after extubation, both groups ZEFTP. Each patient had only $1 \mathrm{~F}^{\prime} \mathrm{O}_{2}$ throughout the study. The data presented in the following table.

\begin{tabular}{|c|c|c|c|c|}
\hline & 1 & & 2 & 3 \\
\hline $\mathrm{PaO}_{2}$ & $140^{ \pm} 26$ & $\begin{array}{l}\text { CPAP } \\
\text { ZEEP }\end{array}$ & $\begin{array}{l}121 \pm 6 \\
118 \pm 28\end{array}$ & $123 \pm 27$ \\
\hline $\mathrm{PaCO}_{2}$ & $35 \div 5$ & $\begin{array}{l}\text { CPAP } \\
\text { ZEEEP }\end{array}$ & $\begin{array}{l}4 \circ \pm 4 \\
38 \pm 3 \\
\end{array}$ & $4 \mathrm{o}^{ \pm}-4$ \\
\hline pH & $7.44 \pm 0.07$ & $\begin{array}{l}\text { CPAP } \\
\text { ZEEPP }\end{array}$ & $\begin{array}{l}7.39 \pm 0.04 \\
7.40 \pm 0.04\end{array}$ & $7.39 \pm 0.04$ \\
\hline $\mathrm{AaDO}_{2} / \Omega$ & $49 \pm 13$ & $\begin{array}{l}\text { CPAP } \\
\text { ZEEPP }\end{array}$ & $\begin{array}{l}55 \pm 13 \\
57 \pm 11\end{array}$ & $53 \pm 12$ \\
\hline RR & 12 & $\begin{array}{l}\text { CPAP } \\
\text { ZEEEP }\end{array}$ & $\begin{array}{l}16 \pm 4 \\
18 \pm 5\end{array}$ & $18 \pm 4$ \\
\hline
\end{tabular}

The variables did not show any statistically significant changes. It is concluded that CPAP did not improve pulmonary gas exchange in patients who had undergone open heart surgery.

\section{5}

SPECTRAL ANALYSIS OF ASCENDING AORTA DOPPLER SIGNAL. A. TEDGUI, D. PAYEN, M. X 'LAARD, B. LEVY and M. MCILROY INSERM U 141, 4I Bd de la Chapelle 75010 Paris, France, CNRS ER 248, 96 rue Didot, 75014 Paris France.

In an attempt to obtain quantitative blood flow informations from Doppler signals recorded in the ascending aorta, the mean Doppler shift frequency must be measured and the extraneous signal from vessel walls represents noise that needs to be recognized and el iminated. If multiple frequencies are present, especially if the signal/ noise ratio is low, zero crossing detectors introduce significant errors (LUNDT 1975) and spectral analysis is necessary to determine the ampititude of each frequency component and to calculate the average frequencies. Several approaches to this problem have been employed, utilizing parallel narrow band filters, or digital fast Fourier transform. We used a laboratory-built Walsh transform analog system to calculate spectral components. The spectrum is displayed in the usual "sonagram" format with frequency as ordinate, the time axis as abscissa, and spectral power as trace brightness. The directional ultrasonic Doppler is also available for digital data acquisition.

The accuracy, reproductibility and ease of use of a puTsed Doppler machine (Alvar $4 \mathrm{mHz}$ ) associated to the directional spectral analysis system has been investigated in normal subjects and in critically $i 11$ patients in artificially or spontaneous ventilation. An ultrasonic probe (diameter $10 \mathrm{~mm}$ ) was positioned in the suprasternal notch. The angle between the ultrasonic beam and the axis of the ascending aorta blood flow is assumed to vary from zero to 3 deg. the angle error is then less than $15 \%$. From first results, it appears that

1) spectral analysis provides a valuable velocity signal even though the signal noise ratio is too low for zero crossing detection.

2) individual stroke volumes values calculated from spectral analysis are well correlated with those simultaneously measured by the thermodilution technique.
OVERESTIMATION OF MEAN CARDIAC OUTPUT DURING AN END EXPIRATORY PAUSE IN CPPV. A. Logmans, A. Versprille, J.R.C. Jansen, Dept. of pulmonary diseases, Pathophysiological laboratory, Erasmus University, P.O. Box 1738, 3000 DR Rotterdam, The Netherlands

Under circumstances of intermittent and continuous positive pressure ventilation (IPPV and CPPV) right ventricular output $\left(\dot{\theta}_{\text {rv }}\right)$ was measured by means of a flow probe on the pulmonary artery in pigs (closed chest) and analysed beat-to-beat. Calibration was done by means of the Fick's method for oxygen.

$\dot{\mathrm{Q}}_{\mathrm{rv}}$ decreased during insufflation and recovered during spontaneous expiration via an overshoot to an end expiratory plateau. This plateau was constant when the expiratory pause was lengthened and appeared to be dependent on the level of positive end expiratory pressure (PEEP). The end expiratory flow was considered to be the baseline value for its changes during insufflation. The deficit of flow during insufflation was much larger than the expiratory overshoot. Thus, mean cardiac output was lower than end expiratory flow.

Decrease of mean cardiac output by PEEP or hypovolemia increased the insufflatory deficit but did not increase the compensatory overshoot. We concluded that

- an estimation of cardiac output during an end expiratory plateau phase overestimates mean cardiac output, which was confirmed with the thermodilution technique,

- the overestimation is higher at lower values of mean cardiac output,

- the end expiratory flow depends on PEEP and mean cardiac output on PEEP and superimposed insufflation.

357

CARDIOVASCULAR AND RENAL EFFECTS OF DOBUTAMINE COMBINED WITH DOPAMINE. N. Spannbrucker, F. Vogel, Medizinische Klinik der Universität Bonn, Bonn, West - Germany

Although the combined use of dobutamine and dopamine in treatment of cardiac failure has been recommended in several recent studies, the effects of this combination have not yet been demonstrated. In 12 patients with severe congestive heart failure we compared the effect of a combined dobutamine/dopamine infusion $(5 \mu \mathrm{g} /$ $\mathrm{kg} / \mathrm{min}$ dobutamine $+5 \mu \mathrm{g} / \mathrm{kg} / \mathrm{min}$ dopamine) on hemodynamics and renal blood flow with changes measured under dobutamine $(10 \mu \mathrm{g} / \mathrm{kg} / \mathrm{min})$ and do pamine $(10 \mu \mathrm{g} / \mathrm{kg} / \mathrm{min})$ given seperately. Dobutamine combined with dopamine and dobutamine alone increased cardiac index by $61 \%$ without changing mean arterial pressure. Under dopamine cardiac index increased $43 \%$ with a slight increase of mean arterial pressure $(+6 \%)$. There was a sig nificant fall in preload under dobutamine and dobutamine combined with dopamine. In contrast, dopamine alone increased left ventricular filling pressure. Corresponding to the rise of cardiac index the renal blood flow increased under dobutamine $59 \%$, whereas dobutamine combined with dopamine and dopamine alone doubled the increase of renal blood flow $(+123 \%)$. 
358

DOSE-RELATED HEMODYNAMIC AND RENAL EFFECTS OF DOPAMINE (DP) IN SEPTIC SHOCK.A.Esteban,M.A. de la Cal,E.Mirava lles, T.Pascual.Hospital Central de la Cruz Roja,Univer sidad Complutense, Madrid, España.

We have studied hemodynamic and renal effects of in creasing dosage of DP in 7 patients with peritonitis and clinical findings of septic shock.

Studies were begun when each patient had reached asteedy hemodynamic state with diuresis greater than. 7 $\mathrm{ml} / \mathrm{min}$ while treated with DP. Once the first determinations were recorded, the dose of DP wes increased by 5$\mu \mathrm{g} / \mathrm{Kg} / \mathrm{min}$. and after $45 \mathrm{~min}$ the determinations were repeated.Glomerular filtration rate and renal plasmatic flow were measured by Inulin and paraminohypurate clea rances respectively (Cin,Cpah).

We have observed augmentation of stoke index $(p<.01)$, and Blood pressure ( $p<.01$ ), without significant increase in Heart Rate, total systemic resistances, pulmonary pre ssure and pulmonary wedge pressure. Renal response showed augmentation of diuresis $(p<.01)$, Cin $(p<.05)$ and sodium Eractional excretion $(p=0.2)$ without significant changes in either Cpah or filtration fraction.

we concluded that incrementing dosage in DP in sep tic shock patients may be useful even with hyh dosageof DP. Increased natriuresis wes not due to changes inplasmatic renal flow.
360

OXYGEN TENSION AND MICROFLOW OF THE MYOCARDIUM FOLLOWING HEMODILUTION WITH FLUOSOL DA $20 \%$.

Vogel, H. ${ }^{+}$, Günther, E., Harrison, D.K., Höper, J. Frank, K.H., and Kessler, M. . Inst. für Physiologie und Kardiologie der Universität Erlangen, Inst. fur Anaesthesiologie der Universität München+ The assumed prerequisite for blood substitutes with a high solubility for oxygen is that an arterial oxygen tension $\left(\mathrm{PaO}_{2}\right)$ of at least $300 \mathrm{mmHg}$ and therefore a high inspiratory oxygen fraction (FiO $)$ is necessary for the adequate oxygen suppIy to the organism. This would seriously limit the application of such substances in clinical practice. In order to investigate the validity of this hypothesis, we measured myocardial oxygen tension ( $\mathrm{PmO}$ ) using a multiwire surface electrode and myocafdial microflow (mMF) by means of hydrogen clearance following hemodilution (HD) with Fluosol DA $20 \%$ (F DA) at FiO of $1.0,0.5$, and 0.3 . Eight anesthetised (Fentanyl/Diazepam) and artificially ventilated dogs were thoracotomised and hemodiluted with Hydroxyethylstarch (HES) to hematocrit (hct) $14 \%$ and then with F DA to het $7 \%$. Fluorocrit (fet) was $10 \%$. Results: At $\mathrm{FiO}, 1.0\left(\mathrm{PaO}_{2} 466 \mathrm{mmHg}\right), \mathrm{F}$ DA led to a $70 \%$ increase of mean $\mathrm{PmO}_{2}$ as compared to HES-HD and $\mathrm{mMF}$ increased by $7 \%$ ? At $\mathrm{FiO}, 0.5(\mathrm{PaO} 212 \mathrm{mmHg})$ Pmo, still exceeded pre-HD control values and mMF remained unchanged. At $\mathrm{FiO}, 0.3 \quad\left(\mathrm{PaO}_{2} 91 \mathrm{mmHg}\right)$ there was no further change in $\mathrm{mMF}$ and $\mathrm{PmO}$ decreased below control values. In those dogs where bypoxic tissue areas were observed acute moycardial failure occured. Conclusion: under our conditions of dilution with Fluosol. DA(het 7 , fet 10) myocardial oxygen supply was well maintained at FiO, 0.5 provided that the coronary reserve was normal. At $\mathrm{FiO}_{2} 0.3$, however, myocardial hypoxia was observed.

\section{1}

OETERMINATTON OF AMYLASE ISOENZYMES AND PANCREATIC HORMONES DURING SHOCK. J.Lohmann, Th. HOSSdorf, N.van Husen, U.Gerlach, Medizinische Universitätsklinik, Münster, w-Germany

In patients with shock of different etiology activity of alpha-amylase in serum is significantly increased. This inerease of total amylase activity represents a relative enhancenent of salivary isoamylase while the activity of the pancreatic isoamylase is decreased. Furthermare we measured in serum of 11 patients by radioimmuno assay human pancreatic polypeptide (Hpp), insulin and C-peptide. In follow-up studies during shock the decrease of pancreatic amylase activity correlates with an increase of $\mathrm{Hpp}$. Concentration of insulin and C-peetide are increased in the beginning of the shock later on followed by a decrease.

Our results suggest that the exocrine function of the pancreas might be diminished during shock whereas Hpo seems to play a regulative role in the endocrine function of human pancreas. 
MODIFICATION OF BLOOD VISCOSITY DURING EXPERIMENTAL HEMORRHAGIC SHOCK. S.Faenza, S.Taddei, Istituto di Anestesiologia e Rianimazione, Università di Bologna, Italia The purpose of this study was to analyze the changes in blood viscosity during hypovolaemic experimental shock in relationship to the simultaneous variations of pulmonary vascular resistance (PVR) and systemic vascular resistance (SVR). Ten piglets were submitted to hypovolaemic shock for 4 hours, and at the end of that period the blood removed was transfused. Arterial and venous blood samples were taken under basal conditions $\left(T_{0}\right)$, after 4 hours of hypovolaemic shock $\left(\mathrm{T}_{1}\right)$ and $30^{\prime}$ after full transfusion $\left(T_{2}\right)$. At the same time hemodynamic parameters (cardiac output, systemic and pulmonary pressure) were determined using a Swan-Ganz catheter.

Viscosity was measured, on citrated samples, by means of a cone-plane viscosimeter under thermostatic condition $\left(36.5^{\circ} \mathrm{C}\right.$ ) ranging from 646 to $8075 \mathrm{sec}^{-1}$.

Results showed a decrease in arterial blood viscosity

(ABV) from $3.41 \pm 0.1$ centipoise (CP) at $T$ to $2.57 \pm 0.2$ $\mathrm{CP}$ at $\mathrm{T}$ followed by an increase to $4.09 \pm 0.4 \mathrm{cp}$ at $\mathrm{T}_{2}$; venous blood viscosity (VBV) was $3.64 \pm 0.3 \mathrm{cP}$ at $\mathrm{T}_{0}$, $2.99 \pm 0.1$ at $\mathrm{T}$ and $4.91 \pm 0.4 \mathrm{cp}$ at $\mathrm{T}$.

An increase in SVR of $27 \%$ was seen at $\mathrm{T}^{2}$ and a reduction of $2 \%$ at $T$ in respect to the basal values. PVR increased of $67 \%^{2}$ from $T$ to $T$.

In conclusion the results showed:

$\mathrm{ABV}$ was aiways smaller than VBV (the principal causes seem to be $\mathrm{pH}, \mathrm{RBC}$ volume, $\mathrm{O}$ and $\mathrm{CO}$ contents)

during hemorrhagic shock we observed a reduction in blood viscosity that partially made up for vascular re sistance increase (depending from hemodilution mechanism?)

at the end of trasfusion ( $T$ ) PVR and SVR showed a different behaviour in relationship to the viscosity modifications: the increase of VBV made worse pulmonary circulation while the rise in ABV didn't modify systemic one.

\section{3}

EVALUAIION OF DOPAMINE IN THE TREATMENT OF SEPTIC SHOCK WITH THE QUANTITATIVE ASSESSMENT OF ARTERIAI AND PORTAI BIOOD FIOW TO THE IIVER BY SEQUENTIAI IIVER PERFUSION SCINTIGRAPHY.

H.J.Klein, A.Thoma,M.schäfer PD, Neurosurgical Dept.univ. ULM. BKH. RFA.

Liver perfusion scintigraphy in 10 patients with septic shock following neurosurgical operations showed significant diminuition of portal blood flow. Portal blood flow contribution dropped to about $34,5 \%$ (normal range $50-75$ $\%$ ). Following the administration of dopamine $(3,5-5,5 \mathrm{~m} / \mathrm{kg}$ body weight $)$ a significant increase of portal blood flow ( $39 \%$ ) is observable in all cases except one.

Our results indicate that the decrease in portal perfusion is caused mainly by the hepatosplanchnic pooling. Dopamine when administered in doses which do not affect mean blood pressure elicits selective vasodilation in the renal, superior mesenteric and celiac vascular beds suggesting that this is the underlying mechanism which causes the increase of portal perfusion after dopamine infusion.

The method of sequential liver perfusion scintigraphy, the criteria of septic shock and the basic pathophysiological mechanisms are discussed in detail.
COMPLICATIONS OF FEMORAL, ARTERY CATHETERIZATION

David Belvedere, Dan Thompson, Robert Lumish, and John O'Donne11; Mercy Hospital, Pittsburgh, PA, USA

A prospective study of all femoral artery catheters inserted in an intensive care unit was undertaken to study the incidence of complications. A total of 138 catheters were placed and remained in place until they were no longer required, malfunctioned, or were suspected as a possible source of infection. Duration ranged from 11 hours to 34 days. There were no instances of mechanical complications. Of these catheters 105 were avajiable for microbiologic study; $51 \%$ showed colonization at the skin site, $20 \%$ colonization of the catbeter, and $5 \%$ resulted in bacteremia. Analysis of risk of bacteremia by days indwelling revealed: $0 \%$ at 4 days, $2 \%$ at $5-6$ days, $5 \%$ at 7 days, and $21 \%$ at 14 days. This data compares favorably with published data for radial artery catheters, and supports the conclusion that catheters placed by the femoral route are as safe as those placed by the radial approach.

\section{5}

M. HUBMANN and A. WEIKL, Cardiol, Dep. (Med. Superintendent: Prof.Dr.E.Lang), Clinic for Internal Diseases of the haldkrankenhaus, Erlangen andat the 3rd Clinic for Internal Diseases (Med. Superintendent:Prof.Dr.H.Kleinfelder),Clinical Center Nuremberg

SELDINGER EFFECT WITH A NEW CENTRAL YEIN CATHETER

A new central vain catheter for puncturing the subclavian vein or the in- or external jugular vein is introduced, and its function is based on a modified Seldinger technique. Its operational principle is that a normal-lumen catheter is inserted through a small puncture needle and therefore a thin capillary tube. This is achieved by puncturing the patient's vessel $w i$ th a small-1umen neadle of only half the dianeter of catheter sets used up to now together with a capillary tube pushed over the needle. After the needle (Braunüle syringe system) is renoved the normallumen catheter is pushed through the thin, tapered Brauniule syringe. The catheter dilates the capillary tube at pre-formed spots and can thus be pushed further and placed. The capillary tube is then pushed back or is pulled of by splitting it totally. The catheter is made of polyurethans. By means of a newiy developped guide which can be pre-formed it is possible to master even vascular anomalies or severe vessel kinks. This new central ein catheter has been applied about 700 tines so far. Vein catheters vere inserted in the subclavian vein, the in- or external jue guiar vein as vell as peripherally. Complications occurring during cathetarisations are reported, but they are by far less critical than with traditional systems. Advantages of the new system are as follows:

1 Evidently less extensive puncture traunas and thus a deanuation of the dangers of a false puncture (arterioal puncture).

$2 \mathrm{~A}$ total sealing of the catheter vithin the vesse]: Due to the small puncture opening and the widening of the puncture site by pushing forvand the normal-lue men catheter a firm, tight sealing is created at the vesse 7 /catheter interface which is vital expecially for anticoagulated patients or for patients suffering from thrombopathy.

3 The catheter is suitable also for juveniles and children due to its saall puncture trauna.

4 The nev steel guide allows pre-forming in the case of vascular anomalies and shovs up quch better on opaque material than traditional guides.

5 Guiding the catheter is stabilized substantially by the new guide.

6 Due to the sealing effect at the vessel this system is quite suitable for arterial puncturing (arterial pressure monitoring), too. 
366

HAEMODYNAMICS IN SEVERE TETANUS: INFLUENCE OF EPIDURAI BLOCK. T. Fiore, A. Brienza, A.M. Leone, R. Giuliani, Institute of Anesthesiology, University of Bari, Italy. Spinal block has been proposed for the control of adrener gic hyperactivity in tetanus (1). This paper is concerned with haemodynamic changes induced by extradural block. Material and method. Through a spinal catheter introduced into the extradural space at $\mathrm{L}_{3}-\mathrm{L}_{4}, 6 \mathrm{ml}$ of $0.25 \%$ bupivacaine were injected twice with a $6 \mathrm{hrs}$ ' interval to 3 patients with severe tetanus, automatically ventilated under neuromuscular block with heavy sedation, in whom signs of adrenergic hyperactivity were evidenced. Values of hae modynamic parameters were obtained with a cardiac output thermodilution apparatus using Swan-Ganz catheters;values in the Table represent post-injection average per cent va riations at different times from mean pre-injection data.

\begin{tabular}{|c|c|c|c|c|c|c|c|c|c|c|c|c|}
\hline Time & & $10^{*}$ & & & $20 *$ & & & $30 \%$ & & & $45 \%$ & \\
\hline Case & $1 \mathrm{st}$ & $2 \mathrm{nd}$ & $3 \mathrm{rd}$ & $1 \mathrm{st}$ & 2nd & $3 \mathrm{rd}$ & $1 \mathrm{st}$ & $2 n d$ & $3 \mathrm{rd}$ & $1 \mathrm{st}$ & $2 \mathrm{nd}$ & 3rd \\
\hline 60 & -10 & -16 & -19 & -13 & -21 & -17 & -14 & -19 & +19 & -7 & -20 & +2 \\
\hline $\mathrm{SV}$ & -8 & -2 & -14 & -12 & -5 & -12 & -8 & -3 & +25 & -6 & +2 & +6 \\
\hline $\mathrm{HR}$ & -5 & -17 & -6 & 0 & -21 & -6 & 0 & -17 & -6 & 0 & -25 & -5 \\
\hline $1 \mathrm{AP}$ & -10 & -15 & -9 & -24 & -10 & -2 & -20 & -14 & +5 & -5 & -13 & +11 \\
\hline PWP & -33 & -10 & -25 & -50 & 0 & -31 & -33 & +10 & -25 & -33 & +10 & -31 \\
\hline SVR & -5 & 0 & +13 & -8 & +11 & +22 & -3 & +3 & -8 & -3 & +7 & +13 \\
\hline
\end{tabular}

$\bar{*}$ minutes after epiaural injection of bupivacaine

Results. Cardiac output and pulmonary wedge pressure show ed a tendency to decrease; data referring to other parame ters indicated wide individual variations.

Conclusions. Under the conditions prevailing in our investigation, adrenergic hyperactivity in severe tetanus did not seem to be effectively influenced by epidural block. References. Mo1laret, P. et a1.:Presse Méd.,73:2153,1965.

\section{7}

ACUTE ALCOHOLIC INTOXICATION IN ADULTS DOES NOT INDUCE LACTIC ACIDOSIS AND HYPOGLYCEMTA : Ph. Auzépy, H.F. Boutron, J.M. Gauthier and G. SouIed - Unité de réanimation médicaleHôpital de Bicêtre - 94270 LE KREMLIN BICETRE (France).

Classically severe acute alcoholic intoxication (A.A.I.) in adults induces hypoglycemia and lactic acidosis (L.A.). According to our clinical experience, this assertion has not proved correct. In this regard, all A.A.I. (without simultaneous drug ingestion) admitted to emergency unit of Bicêtre Hospital from 1976 to 1981 were studied.

METHODS : From admission for 57 A.A.I. (including 30 "pure" ethylic comas) concomitant samples of arterial blood were obtained - $\mathrm{pH}, \mathrm{PaCO}_{2}, \mathrm{PaO}_{2}$ and $\mathrm{HCO}_{3}$ - (ABL 1 Radiometer) lactate (Bohringer and Sigma containers) glucose (Auto analyser Technicon) and ethyl alcool levels (Test U.V. Bohringery. were measured.

RESULTS : 1) Acidosis, if any, was hypercapnic and mechanical ventilation may be necessary. However, no correlations between blood ethyl alcohol and ions $\mathrm{H}^{+}$range in 30 ethylic comas existed $(r=0,14)$. Only two cases (one with anorexia nervosa and other one with prolonged starvation) showed hypoglycemia and L.A.

2) No statistical correlations were found between blood lactate and alcoholemia in 57 A.A.I. $(r=0,01)$. 10 cases had lactatemia higher than $3 \mathrm{mmol} / \mathrm{l}, 4$ blood alcohol of which were higher than $40 \mathrm{mmol} / \mathrm{l}$.

3) For the great majority of subjects, glycemia was normal.

CONCLUSION : Usually severe A.A.I. in adults induces respiratory acidosis but no hypoglycemia. L.A. and hypoglycemia are only reported in cases with starvation or undernutrition.

368

PATIENT NUMBER AND RESOURCE EXPENDITURE IN A MEDICAL INTENSIVE CARE UNIT. M. ReusS, L.S. Weilemann, J. Majdandzic H.P. Schuster, II. Medizinische Universitätsklinik Mainz. Intensive care units (ICU) are the most expensive parts of hospitals. Resource expenditure can be easily estimated by using EDV. In the period from Apr. 1980 to Dec. 1981 (21 mths.) the percentage of covered beds estimated by midnight statistics was $85.95 \%$ in the total hospital and $67.33 \%$ in the ICU. Based upon the daily maximum covered beds the percentage was $72 \%$, and $75 \%$ when calculated upon the maximum number of patients treated daily. The whole hospital (180 beds) had 4515 nursing days per month, the ICU (10 beds) Darticipated with 205 nursing days per month $(4.5 \%)$. The monthly resource expenditure for the hospital averaged 232717 , - DM, for the ICU 93393 ,- DM according to $40.56 \%$ of the total expenditure for $5.6 \%$ of the total number of beds. Resource expenditureswere 91.92 DM per day in general, they were 462.87 DM in the ICU. The mean length of stay was 15 days in the whole hospital and 5.5 days in the ICU. Thus resource expenditure per patient was only 3 times higher for an intensive care patient in comparison to an average hospital patient. The resource expenditures were divided into the following groups:

Hospital

$13.74 \%$ blood product

$26.25 \%$ medical material

$10.81 \%$ others

$1 \mathrm{Cu}$

$42.56 \%$

$27.18 \%$

$25.84 \%$

\section{9}

SHOULD HAVE LIMITED AGE FOR INTENSIVE CARE?R.B.Carrington da Costa,J.Pimentel, J.Gonçalves, A. Rebelo, J.J.da Costa. Intensive Care Unit, Coimbra University Hospital, PORTUGAL. Investigation, teaching,monitoring and practice of Intensi ve Gare Medecine have reached a high level. However, less atention has been paid to the older patients. One of the rea sons for this has been the negative relationship costs/benefits mentioned. We think that the problem must be dealt with. The retrospective analysis of patients admitted in our ICU in the last 22 years has shown that 440 were over 64 years, 273 of them men. The varied pathology that determined adnissions is referred to. This is no intention of comparing results as it is difficult to establish groups corresponding either to different previous heath status or to the severity of acute illness on the day of admission. It was found that mortality among the patients over 64 years was $43.4 \%$, being comparable in both sexes. Among the remaining 3.403 patients it was $28,9 \%$.Dividing our sample of aged patients in groups taking into account the mortality we can see an increasing mortality:39,7\% in the group 65 to 75 years ( $n=312$ ), $50 \%$ in the group 75 to 80 years $(n=82)$ and $56,5 \%$ in the group $>80$ years $(n=46)$. There is a significant difference in these mortalities $\left(x^{2}=6,328 \rightarrow\right.$ $p<0,001)$. A more detailed analysis of the data reveals that the statistical significance is mainly due to the age group over 75 years. On the other hand, the longer the stay in the ICU the smaller the rate of mortality $(p<0,001)$, as more than balf of the patients died during the first 48 hours. The average time of hospitalisation in ICU was 18,1 days against 10,1 days among all the other patients.This study does not cover the period after the discharge, because we are just questioning how acceptable and fair intensive care medecine can be in the group of ages over 64 years. We think that the age, per se, must not be a criterium of exclusion even taking into consideration all sorts of costs. In our opinion the general criteria of investigation, teaching and admission must prevail in these patients. The support of a geriatric ward is assumed. 
370

EVALUATION AND QUANTIFICATION OF STRESS IN CRITICAL CARE PATIENTS. G.Pauser, B.Bunzel, and $\mathrm{CH}$. Gollner, Forschungsstelle für Intensivmedizin, Klinik für Anaesthesie, Univ.Wien, Österreich In combination with 52 self designed iteras we evaluated the answer of 50 patients transferred recently from ICU to regular ward to the question: Are environmental situations as emerging under ICU-conditions comparable in terms of their stress producing power? The patients had to bring the various stress items in a sequence of increasing annoyance just one day after dismission from the intensive care unit. The most annoying factor for all patients, almost sex and diagrosis independent, was the item lack of information and communication. The item noise and unrest caused by the daily routine and the nursing staff on the intensive care unit was quoted on the first place by patients more than 50 years. Helplessness and physical impairment are the most annoying factors by the ventilated patients. The item dependence on technical devices (e.g. ventilators, dialyzer etc.) was surprisingly quoted low by our patients. In conclusion to those facts a human orientated intensive care medicine should be claimed. Further investigations concerning the psychical care and help should be done.

\section{2}

BIOAVAILABILITY OF METRONIDAZOLE ADMINISTERED THROUGH RECTAL AND INTRAVENOUS ROUTE. Fichelle A., Farinotti R., Dauphin A., Mourlon M., Desmonts J.M. Hôpital Bichat Paris - France.

Metronidazole (M) is widely used as prophylactic and cura tive treatment of anaerobic infections in abdominal surge ry. The cost of injectable $M$ led us to use $M$ by rectal route as proposed by Ioannides and al*. This study was designed to compare the bioavailability of intravenous (IV) or rectal (R) metronidazole.

Patients and methods. The inclusion criteria in the study were the following: no alteration in blood volume, no abnormalities in rectum and in sphincter function, no diarrhea. Eight patients were given successively a single dose of $0.5 \mathrm{~g}$ via $\mathrm{IV}$ and $\mathrm{R}$ route. The interval between the successive administrations was 48 hours. The IV M was Flagyl* (Specia) and the suppositories were made of $M 0.5 \mathrm{~g}$ and aerosil $2000.01 \mathrm{~g}$ and suppocire AS2 qsp $2 \mathrm{~g}$. The study started by random administration of $M$ either IV or $R$ according to the admission. Plasma levels of $M$ were measured before and $30,60,90,120,180 \mathrm{~min}$ and $4,5,6,8,12$ and 24 hours after administration.

Results. Peak plasma concentration was observed at 3 hours after the beginning of administration. The mean value + $\mathrm{SD}$ was $8.2 \pm 1.7 \mathrm{ug} / \mathrm{ml}$ (IV route) and $6.8 \pm 1.5 \mathrm{ug} / \mathrm{ml} \overline{(\mathrm{R}}$ route). The elimination half life was $6.26+3.04$ hours (IV route) and $6.29+2.23$ hours ( $R$ route) respectively. Bio availability expressed as extrapolated area under the cur ve was $102.4+41.8 \mu \mathrm{g} / \mathrm{ml} / \mathrm{h}$ (IV route) and $91.1+40.8 \mu \mathrm{g} /$ $\mathrm{ml} / \mathrm{h}(\mathrm{R}$ route) in 7 patients having normal hepatic function ; in one patient with cholestasis bioavailability was increased, $266 \mu \mathrm{g} / \mathrm{ml} / \mathrm{h}$ ( IV route) and $241 \mu \mathrm{g} / \mathrm{ml} / \mathrm{h}(R)$. Eonclusions. This study demonstrated that M plasma concentrations reached same levels after $R$ administration as after IV route. When dosage and intervals of administration of $M$ is adequately determined, $R$ route is a good al. ternative compared to IV route. The main advantage is the drastic reduction in cost of the treatment : the $\mathrm{R}$ form is 35 times cheaper than the IV form.

*Ioannides L. and al: N. Engl. J. Med., 1981, 305.

\section{3}

CORRECTION OF NEUROHUMORAL IMPAIRMENT OF SEVERE CEREBRAL TRAUMA. WITH DIFFERENT METHODS OF PHARMACOLOGICAL PROTECTION OF BRAIN FROM HYPOXIA. LV.Usenko, VP.TUZ, EN. K1 igunenko, GB.Nazarenko, Medical Institute, Dnepropetrovsk, USSR.

Various degrees of impairment of neurohumoral homeostasis according to sympathico-adrenal, kallikrein-kinine, serotonine, histaminreactive system, functional erythrocyte condition data were determined in 310 patients with severe cerebral trauma in an acute period with prolonged loos of consciousness. The following mechanisms of neurohumoral impairment were observed : arterial hypoxemia, respiratory alkalosis, hypercatabolism resulted in activation of the system studied. An impairment of mechanisms of compensation hypoxia was noted : decrease of 2,3 DFG level in erythrocytes, progressive anemia while blood loos was absent. The use of catecholamine and giucocorticoid precursors did nor improve the treatment results. Methods of pharmacological protection of brain from hypoxia were used in a second group of patients with glucocorticoids and an early intensive therapy. The best resluts were obtained with combined administration of barbiturate and dosium hydroxybutyrate. High stability and adaptation of neurohumoral systems to stress and preservation of their reserves, were due to a decreased hypoxia ( $\mathrm{paO} 2+4,1 \mathrm{kPa})$, metabolism restoration in erythrocytes, change of their composition and correlation of hemoglabin fractions. The recovery from coma was shortened by an average of 3 days, fatal outcomes decreased to $15,2 \%$.

Conclusion: Mitogen-induced lymphocyte-proliferation is significantly reduced after injection of Thiopental, and during high Tlevels are high. These results demand further investigation. with particular respect to patients receiving high-dosage Thiopental-therapy for brain protection. 


\section{4}

PROGNOSTIC FACTORS IN SHOCKED PATIENTS. B COWan, H. Burns, I. McA. Ledingham, P. Boyle, Department of Surgery, University of Glasgow, Scotland.

In a prospective study of shocked patients we have assessed the prognostic significance of single and serial estimations of whole blood lactate (WBL) and compared their usefulness with simple haemodynamic measurements. Thirty patients suffering from shock of varying aetiology were studied. Arterial WBL, mean arterial pressure (MTP), urine volume (UV) and core-peripheral temperature gradient (CPTG) were measured after 3 hours and 24 hours resuscitation. There were 15 survivors. There was no significant difference between survivors and non survivors in either lactate or haemodynamic values at the time of admission. In survivors, WBL improved after resuscitation (see table).

$$
\begin{aligned}
& \text { Admission } 3 \mathrm{hrs} \quad 24 \mathrm{hrs} \\
& \text { resus. resus. }
\end{aligned}
$$

Survivors $(n=15) \quad 4.39 \pm 0.73 \quad \overline{3.22 \pm 0.43 * \overline{2} .04 \pm 0.22 *}$

Non survivors $(n=15) \quad 4.95 \pm 0.90 \quad 4.98 \pm 0.90 \quad 4.13 \pm 1.50$

WHOLE BLOOD IACTATE mMol/1 $* \mathrm{p}<0.01$

However, improvement in haemodynamic values was also significant in survivors. Using logistic regression analysis, outcome in a shock episode can be predicted after three hours with $91.5 \%$ accuracy if UV, MAP and CPTG are known. Adding WBL only increases the accuracy of prediction to $93 \%$. Measurements of lactate production in some of the non survivors suggest that in shock, lactate production by skeletal muscle significantly decreases, explaining the relative unreliability of lactate as a predictor of outcome.

\section{5}

HAEMODYNAMIC AND INTRACRANIAL EFFECTS OF A NEW ANTIHYPERTENSIV AGENT KETANSERINE IN DOGS H. Van Aken, C. Puchstein, C. Anger, P. Lawin Klinik für Anästhesiologie und operative Intensivmedizin Mïinster

Increases in intracranial pressure (ICP) occur with the most commonly used antihypertensive drugs. In patients with space-occupying lesions such incrases in ICP may lead to cerebral ischemia from decreased perfusion pressure or even to brain herniation.

Ketanserine is a new quinazoline derivate. It is a potent and selective 5 HT-serotonine-blocker. At high concentrations it has alpha,-adrenergic, antihistaminic, antidopaminergic and antiangiotensin properties. This study examines the effects of high dose Ketanserine up to $14 \mathrm{mg} / \mathrm{kg}$ on haemodynamic parameters and on ICP in dogs without (Group I) and with (Group II) intracranial hypertension.

Haemodynamic measurements including mean arterial pressure (MAP), mean pulmonary arterial pressure (PAP), mean right atrial pressure (RAP), pulmonary wedge pressure (PCWP), heart rate (HR), cardiac output (CO), systemic vascular resitance (SVR), and stroke volume (SV) were made. ICP was measured via an intraventricular catheter. Ketanserine was given as a bolus of $1 \mathrm{mg} / \mathrm{kg}$ followed by an infusion up to a total dose of $14 \mathrm{mg} / \mathrm{kg}$. All data were analyzed by student's t-test $p \leqslant 0,05$ was considered significant.

Uniform blood pressure reductions occured in each group. The maximum decrease ( $35 \% \pm 18$ in group $1,35: \pm 19$ in group II) occured at the end of the Ketanserine infusion. An increase in HR and decrase in SVR could also be observed, ICP did not change. CO, SV, RAP, PCWP remained unchanged. Ketanserine is a safe antihypertensive agent, even in patients with poor intracranial dompliance. 
A NEW MOBILE INTENSIVE CARE UNIT, A.B.M.Telfer, Royal Infirmary, Glasgor, Scotland. The movement of critically ill patients has been described by several authors (Ledingharn, 1980; Aitkenhead, 1980). Special trolleys have been designed or existing ones adapted for local requirements, depending, for example, on whether or not the trolley has to fit into an ambulance.

The new Mobile Intensive Care Unit (M.I.C.U.) in Glasgow Royal Infirmary has been designed to use as many standard and familiar components as possible. It is basically a conversion of a standard hospital trolley and is intended for use only within the hospital complex. It provides facilities for cardiovascular monitoring, continuous infusion of drugs by infusion purns, I.P.P.V. with P.E.E.P. and I.M.V. with any nonhypoxic mixture of Ijitrous oxide and oxygen, and spontaneous respiration with any mixture of air/oxygen and nitrous oxide/oxygen. It is equipped with a defibrillator and suction apparatus and has gas supplies for one hour at normal flow rates. There is an oxygen failure alarm and also a ventilator failure alarm, and quick change-over from one oxygen cylinder to the other.

A detailed description and photographs in colour will be provided in a poster display.

LEDINGHANI, I.MCA, and BAIJKS, J.G. (1980),

Liovement of the Critically Ill patient. Hospital Update, $\underline{6}, 43-49$.

AITKENHEAD, A.r., et al. (1980).

An economical mobile intensive care unit. Brit. Med. J., 1, 1219-1221.

COMPARISON OF THREE SEVERITY SCORE INDEXES IN ACUTE HEMORRAGIC PANCREATITIS (AHP). Ph. LOIRAT, M. GAYRAUD, F. BONNET, S. RIGATTIERI, J.R. LEGALI $X$ HOPITAL FOCH, SURESNES, HOPITAL HENRI MONDOR, CRETEIL, FRANCE. $\times A$, ALPEROYITCH

A severity score index is needed in AHp for classification of patients, comparison of groups and evaluation of new therapies because of the broad spectrun of the illness. The aim of this study was to compare a specific index as the one proposed by RANSON (1) (R) to two non specific indexes, acute physiologic score (APS) (2) and a resumed severity index (RSI). APS is based upon the results of 34 biological and clinical values. RSI is calculated from the results of 14 biological and clinical values generally obtained in all ICU patients. RSI has been validated in 789 French ICU patients.

31 patients with AHP were studied within the first two days after their admission to two ICUs. R, APS and RSI were measured in each patient. The prediction of death was used to evaluate the efficacy of each index. A highly significant correlation $(p<0.001)$ was found between $R$ and APS or RSI $(r=0.744$ and 0.834$)$. The parameters of evaTABLE luation were similar for the three indexes (table). Accor APS RSI $R$ ding to the prediction of Sensibility $0.53 \quad 0.53 \quad 0.65$ death, misclassification raSpecificity 0.831 .000 .64 the patients. MisclassificaPositive pre- $0.83 \quad 1.00 \quad 0.76$ tion rates were not different Positive pre- $0.83 \quad 1.00 \quad 0.76$ among the three indexes. dictive value In Conclusion : A resumed seNegative pre- $0.53 \quad 0.57 \quad 0.50$ verity index based upon the dictive value : results of very usual values performs as well as a specific index for AHP. It may help to classify patients, compare groups and evaluate new therapies. It should be further validated in a large multicentric prospective study.

(1) RANSON J.M.C. et al Surg Gynecol obst. 143 : 209-219,

(2) KNAUS W.A. et al Lancet $1: 642-645,1982$. 1976 .

\section{9}

IN VITRO MEASUREMENTS OF TMMUNORESPONSIVENESS IN SURGICAL PATIENTS ADMITTED TO AN ITU.

J.A. Bradley, V. Jackson, D.N.H. Hamilton,

I.McA. Ledingham, Department of Surgery,

University of Glasgow, Scotland.

Critically ill surgical patients have a reduced response to recall skin antigens. The mechanisms underlying this is unclear but may include altered lymphocyte responsiveness or decreased inflammatory cell mobilisation. Peripheral blood lymphocytes from surgical patients in an ITU were tested for their response to the mitogens Concanavallin A (Con A), Phytohaemagglutinin (PHA) and Pokeweed Mitogen (PWM) and peripheral blood mononuclear cells and granulocytes were tested for their chemotactic response towards casein. The results (median and range) are shown below:

$\begin{array}{cccc}\text { Con A (c.p.m; } & \text { Control }(n=14) & \text { Patients }(n=17) & p \\ \text { x } 10) & 111(36-196) & 36(21-167) & <0.05 \\ \text { PHA (c.p.m. } & & & \\ \text { x 10) } & 159(79-270) & 164(18-371) & \text { n.s. } \\ \text { PWM (c.p.m. } & & & \\ \text { × } 10) & 82(44-268) & 77(11-165) & \text { n.s. }\end{array}$

Monocyte

chemotaxis (u) $74(36-105) \quad 105(68-120) \quad<0.01$

Granulocyte

chemotaxis (u) $102(81-117) \quad 110(54-127) \quad<0.05$

Patients' 1ynphocytes showed a reduced response to Con $A$ and phagocyte chemotaxis was increased. This supports the hypothesis that critically ill patients have a defect in $\mathrm{T}$ cell function. 
380

COMPARATIVE STUDY OF GERM'S COUNT'S (GC) PERFORMED ON PROXI MAL BRONCHIAL ASPIRATION (PBA) AND DISTAL BRONCHIAL ASFIRA TION (DBA) IN INTENSIVE CARE. D. BRUNEL, M. GUENOUNOU,

J.P. NGUYEN, E. RONCO, J. PILIIOT , J. C. RAPHAEI , M. COULON. Clinique de Reanimation. Hôpital Raymond Poincaré.92380. GARCuEs. Fran ce.

Many studies have pointed out the interest of GC in traché obronchial secretions and of DBA about patients under assis ted ventilation by endotracheal tube. The purpose of this study is to compare the data of GC performed, or estimated on proximal and distal secretions of such patients. The $P B A$ are realised by sterile probe.After dilution the secretions are submitted for culture. Bach type of colony is numerated and identified after $48 \mathrm{~h}$ of incubation. Germs are considered as pathogen if the number of colonies is equal or higher

than $10^{6} / \mathrm{ml}$. The $D B A$ are realised on the same day, according to Matthew's technic. The number of colonies, in the distal sample is estimated after incubation. According to the data of a previous study of in vitro simulation, we have considered that the DBA were contaminated by the proximal bronchial flora, when the number of colonies/mI is equal or lower than $10^{2}$, and uncertain between $10^{2}$ and $10^{4} .83 \mathrm{DEA}$ and $P B A$ have been performed on 48 patients with pneumopathy. $38 P B A$ (46\%) did not have any pathogen germs ("sterile"), 24 (29\%) had one; 21 (25\%) more than one. $50 \mathrm{DBA}$ $160 \%)$ were ${ }^{n}$ sterilen, 12 (14\%) had one pathogen germ, 9 (11\%) more than one. 12 DBA were uncertain. For 42 (51\%) simultaneous $P B A$ and $D B A$, the bacteriological information was the same. When the results were different, the DBA was able to isolate one germ 8 times, whereas the PBA stasterile. on the opposite, on 14 times, the DBA was sterile or containingonly one germ whereas several germs were isolated in the corresponding PBA. The GC in $F B A$ and $D B A$ makes the diagnosis easier in pneumopathies in intensive care, owing to the smaller number of identified microbial species. The GC in DBA may give greater information for the diagnosis when the PBA is out. 


\section{Central Nervous System}

381

ELECTROENCEPHALOGRAPHIC PATTERNS IN ACUTE POSTTRAUMATIC COMA. I.F. Comelli, M.G. Pignatelli, G.F. Testa, M. Ayalle, Ospedale San Giovanni, Università di Torino, Torino, Italia.

The aim of this study was to assess the diagno= stic and prognostic value of the electroencepha logram (EEG) in acute post-traumatic coma. Five hundred patients were selected in whom the EEG tracings were recorded upon admission and then repeated over successive periods. Five EEG patterns were identified: borderline (41 cases) diphasic with sleep-like spindles (161 patients) diphasic (139), monophasic (109), and silent (50). Mortality was maximum $(100 \%)$ in the flat EEG (brain death), very high $(86 \%)$ in the mono= phasic pattern (deep coma with decerebration), decreased in both the diphasic $(60 \%)$ and borden line (51\%) types, and minimal (13\%) in the sleep-like pattern. Therefore, the finding of cortical electrical activity resembling that of physiological sleep offered the highest per= centage of remission. On the other hand, the mo nophasic EEG was very unfavourable. Patients with borderline tracings had a high mortality rate in spite of the relatively good EEG orga= nization. The present results tend to confirm the utility of EEG assessment in cases of trau matic coma. Moreover, this procedure may be use fully employed in evaluating the course of pa= tients with head injury and monitoring the effi cacy of the treatment protocol.
382

Central somatosensory conduction time in posttraumatic comatose states.

RumpI,E. ,Pruggex, M. ,Gerstenbrand, F. , Hackl, J.M. and Pallua, $\mathrm{A}$.

Short latency evoked potentials (SEP) were elicted by stimulation of the median nerve at the wrist and recorded simultaneously from the neck and the contralateral scalp in 44 patients with signs of brain stem impairment due to head injury. Brain stem involvement was divided clinically and by CT scan into secondary lesions due to supratentorial mass displacement and primary lesions due to direct violence to the brain stem. The central conduction time (latency between $\mathrm{N} 14$ and $\mathrm{N} 20$ - CCT) and the amplitude ratio (N20/N14-AR) were close to normals in patients with supratentorial lesions and good outcome. CCT increased and AR decreased with the worsening of outcome. Asymmetries in SEP indicated moderate or severe disability outcome. Patients with absent SEP over one or both hemispheres died. In patients suffering from primary brain stem dysfunction, confirmed by a normal or slightly abnormal CT scan, prolonged CCT, asymmetric but also absent SEP were also found in patients with good outcome. AR was generally low in these cases. Early appearance of SEP or early recovery of initially distorted SEP and decrease of CCT in control examinations was a favourable prognostic sign. Therefore even absent or severely distorted SEP should be interpreted cautiously, if patients may suffer from primary brain stem involvement.
383

CREATINE KINASE ISOENZYMES IN SEVERE HEAD INJURY. P. HANS, J.D.BORN, J, LENELLE, E.SPYROPOULOS. Service d'Anesthésiologie, Hônital de Baviēre, boulevard de la Constitution $6 \hat{6}$, 4020 Liège, Belgique.

- The study has been carried out to comoare blood and cerebro-spinal fluid (C.S.F.) creatine kinase (CK) values, to correlate brain tyne CK (CK BB) activity with brain dysfunction and to assess the prognostic value of CK assay. - 53 severe head injured patients (mean age $=24+14$ years) have been included in the study. $34 \%$ suffered from crania] trauma only and $66 \%$ were multiole injured patients. Blood and ventricular C.S.F. samples have been collected at $9 \pm 5$ hours after the trauma. Total CK activity has been measured spectronhotometrically at $37^{\circ} \mathrm{C}$. The isoenzymes have been separated electrophoretically and quantified by densitometry. Brain dysfunction has been graded according to the GTasgow coma scale (G.C.S.) and to the Liège coma scale (L.C.S.) which uses elements of the G.C.S. and the study of 5 brain stem reflexes. The natient's outcome after six months has been assesed according to the $f_{7}$ lasgow outcome scale.

- There is a good correlation between total CK and CK BB activities in C.S.F. only $(r=0.992)$. There is no relationshin between CK BB activities in the serum and in the C.S.F. $(r=0.139)$. There is an inverse relationshin between C.S.F. CK activity and brain dysfunction. The correlation between these two parameters is better with the LCS $(r=0.8)$ than with the GCS $(r=0.635)$. There is a significant difference in C.S.F. CK BB mean values between patient's grouns classified according to a bad and a good outcome $(F=5.85 \mathrm{n} \quad 0.006)$.

- The CSF CK BB activity is more reliable than serum activity. C.S.F.CK BB activity can be correlated with brain dysfunction. The L.C.S. allows a better assessment of brain dysfunction. High C.S.F. CK BB activity is significantly associated with a bad outcome.

\section{4}

AMINOPhyline In CONTROLling the INTRacrani PRESSURE. B.Mazzarelia, P.Mastronardi,T.Cafiero, G.Gargiula, L.Stel1a, R.Falivene; II Facoltà di Medicina e Chirurgia, Universita di Napoli, ItaIia.

The purpose of the study is to check the interferences of aminophylline with intracranial pressure (ICP).

We have monitored, by intraventricular catheter, transducer, amplifier and recording system, 12 patients of either sex, with mean age of 43,5 years and with hypertensive liquoral pathology. We have monitored also mean arterial pressure (MAP) and $\mathrm{PCO}$. After recording the basic values we have administered aminophyline $2 \mathrm{mg} \cdot \mathrm{kg}^{-1} \mathrm{in}$ a single bolus intravenously.

In every cases we have achieved rapid decrease whether in ICP or in cerebral pulse. No significant changes in $P C O$. The values of MAP were steady and consequently we have achieved an improvement of the cerebral perfusion pressure (CPP). 
BRAIN INJURED PATIENTS - THE OUTCOME ONE WEEK AFTER ACCIDENT. D. Hausmann, K. Rommelsheim, K.U. Josten, Institut für Anästhesiologie, University of Bonn, K.O. Mosebach, R. Caspari, R. Lippoldt, Physiologisch-Chemisches Institut, University of Bonn, Germany.

In order to find out guiding parameters for correction of care, the average levels of about 60 substances in plasma and urine of 18 survivors (S), 13 traumatized (T) and 5 burned (B) as well as 16 nonsurvivors (N), $11 \mathrm{~T}$ and $5 \mathrm{~B}$, were compared from day 1 until about 10 days after accident. Only patients were elected who survived the acute phase ( 3 days). The combined enteral and parenteral nutrition included $430 \mathrm{~g}$ mixed carbohydrates, $70 \mathrm{~g}$ fat, and $150 \mathrm{~g}$ amino acids per day. The nutritional assessment comprised the aminograms of serum and urine (24hour excretions), the serum concentrations of 5 proteins and 6 hormones as well as the nitrogen balance taking in account the reflux rates following tube feeding. The mortality passed through a maximum between day 6 and day 7 after accident. During this period about 85 을 of all N died and the reflux rates reached the highest values $(>80 \circ !)$. In the case of $\mathrm{N}$, many parameters showed a corresponding maximum, but 1 or 2 days earlier, for example nitrogen balance, serum urea, total concentration of serum amino acids, GOT, GPT, and prolactin. Due to the high reflux rates we propose a TPN at least until 10 days after accident. We have no explanation for the mentioned maxima.

WATER AND SODIUM BALANCE AND RENAL FUNCTION OVER THREE WEEKS AFTER SEVERE.ACCIDENTAL TRAUMA U. Finsterer, U. Jensen, A. Beyer, U. Schied, $\mathrm{W}$. Kellermann, $\mathrm{K}$. Unert $1, \mathrm{~K}$. Peter, Klinikum Großhadern, University of Munich, Munich, FRG

Careful monitoring of water-electrolyte balance and renal function is not yet common practice in intensive care units and might probably help to reduce acute renal failure (ARF). From March 1980 to May 1982 we studied 32 patients after severe trauma (mainly brain trauma, who could be observed for at least 21 days and did not develop $A R F$, which had to be treated by dialysis. The most prominent features of this study were: a) positive water balance throughout inspite of a significant weight loss (which points to high fluid losses with perspiration), b) high osmolar excretion, due to high urea excretion with posttraumatic protein catabolism, c) antidiuresis throughout with urine osmolality around 600 mosm/ $I$ and high negative free-water-clearance (due to high osmolar clearance), d) cumulated sodium balance was negative and averaged $440 \mathrm{mmol} / 21$ days, e) normal creatinine clearance (occasionally unusual high values), f) normal creatinine excretion. We conclude that patients after severe trauma generally have good renal function and tend to antidiuresis, high osmolar excretion and negative sodium balance.
387

EXPERIMENTAL ACUTE HYPOXIA. EFFECTS OF PHENOBARBITONE PRE-TREATMENT (HYSTOLOGICAL STUDY) G.di Trapani, S.I. Magal ini, A.L. Abbamondi,M.Lazari, A.F.Sabato. Ist. Anestesiologia e Rianimazione, Università Cattolica S. Cuore, Roma, I ta lia.

A histological study is carried out on five groups of 50 quinea pigs each (control-after 20min. of hypoxia-20min. of hypoxia+20min. of oxygen therapy-pretreatment with phenobartitone ( $100 \mathrm{mg} \mathrm{kg}-1$ ) and $20 \mathrm{~min}$. of oxygen therapy).

The light microscopy results can be summarized as follows: The hystological study did not show significant differences between barbiturate-treated and untreated hypoxic brains, in fact, the severity of ischaemic damage as well as its distribution were similar in a 11 the experimental groups. The lesion mainly affects the areas which are known to be most sensitive to hypoxia. It is suggested that in the experimental conditions barbiturates did not act as a protective agents at least as assessed morphologically,

\section{8}

CORRECTION GF NEUROTRANSMITTER FAILING AS PART OF BRAIN RESUSCITATIDN. H. SchoeppNET, L.ROLf, S. Wagner, J.Zander. University hospita l of anesthesiclogy and crtical care medicine, Muenster Federale Republic of Germany.

Greakdoun of neurotransmitter balance represant an essential component of posttraumatic, ischemic encephalopathy. The consequences are seizuIes by overwhelming of cholinergic transmissian and cerebral cama by missing of cortical activa tian. 20 patients, suffering fram brain lesian ( cama scale 3 - 57 have been treated with drugs of GABAergic and cholinolytic potency ( 5 cases each by infusion of barbiturate, etomidate, gamma - $\square H$ - butyrate and procaine.) The effectivity contral has been carried out by 1. Determination of the cellular (platelet) content of serotonin and dopamin by means of spectralfluorametric method.

2. Comparisan of the lactate levies of arterial bloud and CSF.

3. Recording of the EEG ( B channels)

4. Determination of catechalamine and cortisol releasing prae and post the infusian time of 8 hours.

The lasting effect, concerning the augmentation of cellularcontent of Serotanin and dopamin has beenreached, employing butyrate and arocaire. In last case the EEg caurse changed from generalized subdelta activity to finally reinte gration of alpha activity and patients in consciausness.The approach of the lactate levels of arterially blodd and CSF showed to be optamally in case of procaine. The depletion of catecholamin and cortisal secretion develaped step like from barbiturate and otomidate to butyrote and procaine. 
389

SPECIFIC INTENSIVE CARE PROBLEMS IN HIGH-DOSE BARBITURATE THERAPY. C. Krier, K. Wiedemann,

H. Polarz, Department of Anesthesia, University of Heidelberg, F R G

Despite of the fact that the beneficial effect of barbiturates on the outcome of severe headinjury patients remains controversial,high-dose barbiturate therapy is now commonly used in the management of raised intracranial pressure. The purpose of the study was to investigate the potential side-effects of high-dose thiopentone therapy in a total of 30 patients with focused interest on cardiovascular effects. effects on liver metabolism, gastro-intestinal complications and respiratory complications. The barbituratetreated patients were compared to a group of 27 patients with severe head-injury without highdose barbiturate therapy. The data obtained indicate l. a low incidence of hemodynamic changes when a regimen of slow initial loading is adopted. 2. a low incidence of hepatotoxic effects. I case of transient drug-induced jaundice is reported. 3. a high incidence of gastro-intestinal complications, ranging from benign erosions to acute upper gastro-intestinal hemorrhage. The occurence of oesophagitis is related to the esophageal sphincter dilatation and reflux, due to the high-dose baxbiturates and demonstrated by endoscopic findings. 4. a high incidence of contamination of the upper respiratory tract and of pneumonia. It is suggested that the suppressive effect of thiopentone on the immune response is responsible for the high incidence of pulmonary complications. It is concluded that the high-dose barbiturate therapy is connected with high risks for the patient due to the multiple side-effects of barbiturates and that this form of therapy requires a extended monitoring and specific preventive measures. 
Accidental occupational intoxication with di-and trimethytinchloride. Experiences in 6 patients.

Ch. Rey, R. Besser, H.J. Reinecke,L.S.Weilemann, J. Majdandzic, M. ReuB II. Med. Uniklinik Mainz

At the end of June 1981,6 workers were intoxicated with the above mentioned substances while cleaning an industrial basin. After a latent period of 1 to 3 days, symptoms of the neuroloqicpsychic kind occured in all patients with a upward tendency up to a clouding of consciousness and in the most severe cases even to a central respiration depression. A develonment of pulmonary complications with massive infiltrations was observed. Artificial respiration therapy was necessary in 3 patients. In 4 patients epileptic activity was reqistered in the EEG. Iniatially all patients showed a leucocytosis un to $30.000 / \mathrm{mm}^{3}$, transaminases were slightly increased with an upward tendency. The execretion of tin in the urine corralated with the severity of intoxication as well as a hypokalemia un to 1,9 mval/1. The plasmasenaration done in 4 patients did not lead to the expected decline in the urine tin execretion. The application of metalcaptaseR did not show a tendency to a higher tin execretion in the urine. The main treatment consisted in intensive care procedures. One patient died because of putmonary complications, liver cell damage and final kidney insufficiency. The neurohistologic findings showed remarkable changes in the central nervous system. 1 patient still needs intensive care because of hypotone hyperkinetic syndrome. The natient with the third hiqhest tin level stitl suffers from slightly cerebral deficit. Up to now, there is no report of human toxicological and intensive care experiences in the case of acute intoxications with these substances.

\section{1}

RESCUCITATION OF INTENSIVE THERAPY IN PATIENTS POISONED BY ACONITE. AA. Togaybaev, GD. Sheinin, VI.Lapin, BK. Sultanbaev, AA.Sovetov, Hospital Alma-Ata, State Medical Institute, USSR.

We studied 135 patients with aconite poisoning fatal dose taken p.o. is 2-4 mg. The main symptom in this state was acute cardiac arrhythmia developing suddenly during the first 30-50 minutes. The changes were characterized by progressive disturbance in conduction, excitability and automatism of the heart. Antidote therapy was not used, as it doesn' $t$ exist in this sphere. The patients were treated by intense therapy and resuscitation consisted in use of antiarrhythmic drugs (1idocaīne, novocainnamide, eta1), electric-pulsating therapy, electrocardiostimulating procedure, intensive ureapoiesis, gastric lavage and hemoresorption. We noted the high effectiveness of electro-pulsating therapy. The mortality rate was decreased in this group of patients by the described type of treatment.
CLINICAL INFORMATION FURNISHED BY BRAINSTEM AUDITORY EVOKED RESPONSE (BAER) DURING TOXIC COMAS L. BARRET, S. GARREL, Ph. ARSAC, J.L. DEBRU, J. FAURE, C.H.U. GRENOBLE

This is a review of 30 deep toxic comas studied by BAER to establish its value in diagnosici and prognosis in association with a physical determination of the level of the coma and toxic analysies.

Importance in diagnosis, a normal response was the most sommon finding, but in almost $40 \%$ of the cases, we observed a delayed latency at different level of coma of different toxic etiologies. This result is opposed the commonly accepted idea that BAER are always normal in toxic coma and represent a strong argument to evocate the toxic origin. Therefore, delayed latency should not exclude the diagnosis.

Importance in prognosis : a normal response or a delayed latency is always associated with a good prognosis. But in the latter case the duration of the coma seems longer. So BAER might represent an argument for the use of an epuration method. On the other hand if we note a peak disappearrance as observed in 2 cases, the outcome will be poor, perhaps due to anoxia. This could be screened for, rapidiy, using this method.

\section{4}

TOXIC EPIDERMAL NECROLYSIS : COMPLICATIONS SYNDROMES AND TNTENSIVE THERAPY. A.S.Farzar, A.K.Abdullayev,V.P.Kurenkov,A.A.Khon, T.T.Azimova, N.I.Sokolova, N.R .Sukhanova, Advanced Traininy Iustitute for Doctors, Tashkent, IJSSR

In 1956,Dr.Lyell (Britain) described a serious disease of the sikin and mucous membrates resultiny from the use of medications which he called "toxic epidermal necrolys is".By 1760 , the re were some 150 reyistered cases of the disease with a mortality of between 30 and $50 \%$. The case history of a 25 -year-old woman patient illustrates hypersensibilization to penicillin resultiny in overall lesion of the skill and mucous membranes plus universal vasculitis. The patient spent $5 \%$ days in the resuscitation ward axd the followilly range of syndromes was registered in the course of the disease : toxic-alleryic epidermal necrolys is affecting $70-80 \%$ of the skin,blepharoconjuctivitis and temperature of up to $40^{\circ} \mathrm{C}$; leikemoidal-eosinophilic reaction of the blood coupled with the appearance of all types of lymphocytes and enlargement of all lymphatic nodes (leucocytos is -- $\$ 45,000$, e os inophilia -- up to $57 \%$ with appearance of blastocells); acute reval iusufficiency (mild form); acute toxic nepatitis; jneomonia with wet pleurisy : acute myocarditis: coagulating system lesion syudrome with hypocoayulation in all phases; toxic hyperchromic anaemia; alleruic polyarthritis.

Treatment : absteution from medications with the exception of diureties and corticosteroids : absolute fasting with follow-up non-protein diet. forced diuresis with a load of up to $\rightarrow$ litres of liquid to produce 6- 8 litres of urine per day. Result of treatment : full recovery. 
395

OXYTOCIN INDUCED WATER INTOXICATIONS D.Perrot, J.J.Lehot, Y.Bouffard, B.Delafosse, C.Guil Taume, J.Matin.

Hôpita] Edouard HERRIOT 69008 LYON (FRANEE).

We report one new case of acute water intoxication (AWI)

induced by oxytocin (OXY) infusion during therapeutic abor

tion, in a 30 year old primigravida at 20 weeks'gestation

After intraamiotic injection of Prostaglandins $F$, this pa-

tient received 210 units $(u)$ of OXY in 2,5 liters (1) of

a $5 \%$ Dextrose in water solution, during a period of 15

hours (h) 30 minutes (mn) (infusion rate (IR) of about 226 $\mathrm{ml} / \mathrm{mn}$ ), and twice $100 \mathrm{mg}$ IM of Pethidin. Whereas she had vomitings and headache, a grand mal seizure then a deep coma occured. Serum sodium level was $112 \mathrm{mi} 71 \mathrm{mmoles} / 1$ and serum osmolarity 259 mi17i0smoles/1. With interruption of oxytocin and sodium administation, a marked diuresis occured, with positive free water clearance; electrolytes nor malized within 48 hours and consciousness cleared within 4 days. She was discharged completely recovered.

About this new case and 41 cases previously reported in litterature, circumstances of occurence of this uncommon entirely iatrogenic disease were treatment of incomplete abortion ( 13 cases), post partum hemorrhage (5), induction of labour (6) or abortion (18). Isolated or associated symptoms were neurologic. In 11 cases, alarm but disregarded signs were headache, nausea, vomiting, or mental confu sion. In 4 cases, no symptom was observed except oliguria which is a constant finding. No correlation was found between severity of clinical signs sodium serum level, total volume perfused, total dose of oxy and duration of treatment $(p>0,05)$. OXY antidiuretic effect depends on its IR. Then concomitant fluid administration may induce an AWI, facilitated by physiologic water and salt retention in pregnancy, individual sensitivity, and morphinics. In 39 patients recovery was complete. In 3 patients, serious neu rologic sequels were reported. 2 maternal deaths occured. 2 newborns presented severe signs of AllI but rapidly recovered. So, such accidents must be prevented by clinical survey, survey of OXY IR, minim fluid and proportional salt intakes. 
396

CIMETIDINE-PIRENCEPINE VERSUS ANTACIDS FOR STRESS BLEEDING PROPHYLAXIS IN INTENSIVE CARE UNIT PATIENTS. D. Engelhardt, R. Karl, D. Inthorn, D. Hölzel, Klinikum Großhadern, Universität München, München, DeutschIand

Preliminary results of a randomized controlled clinical trial of preventing upper gastrointestinal bleeding in intensive care unit patients were presented. A group of 44 patients (A) receiving a combination of cimetidine and pirencepine is compared with a group of 42 patients (B) receiving an aluminium magnesium hydroxide concentrate (Maalox 70).

For a sensitive and specific detection of blood we tested the chromium-51-activity in the gastric aspirate after having labelled the patients' erythrocytes with chromium-51. The dosis of the medications were adjusted to a gastric juice $\mathrm{pH}$ above 3 .

From the results with 86 patients we draw the following preliminary conclusions:

1. With a sensitive and specific method for detection of blood in gastric juice temporary blood traces could be detected in 30-40 \% patients of group $A$ and $B$; the detected amounts of blood showed no clinical relevance but were far above the physiological blood loss of the gastrointestinal tract.

2. Visible blood in gastric juice was discovered in 3 patients in group $A$ and in 2 patients in group $B$ so far, an event expected in no treatment patients in 15-50\%.

3. The blood loss in the stomach depends on $\mathrm{pH}$; above a pH of 3 blood could hardly been found, below a pH of 3 the blood losses were much higher and were negatively related to the $\mathrm{pH}$. 4. A guajac paper test is not an appropriate method to detect occult blood in gastric juice contaminated with magnesium-aluminium-hydroxide.

397

CONTINUOUS $\mathrm{PH}$ MEASUREMENT AND RANITIDINE IN SERIOUSLY ILL PATIENTS. M. Albin, J. Friedlos, K. Hillman, Intensive Care Unit, Charing Cross Hospital, London, UK.

Stress ulceration is common in patients treated in Intensive Care and when associated with active bleeding carries a high mortality. Antacids effectively increase the stomach $\mathrm{pH}$ and decrease the evidence of GI bleeding, whereas cimetidine is not as effective in increasing $\mathrm{pH}$ nor in preventing GI bleeding in seriously ill patients. (1) A new histamine $H 2$-receptor antagonist, ranitidine, has not been evaluated in these patients. The object of this study was to evaluate the effectiveness of ranitidine in controlling the gastric $\mathrm{pH}$ at above 4 . If the $\mathrm{pH}$ was below 4 a bolus dose of $50 \mathrm{mgm}$ iv of ranitidine was given and an infusion of $1 \mathrm{mgm} / \mathrm{hr}$ commenced. The infusion was increased up to $15 \mathrm{mgm} / \mathrm{hr}$ or decreased according to the $\mathrm{pH}$ of the stomach. A further object of the trial was to evaluate a continuous method for measuring gastric $\mathrm{pH}$. This is necessary if the effectiveness of a continuous technique to increase $\mathrm{pH}$ is to be assessed. A $\mathrm{pH}$ electrode (Novo Industri A/S) was inserted together with the NG tube. The $\mathrm{pH}$ was continually measured and displayed enabling rapid adjustments to infusion rates of ranitidine to be made. This method was successfully employed in all patients and no adverse reactions attributable to ranitidine were noted. It is hoped that this technique will be the basis for a closed loop servo control system for controlling gastric $\mathrm{pH}$ in seriously ill patients.

(1) Priebe HJ, Skillman JJ, Bushnel1 LS et al: Antacid versus cimetidine in preventing acute gastrointestinal bleeding. A randomized trial in $75 \mathrm{criti-}$ cally ill patients. N Eng1 J Med 1980; 302:426-30

\section{8}

MEASUREMENT VS. CALCULATION OF COLLOIDOSMOTIC PRESSURE(COP) JM Mosquera,P Galdos, E Dominguez de Villota, MI Tomas, $\checkmark$ Diez-Balda,JL de la Serna, JJ Rubio.Intensive Care Unit. Clínica Puerta de Hierro.Madrid-35. Spain.

MEASUREMENTS.-COP was measured in duplicate in 316 samples of plasma (217 patients and 99 blood donors)with an IL-WEIL oncometer, at $24^{\circ} \mathrm{C}$. All measured values were corrected for $37^{\circ} \mathrm{C}$, and the arithmetical mean for paired samples was calculated ( $\mathrm{COP}$, 37). Dupl icated measurements differed only in $0.22 \pm 0.26 \mathrm{mmHg}(p=0.81)$. However, paired comparison of mean value of $\overline{C O P}, 24(27.48 \pm 4.11)$ and $\overline{C O P}, 37(28.68 \pm 4.29)$ was significative $(p<0.01)$.

Albumin(A) and total proteins (TP) were measured in each sample, and globulin(G) and $A / G$ ratio calculated.

Normal $C O P$ in the blood donors group (ambulant) was $31.2 \pm 2.3$ $\mathrm{mm} \mathrm{Hg}$.

CALCULATIONS: COP (in $\mathrm{mmHg}$ ) was calculated in all samples according to the following formulas:

$F-1: C O P=2.1 c+0.16 c^{2}+0.009 c^{3} \quad(c=T P$ in $g / 100 \mathrm{ml})$

$F-2: C O P=f c(45.2 A+18.86 G) \cdot T \cdot 0.0735 / 273$ (f $c=$ factor depending of $T P ; T=$ absolute temperature; $0.0735=$ =conversion factor of units)

$\mathrm{F}-3: \mathrm{COP}=268 \mathrm{c} \cdot 0.735 / 1-(0.4+0.9 \mathrm{pH}) \mathrm{c}(\mathrm{c}=\mathrm{TP} ; 0.735=$ conver sion factor of units.

RESULTS. - Mean COP, $37(28.68 \pm 4.29)$ was significantly different from mean $\mathrm{F}-1(26.00 \pm 4.21), \mathrm{F}-2(26.36 \pm 4.20)$ and

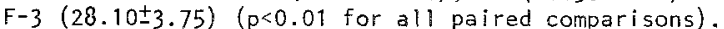
Absolute differences between $\overline{C O P}, 37$ and $F-1, F-2$ and $F-3$ were respectively $3.26 \pm 2.36,2.74 \pm 1.92$ and $2.01 \pm 1.49$. When they were correlated with the $A / G$ ratio and $G$ values, not a high correlation was found.

CONCLUSIONS: None of the above, usually utilized.formulas is fully precise for COP estimation. COP should always be measured and, since measurements are usualiy performed at ambient temperature, corrected for the patient temperature. However, if an oncometer is not available, F-3 offers the closest estimate to the directly measured values.

\section{9}

PHARMACOKINETICS OF PARENTERAL METRONIDAZOLE IN ACUTE RENAL FAILURE. G. DABROWSKI, T. BEN ABDALLAH, B. FLOUVAT, and Ph. LOIRAT. HOPITAL FOCH, SURESNES, HOPITAL AMBROISE PARE, BOULOGNE, FRANCE.

Anaerobic infection is frequently suspected in post surgical acute renal failure (ARF). The aim of this study was to evaluate the pharmacokinetics of parenteral metronidazole in ARF patients treated by hemodialysis.

7 patients with post-surgical ARF, treated every other day by hemodialysis, received parenteral metronidazole in a dase of $500 \mathrm{mg}$ administered in 20 minutes, eight hourly. In the 7 patients serum values of metronidazole (high pressure liquid chromatography assay) were obtained before hemodialysis, after the first injection, every 15 minutes for 2 hours and every hour for 8 hours. During hemodialysis serum levels were obtained after a second infusion every $30 \mathrm{mn}$ for 2 haurs and every hour to the end of henodialysis. In 3 patients the therapy was maintained for 3 to 8 days and peak and trough levels were obtained before and after each injection.

After the first injection peak levels were 19.03 \pm 3.47 $\mathrm{mg} / 1$ (mean $\pm \mathrm{SD}$ ). Elimination half life $(\mathrm{T} 1 / 2 \mathrm{~B}$ ) was $7.06 \pm 1.95 \mathrm{~h}$. Trough levels were $5.92 \pm 2.85 \mathrm{mg} / 1$. These results were not different from those obtained in normal. subjects. During hemodialysis $\mathrm{T} 1 / 2 \mathrm{~B}$ was $3.45 \pm 0.5 \mathrm{~h}$ corresponding to a mean decrease of $35 \%$ in 4 to $6 \mathrm{~h}$. There was no rebound after hemodialysis. In the three patients receiving repeated infusions the mean peak and trough values for the last five infusions were $18.5 \mathrm{mg} / 1$ and $9.0 \mathrm{mg} / 1$, not different from values obtained after repeated infusion in normal subjects. Hemodialysis prevented significant accumulation of the drug.

In conclusion : pharmacokinetics of I.V. metronidazole in ARF are similar to those of normal sujects. Hemodialysis increases the elimination rate. The usual frequency of in fusion in normal subjects is suitable for treatment of ARF patients submitted to hemodialysis every other day. 
DESIALYLATED GLYGOPROTEINS IN CRITICALLY-ILL PATIENTS.

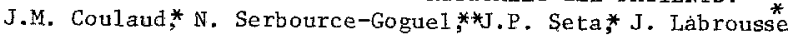
G. Durand, **J. Lissac * Service du Professeur Lissac; Hôpital Boucicaut, Service du Professeur Agneray ;**ôpital Hérold, F 75730 PARIS (France).

Liver is responsible for biosynthesis and degradation of sialoglycoprotein such as $\alpha_{1}$ acid-glycoprotein ( $\alpha_{1}$ ACP) and $\alpha_{1}$ ancitrypsin $\left(\alpha_{1} A{ }^{r}\right)$. The piasma of normal subjects contains negligible amounts of asialoglycoprotein because of the ability of the normal liver to clear them almost instantaneously from the circulation. In hepatic diseases, the presence of serum desialylated material has already been evidenced, but in this study, the hepatic insufficiency was of ten associated with other organ failure ( $\mathrm{J}$. Marsha11 et al, J. Lab. Clin. Med., 1978, .92, 30-37). The actual cause of this desialylation is still not well known : isolated hepatocellular damage (HCD) or multi vis ceral failure.

To answer this question we have studied the degree of desialylation of $\alpha_{1}$ AGP and $\alpha_{1}$ AT in serum of 26 patients ; all had multivisceral failure, associated $(n=9)$ or not $(n=17)$ with HCD evidenced by usual liver tests. The desialylation of $\alpha$, AGP and $\alpha_{1}$ AT was determined by compar ring radial immunodiffusion and electroimmunodiffusion for each glycoprotein. Results were given in percentage $(\%)$ of asialoglycoprotein. The presence of a desialylation $>5 \%$ was considered as a desialylated serum.

$\begin{array}{cccc}\text { Without HCD } & \begin{array}{r}\text { Percentage of desialylated serums } \\ \quad \alpha_{1} \text { AGP\% }\end{array} & \alpha_{1} \text { AT\% } & \alpha_{1} \text { AGP } 4 \text { AT\% } \\ \text { With HCD } & 17.6 & 0 & 17.6 \\ n=9 & 55.5 & 33.3 & 77.7\end{array}$

The results:were statistically different in the two groups ( $p<0.05)$. There was no correlation between high concentra tion of $\alpha_{1}$ AGP $(\bar{x}=1,74 \mathrm{~g} / 1 \pm 0.73)$ and of $\alpha_{1}$ AT $(\bar{x}=4.80 \mathrm{~g} / 1 \pm$ 1.78 ) and presence of desialylation.

Thus desialylation is not concerned by anabolism ; the pre sence df desialylated $\alpha_{1}$ AGP and $\alpha_{1}$ AT is in relation with hepato-cellular damage.

\section{1}

ACUTE RENAL FAILURE IN CRITICALLY ILL PATIENTS : IMPROVEMENT OF INTRADIALYTIC TOLERANCE WTTH BICARBONATE IN DIALYSATE. D. Mathieu, B. Cosselin, A. Durocher, C. Chopin, F. Wattel, Hopital Calmette, C.H.U. Lille, FRANCE Patients hospitalized in critical unit for acute renal failure (ARF) in a multiorgan failure syndrome have often a poor intradialytic tolerance. Change from acetate to bicarbonate for dialysate buffering has been advocated to improve this dialytic tolerance. In a retrospective study, 70 patients who received bicarbonate hemodialysis are compared with 106 patients who received acetate hemodialysis. If the mortality is not different between this two groups, intradialytic tolerance is significantiy better $(p<0.001)$ in the bicarbonate group according to the mean intradialytic systolic blood pressure decrease, the collapse number and the mean vasoular volume infusion. Ultrafiltration rate is higher and reach more often the previous values. On a biochemical point of view, hemodialysis efficacy is the same in the two groups according to the urea and creatinin clearance, but end dialysis bicarbonate plasma concentrations are higher and nearer the normal range in the bicarbonate group even tough predialysis plasma concentrationswere similar. Only. one hypoglycemia without clinical consequence is observed due to the lack of glucose ine the bicarbonate dialysis. Nevertheless, in patients under controlled ventilation, a end dialysis alcalosis can occur if a hyperventilation is imposed.

Conclusion : change from acetate to bicarbonate in dialysate buffering improve the intradialytic tolerance of patients with ARF in a multiorgan failure syndrom. This kind of hemodialysis is now use routnily in our critical unit.
TPN WITH SOLUTIONS OF DIFFERENT AA COMPOSITION:EFFECTS ON CRITICALLY ILL PATIENTS NB.-F.Bobbio Pallavicini, $V$.Emmi, A. Braschi, C.Reposi, G. Negri , F. Raimondi, M. Fischetti, P. Tosi, G. Iotti, A.Gasperi.Ospedale San Matteo, Pavia, Italia. Authors aim was to investigate how IPN with solutions of different AA composition effects on NB in critically ill patients with a medium-high proteic catabolism. Patients were on TPN for 10 days. The work focused on the identifi= cation of the AA solution, if one, whose composition coult let in the NB reach positivity sooner, expecially accor= ding to significantly different BCAA contents. Three ty= pes of AA solutions $(A-B-C)$ were used. They had the follo= wing contents, expressed as grams in $1000 \mathrm{ml}$ of solution.

\begin{tabular}{|c|c|c|c|c|}
\hline & A & B & $\mathrm{C}$ & The were provided with \\
\hline BCAA: & 19.20 & 28.40 & 47.77 & the equivalent daily \\
\hline
\end{tabular}
8.20 quantity total calorie $r$ RME). Each of the 32 patients was suffe= ring from acute generalized peritonitis. They were set in one of 3 groups ( $A-B-C$ ) at random. For survived patients, NB was computed by determinating the urine urea and its evo= lution was daily compared by evaluation of the confiden= tial limits of the means differences, the variances homo= geneity being previously evaluated by $F$ test. No remarka= ble difference in reaching the NB positivy was demonstra= te even if $A$ and $C$ group reached it after 5 days and $B$ group after more than 10 days.Consequently, there is no si gnificant statistical difference inter activity of AA so= lutions used. Altough further studies are necessary, the re sults obtained suggest that "balanced"AA solutions impro= ve the $\mathbb{N}$ utilization in patients with proteic hypercatabo lism. More over BCAA enriching seems not to affect $N B f_{a}=$ vourably.

*Preliminary data presented to the $4^{\text {th }}$ ESPEN Congress.

403

NITROGEN AND ENERGY INTAKE EFFECTS ON NITROGEN BALANCE. G. Iapichino, D. Radrizzani, A. Ferro, M. Solca. Intensive Care Unit, Ospedale Policlinico, and Istituto Anestesiologia e Rianimazione, Università degli Studi, Milano, Italy. onehundred and fiftyseven measurements of daily nitrogen balance (NB) were made on 34 patients (pts) under total parenteral nutrition (TPN). Nitrogen was administered as $10 \%$ essential aminoacid solution, while glucose was the non-protein calorie (Einp) pource. Mean nitrogen intake (Ni) was $0.21 \mathrm{~g} \mathrm{~kg}^{-1}$ (range 0 - 0.39 ), and Einp $31.8 \mathrm{kcal} \mathrm{kg}^{-1}(0-54.6)$. Ni/Einp ratio was $0.0066(0-0.0134)$; mean total calorie intake on basal energy expenditure (Ei/BEE) ratio was 1.64 $(0-2.75)$.

According to Kinney, 17 pts were moderately catabolic (M), and 17 severely catabolic (S). In both groups, NB was positively correlated to $\mathrm{Ni}$, Ni.Einp, Einp and Ei/BEE $(P<0.001)$. However, when these factors were considered together, only $\mathrm{Ni}$ and Ei/BEE appeared to influence $\mathrm{NB}$ :

(M) $\mathrm{NB}=0.025 \mathrm{Ei} / \mathrm{BEE}+0.504 \mathrm{Ni}-0.167$ $(\mathrm{P}<0.005)$;

(S) $\mathrm{NB}=0.046 \mathrm{Ei} / \mathrm{BEE}+0.620 \mathrm{Ni}-0.275$ $(P<0.005)$.

The difference between the 2 groups was statistically significant $(P<0.025)$.

The analysis of the 2 equations evidenced that:

1) NB is always better in M pts;

2) $\mathrm{Ni}$ is the major determinant of NB in both groups;

3) Ei effect on protein sparing and utilization is bigger in $\mathrm{S} p \mathrm{ts}$. 
404

PRE AND POSTOPERATIVE NITROGEN BALANCE IN PATIENTS UNDERGOING OPEN HEART SURGERY, INFLUENCE OF TYPE AND SEVERITY OF CARDIOPATHIES. G. Barbier-Böhm, J.P. Depoix, M. Videcoq, J. Hazebroucq, R. Couturier, E. Bedairia, J.M. Desmonts, Hôpital Bichat, Paris, France

Introduction. The possible incidence of nutritional disturbances in the occurence of post-operative infectious complications led us to study nitrogen (N) balance in forty adult patients undergoing surgical procedures with $\mathrm{CPB}$.

Patients and methods. Three groups were definited: group I and group II, 13 patients class NYHA I-II and 11 patients class NYHA III-IV respectively underwent valve replacement. The third group, 16 patients, submitted coronary artery bypass $(2+1$ grafts $)$. The study was performed in a time interval starting 3 days before operation (D - 3) and ending 11 days after $(D+11)$. The scheme of caloric and $N$ intake was similar in the 3 groups : $1950 \mathrm{KCal} /$ day with $13 \mathrm{~g} \mathrm{~N} /$ day before operation and increased from $700 \mathrm{KCal} /$ day with $5,5 \mathrm{~g} \mathrm{~N} /$ day to 2300 $\mathrm{KCal} /$ day with $14 \mathrm{~g} \mathrm{~N} /$ day over the postoperative period. Nitrogen loss was evaluated from the measurement of daily urinary $\mathrm{N}$ output. The $\mathrm{N}$ balance was calculated from cumulative data of three days.

Results and conclusion. Our study has shown the following points: 1) postoperative $\mathrm{N}$ losses were very high in our patients and were not related to type and severity of cardiac diseases; 2) positive balance could be obtained only 9 days after operation with minimum $N$ intake of $14 \mathrm{~g} / \mathrm{day}$ and in absence of infectious complications. If these complications are related to decreased immunologic responses to infection observed in altered nutritional status, some part of prophylaxis could be afforded by a higher caloric and $N$ intake than it is routinely prescribed after cardiac operation.

405

PHOSPHATE AND CALCTUM METABOL ISM DISFUNCTION FOLLOWING TOTAL PHARYNGOLARYNGECTOMY AND THYROPARATHYROIDECTOMY. A. Elman, C. Metrot-Magny, J.P. Gardin, D. Levy, J.N. Maillard, P. Jolis. Hôpital Louis Mourier, 178 rue des Renouillers, 92701 Colombes Cedex, France et Université de Paris VIr.

The variations of the phosphate and calcium metabolism after total parathyroidectomy on healthy glands have never been reported. This occurs in patients suffering from carcinoma of cervical esophagus treated by total pharyngolaryngectomy. In two years, 17 patients, 14 men and three women (of mean age 53 years with normal thyroid and parathyroid functions checked) were operated. Serum and urinary calcium and phosphate level measurements have been done after operation. The hydroelectrolytic adjustements and the parenteral feeding were carried on with glucose and amino-acid solutions avoiding phosphate and containing known and stable calcium rate. From the enteral feeding on, thyroxine, alumine-hydroxyde and cholecalciferol were added.

After total thyroparathyroidectomy, calcium and phosphate serum and phosphate urinary levels significantly decrease (respectively $10 \pm 9 \mathrm{mg} / 1 \quad p<0,01,5,6 \pm 6,3 \mathrm{mg} / 1 \quad p<$ $0,05 ;-0,28 \pm 23 \mathrm{mg} / \mathrm{mg}$ urinary creatinine $p<0,005)$.

Indicating the lack of parathormone, the urinary calcium excretion increases, depending on the filtrated load (calcium serum level) and as long as the phosphorus intakes remain low, a real low calcium serum level can be noted without clinical signs.

In spite of high frequency surgical complications ( 93 for 17 patients) the variations of phosphate and calcium metabolism are not affected by them.
406

METABOLIC LONGITUDINAL STUDIES IN SEPTTC PATIENTS W.Mouritz, E. Roth ${ }^{x}$, F. Milh Zbacher ${ }^{x}$ J.Funovics ${ }^{x}$, J.Korner ${ }^{x}$, P.Sporn: 1st ICU, Clinic of Anesthesia nd General Intensive Care, and Ist Surgical Cliniex, University of Vienna, Austria

Aim of this study was to evaluate the effect of parenterat nutrition (PN) with high dose amino acids (AA) in malnoumished septic patients. Sepsis is known to cause severe metabolic disorders: recuction of plasma and miscle amino acid levels, especially muscle glutomine (arterio-venous differences showing an increased peripheral release of muscle $A A$ ), decrease in short life plasma proteins, increase in hormone levels, increase in free fatty acids and triglycerides. As we could show earlier there are significant metabolic differences between surviving and non surviving patients.

Five patients with normal renal function were studied. They were manourished transferred from other hospitats, alt survived. The received $2,5 \mathrm{~g} A A, 5 \mathrm{~g}$ glucose, and 1, $5 \mathrm{~g}$ fat/kg BW/day. After starting PN, every 2. day plasma AA (art.\&ven.), plasma short life proteins; plasma insulin, cortisol, and glucagon; fat metabolites; and nitrogen balance were determined until dischorge from the ICU.

Results: Nitrogen balances averaged $-4 \mathrm{~g} /$ day. BUlv was normal and renat excretion of $A A$ below $3 \%$, indicating good utilisation. Side effects, as vomiting, flush, or mind confusion, were not seen. Plasma insulin levels remained unchanged, glucagon levels decreased as well as cortisol levels. Free fatty acid and triglyceride levels normalized. Prealbumin, retinol binding protein and trans ferrin levels increased, indicating stimulated liver protein synthesis.

In conclusion, PN with high dose AA could not establish positive nitrogen balance, but normal levels of total plasma $A A$ and short life proteins were archived. We assume, that inoreased peripherat $A A$ release in septic patients may be lessened by exogenous administered $A A$.

407

PERSONAL EXPERIENCES IN THE TREATMENT OF CRUSCH SYNDROM AFTER THE 1980 EARTHQUAKE IN SOUTHERN ITALY. G.F. Mostarda, E lannuzzi, A. De Sio, D.V. Graziano, C. Lúongo. $1^{\text {st }}$ Faculty of Medicine, Chair of Intensive Care, University of Naples, Naples, Italy

The work aims to report the results obtained in patients with crush syndrom (C.S.), treated with hyperbaric oxygen therapy $(\mathrm{OHB})$ and peritoneal dialysis (PD) or extra-corporeal dialysis (ED). There were 9 patients aged 17 to 45 years with lesions of the limbs (complicated in 3 cases by gaseous gangrene) and acute renal failure (ARF) (7 oligoaniuresis, 2 aniuresis). 7 to 24 hours passed between the quake and their first aid and a period of 1 to 6 days during which they passed into our care. Besides the contribution of calories and hydroelectrolites, therapy was based on contemporary, daily dialysis (7 ED, $2 \mathrm{PD}$ ) ad OHB (2 ATA for 2 hours a day for the first 4 days - 2 ATA for 1 hour a day for the following days). OHB was used for 7 to 70 days and when used for more than 23, gangrene was present. Diuresis started again on the $8^{\text {th }}$ to the $11^{\text {th }}$ day with PD and the $6^{\text {th }}$ to the $15^{\text {th }}$ with ED. Final results: 6 patien ts cured, 1 amputated, 1 trasfered improved, 1 desceased due to hepatitis. We can therefore confirm the validity of the association of precocious ED with OHB. 


\section{Pediatrics}

408

BLOOD VOLUME CHANGES DURING SEPTIC SHOCK IN CHILDREN.

D. DEVICTOR*, J.M. ROCCHISANI**, G. HUAULT*

* Hôpital BICETRE - ** Hôpital COCHIN - PARIS - France

Septic shock may induce hypovolemia by increasing fluid leakage from the capillary bed. The purpose of the present study was to test the effects of macromolecular infusions on the red cell mass (RCM), plasma volume (PV) and total biood volume (TBW). We used Tc 99 labelled erythrocytes to measure RCM in 6 chilforen aged from 4 months to 7 years with infections purpura and shock. Haematocrit was measured simultaneously for calculation of PV and TBV For ethical reasons, the study took place during therapy which included 18 to 72 hours infusions of whole blood and of plasma, albumin, gelatin and dextran. The rate of infusion averaged $180 \mathrm{ml} / \mathrm{kg}$ with large interindividual variations depending on the patient's condition. Results vere as follow:

\begin{tabular}{lrr} 
& age - watched controls & patients \\
$\mathrm{RCM} \mathrm{ml} / \mathrm{kg}$ & $18.5 \pm 3$ & $21 \pm 6 *$ \\
$\mathrm{PV} \mathrm{ml} / \mathrm{kg}$ & $36.6 \pm 6$ & $45.3 \pm 10 *$ \\
$\mathrm{TBV} \mathrm{ml} / \mathrm{kg}$ & $57.1 \pm 9$ & $66.5 \pm 13 *$ \\
\multicolumn{2}{c}{ Mean $\pm \mathrm{SEM}$} & $*$ NS
\end{tabular}

Since statistical significance was not demonstrated by t-test comparison with the controls, these data indicate that TBV vas normalized in the children studied. The fact that the rapid fluid infusion did not increase blood volume beyond its normal limit, suggests that a large fraction of the macromolecular solutions infused disappeared from the vascular bed.
410

MANAGEMENT OF SEVERE HYPONATREMIA IN CHILDREN: UTILITY OF UREA. G. Siro Brigiani, T. Fiore, R. Giuliani,M. Micelli, Institute of Anesthesiology, University of Bari, Italy. Urea has been proposed for continued treatment in cases of syndrome of inappropriate secretion of antidiuretic hormone in adults (1). In the present study, rapid correction of hyponatremia has been attempted in children. Clinical material and method. Two pediatric cases (aged 10 and 8 years respectively) of head injury in deep coma are described, which neurologically exhibited a downfall course, accompanied by 1) hyponatremia and hypoosmolality, 2) inappropriately high urinary osmolality and natriu resis, 3) no impairment of renal function, normal volemia, absence of oedema. Fluid restriction having been followed by no favourable result, the acute adninistration of urea (500 $\mathrm{mg} / \mathrm{Kg}$ in $50 \mathrm{ml}$ of water) through a naso-gastric tube was carried out twice with an interval of 24 hours.

Results. Values of plasma sodium and osmolality, togecher with natriuresis, gradually returned to normal within 16 hours after the second administration of urea(see Table).

C a s s ist 2nd

T i m e s to* $t 1^{*} t 2 * \quad t 0^{*} \quad t 1^{*} t 2^{*}$

$\begin{array}{lllllll}\text { pNa }(\mathrm{mEq} / 1) & 120 & 132 & 141 & 123 & 130 & 136\end{array}$

p0sm (m0sm/Kg H $\mathrm{H}_{2}$ ) $\quad 239 \quad 271 \quad 293 \quad 251 \quad 284 \quad 285$

$\begin{array}{lllllll}\mathrm{uNa}(\mathrm{mEq} / \mathrm{hr}) & 11 & 6 & 3,6 & 11 & 9,6 & 5,4\end{array}$

$\mathrm{uOsm}\left(\mathrm{mOsm} / \mathrm{Kg} \mathrm{H} \mathrm{H}_{2} \mathrm{O}\right) \quad 905 \quad 478 \quad 998 \quad 979 \quad 873 \quad 863$

*t 0 =before, $\mathrm{t} 1$ \& $\mathrm{t} 2=16 \mathrm{hrs}$ after $1^{\circ} \& 2^{\circ}$ dose, respectively Conclusions. Urea, which represents the main solute in the countercurrent mechanism, proved to be effective in the correction of decreased plasma sodium content and osmola lity with a sparing effect on sodium loss; a concurrent improvement of the neurological picture was observed. References. 1) Decaux, G. et a1.: JAMA, 247(4): 471,1982.

\section{1}

TREATMENT OF MENINGITIS ASSOCIATED WITH VENTRICULAR SHONT. EXXERIMNCE OF EXXTERNAI VENTRICULAR DERIVATION OF IONG DURATION.

A.Barois, F.Veber, B.tstournet

Service de Pédiatrie-Réanimation Infantile

Hopital R.Poincaré, 92380 Garches - France.

11 children suffering from meningitis associated with a ventricular shunt were admitted in the department. Mean age : $3+3,5$ y (range : 15 days to 12 years $), 8$ boys and 3 girls.

The ventricular shunt was put for hydrocephalus post neonatal meningitis 3 times, following intracranial hemorrhage once, complicating a spina bifida

5 times and due to congenital malformations twice. Meningitis occured $26,8+40,8$ months after the first shunt was put and $9,9 \pm \overline{8}, 5$ days after a new surgical intervention for obstructed shunt in 9 cases. The germs were meningococous once, staphylococcus 7 times, streptococcus 4 times and Gram negative bacilius twice. Several germs were found 4 times. The treatment included adjusted antibiotics with good CSF penetration and external ventricular derivation, after the contamined material was removed, in all the cases except the meningococcal meningitis.

The cerebrospinal fluid (CSF) became germ-free in $15,8+12$ days and a new internal derivation (ventriculo-peritoneal shunt 5 times, ventriculocardiac shunt 4 times) was put after $33,9 \pm 13.7$ days of external derivation.

Ten children recovered without new sequelae. One died in two days of staphylococcal sepils and peritonitis ; she was 17 days old.

In conclusion treatment of prolonged and severe shunt infections by external ventricular drainage of long duration and specific antimicrobial therapy may offer improvement in most of the cases. 
412

MECHANICAL VENTILATION AT HOME FOR A LONG TIME. RESULTS IN 115 CASES IN CHILDREN. B. ESTOURNET, A. BAROIS. Service de Réanimation Infantile, H8pital R.Poincaré 92380 GARCHES FRANCE.

115 patients, admitted in the department during their childhood for chronic diseases, came back home with an intermittent mechanical ventilation by, oral positive pressure breathing ( 60 cases), tracheostomy ( 46 cases) or iron lung ( 9 cases). The neuromuscular disorders responsible for respiratory failure

included : Polfomyelitis (47 cases) Werdnig Hoffmann diseases (20 cases) Congenital Myopathles (10 cases) Muscular dystrophy of Duchenne ( 8 cases) Myasthenia Gravis ( 4 cases ) and other disorders affecting the lower neuron motor unit ( 5 cases).

Head and spinal cord injuries are responsible in 11 cases. Thoracic distorsion are observed in 5 cases and chronic lung disease by bronchopulmonary dysplasia in 5 cases also.

Mean age when children came back home is $13,5 \pm 6,4$ years.

Death occured in 22 cases.

Mean age of the eurvivors is $20,6 \pm 8,6$ years. The worsening of respiratory insufficiency made tracheostomy indispensable in 7 cases in the group of children ventilated - by oral positive pressure breathing. The experience of mechanical ventilation at home started in 1970 with teenagers, hospitalised in the department since their childhood, permitted to extend its indications and thanks to the equipment improvement to send back home children younger and younger.
414

PRESENCE OF AN ATYPICAL CATHODICALLY 'IIGRATING CREATINE KINASE IN CHILD AFTER CARDIAC SURGERY. A. Dequirot, N.T. Lequang, F. Labrousse, A. Roy, F. Trinquet, C. Rocchiccioli ; Unité de Réanimation de chirurgie cardiovasculaire et Laboratoire de biochimie, Hôpita1 Laënnec, 42, rue de Sèvres, F 75007, Paris, France. Some data concern the presence in human tissues of an atypical creatine kinase $(\mathrm{CK})$ isoenzyme, migrating to the cathod, which is possibly coming from mitochondria (CKm) Sera from 320 infants and children younger than 5 years undergoing open heart surgery were examined. Samples were done at the arrival in ICU and the morning of the next 3 days. We electrophoretically separated and fluorometrically detected CK isoenzvmes according to Rosalki (et al) modified by Szasz (et al).

In 38 patients, besides the 3 well known CKr1, CK B and CKBB isoenzymes, we have isolated an atypical CK isoenzyme. We have verified that this abnomal fraction is antigenically "no $: 1$, no $B^{\prime \prime}$ and have the same cathodic mobility that CKm that we have found in organ extracts (heart, lung, liver, ...). From data profile there is 3 groups in patients. Group I (4/38) where CKm is present as early as the arrival in ICU ; froup II $(9 / 38)$ where CKm appears the day following operation ; Group III (25/38) where CKM is present only the second post operative day whereas $C^{2} \mathbb{B}$ is nearly vanished. Te have verified that CKm does not result from eventual transformation of $M$ or $B B$ isoenzymes. CKm disappears the next days. Tro of the 38 patients are died, that is the mean mortality rate.

CKm occurrence in infants and children after open heart surgery does not seem to have pejorative signification. Significance of this is still uncertain and further studies are necessary.

\section{3}

EFFECT DF OPEH-HEART SURGERY OA PLAS:" 1 FIBROHECTII LEVELS III CHILD. A. Dequirot, F. Labrousse, II.T. Lequang, A. Roy, C. Rocchiccioli, F. Trinquet. Unité de Réanimation de chirurgie cardiovasculaire et Laboratoire de biochimie, Hôpital Laënnec, 42 rue de Sèvres, F 75007 PARIS, France.

opsonic fibronectin depletion decreases resistance to sepsis (19.E. Lanser, T.31. Saba, Ann. Surg., 195, 3, 1982) with the aim of studying factors predisposing to infections complications, we analyse plasma fibronectin (PF) rate variations following open-heart surgery.

This study concerns 10 pediatric patients, aged between 9 months and 13 years, after cardio nulmonary bypass for surgical correction of congenital heart diseases. Blood samples, anticoagulated with ila Citrate, were taken before oneration and ó hours, 1 day and 7 days after surgical procedure. After centrifugation, plasma samples were immediately frozen. lieasurements of $\mathrm{PF}$ were done by $\mathrm{ra}-$ dial immunodiffusion. For statistical analys is non parametric Hilcoxon paired $T$ test were used.

Before operation, baseline level of plasma fibronect in

(1) is $303 \pm 59 \mathrm{mg} / \mathrm{l}$ (mean $\pm \mathrm{SD}$ ). At the sixth postoperative hour (2) $\mathrm{PF}=314 \pm 52 \mathrm{mg} / \mathrm{l}$; the first postoperative day (3) $\mathrm{PF}=270 \pm 26 \mathrm{mg} / \mathrm{L}$; the seventh day (4) $\mathrm{PF}=$ $330 \pm 36 \mathrm{mg} / \mathrm{L}$. Statistical comparison gives : for $1 \mathrm{VS} 2$, 1 Vs3, 2 V\$3, 3 VS4 : $n<0.01$; but for 1 VS 4 iIS. Plasma fibronectin levels decrease as early as the sth hour; the 7 th day PF levels are nearly returned to the baseline rate.

Thus, cardiac surgery with cardiopulmonary bypass may induce a drop of $\mathrm{PF}$ level. It is nossible that fibronectin might lower resistance to sepsis which is a dreaded complication of this surgery.
415

POST SURGICAL BODY WEIGHT (BW) CHANGES WITH CORRECTIVE CARDIAC SURTERY IN PEDIATRIC PATIENTS. CORRELATION WITH VENTILATORY WEANING TIME AND MORBIDITY.

M.E.FAYMONVILLE, Dent of Anesthesiology, Hosn. Bavière, University of Liège, Belgium.

J. CHAREST, Dept of Anesthesiology, Hosn. Ste Justine, University of Montrea1. Canada.

420 natients (oremature : $3 \%$; age $<1$ month : $5 \%$; 1 to 24 months : $31 \% ; 2$ to 6 y.o.: $38 \% ; 6$ y.o.: $22 \%$ ) submitted to congenital corrective cardiac surgery were studied. Cardionulmonary bypass was used in $82 \%$. Weights were measured before and after surgery. 125 patients have lost weight during the procedure, average: $1.56 \%+1.58$ 295 natients have increased their initial $\mathrm{BW}^{\prime}$, average : $1.84 \% \pm 2.02$. Five subgroups were used for statisticaj analysis : Groun 7 : loss $>2 \% \mathrm{BW}$

Froun II: loss $0-2 \% \mathrm{BW}$

Groun III: gain $7 \%$ BW

froun IV: gain $1-2 \% \mathrm{BV}$

Groun $V$ : gain> $2 \% \mathrm{BW}$

The postsuraical comnilications : cardiac failure, arrythmias, atelectasis, pleural effusion, and the nostsurgical ventilatory weaning delay were statistically analysed in these 5 groups. The number of postsurgical comnlications was increased in correlation with the $\mathrm{BW}$ gain during the surgical nrocedure. For instance, mean incidence of compications ner patients averages 0.51 in group $I$ and 1.15 in group $V(n<0.001)$. The nostsurgical ventilatory weaning nrocedure has been more difficult in natients with increased $B W$; ir groun I endotracheal intubation duration averages : $9 \mathrm{H}$; it averages 24 hours in group $V(n<0.001)$.

Conclusion : stability of BW during congenital cardiac surgery is required. BW gain of $1.84 \%+2.02$ increases significantly the incidence of nostsurgical comnlications (cardiac failure, arrythmias, nleural effusion) and delays significantly ventilatory weaning time. 
416

MONITORING OF THE EXPIRED $\mathrm{CO}_{2}$ IN PRETERM INFANTS A.Vuori, P.Jaakkola, Department of Anaesthesiology, University of Turku, Turku, Finland.

The validity and usefulness of capnography in monitoring ventilation in preterm infants was studied comparing the correlation of end tidal $\mathrm{pCO}_{2}$ to arterial $\mathrm{pCO}_{2}$.

A total of 69 samples were included in this study. The patients were preterm infants treated with CPAP or IMV for IRDS (hyaline membrane disease) in most cases. The Baby Bird ventilator was used. Because of small tidal volumes. gas samples were taken from the intubation tube near the patient by cutting the tube and connecting a T-piece between the ends. Gas samples from this T-piece were continuously drawn to a fast-response infrared carbon dioxide analyser connected to a recorder (Datex Normocap DC-102 $\&(R-102)$.

The method turned out to be easy to employ and valid. There was a good correlation between ETPCO and arterial $\mathrm{pCO}_{2}$ in case the plateaux on the capnograms were froad and/or of equal height. The severity of the IRDS had influence on the correlation, whereas gestational age and birth weight seemed not to affect the correlation. 